Contributions to Economics

J. Gács · G. Winckler (Eds.)

International

Trade and

Restructuring

in Eastern

Europe

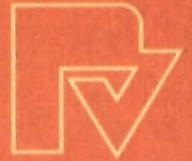

Physica-Verlag

A Springer-Verlag Company
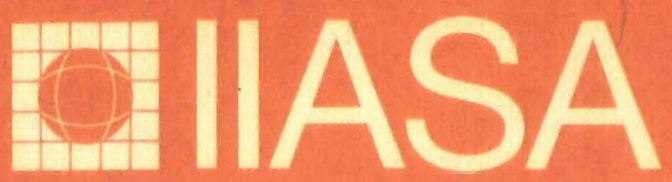

International Institute for Applied Systems Analysis 

János Gács · Georg Winckler (Eds.)

\section{International Trade and Restructuring in Eastern Europe}

With 11 Figures

$\underline{\text { Physica-Verlag }}$

A Springer-Verlag Company 


\section{Series Editor}

Werner A. Müller

Peter Schuster

\section{Editors}

Dr. János Gács

International Institute for

Applied Systems Analysis (IIASA)

Schloßplatz 1

A-2361 Laxenburg/Austria

Professor Dr. Georg Winckler

Department of Economics

University of Vienna

Hohenstaufengasse 9

A-1010 Vienna/Austria

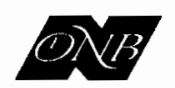 \\ OESTERREICHISCHE NATIONALBANK \\ IIASA gratefully acknowledges the support of the Austrian National Bank which co-sponsored the Conference in Laxenburg and made the publication of this volume possible.}

ISBN 3-7908-0759-1 Physica-Verlag Heidelberg ISBN 0-387-91480-3 Springer-Verlag New York

This work is subject to copyright. All rights are reserved, whether the whole or part of the material is concerned, specifically the rights of translation, reprinting, reuse of illustration, recitation, broadcasting. reproduction on microfilms or in other ways, and storage in data banks. Duplication of this publication or parts thereof is only permitted under the provisions of the German Copyright Law of September 9, 1965, in its version of June 24, 1985, and a copyright fee must always be paid. Violations fall under the prosecution act of the German Copyright Law.

(C) 1994 International Institute for Applied Systems Analysis, Laxenburg, Austria. Printed in Germany

The use of registered names, trademarks, etc. in this publication does not imply, even in the absence of a specific statement, that such names are exempt from the relevant protective laws and regulations and therefore free for general use.

88/2202-543210 - Printed on acid-free paper 


\section{Contents}

List of Contributors vii

List of Figures ix

List of Tables $\quad$ xi

Introduction

János Gács and Georg Winckler 1

PART I: The Role of Exchange Rate Regimes

1 Exchange Rate Policy and Real Exchange Rate Changes in Economic Transition

Gábor Oblath

Comments by Andrew Berg

2 The Polish Exchange Rate Policy and Economic System Transformation

Leszek Jasiński

3 Economic Recovery and Foreign Exchange Rate Regime: The Case of the Czech Republic

Miroslav Hrnčír

4 The Birth and Childhood of a Currency:

The Experience of Slovenia

Jože Mencinger 
PART II: Trade Liberalization and Emerging Trade Patterns

5 Trade Liberalization in the CSFR, Hungary, and Poland: Rush and Reconsideration János Gács

Comments by Giovanni Graziani

6 Changing Trade Patterns and Industrial Policy: The Case of Poland

Dariusz K. Rosati

7 Life Without CMEA:

Foreign Trade in Eastern and Central Europe Sándor Richter

8 Trade Patterns and Comparative Advantages of Central Eastern Europe with EC Countries

Giovanni Graziani

Comments by Elhanan Helpman

9 The Export Performance of the CSFR, Hungary, and Poland: Reform, Transformation, and Competitiveness Herman W. Hoen

PART III: Enterprises and Trade Restructuring

10 Factors and Effects of Trade Reorientation in Hungary László Halpern

11 The Effects of Privatization on Enterprise Production and Trade Strategy

Janusz M. Dabrowski

Comments by Sándor Richter

12 Monopoly Power, Import Competition, and Price Liberalization in the CSFR John S. Earle and Andreas Wörgötter 


\section{List of Contributors}

Andrew Berg

Institute of International Development

Harvard University

Cambridge, MA, USA

\section{Janusz M. Dabrowski}

Gdańsk Institute for Market Economics

Warsaw Branch

Warsaw, Poland

John S. Earle

Central European University

Prague, Czech Republic; also

Stanford University

Stanford, CA, USA

\section{János Gács}

International Institute for Applied

Systems Analysis (IIASA)

Laxenburg, Austria; also

Institute for Economic and Market

Research and Informatics

(KOPINT-DATORG)

Budapest, Hungary

\section{Giovanni Graziani}

Department of Economics

University of Brescia

Brescia, Italy

\section{László Halpern}

Institute of Economics

Hungarian Academy of Sciences

Budapest, Hungary
Elhanan Helpman

Department of Economics

Tel-Aviv University

Tel-Aviv, Israel

Herman W. Hoen

Faculty of Economics

University of Groningen

Groningen, Netherlands

Miroslav Hrnčír

Institute of Economics

Czech National Bank

Prague, Czech Republic

\section{Leszek Jasiński}

Foreign Trade Research Institute

Warsaw, Poland

\section{Michael Jones}

Department of Economics

Bowdoin College

Brunswick, ME, USA

\section{Jože Mencinger}

Institute of Economics

University of Ljubljana

Ljubljana, Slovenia

\section{Gábor Oblath}

Institute for Economic and Market

Research and Informatics

(KOPINT-DATORG)

Budapest, Hungary 


\section{Sándor Richter}

The Vienna Institute for Comparative

Economic Studies (WIIW)

Vienna, Austria

\section{Dariusz K. Rosati}

United Nations Economic Commission for Europe

Geneva, Switzerland; also

Foreign Trade Research Institute

Warsaw, Poland

\section{Georg Winckler}

Department of Economics

University of Vienna

Vienna, Austria

\section{Andreas Wörgötter}

Department of Economics

Institute for Advanced Studies

Vienna, Austria 


\section{List of Figures}

1.1 Hungary: nominal and real effective exchange rates, 1985=100. 18

1.2 Poland: nominal and real effective exchange rates, 1985=100. 19

1.3 CSFR: nominal and real effective exchange rates, $1990=100.20$

4.1 The foreign exchange market, December 1991 to August 1992.114

4.2 The real exchange rate, December 1991 to August 1992.

5.1 Characteristic patterns of trade liberalization in Israel, Argentina, Turkey, and Chile.

5.2 Trade liberalization indices for the CSFR, Hungary, and Poland, 1955-1992.

12.1 Total domestic producer, import, and export prices in the CSFR, December 1990 to June 1992, 1990 December $=100$ percent.

12.2 Development of domestic producer prices of energy and basic materials, December 1990 to June 1992, 1990 December $=100$ percent.

12.3 Development of domestic producer prices of heavy industries, December 1990 to June 1992, 1990 December = 100 percent.

12.4 Development of domestic producer prices of light industries, December 1990 to June 1992, 1990 December = 100 percent. 



\section{List of Tables}

1.1 Exchange rate indices, $1985=100$.

1.2 Consumer price indices (CPI) and producer price indices (PPI), previous year $=100$.

$1.3 \quad$ Indicators of external performance, billions of US dollars. $\quad 36$

$\begin{array}{ll}1.4 & \text { Indicators of real activity, percent change. } \\ 1.5\end{array}$

1.5 Overview of Eastern European exchange rates. 42

2.1 The nominal and real exchange rates of the zloty against the dollar.

2.2 The effective exchange rates, value of money, dollar equivalents of average wages in Poland.

2.3 The profitability of the top 500 exporters and of all firms in 1990-1991.

2.4 The net profitability of enterprises in 1990-1991, in percent.

2.5 Real money supply in Poland, January $1991=1$.

2.6 Budget receipts, outlays, and industrial production in real terms, January $1990=1$.

3.1 Main macroeconomic indicators 1989-1992, annual change.

3.2 Exchange rate (ER), purchasing power parity rate (PPP), and parallel market exchange rate of the CSK in 1989-1992, CSK per US dollar, average per period.

3.3 Effective exchange rates of the CSK, January $1990=100$.

3.4 Consumer prices in the CSFR, Hungary, and Poland from 1986 to 1992 , average annual percentage rates over previous year.

3.5 Distribution of the CSFR trade, percent shares, derived from values in CSK, current prices, and foreign exchange rates.

3.6 Product composition of the CSFR foreign trade, percent shares, SITC classification in parentheses. 
3.7 Balance of payments in convertible currencies.

4.1 The Slovene economy at the outset of independence.

4.2 The daily foreign exchange market, current account transactions, 1 December 1991 to 31 August 1992.

4.3 Weekly supply and demand for foreign exchange, in millions of German marks, 1 December 1991 to 31 August 1992.

4.4 Monetary policy between October 1991 and August 1992, at the end of the period, in millions of tolars.

5.1 Distribution of manufactured industrial products imported from the EC, in percent.

5.2 Sources of domestic supply in Hungary for selected product groups from 1988 to 1990 , in percent.

5.3 Major car lobbyists in the CSFR, Hungary, and Poland.

6.1 Poland: sectoral shares in manufactured exports in 1988 and 1991 , in percent.

6.2 Poland: sectoral shares in manufactured imports in 1988 and 1991, in percent.

6.3 Poland: correlation coefficients between the industrial structure and the export structure.

6.4 Poland: correlation coefficients between the commodity structures of Polish exports in 1988 and in 1991, by trading areas.

6.5 Poland: trade coverage ratios, in trade with CMEA and OECD countries, by industrial sectors, 1988 and 1991.

6.6 Trade similarity coefficients for sectoral composition of exports, by main trading areas, in 1988 and 1991.

7.1 Development of trade with centrally planned economies and market economies between 1985 and 1990 at constant prices.

7.2 CSFR: share of individual countries and groups of countries in total trade.

7.3 Hungary: share of individual countries and groups of countries in total trade.

7.4 Poland: share of individual countries and groups of countries in total trade.

7.5 Soviet Union: share of individual countries and groups of countries in total trade. 
7.6 CSFR's trade with the Soviet Union by commodity groups, 1990 and 1991 , in percent.

7.7 Hungary's trade with the Soviet Union by commodity groups, 1990 and 1991 , in percent.

7.8 Foreign trade of the CSFR with selected former CMEA countries by currency of payments in 1990 and 1991, in percent.

7.9 The share of mutual trade flows in foreign trade of Taiwan, South Korea, Singapore, and Hong Kong, in selected years.

7.10 Economic integration groupings of developing countries: intragroup trade as a percentage of total exports of each group.

7.11 Geographical composition of trade of the CSFR, Hungary, and Poland in 1928, 1989, and predicted, percentages of total.

7.12 Developments of EE5 trade with the EC, 1985-1992.

8.1 Market shares in EC imports, in percent.

8.2 EC import structure with the CEECs, by main commodity groups, in percent.

8.3 Share of EC imports of manufactures classified according to resource dependence, in percent, rounded figures.

8.4 EC imports of non-resource-based manufactures classified according to skill intensity, rate of product development, and factor intensity, in percent, rounded figures.

8.5 Share of EC imports classified according to technology level, in percent, rounded figures.

8.6 Export specialization index on the EC market, by order of importance in 1991.

8.7 Educational, scientific, technical, and R\&D indicators.

9.1 Market shares in the EUR(8), in percent.

9.2 Decomposition of the CSFR, Hungarian, and Polish manufactures' export change, in million dollars.

9.3 Competition effects of the CSFR, Hungary, and Poland, disaggregated to commodities, in million dollars.

9.4 Competition effects in the CSFR, Hungary, and Poland, disaggregated to regions, in million dollars.

10.1 Share in the sample of regularly exporting firms as compared to the whole corporate sector, in percent.

10.2 Final results of the panel model. 
10.3 Ratio of direct and overhead costs to sales in the corporate sector, in percent.

10.4 Structure of sales in the sample of exporting firms, in percent. 274

10.5 Profit rate in the sample of exporting firms, in percent. 275

10.6 Ratio of net subsidies to sales in the sample of exporting firms, in percent.

10.7 Profit rate in different sales directions in the sample of exporting firms, in percent.

10.8 Correlation between the share of exports to total sales and the return on assets in the sample of exporting firms, in percent.

10.9 Distribution and profitability of exporting firms by the rate of return on assets, in units and percent.

10.10 Distribution and profitability of exporting firms by the profit rate of dollar exports, in units and percent.

10.11 Distribution and profitability of exporting firms by the growth rate of dollar exports, in units and percent.

10.12 Distribution and profitability of exporting firms by the share of dollar exports in total sales, in units and percent.

10.13 Distribution and profitability of exporting firms by the value of dollar exports, in units and percent.

10.14 Sectoral distribution and profitability of exporting firms.

10.15 Distribution and profitability of exporting firms by the number of employees, in units and percent.

10.16 Distribution and profitability of exporting firms by the share of foreign assets, in units and percent.

10.17 Distribution and profitability of exporting firms by the organizational form of enterprises, in units and percent.

11.1 Privatization path and size of the firms in the sample.

11.2 Sectors, branches, and privatization paths of firms in sample.

11.3 Profitability relative to the privatization path, in percent.

11.4 Credit arrears and privatization path: receivables to payables ratio.

11.5 First effects of ownership changes and methods of privatization. 313

12.1 Domestic wholesale prices in CSFR industry in 1991, 1 January $1989=100$ percent.

12.2 Industry indicators in the CSFR in 1991. 


\section{Introduction}

János Gács and Georg Winckler

In recognition of the key position of international trade in the transition and the need for concentrated discussions of topical trade issues the International Institute for Applied Systems Analysis (IIASA) organized an international conference on "International Trade and Restructuring in Eastern Europe" which took place in Laxenburg, Austria, on 19 and 21 November 1992. The Austrian National Bank joined IIASA to co-sponsor the event. Participants of the conference were experts of international economics and trade policy from East and West, policy makers, and representatives of international organizations like the IMF, the Commission of the European Communities, the OECD, and the European Bank for Reconstruction and Development (EBRD). The papers prepared for the event and the lively discussions during the conference itself prove that the topics are intellectually challenging and timely for policy makers.

It has widely been recognized that international economic relations play a crucial role in the transition of countries of Central and Eastern Europe. The scope, speed, and success of the efforts to transform the formerly centrally planned economies to market economies have increasingly become dependent on the pattern these countries have in their relation to the rest of the world.

Transition comprises three major processes: macro-stabilization, marketization, and restructuring. The success of these three hinges to a large extent on the response of these economies to the new conditions set by international trade and exchange regimes. 
Many of the new governments in these countries have found that the most appropriate fixed point (the so-called nominal anchor), to which stabilization measures should be attached, is the nominal exchange rate of their own currency. A more reasonable exchange rate than that in the former system of central planning has required a full reorganization of trade and exchange relations including the establishment of some kind of currency convertibility and deregulation of international trade transactions. Part I of this book deals with exchange rate regimes that have played and may play a role in supporting political and macroeconomic stabilization, on the one hand, and competitiveness of domestic production, on the other.

For the new, democratically elected governments of Central and Eastern Europe marketization means primarily the establishment of basic institutions of the market, liberalization of prices, decentralization of financing, providing the opportunity for free entry and fair competition, and privatization of the majority of formerly state-owned companies. It was soon recognized that without an increasing reliance on international trade, as well as external financial and technical assistance, the transition to the market would be delayed for an intolerably long time. Liberalized imports and joint ventures may promote competition in a heavily monopolized economy; privatization would be slower without the participation of foreign investors, and it would be harder to establish basic institutions of the market without the technical assistance of international organizations.

The switch from one system to the other implies an enormous restructuring of trade and production, as well as a major reallocation of the factors of production. In signaling the preferred directions for restructuring, international trade is an extremely sensitive instrument: through world market prices, through demand for exports and supply of imports, international trade gives guidelines to producers who were accustomed to the distorted signals of a planned system. The collapse of trade in the framework of the CMEA has caused additional pressures for international readjustment in these economies.

As a consequence of systemic changes and the demise of the CMEA the countries of Central and Eastern Europe have had to undergo far-reaching geographical and sectoral restructuring of their production and trade since 1990. This restructuring has no parallel in history apart from those countries in the transition to a wartime economy. For foreign trade the structural changes had two implications: (1) shift in the sectoral and geographical composition of trade and (2) the modification of the behavior of enterprises. 
Part II of this book covers the first dimension, and Part III is devoted to the changes in trade-related enterprise behavior. In the following sections we provide a short review of the papers with emphasis on their keypoints or novelty.

\section{Part I: The Role of Exchange Rate Regimes}

The papers collected in Part I deal with the role of exchange rate policy in reform economies. With respect to policy outcomes, as observed in the first paper by Gábor Oblath, there are striking similarities among Hungary, Poland, and the CSFR; to this list one might add Slovenia (see the paper by Jože Mencinger). The similarities are:

1. Indicators of real exchange rate changes point to upward movements, reflecting persistent inflationary pressures, albeit to a different degree among the countries.

2. Although real appreciations occurred, the current account performances are surprisingly favorable.

3. Foreign reserves could be built up.

4. Convertibility of currencies, at least in the form of de facto current account convertibility (Hungary), has been established and is about to be extended.

Of course, many of these similarities were triggered by a universal and sharp output decline which occurred throughout the region. Yet, despite these similarities of policy outcomes, a surprising diversity of exchange rate regimes exists in the four countries mentioned.

Oblath reports that Hungary implemented a significant, yet gradual trade liberalization program. Due to this gradualism and Hungary's relative macro stability, there were no significant devaluations during the reform process (the largest, 15 percent, occurred in early 1991). Recently, the exchange rate has increasingly been used as a major instrument for fighting domestic inflation.

In Poland, as described by Leszek Jasiński in Chapter 2, the shock therapy introduced in early 1990 went along with a nominal anchoring of the exchange rate. This pegging to the US dollar, however, came under pressure by domestic inflation and eroding export profitability. As a consequence, in May 1991 the zloty was devalued and pegging to a basket of five currencies commenced. In October 1991 a crawling peg system was introduced (with 
constant daily devaluations). Hence, in contrast to Hungary, Poland has increasingly moved away from nominally anchoring its currency and now aims at keeping constant its real exchange rate.

In the CSFR, as explained by Miroslav Hrnčír in Chapter 3, the shock therapy of 1 January 1991 was accompanied by pegging the koruna to a basket of five currencies, like in Poland in 1990. But in contrast to Poland, nominal anchoring of the koruna could successfully be maintained, although no formal commitment has been announced.

Jože Mencinger analyzes the creation of Slovenia's new currency in Chapter 4. The description of how this birth came about is worthwhile reading for those engaged in creating new currencies in other parts of the former Eastern bloc.

Although Slovenia experienced similar outcomes to the three other reform countries, its exchange rate regime is different. Due to an initial absence of foreign reserves, Slovenia, like Bulgaria and Romania, opted for floating exchange rates. As a consequence of a lack of confidence in the new currency, nominal depreciations occurred far beyond the purchasing power parity. But these depreciations, backed by an output decline, helped to create a comfortable external position: current account surpluses accompanied the accumulation of foreign reserves, both at the central bank and at the commercial banks.

Obviously, a diversity of exchange rate regimes exists: the exchange rate either has not been changed significantly since the very beginning (Hungary) or, after initial sharp devaluations, has been used as a nominal anchor to cope with inflation (CSFR and Poland in 1990); or the exchange rate changes have served to support the competitiveness of the economy (Poland in 1992). In one case, Slovenia, exchange rate changes were to equilibrate the foreign exchange market, without aiming at establishing nominal or real anchors. Given such differences in policy how can the similarity in outcomes be explained?

One alternative explanation is supported by the common economic argument that, despite real appreciations, the large differences between the purchasing power parity and the real exchange rate, established at the beginning of the reform processes, have since caused the good external performance (reinforced by the output decline at home). This argument is advanced by Oblath. Yet, for Hrnčír, the reform economies of Central Europe are still far from being homogeneous enough to react sensitively to price and exchange rate changes. He doubts that the exchange rate level and the 
exchange rate regime have significant effects at all. Firms might just try to export, whatever the exchange rate is, as they try to sell their production abroad, given the recession at home.

Hence it is not surprising that Oblath and Hrnčír also have differing views concerning the medium and long term. Whereas Oblath again uses common economic wisdom, Hrnćír speaks of long-term costs of devaluationtype approaches. According to him a "hard currency" option would, by disciplining economic agents, contribute to an overhaul of the economy, forcing firms to concentrate more on higher value-added products.

\section{Part II: Trade Liberalization and Emerging Trade Patterns}

Part II deals with trade liberalization and emerging trade patterns, especially with respect to the CSFR, Hungary, and Poland. The papers presented in this section demonstrate that exports of these countries have concentrated on mature low-skill labor-intensive products, or capital-intensive products using old technologies (paper by Giovanni Graziani). As a consequence, the competitiveness of the export sector has been deteriorating (paper by Herman W. Hoen) and even within the Visegrád Group the share of sophisticated manufactures, primarily machinery, has decreased dramatically in mutual trade (paper by Sándor Richter). Obviously industries have become "senile" (paper by Dariusz Rosati quoting Williamson). Yet, despite these difficulties in modernizing industry and in defending international market shares, countries rushed to liberalize their economies between 1989 and 1991 at an unprecedented speed (paper by János Gács). While an opening up seems to be essential in the transition to market economies, restoring external equilibrium in a period of industrial restructuring implies some kind of protection, be it through tariffs or a sufficiently devalued exchange rate. But which protection should be chosen to facilitate the emergence of modern industries?

János Gács in Chapter 5 describes the unprecedented speed of trade liberalization. Even Hungary, which opted for a more gradual stabilization of the macro-economy, rushed to open its markets in 1989. The CSFR was the boldest in opening its market among the three. According to Gács, the usual stumbling blocks of social and entrepreneurial resistance to liberalizing trade were absent, due to the legacy of the shortage economy and the disarray in production and trade. Pressures toward establishing stronger 
protection for domestic production, however, are being unleashed. In 1992, as a consequence, each country attempted to establish at least moderate tariff protection, although international commitments in GATT and to the EC make this task quite difficult.

In Chapter 6 Dariusz K. Rosati refers to the case of Poland and discusses the changes in its trade patterns and trade policies. He offers general observations on the optimal pattern of trade policies in the transition from central planning to a market system. The empirical evidence he finds supports the view that trade liberalization is necessary and has to be carried out early when reforming an economy, yet the sequence and extent of liberalization is crucial. Exchange rate devaluations cannot bear the entire burden of adjustment and of realigning competitiveness. Customs tariffs should be treated as an important instrument of structural policies and should not be constantly changed in pursuance of short-term macroeconomic policy goals (such as budgetary equilibrium). Trade liberalization should not put too much competitive pressure on too many economic agents, otherwise social and political problems inevitably emerge.

Prior to the fall of the CMEA, mutual economic relations among small Eastern European economies were of minor relevance, since trade with the Soviet Union had always dominated the CMEA. Since the fall of the CMEA, economic cooperation among Bulgaria, the CSFR, Hungary, Romania, and Poland has gained in importance. But what trade patterns will emerge is still an open question which Sándor Richter examines in Chapter 7. While the potential for trade with Western Europe is huge, the potential for mutual trade among Eastern European economies is limited. Richter reaches this conclusion by comparing Eastern Europe to other regions of mediumor lower-level economic development. In these regions (e.g., Southeast Asia and Southern Europe), despite all attempts to enhance regional economic integration, mutual trade cannot replace trade with the highly industrialized "core" of the world economy. For Richter, this has an important policy implication: there is no modernization and economic growth for Eastern Europe without intensive trade with the OECD, especially with the European Community.

The chapter by Giovanni Graziani complements Richter's analysis. While Richter follows the structural rearrangements accompanying the demise of the CMEA and the collapse of Soviet Union's trade in Central Eastern Europe, Graziani analyzes the patterns of these region's broadening trade with its most important market: the European Community. He 
confronts recent successes of Central and Eastern European economies in increasing their sales to Western Europe with the shortcomings and weaknesses of the structural composition of this trade. He finds that even after the decline in the share of fuel-based primary products in the exports from Bulgaria, the CSFR, Hungary, Poland, and Romania to the EC, these exports are still relatively biased in favor of resource-based products, many of them requiring substantial amounts of capital. Since Central Eastern Europe is generally not abundant in natural resources and its own sources of capital are scarce, one can conclude that the recent pattern of exports is still reflecting the misallocation of resources caused by the irrational system of prices and other fundamental features of the past regime. The other disappointing characteristic of Eastern European exports, as stressed by Graziani, is that non-resource-based manufacturing is concentrated in mature, standardized, labor-intensive, and low-technology-intensive, as well as relatively slowly expanding, sectors. In these sectors, both the competition of newly industrialized countries and the protection of EC economies are especially strong.

As for the future international division of labor, Graziani forecasts no dramatic changes in Eastern European exports to the EC, at least in the near future. He envisages some rearrangements mainly in favor of food and mature labor-intensive sectors, especially if these shifts are going to be reinforced by appropriate exchange rate policies. An important implication of Graziani's analysis is that future structural changes in Eastern Europe's exports to the EC will be determined perhaps more by the level of protection in the two regions than by the reallocation of resources in Eastern Europe.

Chapter 9 by Herman W. Hoen analyzes the export performance in manufactured products of the Visegrád countries (the CSFR, Hungary, and Poland) on the EC market with the method of constant-market-shares analysis. By separating an effect that he denotes as the competition effect, he finds the astonishing result that from 1989 to 1991 the three countries achieved improvements in their competitiveness in Western markets that surpassed the progress made in any previous four-to-seven-year period. He also observes that the improvements in competitiveness were achieved in the three economies in different commodity sectors. On these grounds he envisages a further development that would bring about no strong competition among the Visegrád three for EC market shares.

What are the policy conclusions to be drawn from Part II of the book? One can argue that only temporary protection is needed, even restricting the 
protection to sector-specific or even product-specific tariffs (Rosati), since according to the Heckscher-Ohlin theory of relative factor abundance, given that these countries have a well-educated labor force and spend a relatively large share on education, there is a comparative advantage in high-skill, hightech products (Graziani). In addition, as Richter points out, the eagerness to cooperate with the EC as well as the proximity to the EC - perhaps triggered by an initial technology transfer from the West, but maintained by profitable, industrial innovation - will make the modernization of industry and sustainable economic growth in Central and Eastern Europe very likely. Yet, the "senile industries" may turn out to have been protected for too long (Rosati), public disappointment with unfavorable liberalization effects may already be too strong (Gács), and protectionist behavior of the EC will require other, more strategic trade reactions by the Visegrád countries.

\section{Part III: Enterprises and Trade Restructuring}

The behavior of enterprises, the topic of Part III, is a very special aspect of trade restructuring in Eastern Europe. The response of the firms in these economies to external demand and supply shocks must have been essentially different from the response of enterprises in long-established market economies. First, recent shocks themselves are very special and extremely strong (we refer here only to the fact that the collapse of the CMEA combined with the effects of stabilization have driven these economies into slumps that can be compared only to the Great Depression). Second, the enterprises themselves go through such fundamental changes (in terms of their ownership structure, management, inter-enterprise and government relations, and financing) that necessarily alter their traditional behavior in coping with the pressing need of restructuring.

All three papers in Part III intend to verify standard wisdom related to microeconomic adjustment and restructuring in Eastern Europe:

1. No real adjustment to the changes in the world market took place in enterprise activity before the collapse of the communist regime, and the enterprises of the new system should start from scratch.

2. Price and trade liberalizations and privatization are urgently needed in these highly monopolized economies to induce competition; the effects of liberalization will soon make themselves felt.

3. Once private companies are established enterprise performance is bound to improve in both domestic and foreign markets. 
Each paper tests one of these hypotheses, yet instead of confirming them they conclude that earlier assumptions should be reconsidered and refined.

A common inference from the three papers is that some past features of enterprises and market structure have lasting impact on enterprise behavior even after the introduction of major reforms. The transition of firms is not so fast and not so radical as many considered it earlier. ${ }^{1}$ Cost and price sensitivity was not absent from earlier enterprise activity (paper by László Halpern), liberalization of prices and imports (at least for the short run) went along with more domestic monopolistic structures (paper by John S. Earle and Andreas Wörgötter), and serious investors deliberately make use of past favorable economic performance of state-owned firms, rather than start with a tabula rasa (paper by Janusz M. Dabrowski).

The studies also suggest, however, that when the changes in the environment reach a certain threshold it is in fact justified to speak about a new era of enterprise behavior, the novel features of which are worth trying to identify. Trade reorientation as interpreted by Halpern was completed in Hungary by 1991 , and a further investigation should look for new characteristics in enterprise activity. Dabrowski has found that if there was a shift in enterprise behavior in recent years it was related more to the change in the general economic environment after the introduction of the reform program of Poland in early 1990 than to changes in the structure of ownership. Earle and Wörgötter have identified a peculiar relation between profitability, market structure, and import liberalization and assert that for the long run the beneficial effects of price and trade liberalization would inevitably unfold.

So much for the common lessons of the three studies. Two of the papers use unique sets of data for their analysis. Halpern uses selected balance sheet as well as profit and loss accounts data of several hundred Hungarian enterprises. Dabrowski analyzes the results of a comprehensive monitoring survey of 55 Polish firms having been privatized using different principles in recent years.

In the estimation of his trade reorientation equation László Halpern in Chapter 10 confirms the hypothesis that Hungarian firms were already cost-responsive before 1989, while the years of fast reorientation (1989-1991) showed a reduced rather than an increased cost sensitivity. It is interesting to learn, however, that the enterprises did not give up calculating (and basing

\footnotetext{
${ }^{1}$ For instance, Blanchard et al. (1991, p. xiv) have argued that most of the ex-state firms that accounted for the bulk of industrial production will have to close; only a few will survive and expand.
} 
their sales decisions on) the level of export subsidies until these subsidies were completely phased out. The most obvious reason for reorienting exports sales to the West (i.e., the sharp decline of CMEA trade) is confirmed by the regressional calculations. With respect to future rational behavior, it is promising that the dollar price of dollar exports have had a long-run effect on enterprise decisions on the direction and the volume of trade.

In addition to these econometric estimates, Halpern provides a comprehensive multidimensional statistical analysis of data collected for almost a thousand major Hungarian exporting firms. The most interesting findings are the following: in the years of reorientation enterprises with high exports polarized in terms of profitability; the tendency that firms with fast-growing exports realize low profits has changed substantially and by 1991 the enterprises achieving a fast-growing dollar export had significantly higher profits than the rest; the share of large firms producing dollar exports decreased, although at a moderate rate.

Janusz M. Dabrowski in his analysis of the behavior of privatized enterprises in Poland uses a sample of Polish enterprises that have gone through different paths (different methods) of privatization in recent years. The separation of the impact of the starting position of the firms, the effects of macroeconomic stabilization, the loss of markets, and ownership transformation have helped to demystify the institutional changes related to privatization.

The Polish experience shows that a combination of a solid starting position and the "proper" method of privatization was necessary for enterprises to achieve a sustained development in domestic and foreign markets. The starting position was favorable when the equipment was relatively modern, employees skilled, the management good, and the enterprise already well established on Western markets. The promising path of privatization was the so-called capital way, where the enterprise was first transformed to a jointstock company and the owner of the shares (the treasury) sold the shares to foreign or domestic investors.

A significant difference could be identified, however, between companies taken over by foreigners and those acquired by domestic businesses. When control parcels of the shares were acquired by foreign investors, the result was usually an accelerated process of financial, production, and market restructuring. The companies privatized in this way had access to new selling outlets, capital, and technology transfer. 
When a company was taken over by a domestic investor, there were seldom quick positive results. Domestic investors, as a rule, do not explore in advance the firm they are going to take over; they do not determine their market position and are rarely aware of how to operate them. Domestic owners do not plan or are simply unable to strengthen their new firm with additional investment, by introducing modern technology, and have no means to provide access to additional markets.

In formerly centrally planned economies where some basic features of the market environment have been established the study of the use and misuse of monopoly power is justified, particularly since planning created an extremely monopolized structure of industry and even services. John S. Earle and Andreas Wörgötter in Chapter 12 start their analysis of monopoly power in the CSFR with the basic dilemma of Eastern European economies embarking on transition: how to sequence measures of liberalizing prices and liberalizing foreign trade, on the one hand, and demolishing non-natural monopolies, on the other. Given the unique opportunity for completely reorganizing the structure of their industry the governments coming into power following the political changes in Eastern Europe had, at least in principle, the possibility of phasing out many of the monopolies before monopolies could take advantage of the newly opening possibilities from price liberalization. For a diversity of reasons, however, none of the Eastern European governments chose this sequence.

Even if sequencing is no more a question of decision, it is highly important whether the enterprises that have received their independence and acquired monopoly power will really behave the way we would expect them to in a market environment: that is, maximizing profit by restricting the volume of output and increasing prices. Given that price liberalization was accomplished simultaneously with trade liberalization in the CSFR, the hypothesis that import competition disciplines the behavior of domestic monopolists is worth considering.

Earle and Wörgötter use industry-specific time series of concentration ratios, domestic producer prices as well as export and import prices to draw preliminary conclusions concerning the development of monopoly power following basic measures of liberalization. They find a strong association of concentration and profitability after price liberalization which indicates that monopoly elements are present and manifest themselves the way we would expect in a market environment. The test of the import discipline hypothesis, however, did not bring the expected results. Different attempts at the 
estimation either did not result in a significant relationship or produced unexpected relationships. They found that, under their specification, an increase of import penetration does not decrease, but rather raises profits in Czechoslovak industries. This unique result of the authors, however, should be handled with caution. As they emphasize, the static effect of monopoly power on inflation of producer prices was negligible if compared to the effects of other policy changes, like the devaluations of the Czechoslovak koruna and liberalization of fuel prices.

The three parts of this book do not contain all papers presented at the conference on "International Trade and Restructuring in Eastern Europe." In order to keep the volume at a reasonable length and to enhance its focus, the editors decided to limit the papers to those on Central Eastern Europe (mostly the CSFR, Hungary, and Poland). This decision required that several interesting papers on Russia and the Baltic Republics had to be omitted. We do not claim that this volume covers all the topics worth analyzing under the heading of trade and restructuring in Eastern Europe. In fact, some important subjects, like joining different regional organizations (EC, EFTA, and others), were deliberately excluded. To enlarge the analytical part of the book and to vary the issues covered, the editors have decided to also include some of those papers that provoked strong critical remarks by the participants of the conference. For all papers, invited comments helped to stimulate the discussion and to prepare the revisions. Since these revisions made some comments obsolete, not all are included.

We think that the issues the papers address are extremely crucial, not only from the point of view of international trade relations but, more generally, in their relation to the success of the transition.

\section{Reference}

Blanchard, O., Dornbusch, R., Krugman P., Layard, R., and Summers, L. (1991) Reform in Eastern Europe (Cambridge, MA: MIT Press). 


\section{Part I}

The Role of Exchange Rate Regimes 



\section{Chapter 1}

\section{Exchange Rate Policy and Real Exchange Rate Changes in Economic Transition}

Gábor Oblath*

\section{Introduction}

The issue of changes in the real exchange rate (RER) has become rather controversial in discussions about exchange rate policy in some of the former socialist, currently transition, economies of Central and Eastern Europe (CEE). ${ }^{1}$ The countries concerned are those that are relatively developed and have achieved a measure of relative macroeconomic and exchange rate stability. These countries - namely, the Czech and Slovak Federal Republic

*This chapter is based on a paper written during the author's stay as a visiting scholar with the Unit for East European Economies of the Bank of Finland. I gratefully acknowledge the research support provided by the Bank of Finland and the comments of the members of the unit. Andrew Berg, the discussant of the paper at the IIASA conference, János Gács, and László Halpern also offered useful comments and suggestions; Glen Harma helped in the language editing. The views expressed are those of the author and should not be attributed to the Bank of Finland.

${ }^{1}$ See, for example, Hrnčír (1992), KOPINT-DATORG (1992), and Winiecki (1992) on the CSFR, Hungary, and Poland respectively. 
(CSFR), Hungary, and Poland - went the furthest among countries of the region in liberalizing the domestic and foreign sectors of their economies and in implementing de facto resident convertibility of their currencies. ${ }^{2}$ This paper focuses on the experiences of these three countries (referred to as the three), but in particular on those of Hungary. The nominal exchange rates of the three countries display either relative (Hungary and Poland) or, for the time being at least, absolute stability (CSFR); in the parallel (black) markets, where they exist, there are no sizable premiums on foreign rates of exchange.

For all three economies, the available indicators of real exchange rate changes show an upward movement, though the time profile and the measure of the real appreciation is different for each country (see Table 1.1 and Figures 1.1, 1.2, and 1.3; exchange rate data for the CSFR can be found in Table 3.3 in Chapter 3 by Hrnčír $)^{3}$

Besides this phenomenon, there are many further similarities in economic trends and conditions in the three countries. First, in each of them a very rapid liberalization of trade occurred. Although, in contrast to the shock approach implemented in the CSFR and Poland, Hungary is considered to have pursued a gradual strategy; actually by international comparison all three countries opened up their economies very rapidly, especially in view of the exceptionally powerful protection these countries had provided for their industries prior to liberalization. A distinctive element that may be considered part of the protection in each country was the special trade and payments arrangement they had with their Eastern trading partners. The formally multilateral, but actually bilateral, arrangements in the Council for Mutual Economic Assistance (CMEA) system offered the producers of the member countries markets almost completely sheltered from international

\footnotetext{
${ }^{2}$ Until the outbreak of the civil war, the former Yugoslavia also went a long way toward liberalizing its economy. The former German Democratic Republic (GDR), after the currency union with an extremely overvalued exchange rate, institutional shock therapy, and the vast resource inflow from the western part of the country, is in no way comparable to the other countries of the region. The stabilization and liberalization efforts in Slovenia and Estonia, though apparently successful, are too new to offer grounds for comparison.

${ }^{3} \mathrm{~A}$ real exchange rate index is interpreted as the ratio of a country's relative price (or cost) index to its nominal exchange rate index. Relative price indices indicate the ratio of the country's domestic price (cost) changes to price (cost) changes abroad. The real exchange rate of a country is considered to appreciate if the nominal devaluation (or depreciation) of its currency is smaller than the country's relative inflation. In this chapter an "upward movement" of the RER signifies a real appreciation and a "downward movement" of the RER indicates a real depreciation.
} 


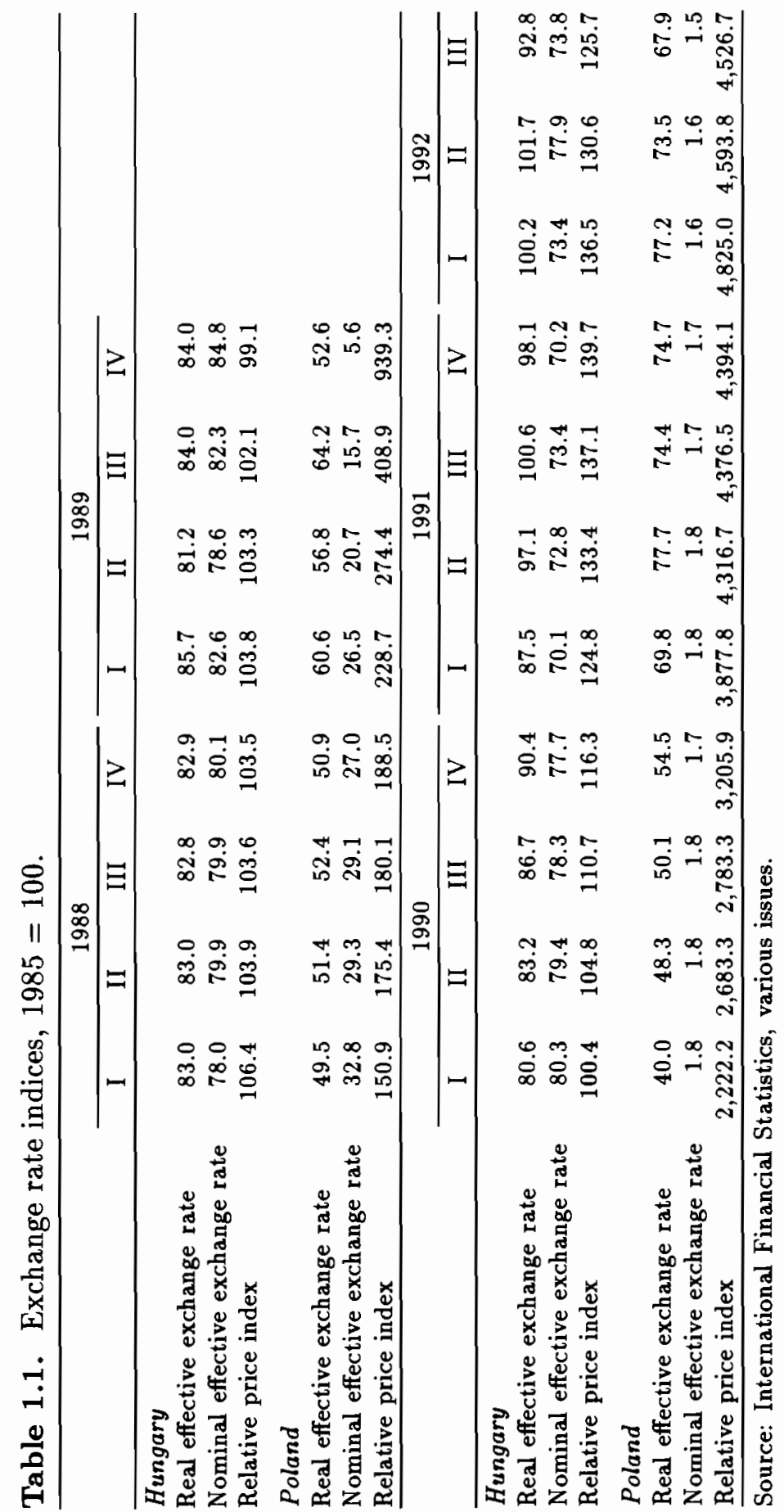




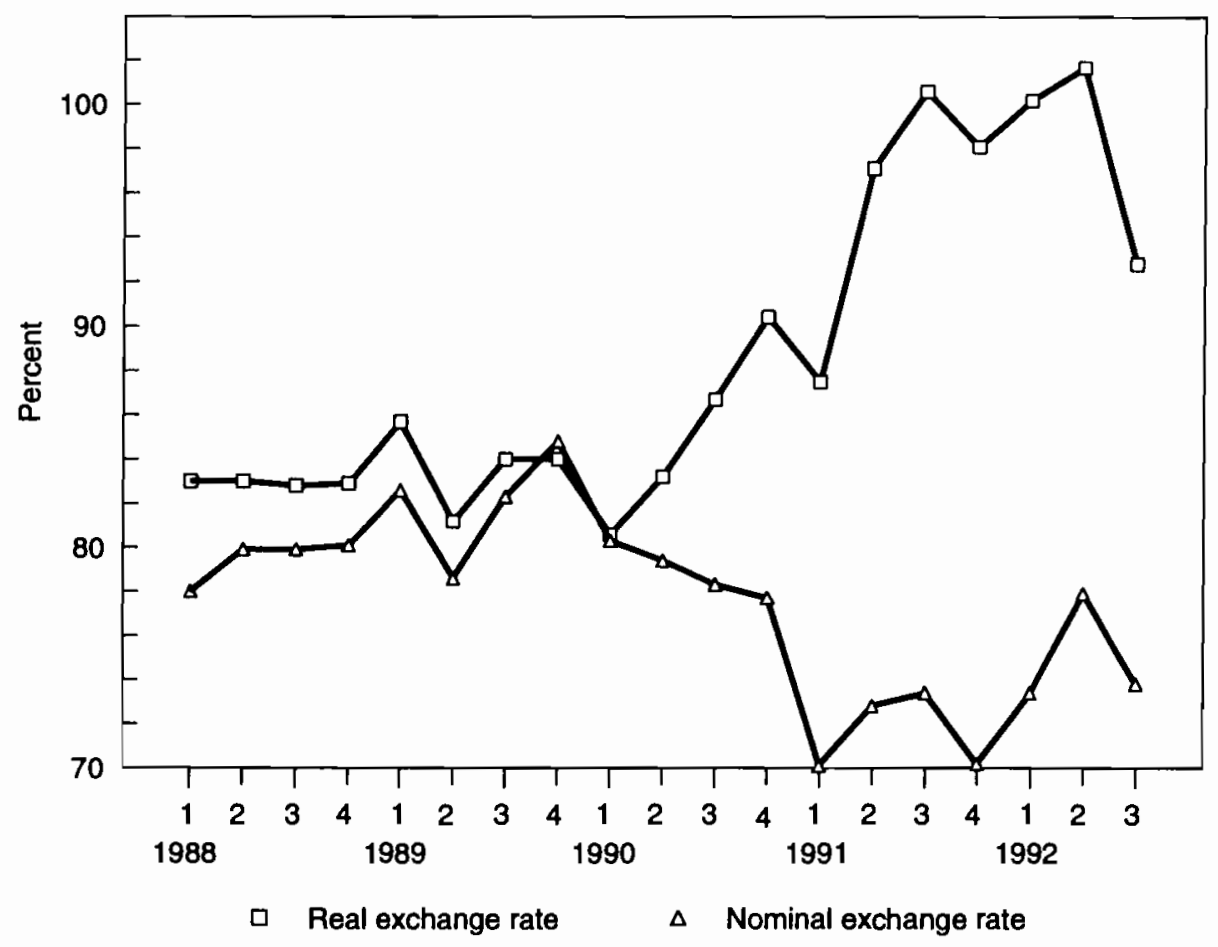

Figure 1.1. Hungary: nominal and real effective exchange rates, $1985=100$. Source: International Financial Statistics, various issues.

competition. The demise of this system and the accompanying collapse of intraregional trade occurred in conjunction with the rapid dismantling of the protection that had been accorded to their industries. Since views concerning the impact of these changes on the required movements in exchange rates differ, one of the themes to be discussed in this chapter is the effect of import liberalization and the collapse of the CMEA markets on "warranted" (that is, economically justified) RER changes.

A further similarity in the three countries is their surprisingly favorable recent foreign trade and payments performance. Capital inflows - most notably in Hungary's case, but in that of the other two countries as well contributed to an increase in international reserves. Trade performance is considered to have been surprisingly good because, in spite of the large drop in exports to the Eastern markets, the trade balance deteriorated much less than originally expected. 


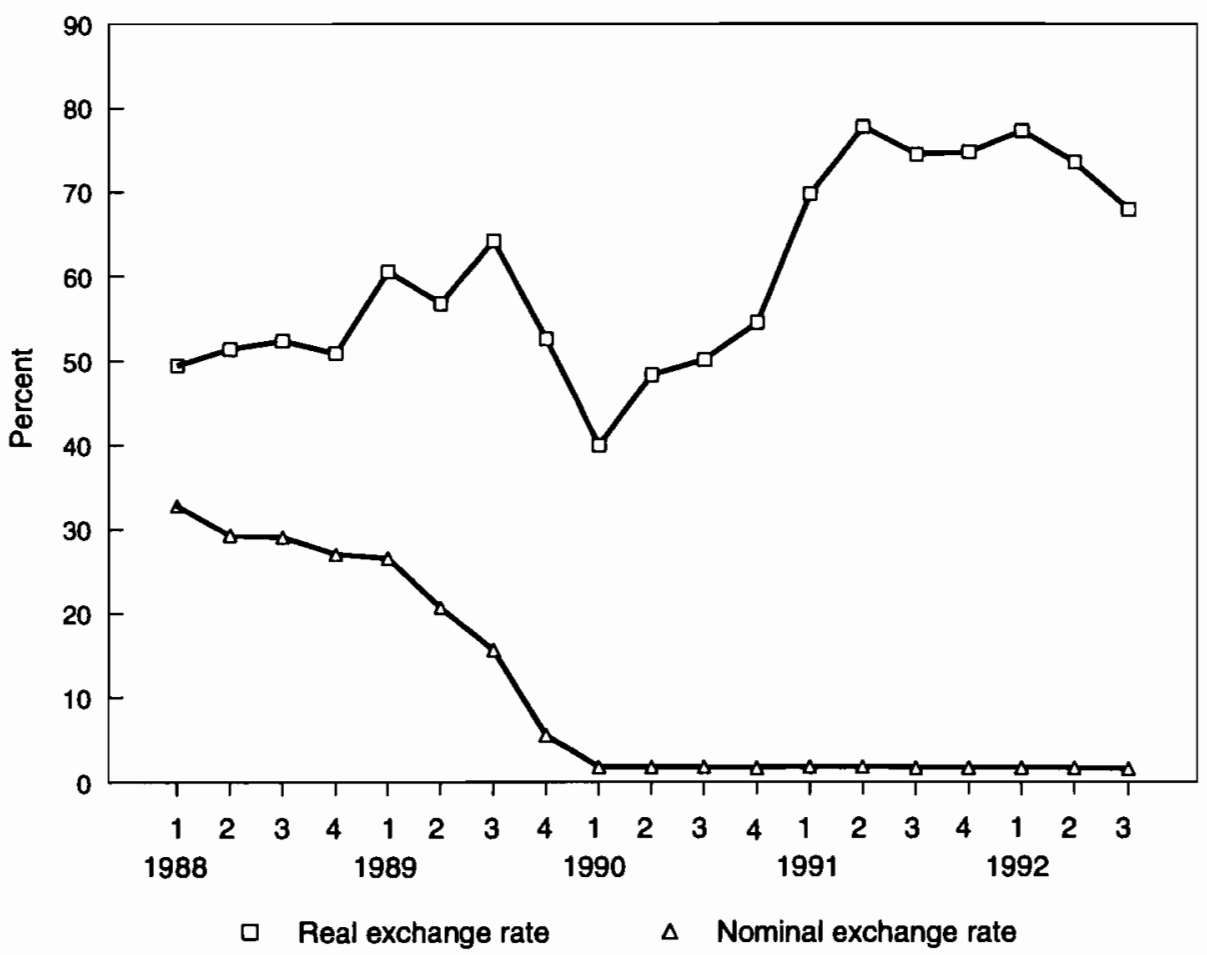

Figure 1.2. Poland: nominal and real effective exchange rates, $1985=100$. Source: International Financial Statistics, various issues.

These favorable developments in the external sector seemingly fully justify the aforementioned upward movements in RERs, as does a further common feature of these countries: the very large difference between the purchasing power parity (PPP) and the exchange rate of their currencies, indicating a very significant undervaluation of these currencies relative to their PPPs.

However, both of the factors that may contribute to the real appreciation of the currencies under discussion, and, by implication, might justify this trend, are subject to further considerations. On the one hand, the impressive trade and payments performance of these countries has been closely associated with the sharp decline in economic activity, involving a substantial and prolonged drop in production (especially that of industry), as well as a significant increase in unemployment. Moreover, the remarkable improvement of the balance of payments, at least in two of the three countries, 


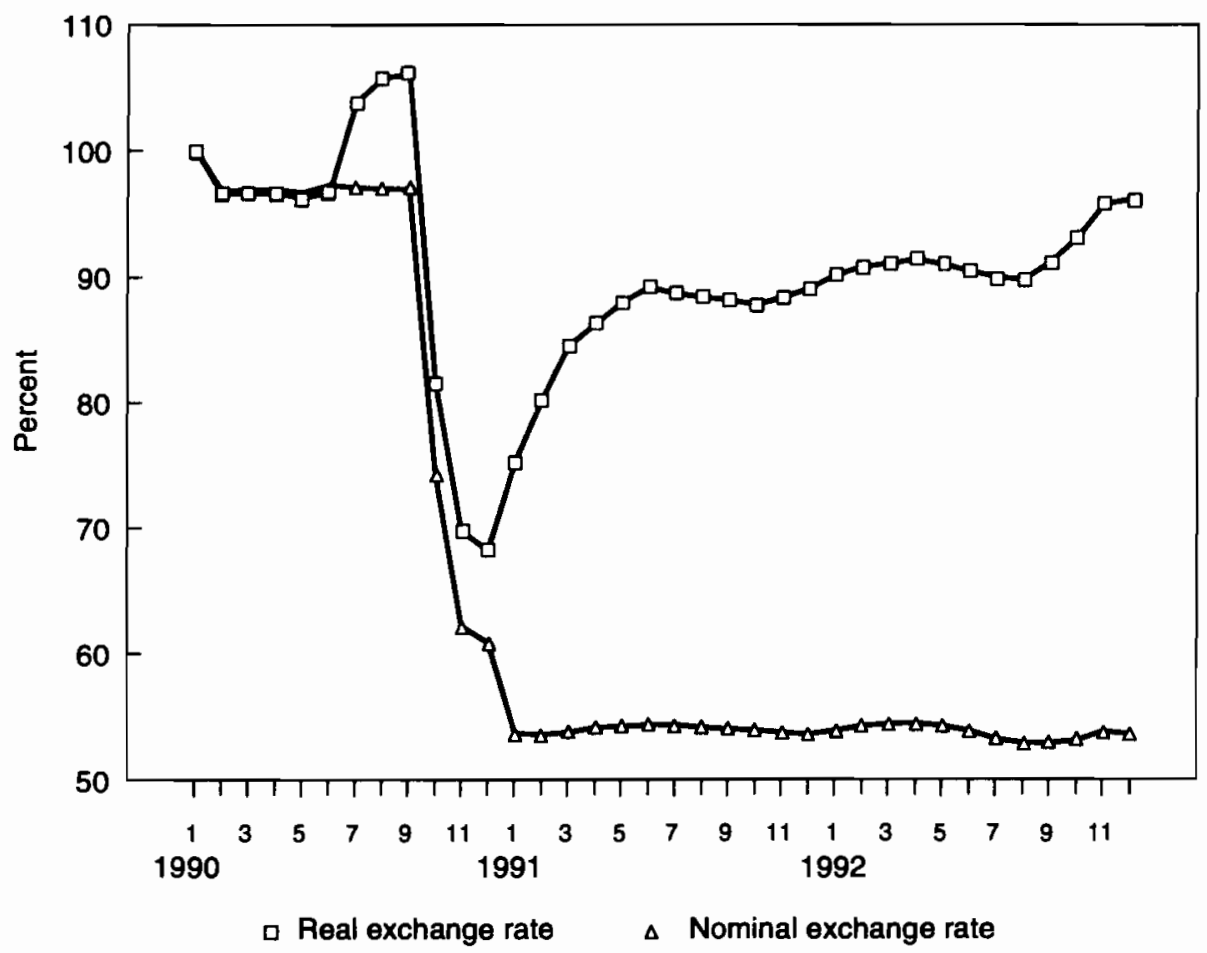

Figure 1.3. CSFR: nominal and real effective exchange rates, January 1990 $=100$. Source: Table 3.3 of Chapter 3 by Hrnčír in this book.

has been partly due to the inflow of foreign capital, the nature and longevity of which requires further analysis. On the other hand, the interpretation of the massive deviations between PPPs and exchange rates also deserves further study. Although it is very likely that the scope of the current differences ought to decrease as these countries are drawn closer - in terms of both institutions and income levels - to Western market economies, it is by no means self-evident that this is to be seen as a short-term process. The case may be just the opposite; that is to say, in the short or even medium run, but especially at the early stages of economic transition and in the deep economic slump that now prevails in these countries, the temporary maintenance of the existing differences between exchange rates and PPPs may be economically justified and, therefore, constitute a legitimate goal for exchange rate policy. 
This brings us to our final topic: exchange rate policy proper. The discussions and controversies over the fundamental determinants of the exchange rate levels and changes become practically relevant through their influence on exchange rate policies. Even if it is true that in the long run exchange rates are determined by "fundamentals," that is, by underlying economic factors, in the case of a pegged exchange rate it is the perception of policy makers that has the most significant short-run influence. Therefore, the role of the exchange rate as a policy instrument demands special consideration.

In all three countries, at one time or another, the goal of controlling inflation came to the foreground; exchange rate policy was seen as an adjunct to this goal. This is true to a lesser degree for Poland after May 1991, when the fixed rate was abandoned, after which a crawling peg was introduced in October 1991, following a substantial increase in domestic prices. But in the CSFR, and in Hungary as well, the exchange rate has become to an increasing extent a major instrument for combating domestic inflationary pressures. In the CSFR the rate fixed in late 1990 has served as a nominal anchor in the tidal wave of inflationary pressure that came with price liberalization; in Hungary, without using it as a nominal anchor, it still became the most important policy device for reducing inflationary expectations and inflation itself. In the case of the latter there was a further argument presented in favor of an exchange rate policy aiming at real appreciation, according to which the burden of foreign debt and debt service expressed in domestic currency could be reduced - at least in relative terms - by a rise in the real exchange rate. Indirectly, this view also concerns the anti-inflationary role of exchange rate policy.

This paper reviews some of these issues concerning real exchange rate changes and their implications for exchange rate policy in the three countries. Although we focus on the experiences of these specific countries, and in particular on Hungary, we also look at some general issues concerning exchange rate policy during the transition. The particular features of the countries will be compared and, if appropriate, contrasted with one another and with those of other transition economies.

In the next section we deal with some of the similarities and differences in the countries' initial conditions and their relation to other countries of the region in terms of exchange rate system and related policy framework. In the third section issues concerning the measurement and interpretation of RER changes are discussed. Next, the specific problems of RER movements in 
transition economies are treated. This is followed by a review of the potential impact of import liberalization and of the special factors behind trade and payments developments. The final section treats the relationship between PPPs and exchange rates in the three countries, discusses its relevance for exchange rate policies, and draws some conclusions.

\section{Economic Transition and Exchange Rate Developments: Preliminary Considerations}

\section{Exchange rates in traditional and modified centrally planned economies}

In the typical centrally planned economy (CPE) the official exchange rate had no economic role whatsoever. It served statistical purposes (it was used for expressing the "devisa equivalent" of foreign trade transactions), but it did not function as an exchange rate. It did not affect export revenues or import costs in the domestic currency, which were determined by the price equalization system. ${ }^{4}$ Comparing the official exchange rate to the (tourist) black-market rates, it may have seemed logical to conclude that the official rate overvalued the currency. This seemingly logical inference, however, would have missed the point, since the "overvaluation" of the currency can be interpreted only in regard to conversion factors that perform at least some of the functions of an exchange rate. But in the traditional CPE no such concept could be interpreted, at least not for foreign trade and payments. Whatever level it assumed, the official rate had no effect on trade flows. ${ }^{5}$ In those economies of CEE that were characterized by the traditional mode of central planning at the start of the transition, an important first step in the stabilization and transformation program was the establishment of an exchange rate. The establishment of an exchange rate in all cases involved a substantial devaluation of the official rate; but, as indicated, these cannot be interpreted as adjustments of already existing exchange rates.

\footnotetext{
${ }^{4}$ The essence of the price equalization (Preisausgleich) system is that producers of exports and users of imports receive and pay, respectively, domestic accounting prices that could be - in fact, were - quite different from foreign prices converted at the official exchange rate (see, for example, Wolf, 1988; and Wiles, 1969).

${ }^{5}$ Though this statement holds as a general proposition, it requires some qualifications. As pointed out, for example, by Schrenk (1991) and Lawson (1988), a change of the official exchange rate could have macroeconomic effects by influencing the net position of the price equalization fund.
} 
The situation was different in Hungary and Poland where, as a result of partial reforms of the traditional central planning introduced earlier (in the late 1960 s and early 1980 s, respectively), commercial exchange rates had been set. True, these were not uniform de facto rates, since an extensive system of export subsidies and import controls was tied in with exchange rates. However, in the case of these reformed, or modified, centrally planned economies (MCPEs) certain concepts and models of exchange rate determination and the entailed effects of exchange rate changes started to make sense. ${ }^{6}$ For example, the concept of overvaluation of the currency at the commercial exchange rate became relevant; the trade regime could be interpreted as one based upon a multiple exchange rate system and the effects of exchange rate adjustments on the trade balance became a relevant issue. However, in spite of these significant changes, partly because of the general characteristics of the MCPEs (limited autonomy of microeconomic agents, price controls, underdevelopment of financial intermediation, and so on) and partly due to the features of the trade regime, the role of the exchange rate remained limited even in those countries that moved furthest toward "marketizing" the Soviet-type economic system. As for the trade regime, even the most "marketized" economies (Hungary and Poland) remained exceptionally closed in terms of institutions and trade policy. There were several insulating features. First, there was the system of import controls, namely, formal and informal quantitative restrictions on foreign purchases (Gács, 1991). Second, the state foreign trade organizations were also involved in checking imports. Third, and of particular importance, the state trading system in conjunction with the CMEA offered sheltered, secure markets for a significant part of domestic output, in particular for industrial production. These features resulted in a limited role for the commercial exchange rate in MCPEs as well.

Therefore, in order that the exchange rate perform its proper role, in MCPEs two tasks were necessary. First, macroeconomic balance had to be achieved and the misalignment of the commercial exchange rate deriving from macroeconomic causes (excess domestic demand at the ruling official exchange rate) corrected. It is not likely that this could be accomplished gradually; it had to be done in one step. The second task pertains to the institutional framework of exchange rate policy, most importantly to the degree of liberalization of foreign trade. The proper approach to opening up these

\footnotetext{
${ }^{6}$ On the concept of MCPE and related effects of devaluations see, for example, Wolf (1985).
} 
economies is far from being self-evident. Several authors hold that there are persuasive arguments for the gradual opening up of extremely protected economies such as those of the transition countries of CEE. ${ }^{7}$ Nowadays, the accepted view seems to be that import liberalization ought to be carried out as rapidly as possible. We return to this point later; for now, suffice it to say that the radical and instant opening up of (as often stated: the immediate introduction of convertibility in) tightly closed economies has no historical precedents. It is likely to involve significant economic and social costs, especially if accompanied by the collapse of a large previously protected foreign (CMEA) market. Nevertheless, the nature and magnitude of these costs, as compared with the potential benefits of a radical opening up, is subject to controversy. From the point of view of this paper, however, it is not the general economic and social costs that are relevant, but rather the impact of these factors on exchange rate policy in general and on the extent of devaluations in particular.

\section{Factors affecting the initial devaluation}

It may be conjectured that at the start of the transition process, the magnitude of the initial devaluation of the official exchange rate depends on the following factors. First, and perhaps most important, is whether or not a commercial exchange rate existed at all prior to the transition. If it did not exist, the primary task is the creation of an exchange rate either by the authorities or by economic agents. It should not be presumed that the participants in a newly established foreign exchange (auction) market have better information than the authorities about what the "proper" level of the exchange rate is. To be sure, both are likely to possess very limited knowledge, especially regarding its medium- or longer-run level. Therefore, the initial devaluation is likely to depend on the parallel (black) market rate, which offers at least some guidance, however biased and distorted it may be. Since, as already mentioned, in the traditional centrally planned economies the official exchange rate had no economic role (its level was often fixed at some outmoded gold parity meant to express the "strength" of the currency), it is reasonable to expect that the creation of an exchange rate will normally involve a substantial devaluation. Its magnitude may be larger if left to the market, because uncertainties over government policies, spillover effects from other markets, and the lack of other financial assets are bound

\footnotetext{
${ }^{7}$ See, for example, Levcik (1991), McKinnon (1991), Köves and Oblath (1991), and Oblath (1991).
} 
to push the domestic price of foreign exchange to an artificially high level (see, for example, the early experiences of Bulgaria or the sharp depreciation of the ruble in 1992). However, if a country has no international reserves, it may have no choice but to let the currency float.

Second, the extent of the initial devaluation depends on the intensity of the inherited macroeconomic imbalances, in particular excess domestic demand. This, as is well known, may have two components: a "stock," often referred to as monetary overhang, and a "flow" deriving from budgetary deficits and/or wage increases that are unsustainable at current price and exchange rate levels. It is worth noting that the second (flow) type of macro imbalance may also occur in a market economy maintaining fixed exchange rates, though the latter would normally not have to deal with the peculiarities stemming from the prevalence of officially fixed (controlled) prices, and the magnitude of such an imbalance would likely be much smaller. At any rate, the problem in this case is in the incompatibility between the level (or growth) of aggregate domestic demand, on the one hand, and that of the fixed exchange rate, on the other. To tackle this imbalance, it is necessary to devalue the currency and reduce domestic demand. Note, however, that this may be accomplished at any (for example, unchanged) level of protection of the domestic economy.

This takes us to the third factor that may affect the initial extent of the devaluation: the change of the institutional setting, most importantly the trade regime. In this context, issues concerning two important and partly related matters are raised: the impact of trade liberalization on exchange rates and the collapse of Eastern (CMEA) trade. As for trade liberalization, it can be expected that, other factors being equal, the further an economy has been from an open trade regime (that is, the closer it has been to the traditional model of central planning ${ }^{8}$ ) and the more swift and radical the trade liberalization, the larger is the necessary initial devaluation. This conjecture, in agreement with the standard literature of trade theory and policy, implies that a more gradual import liberalization and/or a transitory "tariffication" of former quantitative restrictions would require a smaller devaluation than would otherwise be the case. ${ }^{9}$.

The impact of the collapse of Eastern trade is less clear-cut. While some implications of this shock indicate the necessity of additional devaluation

${ }^{8}$ The former nonexistence of a commercial exchange rate may indeed be considered an indication that the economy had approached the ideal type of "total closedness"; see Oblath (1988) on this point.

${ }^{9} \mathrm{See}$, for example, Corden (1987), Krueger (1978), Edwards (1992), and Rodrik (1992). 
(beyond that warranted by the foregoing factors), some others point in the opposite direction. Although we return to this point in a later section, some preliminary remarks are in order. On the one hand, the dramatic fall in exports to the former CMEA area necessitates the reorientation of this trade toward the West (at least a part of it), involving higher costs and/or lower prices - suggesting the necessity of further devaluation. The terms-oftrade shock associated with the switch from ruble (clearing) trade at CMEA prices to dollar trade at world prices and the resulting deterioration in the trade balance carry the same implication (Oblath and Tarr, 1992). On the other hand, the large fall in exports to the East could contribute to an easing of the domestic imbalance (excess demand) or induce companies to explore Western markets. Furthermore, depending on the institutional details, in particular the former domestic cross rate between the dollar and the ruble, the switch could even increase the home currency revenues of those companies that manage either to reorient their former Eastern exports or to keep their Eastern markets. All in all, the effect of the collapse of Eastern trade on the exchange rate is ambiguous and without further inquiry definite statements cannot be made.

Let us now try to apply this framework to the three transition countries. While Hungary and Poland, the two former MCPEs, already had commercial exchange rates before the transition, the CSFR introduced one only in 1990. The CSFR's economy had clearly been the most closed of the three. However, from the point of view of macroeconomic imbalances, it was perhaps in the best situation. In this respect, Poland clearly was in the worst state: before the stabilization and liberalization program its inflation approached rates associated with hyperinflation, with simultaneously increasing shortages. Hungary's domestic market in turn was relatively stable (at the cost of very large foreign indebtedness), and it probably went the furthest among countries of CEE in reforming its economy under the predemocratic political system. In the present context, it is particularly noteworthy that, in 1989, Hungary launched a significant, but gradual, trade liberalization program aimed at removing administrative (nontariff) trade barriers on its imports. The other two countries chose a more radical approach to trade liberalization. Poland opened up its economy in one stroke and introduced the (resident) convertibility of its currency in early 1990. Although there are some differences in details between the Polish and the CSFR trade and foreign exchange reforms, the similarities are more significant (see Chapter 5 by Gács). 
The foregoing discussion helps explain the similarities and differences in exchange rate changes and related policies in the three countries. Given Hungary's relative macro stability and gradual liberalization strategy, there were no significant devaluations (the largest, 15 percent, occurred in early 1991). ${ }^{10}$ In Poland and in the CSFR, in turn, very large devaluations were effected. Although at the outset Poland was considerably more open than the CSFR, its macroeconomic imbalances were far more severe; and since both opted for a radical and rapid opening, in spite of their initial differences, both had to devalue their currencies drastically.

It should be noted that up to this point only nominal devaluations have been discussed. The real impact of nominal exchange rate changes depends on factors affecting domestic price changes following exchange rate adjustments; this issue is treated in the next section.

An important topic, however, should be addressed before treating the problems of real exchange rate changes: domestic price liberalization. If the formerly controlled prices are liberalized simultaneously with the devaluation, the change in the real exchange rate is necessarily much smaller than what might be expected without the removal of price controls. A crucial question here is whether a real devaluation is necessary in the context of the reform package or would a nominal adjustment suffice. For reasons to be discussed, there are several conceptual problems with the precise interpretation of this question, but at least a preliminary assessment can be given. Berg and Sachs (1992) explicitly address this matter; their answer is no. In an analysis of the Polish experience, they assert that in a situation characterized by large monetary overhang and price controls (and, as a consequence, shortages and queuing), a nominal devaluation accompanied by price liberalization solves the macroeconomic imbalance without a realdevaluation. The point where their reasoning appears to be at odds with the implications of the framework presented above is in the impact of trade liberalization. While they claim that opening up (convertibility of the currency) requires just a nominal devaluation and price liberalization to absorb the overall excess demand (see, in particular, Berg and Sachs, 1992, pp. 121124), our framework builds on the assumption that opening up the economy necessitates additional devaluation as compared with the one required for restoring macroeconomic balance at an unchanged level of protection. This,

\footnotetext{
${ }^{10}$ It is worth noting that export subsidies have also been removed gradually, thus the former de facto multiple exchange rate regime was unified.
} 
though it has not been stated explicitly, implies that opening up warrants a devaluation in real terms.

The two views are not necessarily mutually exclusive. There are two potential ways to reconcile them; both are treated in the sections that follow. One is through rendering due attention to the effects of changes in the level of activity - an issue not even touched upon as yet. Thus it is conceivable that a stabilization package aimed at absorbing excess domestic demand and correcting macroeconomic disequilibria, combined with instant trade liberalization and nominal devaluation, results in so deep a recession that the liberal trade regime turns out to be sustainable even without a real depreciation. The other possibility is that the conventional indicators of real exchange rate changes should not be taken at face value with respect to transition economies. We now turn to the problems involving the measurement and interpretation of RER changes.

\section{Real Exchange Rate Movements: Problems of Measurement and Interpretation}

The measurement and interpretation of real exchange rate changes in general raise several difficult issues. Nevertheless, it is no exaggeration to say that the problems in the case of market economies seem trifling compared with those involved in quantifying and interpreting RER movements for transition economies.

Generally speaking, three types of seemingly technical questions have to be resolved when measuring changes in RERs. First, a choice has to be made of whether the RER is calculated using just two currencies or all partner currencies, that is, whether a bilateral or a multilateral comparison is made. In the latter case, the question arises as to the proper basket (weighting system). We rely mainly on the latter concept, but, as it would lead us too far afield and, moreover, it is not specific to transition economies, we shall ignore the weighting issue in this chapter. Second, a choice has to be made of the relevant price (cost) index or indices. Third, the base period has to be determined relative to which the RER changes are measured (see the thorough survey by Maciejewski, 1983).

These questions are evidently not just technical; they are closely related to the conceptual issues in interpreting RER changes. In broad terms, RER indices reflect deviations of a currency's exchange rate from purchasing power parity (PPP). Given that RER indices are, by definition, ratios 
of index numbers, they are conceptually related to the relative version of the PPP theory. But this doctrine, even in its relative form, is not a single theory; it consists of several alternative theories (see Officer, 1982; and Dornbusch, 1985). An important aspect in which the various approaches differ is which price (cost) index is considered relevant for PPP computations. This underscores that the choice of the price index in RER calculations is likely to be more than just a technical issue. More to the point, the interpretation of RER indices requires either the acceptance of (or some version of) the PPP theory or a broader theoretical framework, involving the concept of an equilibrium exchange rate. This framework, in turn, would have to specifically address the role of relative prices (thus PPP) in determining the equilibrium exchange rate. By implication, not just the role of relative price changes would have to be clarified, but also that of the absolute PPP, specifically the relationship between price levels and exchange rates, as well as the association between exchange rate equilibrium and equilibrium relative prices (specifically between those of traded and nontraded goods) in the home country.

Needless to say, this paper does not address all these issues. The purpose here is to demonstrate that the measurement and interpretation of RER changes raise a number of general conceptual and methodological problems even in market economies. In the following sections, we show that the problems involved are yet more complex and difficult for transition economies.

\section{RER Changes and Economic Transition}

In the case of the transition economies, three points deserve special attention: the distinctive problems associated with the selection and interpretation of the relevant price indices; the choice of the base period; and the interpretation of the structural factors related to, or affecting, RER changes.

\section{Price indices}

As pointed out by Maciejewski (1983), there are at least as many choices regarding the "correct" price indices for calculating RERs as there are analytical or policy questions pertaining to price (cost) movements (expressed in a common currency) of a given country relative to the rest of the world. This is important because different price and cost levels in any country may change in different proportions, and so can the cross-country ratio of the various price and cost indices. There is, however, a special issue in the case 
Table 1.2. Consumer price indices (CPI) and producer price indices (PPI), previous year $=100$.

\begin{tabular}{|c|c|c|c|c|}
\hline & \multicolumn{2}{|l|}{1990} & \multicolumn{2}{|l|}{1991} \\
\hline & CPI & PPI & CPI & $\overline{\text { PPI }}$ \\
\hline CSFR & 110 & 104 & 174 & 177 \\
\hline Hungary & 129 & 122 & 135 & 129 \\
\hline Poland & 685 & 722 & 170 & 148 \\
\hline
\end{tabular}

Source: International Financial Statistics, October 1992.

of transition economies involving unusual problems - namely, the liberalization of prices. Depending on the timing and the type of domestic price liberalization, producer and consumer price changes can deviate to a significantly larger extent than is normal in market economies. This, as shown in Table 1.2, holds the least for the CSFR, where some important consumer prices have still not been liberalized. In Hungary consumer prices consistently increased to a larger degree than producer prices as prices were being liberalized, whereas in Poland there were significant differences between the rates of change of the two price levels in the years 1990 and 1991, but in the reverse fashion.

Therefore, depending on whether a producer or consumer price index is used in calculating the RER index and which particular subperiod is considered, quite different results may be obtained, indicating divergent movements in RERs. One reason why it is vital to be aware of this divergence is that the informational content of the two types of RERs - the one based on the consumer price index (CPI) and the other on the producer price index (PPI) - is quite different. With some simplification, the RER index based on relative PPIs may be considered to reveal changes in domestic exporters' price or cost competitiveness in foreign markets. The RER index involving CPI comparisons in turn offers a rough indication of changes in domestic producers' price competitiveness vis-à-vis imports. This, of course, should be regarded as a very rough indicator; nonetheless, it should be taken seriously, especially at a time of radical trade liberalization. We shall return to this point later.

The other aspect of the divergence between the RER indices based on PPI and CPI comparisons has been amply treated in the international literature (see, for example, Aghevli et al., 1991; and Edwards, 1992): it may offer a rough idea of the change in the relative price of the tradable relative 
to the nontradable sector in the domestic economy. ${ }^{11}$ This relative price is an especially important one: it is often referred to as "the" real exchange rate in the theoretical literature (see Bruno, 1976; Dornbusch, 1988; and Neary, 1988). Its particular significance lies in the fact that changes in it affect the domestic demand for and supply of tradable and nontradable goods (services), respectively; it influences relative profitability of, and therefore the incentives for investment in, the alternative sectors - a central issue in transition economies. ${ }^{12}$

These observations are meant to call attention to some implications of applying alternative price indices to RER calculations and to caution against judgments based on a single RER index. The case in point is using only the RER index based on PPI comparisons for evaluating exchange rate developments. This, as mentioned above and discussed later, might be a suitable indicator of changes in export price competitiveness, but in itself may turn out to be misleading.

Beyond the actual choice among the available price indices, there is a further difficulty, quite specific to transition economies, concerning the computation and interpretation of RERs. ${ }^{13}$ This stems from the difficulty of comparing price indices between a period in which acute shortages prevail, with another in which the shortages have already been eliminated. The practical implication of this problem is that RER movements before and after the elimination of shortages (namely, the pre- and post-stabilization periods) are not likely to be directly comparable. As a result, the presentation of RER indices as a continuous time series over the two periods may give rise to misleading interpretations. This is the case because with the elimination (or significant alleviation) of shortages, various types of costs previously associated with the shortages, for example, queuing (Kornai, 1980) - evidently not included in the official price index - are also eliminated. This issue may be especially relevant for Poland (where, as we shall see, the RER appreciated to the greatest extent since 1990); less for the CSFR; and probably the least for Hungary.

\footnotetext{
${ }^{11}$ If traded goods' prices were equalized internationally, the ratio of the price of traded goods to that of nontraded goods would move in line with relative CPIs; see the derivation in Aghevli and Montiel (1991).

${ }^{12}$ This point was made especially forcefully by Winiecki (1992).

${ }^{13}$ Though the other price (cost) indices (GDP deflators, unit labor cost index, and so on) have not been treated, the problems regarding their use may be traced to those already discussed.
} 


\section{Base period}

This perhaps is an even more difficult issue than the previous one. In order that the interpretation of RER movements not lead analysts and policy makers astray, the base period should, at least in principle, be a period in which the actual exchange rate corresponds to its equilibrium value. Although the concept of an equilibrium exchange rate is far from unambiguous, most definitions associate it with an exchange rate consistent with both external and internal balances. External balance normally refers to a sustainable balance on the current account; internal balance is related to full employment or the natural unemployment rate. Understandably, the literature on equilibrium exchange rates does not consider the absence of general shortages a component of the definition of "internal balance." 14 The incorporation of the concept of "internal balance" is due to the recognition - presented first and most forcefully by Robinson (1937) and Harrod (1939) - that equilibrium in the balance of payments may be achieved at any (low) level of economic activity. For contemporary market economies, the significance of this element in the definition is related to the fact that, while the balance of payments may be influenced by cyclical fluctuations in economic activity, the equilibrium exchange rate, at least if interpreted as its medium- or longer-term value, is not subject to such cyclical variations.

Evidently, it is not easy to identify real-world situations corresponding to this definition of the equilibrium exchange rate. The less so, since neither the concept of external nor that of internal balance is really clear-cut. Nevertheless, there are pragmatic ways of forming rough judgments of how far the exchange rates of certain OECD countries have deviated from their medium-term levels in specific time periods. This is clearly not saying a great deal, but it certainly is more than what we can say about the level of exchange rates in transition economies, where the problem is not in identifying a period of exchange rate equilibrium, but the certainty that in the past (namely, under central planning) no such period could possibly have existed. This is clear enough in the case of countries where commercial exchange rates simply did not exist. But the statement holds also for MCPEs, where, as discussed earlier, serious domestic and external imbalances and/or

\footnotetext{
${ }^{14}$ Officer (1982) presents a comprehensive review of the historical evolution and alternative interpretations of the concept of an equilibrium exchange rate. We bypass that branch of the literature which considers this concept irrelevant or misleading (for example, Robinson, 1937; and Balassa and Schydlowski, 1968), but we certainly agree with Edwards's (1992) contention that "there is not a single equilibrium exchange rate."
} 
a large arsenal of nontariff and nonmarket barriers to imports, as well as complicated and differentiated export subsidies, held sway.

The foregoing explanation has both practical and theoretical implications. Practically speaking, the choice involving a pre-transition base period does not make much sense, or may lead to false conclusions. It may, of course, be interesting to look at the RER before and after significant stabilization and liberalization measures were introduced, but, as noted above, time series of RER indices for the transition period should not be interpreted simply as the extensions or continuations of pre-transition time series, even if the price indices and weighting systems are the same for the two periods (that is, the RER index is formally of the same type). Thus, the correct, or at least conceptually acceptable, base period would be one involving the identifiable beginning of the transition (or one immediately following it). This is easy in the case of countries where stabilization-cum-liberalization measures were introduced in a single policy package (Poland) or where these measures followed one another within a short time span (CSFR). Hungary is a special case in this respect, since both reform and stabilization measures were introduced gradually and stretched over a long period. Nevertheless, as we shall see, some signals, stemming from the sequencing of liberalization, may assist us in chosing the potential base periods.

Turning to the theoretical implications, the most significant is that in the case of transition economies no proper standards exist for evaluating the level of the exchange rate. To put it differently, it is not simply difficult, but literally impossible, to interpret the concept of an equilibrium exchange rate in the pre-transition period, even in the very loose sense referred to above. That exchange rate, in turn, which is introduced as part of a major reform package is not likely to represent an equilibrium rate; as a matter of fact, it is not meant to and, indeed, cannot possibly be one. It is worth recalling that the concept of an equilibrium exchange rate incorporates the notion of full employment (or natural unemployment rate); that is to say, some normal level of activity over the business cycle. Now, in the case of transition economies, it is hopeless to try to interpret either the normal level of activity or cyclical movements. The level of activity is falling everywhere in CEE, and, since nothing is known about its normal level, there are no clues as to whether the observed decline is already too large or further falls are still inevitable, and, if so, how large these are supposed or expected to be. The relevance of this question, as we have already seen, stems from the fact that a sustainable external balance may be achieved at any (low) 
level of activity, and - before turning to empirical matters - one should be aware that there were good reasons for adding the activity criterion to the definition of exchange equilibrium.

Therefore, there are no solid grounds for assessing what constitutes an equilibrium exchange rate in an economy under transition. Except for very drastic misalignments, it is impossible to tell whether an observed rate is below or above its normal level. As a consequence, the question whether or not RER changes of particular currencies have already gone too far in either directions is more or less irresolvable. It is, or at least should be, possible, however, to look at current and past movements of RERs and form some judgment on the direction of change. When making a judgment, several factors are considered either explicitly or implicitly. In what follows we try to be explicit and present an overview of the structural factors that are likely to affect RER changes in the transition period.

\section{Factors influencing RER movements}

It is worth recapitulating: changes in RERs may offer relatively unambiguous guidance to the evaluation of actual exchange rate movements if the base period entails an equilibrium exchange rate, the alternative relative price indices do not deviate significantly, and, most importantly, there are no such structural changes which in themselves warrant RER changes. ${ }^{15}$ From the above discussion it should be clear that neither of the first two conditions are fulfilled in the transition economies of $\mathrm{CEE}$. In this section we concentrate on the third item: structural changes.

It should be emphasized at the outset that in this context two issues are actually involved. One concerns the explanation of observed RER movements. The other is related to the identification of factors that may affect the warranted changes in RERs. The two do not necessarily correspond to each other - at any rate, not in the short term. Actual RER changes, unless the currency is freely floating, are influenced mainly by decisions of policy makers regarding nominal exchange rates in the face of domestic price inflation (the latter only partly under policy control, and itself a function of nominal changes in the rate of exchange). The real exchange rate, therefore, is not a direct policy instrument. In case of a floating rate, the decision

\footnotetext{
${ }^{15}$ See, for example, Dornbusch (1985). The reader is reminded that the fourth related issue, the "appropriateness" of the weighting system for calculating real effective exchange rates, is not discussed in this paper.
} 
maker with respect to the change in the nominal exchange rate is the market. But, as discussed, the participants in foreign exchange markets in transition economies may be driven to their decisions by the lack of financial instruments other than foreign exchange, and their information on factors affecting the exchange rate is likely to be more limited than that of the official decision makers.

The term warranted RER movements is meant to express changes justified or required by underlying economic factors, be they taken into consideration by policy makers (or/and the market) or not. Note that, for reasons treated earlier, the concept of the equilibrium exchange rate is avoided. This is not just a difference in terminology. On the one hand, warranted changes in RERs may be influenced by factors not directly related to observed balance of payments (BOP) performance. On the other hand, as we shall try to demonstrate, factors affecting BOP developments may induce unwarranted RER movements. In the following, we first review the factors related to warranted RER changes; this may serve as a reference for explaining actual movements in RERs.

Four major factors, in principle, should have a significant impact on RER movements in the transition period. The first is trade liberalization; this is treated in a following section. (As mentioned earlier, we consider the liberalization of imports a factor warranting a real depreciation.) The second is the collapse of Eastern trade. The third is the elimination of various domestic and external impediments constraining these countries' exports to the West. The fourth factor is the emancipation of the service sector in the transition period.

It is difficult to asses the impact of the collapse of Eastern markets: the effects in the short run may be the opposite to those in the long run. There are three quite different sets of factors at work here. One is the impact on the domestic currency costs and revenues of companies that used to trade with the CMEA countries; another is the reaction of these companies to the trade collapse in terms of their attempts to increase sales to the West; and the third relates to the combined influence of these factors on the convertible-currency balance of trade in the countries concerned.

The first and early assessment of these factors (see Table 1.3) may lead to the conclusion that the overall trade performance of the three countries following the demise of the CMEA trade arrangements was remarkably good, certainly much better than could be expected after a roughly 50 percent decline in their exports to former CMEA partners. 
Table 1.3. Indicators of external performance, billions of US dollars.

\begin{tabular}{lrrr}
\hline Country & 1990 & 1991 & 1992 \\
\hline Trade Balance & & & \\
CSFR & -0.78 & -0.45 & -0.90 \\
Hungary $^{a}$ & 0.94 & -1.11 & -0.37 \\
Poland & 2.20 & 0.10 & 0.50 \\
Current Account & & & \\
CSFR & -1.10 & 0.36 & 0.20 \\
Hungary & 0.13 & 0.27 & 0.32 \\
Poland & 0.70 & -1.70 & -0.30 \\
Foreign Direct Investment & & & \\
CSFR & 0.18 & 0.60 & 1.06 \\
Hungary & 0.31 & 1.46 & 1.47 \\
Poland & n.a. & 0.09 & 0.76 \\
\hline
\end{tabular}

a Trade balance in the current account differs significantly from these data: for $1990,0.35$; for 1991, 0.19 ; for $1992,-0.05$.

n.a. = not available.

Sources: International Financial Statistics, OECD Economic Outlook, East-West Investment News, and national statistics.

The other factor to be considered is the impact on the domestic price level (and by implication on relative price and RER movements) of the elimination of the special pricing system associated with CMEA trade. As discussed and formally demonstrated in Oblath and Marer (1992), the existence of the peculiar trading and pricing system associated with the CMEA resulted in the extension of the nontraded sector to involve actually traded goods, but with prices differing from (in fact lower than) world market prices. Looking at warranted RER changes from this angle, the switch to dollar trade and world market prices should contribute to the real appreciation of the currencies involved. Nevertheless, it is by no means evident that this factor is supposed to work in the short run. The third aspect related to the discontinuation of CMEA trade certainly offers a different indication: the abandonment of this special trade regime amounts to a much more extensive trade liberalization than that indicated by customary measures - the last factor, therefore, points toward the need for a real depreciation.

However, before discussing the effects of trade liberalization, it is worth taking a brief look at the other factors influencing warranted RER changes. The removal of various domestic and external impediments that formerly constrained exports is particularly important. As for the domestic factors, 
the efficiency-enhancing effects of the elimination of the monopolistic position of foreign trade organizations (FTOs) in trading with foreign countries are likely to have a favorable impact on the relative cost and price position of domestic exporters. This factor, therefore, in and of itself would call for a real appreciation of the currency, as would the beneficial effects of trade liberalization with respect to the availability of imported inputs for export goods. As for the external factors, the dismantling of foreign trade barriers, in particular those of the EC, also point toward a real appreciation.

This conclusion may be reinforced by the required relative price changes within the countries. In each of the economies of CEE, services were substantially underpriced. What was referred to as the emancipation of this sector, also argues for the increase of its relative prices - pointing to the necessity of a real revaluation.

All in all, most factors considered thus far seem to point to the necessity of an appreciation of the RER in transition economies. However, the time horizon in which these factors are supposed to exert their influence is far from clear. Two major issues still have to be discussed to clear up this point. One is trade liberalization, and the other is foreign economic (balance of trade and payments) performance. But before reviewing these crucial issues, it is worth taking a look at actual RER developments in the three countries.

\section{Actual RER movements}

As indicated by Figures 1.1, 1.2, and 1.3, RER indices based on consumer prices displayed a marked upward movement in both the CSFR and Poland following the implementation of radical stabilization-cum-liberalization programs. The real appreciation appears to be more pronounced in the latter country. The reasons for this difference are related to the fact that while both countries decided to use the exchange rate as a nominal anchor during the introduction of major price liberalization measures, Poland did not, whereas the CSFR did, succeed in promptly bringing down the rate of inflation. The CSFR still maintains the nominal exchange rate introduced in late 1990 , at the outset of its program. Poland in turn had to give up its adherence to a fixed rate and introduced a crawling peg in 1991, in order to arrest the deterioration of its producers' international price and cost competitiveness. At the end of 1992, RER indices of the two countries indicate a real appreciation of roughly 24 percent in the CSFR and 80 percent in Poland since 
the beginning of their respective programs. ${ }^{16}$ This is a significant difference indeed, even if the fact that Poland started its program one year earlier than the CSFR is taken into account. It is possible, but not very instructive, to compare the RER index to its level in the pre-transition period. The real effective exchange rate of the CSFR koruna is still somewhat below its level in early 1990, while that of the Polish zloty has increased to above the level prevailing in 1988-1989.

In Hungary, as already mentioned, there was no identifiable starting point of the transition; therefore, there is no single obvious choice regarding the base period. As shown in Table 1.1 and Figure 1.1 during 1988 and 1989 both the nominal and real exchange rates (based on consumer prices) were fairly stable. However, beginning in early 1991, a sharp upward trend can be observed. True, there was a real depreciation of about 13 percent between 1985 and 1988, but since the first quarter of 1990, the real effective exchange rate of the forint appears to have increased some 27 percent. The reason why early 1990 may have particular relevance as a base period is that this marked the start of the second stage of the country's trade liberalization program, involving the liberalization (more specifically, "de-licensing") of a major part of competitive imports. (In the preceding stage, namely, in 1989, mainly noncompetitive imports were liberalized.)

If producer, rather than consumer, prices are used to quantify RER changes (Table 1.2), the real appreciation of the forint appears to be more modest. It is the PPI that is used by the National Bank of Hungary for monitoring RER movements. However, as noted above, the content of the two indices differs and, especially in a period of large-scale import liberalization, due attention has to be given to the differences.

In the case of the other two countries, the CPI and the PPI do not display a consistent divergence (at least not for the two years reviewed). Thus, unless a specific and very short time span is surveyed, the divergence between the two indices should not fundamentally change the assessment regarding the CSFR and Poland.

Finally, the question naturally arises: how can the observed movements in RERs be explained, and to what extent do they correspond to the warranted movements discussed above? Although we do not claim to be able to give definite answers, an attempt is made in the next section to address these

\footnotetext{
${ }^{16}$ If the last quarter of 1989 is taken as the base period for Poland, the real appreciation is smaller, roughly 40 percent.
} 
fundamental questions as we turn to a discussion of the impact of import liberalization and external performance.

\section{Import Liberalization and External Economic Performance}

Foreign trade liberalization was one of the most important measures introduced in the reform packages aimed at achieving economic transition; as a matter of fact it was often considered the cornerstone of liberalization policies. Nevertheless, the implications of very rapid and radical import liberalization in countries of CEE is still a subject of controversy.

In our interpretation, other factors being equal, it is necessary that the drastic liberalization of imports be associated with, in fact compensated by, a real depreciation. If this is not the case, then other, more powerful, factors have to be influencing RER changes. However, it should be important to clarify whether these counteracting factors are of a short- or long-term character.

First, it may be useful to spell out the reasons why a real depreciation is warranted at the time of a wide-scale import liberalization. One is that companies having been well protected (including the noted effects of CMEA trade) are not likely to become competitive unless the former protection built on administrative controls is, at least temporarily, replaced by marketoriented policy instruments. The best solution is the introduction of provisional tariffs, but, if this is not a viable alternative (as in the case of Hungary, see, for example, Oblath, 1991), then a real devaluation is necessary. In both the CSFR and Poland some temporary surcharges were introduced at the time of trade liberalization; nevertheless, their economies became the most open ones in Europe (see ECE, 1992). Later on, the surcharges were rapidly reduced or removed - indicating a larger real appreciation de facto than indicated by RER indices only. Nowadays, in turn, there are indications that in both countries, and also in Hungary, pressure is mounting for increasing protection of domestic activities, and the authorities are likely to yield, at least to some degree, to this demand. This turn of events, in our view, is partly a result of the real appreciation of these currencies.

But why and how was the real appreciation sustainable? This question leads to the other reason why the exchange rate is normally expected to depreciate in real terms in the context of trade liberalization. The effects of such measures on the balance of trade and payments are usually adverse, 
Table 1.4. Indicators of real activity, percent change.

\begin{tabular}{lccr}
\hline & 1990 & 1991 & 1992 \\
\hline GSFR & & & -7.5 \\
Industrial production & -1.5 & -16.0 & -15.2 \\
Hungary & -3.7 & -21.2 & \\
GDP & & & -4.5 \\
Industrial production & -3.3 & -10.2 & -9.8 \\
Poland & -9.6 & -14.1 & \\
GDP & & & 1.0 \\
Industrial production & -11.6 & -9.0 & 3.5 \\
\hline
\end{tabular}

Source: National statistics and KOPINT-DATORG, 1992 and 1993.

at least in the short run. These effects are supposed to be counteracted by devaluation or depreciation. But in the three countries reviewed, the trade and payments balances did not deteriorate significantly; the external economic performance of these countries, as noted, was surprisingly good. Two components of external economic performance should be treated separately. One is trade performance proper; the other concerns the balance of payments.

Some recent statistics on foreign trade and payments of the three countries are presented in Table 1.3. There is a clear tendency toward improvement in the current account. Trade balances have also been improving, and, due to the significant inflow of foreign capital, the overall balance of payments performance may be considered very satisfactory.

Trade performance in all three countries seems to be very much dominated by developments in the domestic real economy, most notably by the sharp recession (see Table 1.4). The demand for imports has been falling, and companies having lost their Eastern and domestic markets had no choice but to try to increase their exports to the West, even when such trade was unprofitable. Although no systematic analysis is available, there is casual evidence from Hungary on the behavior of firms under such circumstances. Many of them cover current losses on export sales by living off their assets, for example, selling their branches, real estates, and so on. ${ }^{17}$ Evidently, this process is not sustainable. Moreover, it should be recalled that in Hungary's case the alternative RER indices reflect a weaker (or more rapidly

\footnotetext{
${ }^{17}$ On average, industrial exports were not profitable in 1991 (see Antalóczy and Koltainé, 1992).
} 
weakening) competitive position for domestic producers (vis-à-vis imports) than that for exporters. All in all, the favorable trade performance of these countries seems to be strongly associated with economic recession.

But what about the other component of balance-of-payments performance, e.g., foreign capital inflow? The evidence is even more sporadic on this than on factors affecting trade flows. Experiences in Hungary the country that has recorded the largest capital inflow within the CEE region (see Table 1.3) - indicate that a major part of the capital inflow recorded as "foreign direct investment" is in the form of short-term deposits with commercial banks. (Note that due to tight monetary policies in the three countries, interest rates have been high by international standards.) Therefore, this capital inflow, unless spent on imports, which would actually constitute a healthy and welcome development, directly contributes to either real appreciation or - by increasing international reserves of the central bank and thus the monetary base - inflation in these countries. "Once foreign investments and other private long-term capital inflows make their way into the countries [as is happening in Hungary] a Latin American-type real appreciation syndrome may set in," warned Bruno (1992). Still, he was mildly optimistic, expecting that there are substantial untapped sources of productivity growth in these economies.

This, indeed, is likely to be the case. But the critical question facing policy makers and analysts is whether the short-term real appreciation of the currencies of transition economies actually helps, or hinders, the tapping of these sources. The Latin American experiences alluded to certainly indicate that the real appreciation of the currency may be the factor most detrimental to trade liberalization and related outward-looking development strategies.

\section{Exchange Rate Policy and Purchasing Power Parities: Concluding Remarks}

In the three countries reviewed, a major objective of recent exchange rate policy has been to try to provide a firm basis for the anti-inflationary aims of overall economic policy. This policy line was abandoned in Poland after having proved unrealistic and unsustainable, but in the other two countries it still prevails. The real appreciation of the currencies of the other two countries certainly had, and may even continue to have, beneficial effects on price performance, but, as we have tried to indicate, it may not be sustainable in the long run, or only at the cost of further losses in output. 
Table 1.5. Overview of Eastern European exchange rates. For most of 1992 data are forecast.

\begin{tabular}{lrrrrr}
\hline & & Jan. & Apr. & \multicolumn{1}{c}{ Jul. } & Oct. \\
\hline CSFR koruna & & & & & \\
Market/Official exchange rate (koruna/\$) & 1990 & 16.29 & 16.67 & 16.37 & 20.18 \\
& 1991 & 27.65 & 29.92 & 31.00 & 29.89 \\
& 1992 & 28.36 & 28.85 & 29.70 & 29.95 \\
PPP exchange rate (koruna/\$) & 1990 & 6.20 & 6.15 & 6.51 & 6.83 \\
& 1991 & 8.54 & 9.71 & 10.01 & 9.93 \\
& 1992 & 10.27 & 10.34 & 10.89 & 11.28 \\
Ratio of Market/PPP exchange rate & 1990 & 2.63 & 2.71 & 2.52 & 2.95 \\
& 1991 & 3.24 & 3.08 & 3.10 & 3.01 \\
& 1992 & 2.76 & 2.79 & 2.73 & 2.65 \\
Hungarian forint & & & & & \\
Market/Official exchange rate (forint/\$) & 1990 & 62.36 & 65.21 & 64.01 & 61.37 \\
& 1991 & 68.59 & 75.18 & 77.29 & 75.21 \\
PPP exchange rate (forint/\$) & 1992 & 76.92 & 79.80 & 82.14 & 82.83 \\
& 1990 & 29.00 & 31.75 & 32.60 & 33.76 \\
Ratio of Market/PPP exchange rate & 1991 & 37.37 & 41.42 & 43.32 & 44.24 \\
& 1992 & 46.82 & 49.18 & 50.09 & 50.12 \\
& 1990 & 2.15 & 2.05 & 1.96 & 1.82 \\
Polish zloty & 1991 & 1.84 & 1.81 & 1.78 & 1.70 \\
Market/Official exchange rate (zloty/\$) & 1990 & 9,500 & 9,500 & 9,500 & 9,500 \\
& 1991 & 9,500 & 9,500 & 11,453 & 11,153 \\
PPP exchange rate (zloty/\$) & 1992 & 11,247 & 13,500 & 14,313 & 14,794 \\
& 1990 & 2,450 & 3,360 & 3,720 & 4,093 \\
Ratio of Market/PPP exchange rate & 1991 & 5,081 & 5,790 & 6,204 & 6,655 \\
& 1992 & 7,578 & 7,931 & 8,359 & 8,701 \\
& 1990 & 3.88 & 2.83 & 2.55 & 2.32 \\
& 1991 & 1.87 & 1.64 & 1.85 & 1.68 \\
& 1992 & 1.48 & 1.70 & 1.71 & 1.70 \\
\hline
\end{tabular}

Source: PlanEcon, 1992.

Both domestically and abroad, however, there is a school of thought that considers real appreciation not a source of problems, but rather a sign of becoming a normal country. Those who support this view refer to the fact that in transition economies the official exchange rate strongly undervalues the domestic currency relative to purchasing power parity (PPP). This claim is clearly borne out by the data (see Table 1.5) taken from PlanEcon 
(1992). The latest comprehensive review of real income levels and PPPs (Summers and Heston, 1991), in which Hungary and Poland were included, reveals figures for 1988; they are more or less in line with those suggested by PlanEcon.

These findings are subject to several interpretations. They may indeed reflect the fact that there is ample room for further real appreciation of these currencies, and, generally speaking, there is nothing wrong with this assertion. If, however, it is claimed on the basis of PPP figures that the currencies of CEE transition economies may, or should, appreciate in real terms in the short run, then this proposition has to be handled with care. It is well known that countries of different income levels have currencies whose exchange rates deviate from PPPs more or less in line with differences in relative real incomes. ${ }^{18} \mathrm{But}$ in the case of transition economies there are good reasons for more than normal deviations. For overcoming the legacies of central planning, and, in particular, the consequences of the extreme closedness of the economy, to establish a viable export sector and enable domestic industries to compete with foreign exporters, the maintenance of a substantial difference between exchange rates and PPPs may be crucial. The gap between exchange rates and purchasing power parities will surely narrow as the real performance provides support. But there is no need to hurry. Even newly industrialized countries, with much more competitive export sectors, suffered when they experienced the inevitable eventual real appreciation of their currencies (Park and Park, 1991). Central Eastern Europe is far from being too competitive, and its industry badly needs clear signals for export-oriented investments.

\section{References}

Aghevli, B.B., and Montiel, P.J. (1991) "Exchange rate policies in developing countries," in E.M. Claassen (ed.) Exchange Rate Policies in Developing and PostSocialist Countries (San Francisco: IPC Press).

Aghevli, B.B., Khan, M.S., and Montiel, P.J. (1991) Exchange Rate Policies in Developing Countries: Some Analytical Issues, IMF Occasional Paper No. 78 (Washington, DC: International Monetary Fund).

Antalóczy, K., and Koltainé, N.Á. (1992) Az ipari export gazdaságosságának alakulása 1988 és 1991 kozött (The profitability of industrial exports in the years 1989-1991) (Budapest: Financial Research Ltd.).

${ }^{18}$ The idea has already been raised by Ricardo, but its modern presentation is due to Balassa (1964). 
Balassa, B. (1964) "The purchasing power parity doctrine: A reappraisal," Journal of Political Economy, December.

Balassa, B., and Schydlowski, D.M. (1968) "Effective tariffs, domestic cost of foreign exchange and the equilibrium exchange rate," Journal of Political Economy, June.

Berg, A., and Sachs, J. (1992) "Structural adjustment and international trade in Eastern Europe: The case of Poland," Economic Policy, April.

Bruno, M. (1976) "The two-sector open economy and the real exchange rate," American Economic Review, September.

Bruno, M. (1992) Stabilization and Reform in Eastern Europe: A Preliminary Evaluation, IMF Working Paper 92/30, May (Washington, DC: International Monetary Fund).

Claassen, E.-M. (ed.) (1991) Exchange Rate Policies in Developing and PostSocialist Countries, International Centre for Economic Growth (San Francisco: ICP Press).

Corden, M.W. (1987) Protection and Liberalization: A Review of Analytical Issues, IMF Occasional Paper No. 54 (Washington, DC: International Monetary Fund).

Dornbusch, R. (1985) Purchasing Power Parity, NBER Working Paper No. 1591 (Cambridge, MA: National Bureau of Economic Research).

Dornbusch, R. (1988) Real Exchange Rates and Macroeconomics: A Selective Survey, NBER Working Paper No. 2775 (Cambridge, MA: National Bureau of Economic Research).

ECE (1992) Economic Survey of Europe in 1991-1992 (New York: United Nations Economic Commission for Europe).

Edwards, S. (1992) "Capital and current account liberalization and real exchange rates in developing countries," in E.M. Claassen (ed.) Exchange Rate Policies in Developing and Post-Socialist Countries (San Francisco: ICP Press).

Gács, J. (1991) "Foreign trade liberalization (1968-1990)," in A. Köves and P. Marer (eds.) Foreign Economic Liberalization (Boulder, CO: West view).

Harrod, R.F. (1939) International Economics (London: Nisbet).

Hrnčíŕ, M. (1992) "Foreign trade and exchange rate in Czechoslovakia: Challenges of the transition and economic recovery," Review of Economies in Transition, No. 6 (Helsinki: The Bank of Finland).

KOPINT-DATORG (1992) Economic Trends in Eastern Europe, No. 2 (Budapest: KOPINT-DATORG Institute for Economic and Market Research and Informatics).

KOPINT-DATORG (1993) Economic Trends in Eastern Europe, No. 2 (Budapest: KOPINT-DATORG Institute for Economic and Market Research and Informatics).

Kornai, J. (1980) The Economics of Shortage (Amsterdam: North Holland). Köves, A., and Marer, P. (eds.) (1991) Foreign Economic Liberalization (Boulder, CO: Westview).

Köves, A., and Oblath, G. (1991) "Stabilization and foreign economic policy in Hungary," Acta Oeconomica, Nos. 1-2. 
Krueger, A.O. (1978) Foreign Trade Regimes and Economic Development: Liberalization Attempts and Consequences (Lexington, MA: Ballinger).

Lawson, C. (1988) "Exchange rates, tax-subsidy schemes, and the revenue from foreign trade in a centrally planned economy," Economics of Planning, Nos. $1-2$.

Levcik, F. (1991) "The place of convertibility in the transition process," in J. Williamson (ed.) Currency Convertibility in Eastern Europe (Washington, DC: Institute for International Economics).

Maciejewski, E.B. (1983) "'Real' effective exchange rate indices: A re-examination of the major conceptual and methodological issues," IMF Staff Papers No. 3.

McKinnon, R.I. (1991) The Order of Economic Liberalization: Financial Control in the Transition to a Market Economy (Baltimore and London: Johns Hopkins University Press).

Neary, P. (1988) "Determinants of the equilibrium real exchange rate," American Economic Review, March.

Oblath, G. (1988) "Exchange rate policy in the reform package," Acta Oeconomica, Nos. 1-2.

Oblath, G. (1991) "Trade policy recommendations," A. Köves and P. Marer (eds.) Foreign Economic Liberalization (Boulder, CO: Westview).

Oblath, G., and Marer, P. (1992) Exchange Rates and Purchasing Power Parities in Central and Eastern Europe, Paper prepared for World Bank Research Project "Statistical Issues in Economic Transition" (Washington, DC: World Bank).

Oblath, G., and Tarr, D. (1992) "The terms-of-trade effects from the elimination of state trading in Soviet-Hungarian trade," Journal of Comparative Economics, March.

Officer, L.H. (1982) Purchasing Power Parity and Exchange Rates: Theory, Evidence and Relevance (Greenwich and London: JAI press).

Park, Y.C., and Park, W.-A. (1991) "Exchange rate policies for the East Asian newly industrialized countries," in E.M. Claassen (ed.) Exchange Rate Policies in Developing and Post-Socialist Countries (San Francisco: ICP Press).

PlanEcon (1992) The Role of Exchange Rates in Western Investment Decisions in Eastern Europe, May 7 (Washington, DC: PlanEcon).

Robinson, J. (1937) "The foreign exchanges," in Essays in the Theory of Employment (New York: Macmillan).

Rodrik, D. (1992) "The limits of trade policy reform in developing countries," Journal of Economic Perspectives, Winter.

Schrenk, M. (1991) The CMEA System of Trade and Payment (Washington, DC: World Bank).

Summers, R., and Heston, A. (1991) "The Penn world table (Mark 5): An expanded set of international comparisons, 1950-1988," The Quarterly Journal of Economics, May.

Wiles, P. (1969) Communist International Economics (New York: Praeger).

Williamson, J. (ed.) (1991) Currency Convertibility in Eastern Europe (Washington, DC: Institute for International Economics). 
Winiecki, J. (1992) "The Polish transition programme: Underpinnings, results, interpretations," Soviet Studies, No. 5.

Wolf, T.A. (1985) "Exchange rate systems and adjustment in planned economies," IMF Staff Papers No. 2.

Wolf, T.A. (1988) Foreign Trade in the Centrally Planned Economy (London: Harwood). 


\section{Comments on Gábor Oblath's Paper}

\section{Andrew Berg}

I would like to begin by complementing the author on a careful and thorough analysis of a complex issue. He reviews the facts and the arguments about trade policy (particularly import liberalization) and nominal exchange rate policy in the peculiar environment of reforming Soviet-style economies.

These remarks come in two sections. The first discusses the primary analytic question raised by the author: the coexistence of real exchange rate appreciation, substantial import liberalization, and large (initial) trade surpluses in all three countries. The second section turns to some of the policy questions raised by the author.

The author notes three basic facts: the substantial real appreciation observed in each country since liberalization (using official price indices); the sudden (to varying degrees) liberalization of foreign trade; and the surprisingly large trade surpluses observed in all three countries. The author proposes, then, a basic puzzle: How can we explain this apparently anomalous combination of events, since trade liberalization would seem to call for a real depreciation to maintain external balance?

He suggests four possible answers: the CMEA trade shock; the fact that the currencies were undervalued according to measures of purchasing power parity (PPP); large capital inflows; and the results of the domestic recession on demand for imports and exportables.

I have little to add to his discussion of PPP and capital inflows, except to say that I agree that there are good theoretical and empirical reasons for PPP to fail to hold even in the long term. He makes an interesting point about the impact of the CMEA trade shock: the decline in CMEA trade is not like a usual terms-of-trade shock. We normally think of a model with at most one export and one import good, and in this situation it is difficult for a terms-of-trade shock to result in an improvement of the trade balance, with the real exchange rate held constant. To the extent that there are two trade sectors of the economy where the goods are not close substitutes, as they may plausibly be assumed to be in this context, it is possible that the decline in domestic demand stemming from the decline in demand for CMEA exports will cause an increase in the trade surplus with the convertible currency area.

It is important to note, though, that the timing of events in Poland helps to eliminate the CMEA shock as a candidate for explaining the author's puzzle. The combination of a strongly positive trade balance, an appreciating real exchange rate, and rapid import liberalization was observed in Poland in 1990, before the brunt of the CMEA shock.

The author seems to put considerable weight on the explanation that domestic recession explains the three facts mentioned above. This is possible, of course, but the story is not so simple as the author makes out; and the facts, at least in Poland, are not so kind to this interpretation. First, it must be a domestic 
recession somehow caused by the trade liberalization that justifies the appreciation and positive trade performance. For if the primary cause of the recession were to lie elsewhere, for example, in domestic monetary policy, then the huge increase in convertible-currency imports observed in 1990 in Poland would be anomalous.

But the evidence is inconsistent with the view that the flood of imports was an important cause of the recession. First and most importantly in Poland the rise in imports in 1990 took place after the fall in the state sector industrial production which is the primary component of declining activity. The decline in industrial production in Poland in 1990 was complete by the end of the first quarter (of course the CMEA shock led to a further decline in 1991). Imports did not increase sharply, however, until after this point. In support of this point, Berg and Sachs (1992) show that there is no positive relation between import penetration and declines in output across 2-digit industries, either in 1990 or in 1991.

Of course over time the logic of the reform program suggests that domestic output should decline and imports grow in those sectors in which the reforming country does not have comparative advantage. But in the context of the elimination of pervasive shortages that characterized particularly Poland of these three countries, this effect could easily be swamped. Specifically, the pre-reform situation was not a market equilibrium. In part, this meant that some sectors were overproducing and some underproducing compared to a market equilibrium, with forced substitution ensuring that all was consumed (see Berg, 1993, for such a model). With liberalization, some sectors that had been discriminated against could then observe an increase in both imports and domestic demand as the forced substitution away from this sector ended with liberalization.

I would argue that something like this process, in which sales declined for many goods that could no longer find demand due to the end of forced substitution, was behind the recession of 1990 . Thus, the dominant economic process since radical reform, in addition to the CMEA shock, has been a reallocation of factors in more productive directions, as the large-scale state industry favored in the previous era gave way to small-scale private enterprise, at least initially concentrated in services.

In this context, estimates reported in Berg and Sachs (1992) generate two results worth emphasizing here. First, the overall decline in GDP was much smaller than the official estimate of 12 percent. Our best guess of the decline as measured from the demand side was 5 percent. Second, a large part of the output decline in 1990 was surely due to inventory disinvestment, especially in material. Holding of excessive materials inventories was a prominent feature of Soviet-style economies. Indeed, even using "conservative" assumptions (in the sense of tending to understate the decline in inventory investment), we calculated that the decline in inventories of 6 percent more than matched our estimate of the decline in GDP calculated from summing the components of final demand of 5 percent. ${ }^{1}$

\footnotetext{
${ }^{1}$ Berg and Sachs (1992) also estimated the change in GDP by summing value added across sectors. Here, however, the only adjustment made was to substitute official estimates of private sector employment changes for GUS (Central Statistical Office) measures of
} 
This estimate has recently received support from a GUS/Polish Academy of Sciences study of the change in national income between 1989 and 1992. Rajewski (1993) discusses a variety of problems with official statistics and tries to estimate directly the size of the unmeasured "second economy." His conclusion is that: "The size of the second economy, carefully estimated, has reached a level of 20 percent of GDP in 1992. Therefore, if the second economy is taken into account the 1989-1992 fall in GDP was of the 5 percent to 10 percent magnitude." Given the fact that the collapse of the CMEA trade regime in January 1991 represented a large negative shock to all the countries in Eastern and Central Europe, perhaps on the order of 3 percent of GDP (Berg and Sachs, 1992; Rodrik, 1992), and that much or all of the remaining GDP decline can be accounted for by inventory disinvestment, little room is left for traditional aggregate demand shocks to play an important role.

Having reviewed the author's explanations of the puzzle he presented, I would like to propose a further possibility that he seems to reject. He is careful to emphasize the non-market-clearing nature of the pre-liberalization equilibrium in these countries, in terms of both the initial exchange rate, as is common particularly in LDCs, and domestic prices, which is more unusual. He does not quite, however, add this to his list of possible explanations.

In Berg and Sachs (1992), as mentioned by the author, liberalization is not associated with a devaluation of the real exchange rate. Initially, the model economy is characterized by a monetary overhang. Foreign exchange is rationed, the currency is not convertible, and most domestic goods markets do not clear. Capital flows are exogenous, so the volume of imports is determined by the volume of exports. The excess domestic demand reduces the supply of exportables available for export, hence reducing the quantity of imports. The overhang is eliminated by a sharp devaluation and proportional increase in the domestic price level. The overall effects are: (1) the elimination of shortages on all markets; (2) a proportional rise in the overall price level and nominal exchange rate, hence no change in the real rate; (3) a tendency for both imports and exports to rise as the result of elimination of the monetary overhang.

Thus, while the author is correct to point out that in a market economy import liberalization ceteris paribus requires a devaluation, the initial exchange rate in the countries under consideration is precisely not a market-equilibrium rate, and furthermore the domestic prices implied by that rate are not market-equilibrium prices, as required by this framework.

As the author correctly emphasizes, policy questions revolve around the nominal exchange rate, not the real exchange rate. He discusses primarily three

output changes in private sector services, so the resulting estimate of -10 percent is close to the official estimate. The demand-side estimates should be given more weight, as they rely heavily on consumer survey data which are much less susceptible to the danger that they mismeasure private-sector activity. The supply-side estimates place the greater reliance on data coming from traditional methods of measurement which emphasize socialized sector production. 
questions: Was the initial devaluation appropriate? Should radical trade liberalization be undertaken? And how should the nominal exchange rate be used in bringing down the rate of inflation?

I would like to frame the policy debate somewhat differently. One of the goals of rapid trade liberalization in Poland was to import a system of relative prices into an economy which had not had a sensible and reliable price system for decades, and indeed the rapid liberalization of January 1990 fulfilled one of the goals of the policy: relative prices seem to have moved toward world prices. This is in contrast to a decade of partial and failed attempts to adjust relative prices. One of the basic reasons for reforming trade rapidly in a post-Soviet-style economy such as Poland's is the special need to realign relative prices in an environment from which competition has been absent for many decades. Trade and current account liberalization play a special role in "importing" a relative price structure and imposing price and market discipline.

In support of this proposition, note that relative prices seem to have approached much more closely those of Western countries since liberalization. Using data from 30 consumer goods, the simple correlation between the Polish relative prices and the West German relative prices was 0.29 in 1987 and 0.81 in January 1990 (FTRI, 1990; Jasiński, 1990). ${ }^{2}$

To get a better idea of the dynamics of price adjustment, Berg (1993) examines the correlation between 3-digit producer price vectors for 85 branches of industry in Poland at different points in time.

Three points emerge: (1) leading up to and during the hyperinflation, relative nonfood prices actually diverged from world prices, except for some convergence in November 1989; (2) the largest relative price movements were in January 1990; (3) after liberalization in January 1990 price movements were small.

There has been much discussion about whether trade liberalization succeeded in "importing competition," that is, in weakening the monopoly power in domestic industry that had been feared would be destructive after price liberalization. Looking at whether relative prices converged seems to me to be a much more robust test of this proposition than an examination of, for example, correlations between profitability and import penetration. The above data strongly suggest that trade liberalization did indeed promote domestic competition and weaken the power of domestic traded goods monopolies by reducing their ability to distort relative prices.

Thus there is little evidence that trade liberalization was responsible for the initial output decline. Instead, along with macroeconomic policy, it established an appropriate set of relative prices. More generally, a return to the European economy is a key aspect of Polish economic and political strategy, and, while there have been some increases in tariffs and reimposition of trade controls, the dramatic opening did more than anything to signal to producers and consumers that the old system

\footnotetext{
${ }^{2}$ That is, 0.29 is the simple correlation between the price vectors for the two different countries, where the components of the vectors are the relative prices for the various goods in the basket in terms of a common numeraire.
} 
would not return. Furthermore, not mentioned at all in the paper in its discussion of trade liberalization is the fact that liberalization brings immediate direct benefits, in terms of new consumer and investment goods (imports of bananas and Western machine tools increased manifold in Poland in 1990).

Finally, a need for import liberalization does not of course, imply that tariffs should be eliminated. But the author's remark that the "first-best" response to widescale import liberalization is introduction of provisional tariffs seems rash. Barring externalities in adjustment [adjustment costs alone are not enough, as Mussa (1982) pointed out], the optimal response is to do nothing. If there are externalities in adjustment, such as capital or labor market imperfections, the first-best response is to directly address those externalities. Second-best might well be a temporary devaluation, which would have the advantage over tariffs that it would not discriminate against exports. Only after this would temporary import tariffs be preferred.

\section{References}

Berg, A. (1993) "Economic reform in Eastern Europe: Lessons from the Polish experience," Mimeo (Cambridge, MA: Harvard Institute for International Development).

Berg, A., and Sachs, J. (1992) "Structural adjustment and international trade in Eastern Europe: The case of Poland," Economic Policy, April.

FTRI (1990) Polish Foreign Trade in 1989, Annual Report (Warsaw: Foreign Trade Research Institute).

Jasiński, L. (1990) Kurs Zlotego A Poziom Cen Krajowych I Ich Relacje Do Cen Za Granica, Studia I Materialy No. 18 (Warsaw: Foreign Trade Research Institute).

Mussa, M. (1982) "Government policy and the adjustment process," in J. Bhagwati (ed.), Import Competition and Response (Chicago: Chicago University Press).

Rajewski, Z. (1993) "Gross domestic product," in L. Zienkowski (ed.), The Polish Economy 1990-1992 (Warsaw: Central Statistical Office and Polish Academy of Sciences).

Rodrik, D. (1992) "Foreign trade in Eastern Europe's transition: Early results," Transition in Eastern Europe (Cambridge, MA: National Bureau of Economic Research). 



\section{Chapter 2}

\section{The Polish Exchange Rate Policy and Economic System Transformation}

Leszek Jasinsski

\section{The Internal Convertibility and System Transition}

The establishment of the internal convertibility of the Polish zloty was one of the most important ingredients of the system transition program that was launched in the beginning of 1990 . A solid currency was necessary to start the process of liberalization of foreign trade and the economy as a whole. The efficient functioning of a market economy is impossible without free access for every economic agent to foreign exchange. All forms of central allocation of foreign currencies, typical for centrally planned economies, had to be terminated.

In 1989 , when the first non-communist government came to power in Poland, the zloty was considered one of the weakest European currencies: the inflation rate was 20 to 30 percent a month, real interest rates were negative, and the economy as a whole suffered from severe disequilibrium. The zloty did not adequately fulfill the functions of money. It was neither a good medium of exchange because of permanent shortages nor a good unit of account because prices for many services were in fact denominated by US dollars. It was not a good medium of storing value either, because it did 
not pay to save the domestic currency. The Polish economic problem of that time was not only to manage the transformation from a centrally planned to a market economy, but also to contain galloping inflation or "shortflation," i.e., the peculiar combination of inflation and shortages.

The currencies of communist economies were, in fact, never convertible, neither for residents nor for foreigners. This feature has been a decisive element of the economic, social, and political isolation of these societies and remained a stumbling block to a rapid opening to the world economy.

\section{The System of Internal Convertibility}

In the last days of 1989, many Polish economic laws, including one on foreign currencies operations, were changed. With the adoption of the revised foreign currency law the zloty was made convertible for firms and resident citizens. According to this law, commercial banks running foreign exchange operations were licensed to sell foreign currencies to firms that needed them to pay for imports, and exporters had to sell to banks the foreign exchanges they received for exports. Payments for imports, as well as revenues from exports, were kept in bank accounts in national currency, and banks converted the payments into foreign exchange. The official exchange rates were fixed by the central bank, the National Bank of Poland, and published every day.

Now there are about 20 commercial banks licensed to run the foreign currency operations; however, in 1989 there were only three. Households can buy and sell foreign currencies at a chain of exchange offices, which are either private or state-owned. The rates they offer are not controlled, but differences between them and the rates the central bank maintains are negligible.

Foreign reserves in Poland have been sufficient to meet the demand for the foreign exchange since the beginning of 1990 . The system has operated smoothly, and its existence has never been endangered. The surpluses in Poland's foreign trade in 1990 and 1992 made it possible for the country to accumulate reserves. Before implementing the program of currency convertibility, Poland was granted a one-billion-dollar stabilization fund by the Western democracies to support the system, but until now it was not necessary to use it. Poland was the first Eastern European country that could establish a sound system of current-account convertibility. 


\section{The Exchange Rate Policy since 1990}

The internal convertibility of the zloty was introduced on 1 January 1990 . On the same day the new exchange rate was fixed at 9,500 zlotys per US dollar. This was achieved by a substantial devaluation and was preceded by a series of "predevaluations" in December 1989. The new exchange rate was high enough to enable the authorities to keep it stable for a long time, which was much longer than originally expected.

The devaluation was accompanied by new currency arrangements; the zloty was pegged to the dollar. Earlier, it had been pegged to a basket of currencies.

The new solution has met some criticism. The American currency serves as a means of payment for approximately 50 percent of all Polish foreign trade. In 1990, the main Western European currencies appreciated in value to the US dollar, which has made this system advantageous for exporters who used, for example, the German mark as a currency of contract. But in 1991, after the Gulf War, the position of the dollar on the international financial markets improved, and this made the position of "non-dollar" exporters worse.

Nowadays, in fact, only very few currencies are pegged to the dollar. This currency arrangement of 1990 made Poland a member of the small club of the "dollar followers."

The new exchange rate, 9,500 zlotys per US dollar, remained unchanged until May 1991, despite a hefty 250 percent inflation in 1990, which was a big surprise for many observers. The real appreciation of the Polish currency did not prevent the record-high level of exports, amounting to US\$11.8 billion in 1990. The high level of trade surplus gave rise to many arguments for lowering the rate. There is some evidence that this would have been carried out in the summer of 1990, but the Iraqi occupation of Kuwait pushed the price of crude oil much higher and the idea was rejected.

In May 1991, the pressure of the exporters' lobby and the political opposition for changing the rate was very strong. The zloty was devalued by 17 percent, and the new price of the dollar was increased from 9,500 to 11,100 zlotys. The devaluation coincided with the introduction of the new currency arrangement. Instead of a single currency, the zloty was pegged to a basket of five currencies: the American dollar, the German mark, the British pound, and the French and the Swiss francs. The weights of particular currencies in 
the basket corresponded to the frequency of their use in payments in respect to Polish foreign trade and were $45,35,10,5$, and 5 percent, respectively. This arrangement is still in use.

In October 1991, the crawling peg system was introduced: every bank day the value of the basket was increased by nine zlotys. The rates of the zloty against the five currencies was based on their actual prices on the international exchange markets.

In February 1992, the zloty was once more devalued, this time by 12 percent. The crawling peg system, despite the devaluation, remained unchanged.

Since January 1990 the nominal exchange rate has grown (nominal depreciation), but in fact, taking inflation into account, the zloty has appreciated in real terms. To analyze how this has happened we shall use the real effective exchange rate, the dollar equivalent of the average wage in Poland and the so-called money-value coefficient (see Tables 2.1 and 2.2).

The real exchange rate is the price of a foreign currency after eliminating the inflationary effects in all countries concerned. We have chosen two moments in the past to define the constant values of the zloty: the beginning of 1990 , when internal convertibility was introduced, and the beginning of 1991.

To calculate the real effective exchange rate we used the five currencies of the arrangement basket and the same weights as in this basket. The coefficient of the money value indicates the overall changes of the money value, both internal and external, and is the weighted average of the inflation rate and the real effective exchange rate. The weight for the effective rate is the ratio of exports to the gross national product.

The real exchange rate of the zloty against the dollar declined in 1991 by 26 percent, while the real effective rate grew by 38 percent. Accordingly, the zloty's appreciation was very high in this period. One must realize that the de facto exchange rate for importers was much higher than indicated because of customs and tax duties. But if compared with the first part of 1989 , that is, the time before the galloping inflation and the introduction of the internal convertibility of the zloty, the exchange rate was lowered by more than a third. This meant that exporters had to substantially reduce their costs or accept a much lower level of profitability.

By August 1992, the situation had, in fact, changed very little compared with December 1991. The real exchange rate against the dollar was a little lower than it had been eight months earlier, and so was the real effective rate. 
Table 2.1. The nominal and real exchange rates of the zloty against the dollar (at the end of the month).

\begin{tabular}{|c|c|c|c|c|}
\hline \multirow{2}{*}{$\begin{array}{l}\text { Months } \\
1989-1991\end{array}$} & \multirow{2}{*}{$\begin{array}{l}\text { Nominal } \\
\text { rate }\end{array}$} & \multicolumn{2}{|c|}{ Real rates in zlotys as of } & \multirow{2}{*}{$\begin{array}{l}\text { Real rate } \\
\text { Jan. } 1,1991=1.00\end{array}$} \\
\hline & & Jan. 1, 1990 & Jan. 1, 1991 & \\
\hline January 1989 & 508 & 3,581 & 11,247 & 1.184 \\
\hline July & 830 & 3,710 & 11,654 & 1.227 \\
\hline December & 6,500 & 7,621 & 23,938 & 2.520 \\
\hline January 1990 & 9,500 & 9,500 & 29,839 & 3.141 \\
\hline April & 9,500 & 4,150 & 13,036 & 1.372 \\
\hline July & 9,500 & 3,611 & 11,341 & 1.194 \\
\hline October & 9,500 & 3,319 & 10,424 & 1.097 \\
\hline December & 9,500 & 3,025 & 9,500 & 1.000 \\
\hline January 1991 & 9,500 & 2,654 & 8,336 & 0.877 \\
\hline February & 9,500 & 2,500 & 7,852 & 0.827 \\
\hline March & 9,500 & 2,402 & 7,545 & 0.794 \\
\hline April & 9,500 & 2,348 & 7,376 & 0.776 \\
\hline May & 11,105 & 2,684 & 8,431 & 0.887 \\
\hline June & 11,458 & 2,650 & 8,324 & 0.876 \\
\hline July & 11,304 & 2,622 & 8,234 & 0.867 \\
\hline August & 11,270 & 2,606 & 8,186 & 0.862 \\
\hline September & 11,096 & 2,467 & 7,750 & 0.816 \\
\hline October & 11,203 & 2,420 & 7,600 & 0.800 \\
\hline November & 11,154 & 2,340 & 7,350 & 0.774 \\
\hline December & 10,957 & 2,233 & 7,014 & 0.738 \\
\hline January 1992 & 11,483 & 2,182 & 6,854 & 0.721 \\
\hline February & 13,200 & 2,470 & 7,757 & 0.817 \\
\hline March & 13,497 & 2,482 & 7,797 & 0.821 \\
\hline April & 13,746 & 2,444 & 7,678 & 0.808 \\
\hline May & 13,827 & 2,370 & 7,445 & 0.784 \\
\hline June & 13,512 & 2,286 & 7,179 & 0.756 \\
\hline July & 13,618 & 2,278 & 7,154 & 0.753 \\
\hline August & 13,449 & 2,196 & 6,897 & 0.726 \\
\hline
\end{tabular}

${ }^{a}$ Calculations from previous column.

Source: Author's calculations.

The decline of the effective rate was mainly the result of the appreciation of the German mark against the dollar.

The money-value coefficient decreased in 1991 by 30 percent, that is, at a slower pace than the inflation rate. This resulted from the appreciation of 
Table 2.2. The effective exchange rates, value of money, dollar equivalents of average wages in Poland (at the end of the month).

\begin{tabular}{|c|c|c|c|}
\hline \multirow[b]{2}{*}{$\begin{array}{l}\text { Months } \\
1989-1991 \\
\end{array}$} & \multicolumn{2}{|c|}{ Jan. $1,1990=1.0$} & \multirow[b]{2}{*}{$\begin{array}{l}\text { A verage wage } \\
\text { in dollars }\end{array}$} \\
\hline & $\begin{array}{l}\text { Real effective } \\
\text { rate }\end{array}$ & $\begin{array}{l}\text { Money value } \\
\text { coefficient }\end{array}$ & \\
\hline January 1989 & 0.923 & 21.83 & - \\
\hline July & 0.918 & 13.54 & - \\
\hline December & 0.432 & 3.50 & - \\
\hline January 1990 & 0.345 & 2.97 & 64 \\
\hline April & 0.784 & 1.35 & 97 \\
\hline July & 0.873 & 1.18 & 106 \\
\hline October & 0.918 & 1.09 & 137 \\
\hline December & 1.000 & 1.00 & 158 \\
\hline January 1991 & 1.138 & 0.90 & 157 \\
\hline February & 1.228 & 0.86 & 177 \\
\hline March & 1.361 & 0.85 & 184 \\
\hline April & 1.417 & 0.83 & 181 \\
\hline May & 1.212 & 0.79 & 152 \\
\hline June & 1.268 & 0.77 & 150 \\
\hline July & 1.264 & 0.77 & 159 \\
\hline August & 1.267 & 0.76 & 160 \\
\hline September & 1.317 & 0.74 & 167 \\
\hline October & 1.340 & 0.73 & 180 \\
\hline November & 1.359 & 0.71 & 189 \\
\hline December & 1.378 & 0.70 & 209 \\
\hline January 1992 & 1.451 & 0.67 & 181 \\
\hline February & 1.295 & 0.64 & 160 \\
\hline March & 1.293 & 0.63 & 171 \\
\hline April & 1.316 & 0.62 & 175 \\
\hline May & 1.342 & 0.60 & 165 \\
\hline June & 1.339 & 0.59 & 173 \\
\hline July & 1.329 & 0.59 & 181 \\
\hline August & 1.340 & 0.58 & 184 \\
\hline
\end{tabular}

Source: Author's calculations.

the Polish currency in real terms. Furthermore, in August 1992 it was 12 percent lower than in December 1991.

The dollar equivalent of average wages in Poland since January 1991 has ranged between 157 and 209. The dispersion was high and many ups and downs could be noted. 


\section{The 1991 Devaluations and Inflation Rate}

Poland is still a country with high inflation. The prices are now generally not controlled by the state. The only exceptions are the prices of energy carriers, rents, and public transportation rates. They also represent the last products and services that are still centrally subsidized.

The inflation in Poland has been of both the cost-push and demand-pull type. Many factors make prices rise, for example, the monopoly market structure, wages growing more rapidly than labor productivity, the budget deficit, the credits granted for firms unable to repay them, reduction of subsidies, and the crawling peg system.

The open inflation in Poland and the introduction of currency convertibility have changed the role of devaluation in the economy as a whole: the relation between changes in the zloty price of the dollar and the aggregate price level has become close.

As the analysis based on input-output calculations indicates, after May 1991 , following the 17 percent devaluation of the zloty, the average level of wholesale prices increased by 9.4 percent. ${ }^{1}$ Following the introduction of the crawling peg system in October 1991, wholesale prices increased by 5.2 percent by the end of the year. The impact of devaluations on consumer prices was 12.3 and 6.5 percent, respectively, for the two devaluation episodes.

\section{Purchasing Power Parity of the Zloty}

The estimation of the purchasing power parity (PPP) of a currency is sometimes quite a complicated problem. To accomplish a calculation we analyzed the prices of about 100 consumer goods and services in Poland and Germany. To find the PPP of the zloty against the US dollar, we used the PPP of the German mark against the dollar. Since we had at our disposal two different estimates of PPP for the currencies of Germany and the United States, we could also calculate two PPP estimates for the currencies of Poland and the United States. The PPP of the zloty in August 1992 was 6,800 or 8,850 zlotys per US dollar. The first result seems to us more credible. In the case of the former estimate the rate was 45 percent higher than the exchange rate, while in the latter it was 29 percent higher. At the beginning of 1991 these deviations were 154 and 95 percent, respectively. The relative convergence

\footnotetext{
${ }^{1}$ The calculations were carried out by Vingo Borzym of the Foreign Trade Research Institute, Warsaw.
} 
of the exchange rate and the purchasing power parity of the Polish currency can be observed.

We are of the opinion that the zloty's exchange rate will remain overvalued for a long time. Important proof of this is the very low current level of wages in Poland (from the point of view of Westerners), denominated in dollars.

As far as the structure of prices is concerned, the statistical analysis of 110 products and services leads to the conclusion that we have been experiencing a relative convergence of price structures between Poland and the countries of Western Europe since 1989.

\section{Convertibility and Profitability of Exports}

The level of the exchange rate has its impact on the preference of domestic producers to sell on export markets. In 1990, there was a rapid growth of exports in Poland: the exports to hard currency markets have amounted to US $\$ 11.8$ billion, its volume increased by about 40 percent. This growth was made possible by the significant devaluation of the zloty at the beginning of 1990 and the declining aggregate demand on the domestic market, a result of the measures aimed at containing inflation. The stable exchange rate in 1990 and in the first months of 1991 decreased the profitability of exports and also influenced the export preference.

The profitability of the top 500 exporters and all Polish enterprises in 1990-1991 is shown in Tables 2.3 and 2.4. One can clearly see that there has been a rapid decrease of gross and net profitability in 1991 both of big exporters and of all firms.

During the entire span of time under investigation, the profitability of big exporters was significantly higher than that of all the enterprises. The relative difference between the gross profitability of the two groups of enterprises was much larger in 1991 than in the previous year. From January to August 1991, however, the profitability in both groups declined and the gap between the two groups became narrower.

Polish exporters have amalgamated in an informal strong lobby. The lobby has always based its activity on the expectation of the devaluation of the zloty which, to some extent, can be seen as typical old-style pressure on the central administration against the financial regime. Nevertheless, the need for substantial export profitability and the necessity for new investments in exporting industries cannot be ignored. 
Table 2.3. The profitability of the top 500 exporters and of all firms in 1990-1991.

\begin{tabular}{llll} 
& \multicolumn{3}{l}{ Gross profitability (in percent) } \\
\cline { 2 - 4 } Time & Top 500 exporters & \multicolumn{2}{c}{ All firms } \\
$(2)$ & $(1):(2)$ \\
\hline Jan.-Dec. 1990 & 39.8 & 29.4 & 135.4 \\
Jan.-Mar. 1991 & 14.7 & 8.3 & 177.1 \\
Jan.-Jun. 1991 & 12.6 & 6.7 & 188.1 \\
Jan.-Aug. 1991 & 10.3 & 6.2 & 166.1 \\
Jan.-Oct. 1991 & n.a. & 6.1 & n.a. \\
\hline
\end{tabular}

aThe gross profitability is defined as the relation of the gross profits to the costs. This ratio is usually lower than that using the costs of the production sold.

Source: J. Piotrowski in The Polish Foreign Trade in 1991, Foreign Trade Research Institute, Warsaw.

Table 2.4. The net profitability of enterprises in $1990-1991$, in percent. ${ }^{a}$

\begin{tabular}{llc}
\hline Time & Exporters & All firms \\
\hline Jan.-Dec. 1990 & n.a. & 10.6 \\
Jan.-Mar. 1991 & 5.4 & 0.7 \\
Jan.-Apr. 1991 & 4.3 & 0.1 \\
Jan.-Aug. 1991 & 3.4 & -0.1 \\
\hline
\end{tabular}

${ }^{a}$ Net profitability is the relation of net profit to total revenues.

Source: J. Piotrowski in The Polish Foreign Trade in 1991, Foreign Trade Research Institute, Warsaw.

The financial standing of particular exporting industries has varied substantially. There were industries in which the export profitability was smaller than the profitability of sales on the domestic market. These have been for a long time, for example, metal-processing, precision instruments, engineering, steel, paper, and leather manufacturing industries.

The devaluation of the zloty in May 1991 was, in fact, intended to promote Poland's exports. It has virtually stopped the diminishing export profitability, but did not bring a radical change in the financial situation of exporters in the long run. Another move toward the exporters' requirements was introducing the crawling peg exchange regime in October 1991, and the devaluation of the zloty in early 1992 .

Unfortunately we have no exact data on the profitability of enterprises for 1992. The devaluation in February 1992 was followed by a relatively high current account surplus in the spring of 1992 . It is not yet easy to answer 
the question whether or not the new zloty price of the dollar was the main reason for the advantageous development of the balance of payments.

\section{The General Economic Background of Exchange Rate Policy}

One of the fundamental principles of centrally planned economies was the allocation of foreign exchange by command of the central administration. The establishment of the convertibility of the zloty brought with it the danger that foreign reserves, which now are available to all economic agents, can be easily exhausted. As we already know, this danger did not become a reality in Poland. This, however, poses the question: What factors helped the foreign exchange market achieve a balance?

As a first factor we have to stress that, according to the main target of consecutive Polish governments, the money supply was kept under control. Table 2.5 lists the development of the transaction money $\left(\mathrm{M}_{1}\right)$, broad money $\left(\mathrm{M}_{3}\right)$, and net domestic assets, all in real terms. The data clearly show that since a decline in the first months of 1990, the money supply grew and afterwards has remained at a relatively stable level.

In addition, the Polish economy has been in a recession, which has mainly hit the sector of big state-owned enterprises. Data for the industrial production of this sector are given in Table 2.6. One can observe that industrial production declined sharply in recent years, but in 1992 it showed the first signs of recovery.

Table 2.6 also gives evidence that budget receipts and outlays have diminished seriously in real terms after the implementation of the new economic policy in 1990. The first impulse was the fall of budget receipts in late 1990. This prompted the government to execute stricter control over outlays which, however, could not prevent a relatively high level of deficit. At the end of 1992, this stood at about 8 percent of the GDP. The deficit might have been much higher if outlays had not been cut down. The money supply was kept under control all the time, and crowding out, not printing paper money, was the main instrument used to finance the budget deficit.

As a further factor contributing to the rapid restoration of balance on the market of foreign exchange we refer to the favorable performance of foreign trade in 1990-1992. As already mentioned, the surpluses achieved in these years contributed substantially to the accumulation of foreign exchange reserves. 
Table 2.5. Real money supply in Poland, end of month, January $1991=1$.

\begin{tabular}{|c|c|c|c|c|}
\hline Year & Month & $\mathbf{M}_{1}{ }^{a}$ & $\mathrm{M}_{3}{ }^{b}$ & $\begin{array}{l}\text { Net domestic } \\
\text { assets }\end{array}$ \\
\hline 1989 & 12 & 0.7507 & 0.7751 & 2.5834 \\
\hline \multirow[t]{12}{*}{1990} & 1 & 0.6136 & 0.6106 & 1.3943 \\
\hline & 2 & 0.5982 & 0.5999 & 1.1186 \\
\hline & 3 & 0.7019 & 0.6995 & 1.1248 \\
\hline & 4 & 0.7587 & 0.7445 & 1.0869 \\
\hline & 5 & 0.8181 & 0.7945 & 1.0540 \\
\hline & 6 & 0.9093 & 0.8738 & 1.0871 \\
\hline & 7 & 1.0159 & 0.9630 & 1.1155 \\
\hline & 8 & 1.1369 & 1.0641 & 1.1995 \\
\hline & 9 & 1.1661 & 1.0925 & 1.1777 \\
\hline & 10 & 1.1729 & 1.1024 & 1.1909 \\
\hline & 11 & 1.1970 & 1.1270 & 1.2165 \\
\hline & 12 & 1.1379 & 1.1161 & 1.0698 \\
\hline \multirow[t]{12}{*}{1991} & 1 & 1.0000 & 1.0000 & 1.0000 \\
\hline & 2 & 0.9596 & 1.0025 & 0.9980 \\
\hline & 3 & 0.9510 & 1.0393 & 1.0344 \\
\hline & 4 & 0.9605 & 1.0880 & 1.1132 \\
\hline & 5 & 0.9637 & 1.1052 & 1.1244 \\
\hline & 6 & 0.9436 & 1.1035 & 1.1436 \\
\hline & 7 & 0.9883 & 1.1551 & 1.1695 \\
\hline & 8 & 1.0210 & 1.1933 & 1.2086 \\
\hline & 9 & 1.0014 & 1.1813 & 1.1970 \\
\hline & 10 & 0.9959 & 1.1593 & 1.2207 \\
\hline & 11 & 0.9686 & 1.1345 & 1.2049 \\
\hline & 12 & 0.9541 & 1.1323 & 1.2158 \\
\hline \multirow[t]{5}{*}{1992} & 1 & 0.9152 & 1.1011 & 1.1735 \\
\hline & 2 & 0.9037 & 1.1109 & 1.1915 \\
\hline & 3 & 0.9126 & 1.1302 & 1.1962 \\
\hline & 4 & 0.9257 & 1.1365 & 1.1723 \\
\hline & 5 & 0.9033 & 1.1152 & 1.1549 \\
\hline
\end{tabular}

${ }^{a} M_{1}=$ transaction money.

${ }^{b} \mathrm{M}_{3}=$ broad money.

Source: Author's calculations based on data from the National Bank of Poland.

\section{Consequences of Convertibility}

We can say that while nearly all the elements of the economic policy of all Polish governments after 1989 were criticized by the opposition, the internal convertibility of the zloty was an exception. But this does not mean that 
Table 2.6. Budget receipts, outlays, and industrial production in real terms, January $1990=1$.

\begin{tabular}{|c|c|c|c|c|}
\hline Year & Month & $\begin{array}{l}\text { Budget } \\
\text { receipts }\end{array}$ & $\begin{array}{l}\text { Budget } \\
\text { outlays }\end{array}$ & $\begin{array}{l}\text { Industrial } \\
\text { production }\end{array}$ \\
\hline \multirow[t]{12}{*}{1990} & 1 & 1.0000 & 1.0000 & 1.0000 \\
\hline & 2 & 0.8697 & 0.8890 & 1.0408 \\
\hline & 3 & 0.8454 & 0.9059 & 1.1038 \\
\hline & 4 & 1.0568 & 0.9239 & 0.9821 \\
\hline & 5 & 0.9678 & 0.9168 & 1.0036 \\
\hline & 6 & 0.8704 & 0.9882 & 0.9688 \\
\hline & 7 & 0.8252 & 0.7792 & 0.9422 \\
\hline & 8 & 0.7778 & 0.7964 & 1.0207 \\
\hline & 9 & 0.8064 & 0.9014 & 1.0206 \\
\hline & 10 & 0.9045 & 0.9166 & 1.1228 \\
\hline & 11 & 0.8613 & 0.9906 & 1.0823 \\
\hline & 12 & 1.1045 & 1.4951 & 0.9954 \\
\hline \multirow[t]{12}{*}{1991} & 1 & 0.5059 & 0.5088 & 0.9129 \\
\hline & 2 & 0.6277 & 0.7455 & 0.7998 \\
\hline & 3 & 0.5864 & 0.7944 & 0.8230 \\
\hline & 4 & 0.5578 & 0.7393 & 0.7181 \\
\hline & 5 & 0.5701 & 0.5831 & 0.6747 \\
\hline & 6 & 0.4317 & 0.6497 & 0.6703 \\
\hline & 7 & 0.5785 & 0.6643 & 0.6739 \\
\hline & 8 & 0.4948 & 0.6840 & 0.6785 \\
\hline & 9 & 0.4765 & 0.6346 & 0.6814 \\
\hline & 10 & 0.5835 & 0.7271 & 0.7326 \\
\hline & 11 & 0.4999 & 0.6155 & 0.6634 \\
\hline & 12 & 0.7095 & 0.8588 & 0.6702 \\
\hline \multirow[t]{7}{*}{1992} & 1 & 0.3773 & 0.5288 & 0.6228 \\
\hline & 2 & 0.4875 & 0.6233 & 0.5937 \\
\hline & 3 & 0.6053 & 0.7286 & 0.6995 \\
\hline & 4 & 0.6136 & 0.6827 & 0.6595 \\
\hline & 5 & 0.5037 & 0.6054 & 0.6154 \\
\hline & 6 & 0.4920 & 0.8147 & 0.6542 \\
\hline & 7 & 0.5900 & 0.7640 & 0.6560 \\
\hline
\end{tabular}

Source: Author's calculations based on data from the Central Statistical Office.

the actual exchange rates were not criticized - on the contrary; there were many arguments claiming that they were either too low or too high.

It is not easy to separate the consequences of the introduction of currency convertibility from the consequences of other elements of the economic policy. 
But let us try to enumerate at least some occurrences in Poland that we believe took place due to the internal convertibility.

First of all, economic calculations in Polish firms have changed. The competition of foreign products has had an effect on pricing, management, and marketing. The progress has been impressive and unprecedented. Easy access to foreign exchange has resulted in a large inflow of imported goods - sometimes of high quality, sometimes of low quality. The competition of the imports has changed the market structure, and most state-owned firms could only lose against foreign competitors. It was argued by the political opposition that the government did nothing to protect the national economy.

The current account convertibility has also been advantageous for the position of the Polish zloty on the home market, increasing confidence in the currency. For many decades in the past, due to the absence of the capital markets and due to negative real interest rates on zloty deposits, the best way to save was to buy dollars or other Western currencies, which served as a kind of security. For years, the black-market exchange rate of the dollar increased according to the rate of inflation of the zloty, or even to a faster rate.

\section{Full Convertibility Ahead?}

Can one expect the full convertibility of the zloty? In 1992 this problem was not publicly discussed. But what are the obstacles to full convertibility? First of all, Poland belongs to the group of highly indebted countries. If Poland's debts are reduced, or servicing the debts becomes easier, the central financial authorities will be in a better position to declare full convertibility. Still today, high inflation and, because of this, high interest rates make Poland's financial position much different from that of the countries of the European Monetary System.

The Polish law on foreign investments allows foreign investors to transfer their profits home. From this point of view, the rapid implementation of full convertibility is not necessary.

Poland is a candidate for membership in the European Community. All available evidence points to the possibility that Poland can join the EC soon after 2000. Full convertibility, however, is one requirement that has to be fulfilled before that time.

The Western European democracies did not make their currencies fully convertible immediately after the Second World War; it took several years 
until they reached that stage. I believe that for Poland and for foreigners possessing the Polish zloty and using it in their businesses the (at least) five years' time that we can expect before full convertibility is not too long. 


\section{Chapter 3}

\section{Economic Recovery and Foreign Exchange Rate Regime: The Case of the Czech Republic}

Miroslav Hrnčír $\check{r}^{*}$

\section{Introduction}

The key issue facing transition economies in Central Europe has been the initiation of economic recovery.

The transition economies suffered a rather severe decline in economic activity and in real incomes. The former CSFR, ${ }^{1}$ despite its relatively stabilized initial macroeconomic conditions, experienced a 15 percent decrease in its GDP and a 24 percent decrease in real wages in 1991 (see Table 3.1).

*The author is grateful to G. Fink, R. Portes, C. Wihlborg, and S. Wright for helpful comments on the first version of the paper.

${ }^{1}$ As of early 1993 , the CSFR ceased to exist as a federal state. Its successors are two separate entities, the Czech and Slovak republics which form a special type of customs union. Their "inherited" common currency survived, however, only during the first month of the existence of the new states.

The discussion of this article, written in late 1992, while referring to the developments in the former the CSFR addresses issues relevant to both newly created national states. 
Table 3.1. Main macroeconomic indicators 1989-1992, annual change in percent.

\begin{tabular}{lrrrr}
\hline & 1989 & 1990 & 1991 & $1992^{a}$ \\
\hline GDP & & & & \\
CSFR & 1.4 & -1.8 & -15.1 & -8.5 \\
Czech Republic & n.a. & -1.9 & -14.5 & -6.7 \\
Gross industrial production CSFR & 1.0 & -3.7 & -21.2 & -12.4 \\
Unemployment rate (end of period) & & & & \\
CSFR & n.a. & 1.0 & 6.6 & 5.0 \\
Czech Republic & n.a. & 0.8 & 4.1 & 2.6 \\
Inflation rate CSFR (CPI, average) & 1.4 & 10.0 & 57.9 & 10.3 \\
Real wages CSFR & 0.9 & -5.6 & -24.3 & 8.0 \\
\hline
\end{tabular}

a 1992 preliminary.

Source: Statistical Bulletin, Federal Statistical Office.

In 1992 the decrease in the overall economic activity persisted; according to preliminary figures, GDP declined by 8.5 percent (in the Czech Republic, by 6.7 percent). Real wages, on the other hand, have recovered and, despite the significant drop in economic activity, the level of unemployment has decreased. ${ }^{2}$ Data for the second half of 1992 signaled certain stabilization of the level of economic activity, particularly in construction, trade, and services; however, these sectors have not yet revealed a reversal of the underlying trends.

In 1992, the GDP in real terms was thus in the former CSFR about only three-quarters of the 1989 level. Such a deterioration in macroeconomic performance exceeded by far the worst recession recorded in any comparable market economy over a period of several decades.

Unlike in stabilized market economies, cyclical factors were not the main causal factor. Rather, this deterioration was caused by the legacy of the progressing decay under the former centrally planned economy framework,

\footnotetext{
${ }^{2}$ The ratio between the trends in economic activity and in the level of unemployment which developed in the former CSFR in 1991 and 1992 was rather peculiar. An extraordinary deep fall of GDP was not accompanied by a corresponding increase of unemployment. As follows from data in Table 3.1, compared to the 15.1 percent fall of GDP in 1991 the level of unemployment increased to a relatively modest 6.6 percent from almost zero rate in 1989. It remained well below the current European standard.

Even more startling, a subsequent drop in the volume of economic activity of 8.5 percent occurred in 1992 while the level of unemployment decreased to 5 percent. In the Czech Republic this divergence was even more pronounced (compare Table 3.1).
} 
and intensified by the impact of restrictive macroeconomic policies and by a number of shocks, both external and domestic, in the still mostly unchanged institutional and systemic environment.

The situation in the transition economies was rather a structural depression, if not a slump, significantly dissimilar to the "classical" case of a cyclical recession in market economies. The character of the problem faced points to the limitations of anti-cyclical policies in the context of transition economies.

A reversal of "downward" expectations, reflected by an extremely sharp decline in investments, is hindered not only by demand-side constraints, but also by perseverance of institutional rigidities interrelated with policy flaws in the promotion of supply-side adjustment.

Under a rather imperfectly competitive environment in the domestic economy the incentives to invest and the prospects for any "real" investment to turn profitable are conditioned by the parallel behavior of other investors. A reversal of existing expectations could evidently take place, more likely and more timely, provided a positive solution of the implied coordination problem is achieved. Dornbusch (1990) has identified this coordination problem in the context of the IMF model and through the lessons from Latin America as an "economy wide" externality, and found that its solution could hardly be left to market forces only.

The effects of the domestic environment on expectations of economic agents have become increasingly interrelated with those of the external environment also in transition economies. Given the stage of openness to the outside world already achieved and a desirable continuation of this process, any recovery of domestic activities in the Czech Republic could be made sustainable only if an adequately growing export potential matches the increasing import over the medium-term horizon. The economy-wide privatization process initiated, along with hoped-for increased inflow of foreign direct investment, should make this desired outcome more probable.

The legacy of past developments under the virtually closed economy framework represents, however, another "externality" in transition economies. To cope with it, an export-oriented strategy, including export promotion schemes and support of related services, institutions, and infrastructure, seems necessary to correct for the inherited drawbacks.

In this context, this chapter examines the role of the foreign exchange rate in transition and in economic recovery of the Czech Republic: options of foreign exchange rate regimes are analyzed to determine how they could 
affect the development path of the economy and to find the one that could be used.

\section{Foreign Exchange Rate in the Former CSFR}

\section{Changed institutional setting}

Despite being "nominally" in existence, the foreign exchange rate was considered to be of minor importance under the centrally planned economy framework, maintained in the CSFR up to the late 1980s. The "official" exchange rate was kept overvalued, while, on the other hand, various blackand parallel-market rates tended to depress unrealistically the external value of the currency. Moreover, the "implied" exchange ratios were widely diversified across both trade and non-trade flows.

With the start of the transition in early 1990 , a unified exchange rate was introduced that eliminated the duality of so-called commercial and tourist rates. A radical move toward opening of the CSFR economy, including the implementation of limited (internal) currency convertibility and foreign trade liberalization in early 1991 , was paid for "in advance" by the three consecutive devaluations of the unified exchange rate of the CSFR koruna (CSK) vis-à-vis convertible currencies in the course of $1990 .^{3}$

Since January 1991, the nominal effective exchange rate (NEER) of the CSK has been pegged to a basket of five currencies. ${ }^{4}$ The aim was to use the fixed exchange rate as an instrument of macroeconomic stabilization. This approach followed the stabilization programs applied elsewhere, reflecting that the foreign exchange rate is a special "macroeconomic" price, with substantial impact across the entire national economy. Although advancing along this strategy of "nominal exchange rate anchor," the CSFR authorities

\footnotetext{
${ }^{3}$ The CSK was devalued by 16.6 percent on January 8 , by 55.3 percent on October 15 , and by 15.98 percent on December 28 . Though it could be argued that the initial ratio hardly represented an exchange rate proper, the cumulative depreciation in the course of 1990 was substantial: after the third devaluation in late December 1990, the exchange rate changed to CSK 28 per US dollar, as compared to CSK 14.29 per US dollar in late December 1989.

${ }^{4}$ Both the composition of the basket and the relative weights of individual currencies are, however, revised on an annual basis. The respective shares in 1991 were: German mark 45.52 percent, US dollar 31.34 percent, Austrian schilling 12.35 percent, Swiss franc 6.55 percent, British pound 4.24 percent. The revised composition in 1992 was German mark 36.15 percent, US dollar 49.07 percent, Austrian schilling 8.07 percent, Swiss franc 3.79 percent, French franc 2.92 percent.
} 
did not commit themselves to any preannounced period of keeping the given exchange rate unaffected.

In reality, the peg has been kept since January 1991. The changes in the CSK's exchange rate during this period reflected only the development in the cross rates of the basket currencies.

Given all the upheavals accompanying the start of transition, the untouched peg (for more than two years) may appear surprising. It has been made possible by an unexpectedly favorable development of foreign exchange flows in the period mentioned. Both trade balance and current account in convertible currencies have substantially recovered after a sharp deterioration in 1990. In 1991, a surplus of US\$0.3 billion on current account was achieved instead of an envisaged deficit of US $\$ 2.5$ billion. And again in 1992, instead of a predicted deficit of US\$0.6 billion a surplus of US\$1 billion to US $\$ 1.5$ billion was attained.

This outcome is to be viewed as a coincidence of two factors which worked in the same direction during this period:

- The first, in fact, "programmed" impact was that of the wide margin between the current exchange rate and the domestic purchasing power parity (PPP) of the currency, which was purposely further widened by three devaluations of the domestic currency in the course of 1990.

- The second one, a deep protracted recession in the domestic economy, represented, on the other hand, both an unpredicted and unwelcomed phenomenon. The extent of the recession in reality substantially outran not only the government forecasts, but also "the black vision" of the skeptics.

\section{Divergent foreign and domestic purchasing power of the CSK}

A wide gap between the domestic and external values of their currencies was a common feature of the former centrally planned economies. In the case of the CSFR, the gap widened further in nominal terms in the very beginning of the transition as a result of the devaluations in the course of 1990 .

Most expert studies identified the domestic PPP of CSK in early 1990 , i.e., the start of the transition, in the range of CSK 7 to 8 per US dollar. Using the midpoint of the interval, i.e., CSK 7.50 per US dollar, as a benchmark, the resulting development of the PPP in the course of the transition is presented in Table 3.2.

The identified decrease in the implied purchasing power of the CSK with respect to the US dollar from CSK 7.50 in January 1990 to CSK 12.52 in 
Table 3.2. Exchange rate (ER), purchasing power parity rate (PPP), and parallel market exchange rate of the CSK in 1989-1992, CSK per US dollar, average per period.

\begin{tabular}{|c|c|c|c|c|}
\hline & $\begin{array}{l}\text { Official } \\
\text { ER } \\
(1) \\
\end{array}$ & $\begin{array}{l}\text { PPP } \\
(2)\end{array}$ & $\begin{array}{l}\text { ER/PPP } \\
\text { ratio } \\
(1: 2) \\
\end{array}$ & $\begin{array}{l}\text { Parallel } \\
\text { market } \\
\text { rate }\end{array}$ \\
\hline 1989 & 15.05 & 7.50 & 2.01 & 42.39 \\
\hline $1990 / 1$ & 16.29 & 7.50 & 2.17 & 40.39 \\
\hline 2 & 16.60 & 7.49 & 2.22 & 43.46 \\
\hline 3 & 16.72 & 7.46 & 2.24 & 40.88 \\
\hline 4 & 16.67 & 7.46 & 2.23 & 39.81 \\
\hline 5 & 16.64 & 7.45 & 2.23 & 33.20 \\
\hline 6 & 16.58 & 7.42 & 2.23 & 35.88 \\
\hline 7 & 16.37 & 7.96 & 2.06 & 33.55 \\
\hline 8 & 15.89 & 8.09 & 1.96 & 32.99 \\
\hline 9 & 15.71 & 8.08 & 1.94 & 33.42 \\
\hline 10 & 20.18 & 8.12 & 2.49 & 38.52 \\
\hline 11 & 23.63 & 8.27 & 2.86 & 42.45 \\
\hline 12 & 24.19 & 8.27 & 2.92 & 42.10 \\
\hline $1991 / 1$ & 27.65 & 10.35 & 2.67 & 36.34 \\
\hline 2 & 27.24 & 11.07 & 2.46 & 32.04 \\
\hline 3 & 28.74 & 11.61 & 2.48 & 33.93 \\
\hline 4 & 29.94 & 11.78 & 2.54 & 31.60 \\
\hline 5 & 30.12 & 11.98 & 2.51 & 31.18 \\
\hline 6 & 30.89 & 12.16 & 2.54 & 32.45 \\
\hline 7 & 31.00 & 12.15 & 2.55 & 32.37 \\
\hline 8 & 30.53 & 12.13 & 2.52 & 32.85 \\
\hline 9 & 30.03 & 12.11 & 2.48 & 32.30 \\
\hline 10 & 29.89 & 12.08 & 2.47 & $\mathbf{3 1 . 2 7}$ \\
\hline 11 & 29.15 & 12.23 & 2.38 & 30.74 \\
\hline 12 & 28.55 & 12.36 & 2.31 & 30.44 \\
\hline $1992 / 1$ & 28.36 & 12.47 & 2.27 & 30.12 \\
\hline 2 & 28.78 & 12.49 & 2.30 & 30.19 \\
\hline 3 & 29.16 & 12.49 & 2.33 & 30.21 \\
\hline 4 & 29.06 & 12.52 & 2.32 & 29.76 \\
\hline 5 & 28.84 & 12.54 & 2.30 & 29.37 \\
\hline 6 & 28.42 & 12.53 & 2.27 & 30.44 \\
\hline 7 & 27.61 & 12.61 & 2.19 & 29.16 \\
\hline 8 & 27.25 & 12.64 & 2.16 & 28.79 \\
\hline 9 & 27.18 & 12.84 & 2.12 & 29.36 \\
\hline 10 & 27.38 & 13.05 & 2.10 & 29.61 \\
\hline 11 & 28.54 & 13.28 & 2.15 & 31.40 \\
\hline 12 & 28.60 & 13.39 & 2.14 & 31.30 \\
\hline
\end{tabular}

Source: International Financial Statistics; PlanEcon, 1992; State Bank of Czechoslovakia. 
April 1992 reflects the CSFR's inflation differential as measured by ratios of consumer price indices (CPIs) for the given period.

As follows from data in Table 3.2 (see also Table 1.5 in Chapter 1), the disparity between the PPP and the CSK's exchange rate culminated toward the end of 1990 (after devaluations and a sweeping liberalization of domestic prices). In December 1990 the implied exchange rate/PPP ratio amounted to 2.92 , since then it has decreased continuously; by April 1992 it was at the level of 2.32 .

The study by PlanEcon (1992) evaluated the PPP of the CSK in early 1990 even more favorably, CSK 6.20 per US dollar in January 1990 and CSK 10.34 per US dollar in April 1992. While diverging in their initial level, the resulting rate of change of the PlanEcon estimates coincides with the above estimates for the period examined.

The exchange rate/PPP ratio that study gave for the Hungarian forint was 2.15 in January 1990, decreasing to 1.62 by April 1992. For the Polish zloty the corresponding figures were 3.88 and 1.70 , respectively.

Comparing these findings for Hungary and Poland with the above results for the former the CSFR, the following conclusion may be drawn:

- While in the beginning of 1990 the extent of the disparity in all three reforming countries appeared to be significantly wider than in comparable market economies, ${ }^{5}$ the implied exchange rate/PPP ratio for the CSK fell only modestly up to mid-1992, unlike in Hungary and Poland.

- This implies that the CSK has been kept relatively undervalued with respect to convertible currencies, and in the course of the recent period this has become the case with respect to the Polish zloty and the Hungarian forint.

\section{The impact of the transition on nominal and real exchange rates}

In the period from January 1990 to May 1992 the NEER of the CSK depreciated to 56 percent of its value, as a result of devaluations in 1990 . However, the real effective exchange rate (REER) ${ }^{6}$ calculated on the basis of the CPI, depreciated as well despite a high inflation differential against

\footnotetext{
${ }^{5}$ According to Summers and Heston (1988), the respective ratios (ERDI coefficient) for comparable European countries in 1985 were as follows: Spain 1.81, Ireland 1.34, Greece 1.70, Portugal 2.28, and Turkey 2.99 .

${ }^{6}$ Greater value than 100 signifies appreciation and less than 100 depreciation.
} 
the countries of basket currencies. Though only by 6 percentage points, the level of the REER was in May 1992 still below its January 1990 base (see data in Table 3.3).

Parallel calculations for Hungary and Poland indicate REER appreciation of both the forint and the zloty in 1990 and 1991. Between January 1990 and May 1992 the forint's REER appreciated by 32 percent, while the zloty's appreciation was much sharper, by 140 percent.

However, the CSK's REER has tended to appreciate as well recently. Along with a marginal appreciation of the NEER expressed in terms of US dollars, CSK's REER appreciated by 7 percent in the year ending May 1992.

The divergent trends in the REERs across the reforming countries were conditioned by substantial differences in their inflation records and to some extent also by the difference in the transition strategies adopted:

- In Poland at the beginning of 1990 , and in the CSFR a year later, the move to a limited currency convertibility was associated with substantial devaluations. Moreover, the authorities in both cases opted for a deliberate overshooting of devaluation, setting the exchange rate close to a parallel market or a "marginal" rate. Hungary, on the other hand, followed a more gradual path of liberalization, accompanied by repeated, but relatively modest, devaluations of the forint. Reflecting these differences, the nominal exchange rate of the Polish zloty depreciated between 1989 and 1992 much more than the CSK rate, while the Hungarian forint, on the other hand, depreciated significantly less in nominal terms.

- As for inflation in the respective period, the CSFR record was more favorable than that of Hungary, and certainly much more favorable than Poland's (compare Table 3.4). In the CSFR, apart from a price jump in January 1991 following the sweeping price liberalization (CPI increased by 25.8 percent only in this month), inflation was well under control during the entire period examined, with the monthly average at 0.6 percent for the year ending May 1992.

To conclude, due to a substantial devaluation of the CSK's NEER associated with a relatively modest increase in the domestic price level since the start of the transition, the implied exchange rate/PPP ratio decreased much less in the CSFR than in Hungary and Poland. Consequently, in comparative terms the CSK has continued to be undervalued. 
Table 3.3. Effective exchange rates of the CSK, percent, January $1990=$ $100{ }^{a}$

\begin{tabular}{|c|c|c|c|c|}
\hline & NEER $^{b}$ & $\begin{array}{l}\text { Consumer prices } \\
\text { of basket countries }\end{array}$ & $\begin{array}{l}\text { Consumer prices } \\
\text { of the CSFR }\end{array}$ & REER \\
\hline $1990 / 1$ & 100.00 & 100.00 & 100.00 & 100.00 \\
\hline 2 & 96.78 & 100.36 & 100.19 & 96.62 \\
\hline 3 & 96.91 & 100.65 & 100.39 & 96.66 \\
\hline 4 & 96.91 & 100.83 & 100.58 & 96.67 \\
\hline 5 & 96.72 & 100.98 & 100.48 & 96.25 \\
\hline 6 & 97.26 & 101.29 & 100.77 & 96.76 \\
\hline 7 & 97.11 & 101.42 & 108.49 & 103.89 \\
\hline 8 & 96.95 & 101.95 & 111.29 & 105.84 \\
\hline 9 & 97.02 & 102.53 & 112.16 & 106.13 \\
\hline 10 & 74.26 & 103.20 & 113.42 & 81.62 \\
\hline 11 & 62.19 & 103.15 & 115.73 & 69.78 \\
\hline 12 & 60.87 & 103.20 & 115.73 & 68.26 \\
\hline $1991 / 1$ & 53.69 & 103.81 & 145.56 & 75.29 \\
\hline 2 & 53.58 & 103.99 & 155.60 & 80.18 \\
\hline 3 & 53.77 & 103.99 & 163.42 & 84.50 \\
\hline 4 & 54.17 & 104.38 & 166.31 & 86.30 \\
\hline 5 & 54.21 & 104.51 & 169.59 & 87.96 \\
\hline 6 & 54.36 & 105.20 & 172.59 & 89.18 \\
\hline 7 & 54.36 & 105.85 & 172.68 & 88.69 \\
\hline 8 & 54.17 & 105.95 & 172.88 & 88.40 \\
\hline 9 & 54.03 & 106.22 & 173.26 & 88.14 \\
\hline 10 & 53.96 & 106.46 & 173.17 & 87.76 \\
\hline 11 & 53.74 & 106.89 & 175.77 & 88.37 \\
\hline 12 & 53.58 & 106.98 & 177.80 & 89.05 \\
\hline $1992 / 1$ & 53.89 & 107.30 & 179.54 & 90.16 \\
\hline 2 & 54.28 & 107.85 & 180.41 & 90.79 \\
\hline 3 & 54.42 & 108.24 & 181.08 & 91.05 \\
\hline 4 & 54.49 & 108.51 & 181.95 & 91.37 \\
\hline 5 & 54.27 & 108.90 & 182.63 & 91.01 \\
\hline 6 & 53.90 & 109.18 & 183.20 & 90.45 \\
\hline 7 & 53.22 & 109.25 & 184.65 & 89.96 \\
\hline 8 & 52.93 & 109.49 & 185.71 & 89.78 \\
\hline 9 & 52.90 & 109.76 & 189.09 & 91.14 \\
\hline 10 & 53.13 & 110.16 & 192.95 & 93.06 \\
\hline 11 & 53.85 & 110.58 & 196.62 & 95.75 \\
\hline 12 & 53.66 & 110.64 & 198.26 & 96.16 \\
\hline
\end{tabular}

${ }^{a} \mathrm{DM} 0.65$ and US $\$ 0.35$ per CSK.

${ }^{b}$ NEER: Nominal effective exchange rate.

${ }^{c}$ REER: Real effective exchange rate.

Source: State Bank of Czechoslovakia; International Financial Statistics. 
Table 3.4. Consumer prices in the CSFR, Hungary, and Poland from 1986 to 1992 , average annual percentage rates over the previous year.

\begin{tabular}{lrrrrrrr}
\hline & 1986 & 1987 & 1988 & 1989 & 1990 & 1991 & 1992 \\
\hline CSFR & 0.5 & 0.1 & 0.2 & 1.4 & 10.0 & 57.9 & 10.3 \\
Hungary & 5.3 & 8.6 & 15.5 & 17.0 & 28.9 & 35.0 & 23.0 \\
Poland & 17.7 & 25.0 & 60.0 & 251.0 & 586.0 & 70.0 & 43.0 \\
\hline
\end{tabular}

Sources: Statistical Bulletin; International Financial Statistics; OECD Economic Outlook.

\section{Inflation differential}

Though the inflation record of the former the CSFR was relatively favorable in terms of transition economies, the inflation rate experienced was considerably above the "standard" of the European market economies, and is likely to remain so in the Czech Republic in 1993 as well.

In 1992 , the projected inflation rate was between 12 percent and 15 percent. In reality CPI increased by 11.5 percent compared to the end of December 1991, and by 10.3 percent compared to the year 1991 .

The inflation rate in 1993 is again expected to range between 17 percent and 20 percent. As in 1992, the main "culprits" are increases in still administered prices and institutional changes. Whereas in 1992 these were increases in energy prices and in rents, the shift to a value-added tax (VAT) regime in the beginning of 1993 and some further increases of energy prices are expected to be the main factors inflating the price level in 1993. The changeover to VAT alone increased the domestic price level by more than 7 percent at the beginning of 1993 . Moreover, the split of the federal state inevitably generated further inflationary pressures.

Given a "positive" inflation differential vis-à-vis countries of basket currencies to which the currency of the Czech Republic, the Czech koruna (CK), is pegged, the trend toward a further appreciation of the REER of the CK will persist. It implies a gradual erosion of the gap between the current exchange rate and $\mathrm{PPP}$ of the $\mathrm{CK}$. In the past, however, the competitiveness of the exchange rate was based on this particular gap.

Along with the impact of inflation differential, the hoped-for revival of economic growth is expected to add pressures to balancing foreign exchange flows. Consequently, both of the main factors which worked up to the second half of 1992 to increase the current account surplus are likely to subside or to disappear altogether. The Czech Republic, though later than Poland and Hungary, is thus faced with the issue of what type of foreign exchange rate strategy to adopt in coping with the challenges of competitiveness in the 
world market and of balancing foreign exchange accounts in the medium run.

Both Hungary and Poland have recently adjusted their nominal exchange rate level to reestablish balance in their external accounts. In 1990, the Polish authorities fixed the nominal exchange rate of the zloty as part of a stabilization package to fight existing hyperinflation. The peg was in reality maintained far beyond the preannounced period, despite considerable deterioration of competitiveness and emerging balance of payments deficits in late 1990. This development was criticized by a number of observers as an outright policy mistake (see, for instance, Chapter 2 by Jasiński and Chapter 6 by Rosati). The growing inflation differential ultimately induced the authorities to resort to repeated devaluations of the zloty in 1991 and 1992, which were later accompanied by the adoption of a crawling peg system.

In a less inflationary environment, the Hungarian authorities coped with the ensuing price-level differential via repeated discrete devaluations of the forint. The policy followed, however, was not to correct for its entire extent, but to press the Hungarian firms for a gradual competitive adjustment.

\section{Exchange Rate Regime Options}

Despite significant progress toward a market economy framework accomplished within a relatively short time span, the transition economies of Central Europe are still far from being homogeneous enough to react sensitively to price and foreign exchange rate developments. It appears therefore, justified to claim that given this state of affairs the impact of the foreign exchange rate level and the foreign exchange rate regime must be less significant compared to market economies.

In the dislocated economies of Eastern Europe, the exchange rate is far from the pervasive price that it is thought to be in the West.... In other words, the exchange rate can hardly be relied upon to anchor an economy in which competition is limited, marketing nonexistent and communications appalling. [Fry and Nuti, 1992]

On the other hand, however, the transition alone gives specific importance to the present stage: a "code of behavior" of newly created and restructured agents, including private and privatized firms, trade unions, and government authorities, is being forged and "built in." The alternative options of the exchange rate regime evidently differ in the requirements and signals sent to economic agents. And given that the Czech Republic is a 
small economy, increasingly open to the outside world, the impact of the foreign exchange rate regime adopted at present is likely to co-determine the type of expectations and behavior of economic agents at least in the medium run.

\section{Arguments in the choice of exchange rate regime}

Though the literature on optimum currency area cannot give any definite answer as to the concrete type of the foreign exchange regime, it does provide a number of relevant arguments and discussions on the issue (e.g., Wihlborg and Willett, 1992).

The literature suggests that there is often a trade-off between the macroeconomic advantages of flexible exchange rates and the microeconomic advantages of fixed rates. The relative costs and benefits of fixed versus flexible exchange rates vary from country to country, depending on the size, structural and institutional characteristics, the nature and source of shocks, the objectives, and the current economic situation. Other dimensions given, the case for a fixed exchange rate regime in a transition economy is evidently strong for a small country with a high share of export and import flows. (In an extreme case, with only a few non-traded goods and services, the impact of exchange rate changes would be more or less confined to the changes in domestic price level.)

\section{"Simple rules" or "managed" types of exchange rates}

The "simple rule" alternative comprises two extreme options: freely floating rate or firmly fixed rate. This type of solution, however, does not appear smoothly applicable. In contemporary economies more objectives are as a rule simultaneously aimed at, with different weights attached to them across countries and periods. Moreover, various shocks, external as well as domestic, must be treated.

The experience suggests that exchange rates tend to be mostly more-orless managed in the present world economy. After the collapse of the gold standard there were only a few cases of entirely fixed rates in the long run, while, on the other hand, free floating was also mostly confined to several episodes.

Under the conditions in transition economies the free-floating option has been suggested as a reasonable approach to establish a proper initial value of the currency after the breakdown of the former centrally planned 
economy framework. There are, however, severe constraints on its potential merits in the environment of the transition economies: rather thin currency markets, underdeveloped institutions, lack of forward foreign exchange markets and of short-term "arbitrage," and speculative capital flows which could under certain conditions work toward destabilizing the exchange rate (Williamson, 1991).

Consequently, the extent of misalignments and exchange rate volatility would evidently be much greater in these countries than in consolidated market economies of a similar type. And even in the stabilized economies the experience with free floating has not been particularly encouraging. This type of solution seems therefore unsuitable for the environment and objectives aimed at in the former CSFR.

With regard to irrevocably fixed exchange rates the comparison with developed open market economies seems again to suggest that this solution is nonviable for transition economies. Given the profound changes, including institutional uncertainties and shocks involved in the transition process, any attempt to fix an "equilibrium rate" for the long-term appears unrealistic. Moreover, apart from the issue of deciding at what level to set the original fixing, even more controversial appears to be the adoption of a reasonably sustainable rate in the long run, without inflicting unbearable costs on the economy.

It follows that neither free-floating options nor irrevocably fixed rate options seem to be realistic for the transition economies, however attractive the simple rule approach might be. Some type of a compromise "managed" solution, involving some discretion, appears therefore the justified way out.

\section{The "managed" option as applied in transition economies}

In the former CSFR, a version of the adjustable peg system seemed to be applied. While maintaining a fixed rate pegged to the basket, the authorities made no commitments as to its duration, not excluding thus its possible adjustment.

Hungary has adopted a similar solution: discrete adjustments of the forint's exchange rate aimed at keeping the real rate more or less stabilized. Over the course of time they have become smaller and have happened more often.

In the Polish case, on the other hand, a crawling peg system was adopted in 1991 to cope with the inflation differential. A crawling peg implies that 
the exchange rate is adjusted by small changes at regular intervals (daily, weekly, or monthly); in the case of Polish zloty, a daily base was chosen.

The apparent advantage of this type of solution is to avoid abrupt changes in the real exchange rate's level, which has certainly some merits in the still relatively inflationary Polish economy. On the other hand, there is the danger of embedded inflationary expectations. The crawling peg arrangement may then become an additional source of inflation differential rather than the way of coping with it.

Though in a different way, the "managed" alternatives of exchange rates in Hungary and Poland recently tended, by and large, to adjust for the differences in relative price performance vis-à-vis their partners. The policy was thus - at least to some extent - developing along the real exchange rate anchor concept suggested for transition economies by Nuti (1990) and Fry and Nuti (1992).

The concept of real exchange rate anchor certainly has some advantages, given the environment of the transition economies with "positive" inflation differential. It tends to provide relatively stabilized conditions visà-vis the outside world for investors and traders, which may positively affect their activities and expectations. Assuming that the starting point is chosen correctly, it could be expected to yield a medium-term balanced current account.

However, there are some constraints implied as well. Data on price level developments are available with some lags only. Applying them means that the real exchange rate is only $e x$ post accommodating the price differential, without exercising any disciplining effect on economic agents. To establish instead a real "anchor" $e x$ ante would require some kind of forecasted or targeted data on relative inflation rates, which is by itself open to a considerable margin of misassessment.

To conclude, the managed types of exchange rates appeared as the only feasible alternative in the first stage of the transition. The policy of a stabilized real rate, while accommodating for ensuing inflation differential, was likely to work toward balancing foreign exchange accounts and at the same time to provide a stable parameter in real terms for investment and trade activities.

On the other hand, however, this type of solution is not particularly helpful to restructuring in microsphere and to exercising a disciplining role on the behavior and performance of economic agents. Without doubt, just these 
microeconomic dimensions are of key importance, conditioning any economic recovery and revival of sustainable growth in the transition economies.

\section{Structural Defect of Czechoslovak Exports and "Soft" Exchange Rate Regime}

As discussed above, a common feature of the centrally planned economies, including the former the CSFR, was a wide gap between the domestic and external values of their currencies. The mentioned dispartity was not only due to technical and technological gaps with respect to developed market economies as elsewhere, but also due to the institutional, systemic, and policy peculiarities of centrally planned economies. ${ }^{7}$

\section{Legacy of the centrally planned economy}

The CSFR (Czech lands in particular) was one of the top 10 industrial countries before World War II and in the early postwar period. Since then it has lost its position in a dramatic way. The gap is particularly large in manufacturing branches, where the productivity level is estimated at between 25 percent and 30 percent of the German standard.

The manifold reasons for this rather unfavorable trend have a common denominator: the almost "perfect" shelter provided to enterprises both domestically, within the framework of a centrally planned economy, and from the outside, by CMEA institutions. ${ }^{8}$

As a consequence, Czechoslovak manufacturing firms did not experience for decades any real competitive pressure, either domestically or from the

\footnotetext{
${ }^{7}$ The existence of such gaps is hardly an exceptional case in the world economy. The countries at a relatively lower level of development inevitably face productivity and efficiency gaps with respect to their more developed partners. Balassa (1964) developed an argument on "productivity bias" to PPP, implying that divergent productivity levels lead to systematic trend deviations from PPP. Nonetheless, the extent of the mentioned gap in the former centrally planned economies tended to be significantly wider than in other countries at a similar level of development, suggesting the existence of "specific" causa] factors.

${ }^{8}$ The CSFR maintained the second largest share of CMEA trade among the CMEA members and, unlike Hungary and Poland, started to reallocate its trade only in the early 1990s. The detrimental impact of the CMEA "shelter" was thus rather high also in comparative terms.
} 
world market. Along with the resulting gap in technical and quality standards, their products were losing Western markets and/or experiencing relatively declining prices because of lacks in marketing, distribution networks, business contacts, and expertise; deficient financial payment; and inadequate insurance, telecommunication infrastructure, and services. These flaws appeared even more detrimental to the competitiveness of the Czechoslovak manufacturing products than its technical and technological shortcomings.

According to a survey, in 342 cases out of a total of 866 firms surveyed, exports to market economies did not exceed 1 percent of total deliveries (Kolanda and Kubišta, 1990). This implies that four out of every ten firms had almost no contact with the world market and had no grasp of what real competition actually meant and required.

The phenomena, which were developing under the given institutional and incentive framework, would be entirely paradoxical within the logic of an open market economy:

- Various industries and branches as well as individual firms could go on extending their activities at a widely differentiated efficiency level in terms of the world market's criteria. The cases of entire branches with negative value added at world market prices were not exceptional ones (Hughes and Hare, 1992).

- The relative efficiency of individual firms within the same industry, i.e., under the same institutional and incentive regime, was estimated to be dispersed up to 10 times more compared with the standard in developed market economies (Kolanda, 1989).

As the "soft budget constraint" was claimed responsible (Kornai, 1986), its important component was "soft" exchange rate regime. The implied exchange ratio adjusted $e x$ post in a freely floating way, without exercising any significant impact on changing the behavior of domestic firms.

- The number of manufacturing stages was as a rule negatively correlated with the profitability of sales in the world market. It means, the higher the level of processing, the lower the gains from trade appeared. ${ }^{9}$

This paradox in terms of a manufacturing economy (which was, however, not confined to the CSFR) can be explained as a result of a cumulative impact of both "real" and "valuation" factors:

${ }^{9}$ However anecdotical it may seem, exporting furniture appeared as a rule less favorable than prefabricated parts; these intermediate products were in turn less profitable than timber, and timber less profitable than selling just trees. 
- An increasing gap in productivity and technical and quality standards with respect to the competitors.

- Depressed prices of CSFR manufactures in the world market because of marketing and institutional flaws.

- Biased ratios of foreign to domestic prices due to the deficiencies of domestic price setting (lacking, e.g., a proper evaluation of natural resources) and due to the distortive impact of widely differentiated tax and subsidies schemes.

The institutional peculiarities of the centrally planned economy framework resulted in the CSFR's long-run declining share of the world's exports coupled with the increasing replacement of higher value-added products by lower value-added ones, such as raw materials, intermediate products, and standard consumer goods in its exports to the convertible currency markets.

In the period from 1975 to 1989 the CSFR's share in imports of OECD countries fell from 0.28 percent to 0.18 percent. Its share of machinery imports fell even more drastically, from 0.21 percent to 0.07 percent (OECD trade statistics).

Simultaneously, a tendency toward a "dual" structure of export flows to the former "socialist" and developed market economies became increasingly pronounced. Manufactures (SITC 6-8) accounted for 87 percent of exports to former socialist countries in 1990, but for only 66 percent in exports to market economies (Facts on Czechoslovak Foreign Trade, 1991).

This legacy inevitably affected the initial conditions for transition and, consequently, constrained the rationality of conventional policy schemes and instruments.

\section{Trade and balance of payments in the period from 1989 to 1992}

The previous inertia of both the domestic and external environments ended abruptly in the early 1990s. The impact of external shocks interacted with institutional changes initiated in the domestic economy and with a parallel severe contraction of domestic demand. ${ }^{10}$

The volume of foreign trade decreased in absolute terms throughout the transition period, thus accelerating a long-term decline in the CSFR's share

\footnotetext{
${ }^{10}$ According to Landesmann (1991), the CSFR may have been hardest hit by the trade shocks (due to the collapse of CMEA trade and institutions, in particular) of all the Central and Eastern European countries.
} 
Table 3.5. Distribution of the CSFR trade, percent shares, derived from values in CSK, current prices, and foreign exchange rates.

\begin{tabular}{|c|c|c|c|c|c|c|c|c|}
\hline & \multicolumn{4}{|c|}{ Exports } & \multicolumn{4}{|c|}{ Imports } \\
\hline & 1989 & 1990 & 1991 & $1992^{a}$ & 1989 & 1990 & 1991 & $1992^{a}$ \\
\hline Former CPEs & 60.8 & 49.0 & 39.3 & 24.7 & 62.3 & 51.2 & 42.8 & 35.2 \\
\hline Former CMEA & 54.9 & 43.4 & 32.8 & 23.9 & 56.1 & 44.4 & 39.5 & 34.6 \\
\hline Former USSR & 30.5 & 25.2 & 19.4 & 10.4 & 29.7 & 21.6 & 31.8 & 27.8 \\
\hline Market economies & 39.2 & 51.0 & 60.6 & 75.3 & 37.7 & 48.8 & 57.1 & 64.8 \\
\hline Developed & 31.2 & 42.4 & 51.9 & 64.5 & 31.1 & 42.6 & 48.9 & 59.3 \\
\hline EC & 18.2 & 26.5 & 40.7 & 50.2 & 17.8 & 23.8 & 33.0 & 41.0 \\
\hline Developing & 8.0 & 8.6 & 8.7 & 10.8 & 6.6 & 6.2 & 8.2 & 5.5 \\
\hline
\end{tabular}

${ }^{a}$ January-September 1992.

Source: Facts on Czechoslovak Foreign Trade.

in the world market. Between 1989 and 1991 its share in world exports dropped from 0.46 percent to 0.33 percent.

In 1991 imports were 20 percent lower than in 1990 (reflecting a deep domestic recession), while exports declined by 7 percent, recovering in the second half of the year. The level of exports remained stabilized in the first half of 1992 compared with the same period in 1991 (index 99.2), while imports continued to decrease (index 87.8). A reversal of this trend, i.e., a recovery of imports, has taken place since the second half of 1992 .

With regard to changes in the territorial distribution, up to 1989 the share of former centrally planned economies was dominant in Czechoslovak foreign trade. Since then substantial shifts have taken place (Table 3.5).

Discontinuities experienced in both the domestic and external environments have substantially affected the commodity composition of trade flows between 1989 and 1992. According to the data in Table 3.6, the implied changes in the export pattern (as reflected in the aggregate product groups) were unfavorable. The share of machinery and transport equipment (SITC 7) decreased dramatically during this period: from 44.4 percent in 1989 to 27.9 percent in 1991 and to a mere 22.1 percent in the period from January to September 1992. On the other hand, the role of raw materials, intermediate products, and foodstuffs in total exports has been increasing.

It may be argued that the recent shift to a higher share of raw materials and intermediate products in total exports only reflects the legacy of the "dual" structure of Czechoslovak trade in the past. As the role of lower value-added products was higher in the trade with market economies, given the materialized substantial reallocation of exports to them, the share of 
Table 3.6. Product composition of the CSFR foreign trade, percent shares, SITC classification in parentheses.

\begin{tabular}{lrrrrrrr}
\hline & \multicolumn{3}{l}{ Exports } & & \multicolumn{3}{l}{ Imports } \\
\cline { 3 - 4 } \cline { 7 - 8 } & 1989 & 1991 & $1992^{a}$ & & 1989 & 1991 & $1992^{a}$ \\
\hline Food and beverages (0+1) & 5.0 & 8.6 & 8.7 & & 7.6 & 6.9 & 7.3 \\
Crude materials, excluding & & & & & & \\
$\quad$ Fuels (2+4) & 3.8 & 5.5 & 6.5 & 9.1 & 9.5 & 7.1 \\
$\quad$ Fuels (3) & 5.2 & 4.2 & 4.3 & 17.3 & 29.8 & 24.3 \\
Chemicals (5) & 7.6 & 10.6 & 10.0 & 9.3 & 9.8 & 10.4 \\
Products classified according & & & & & & \\
$\quad$ to the material (6) & 23.4 & 30.4 & 36.1 & & 10.4 & 9.0 & 9.8 \\
Machinery and transport (7) & 44.4 & 27.9 & 22.1 & & 37.0 & 28.1 & 32.6 \\
Manufactures (8) & 9.7 & 12.7 & 12.4 & 6.2 & 7.0 & 8.6 \\
\hline
\end{tabular}

a January-September 1992.

Source: Facts on Czechoslovak Foreign Trade Bulletin, Federal Statistical Office, Prague.

materials and intermediate products in total exports was likely to increase accordingly.

It is true that the collapse of CMEA trade, with the former USSR in particular, was the main cause of the dramatically decreasing share of machinery and transport equipment in total exports. Its increasing role in exports to market economies in 1990-1991 (the share of SITC 7 on exports to the EC countries increased from 13.9 percent in 1989 to 18.1 percent in 1991) could not compensate for the losses in CMEA markets, and therefore remained rather low.

The shifts in the composition of imports were not particularly encouraging either, when viewed from the point of the future prospects. In imports from both the EC and EFTA countries the share of machinery imports diminished while that of foodstuffs and consumer goods increased in the first half of 1992 compared to 1991.

Unlike the volume of trade flows, the current account balance in convertible currencies has recovered after a sharp deterioration in 1990, with surpluses steadily increasing in the course of 1991 and the first half of 1992 as well. Correspondingly, the foreign exchange reserves also recovered and in mid-1992 reached the highest level in the entire postwar period.

Compared to the past when merchandise trade flows were dominant, a tendency to an increased share of various services, tourist trade, and income transfers was clearly surfacing and contributing to favorable changes in the current account (see Table 3.7). While trade balance is likely to deteriorate 
Table 3.7. Balance of payments in convertible currencies, in million dollars.

\begin{tabular}{lrrrr}
\hline & 1989 & 1990 & 1991 & $1992^{a}$ \\
\hline Current account & 439 & $-1,105$ & 356.5 & 895.3 \\
Trade balance & 419 & -785 & -447.4 & -441.4 \\
Service balance & 218 & 37 & 827.4 & $1,128.4$ \\
Income balance & -163 & -316 & -65.4 & 58.3 \\
Transfers & -35 & -40 & 41.8 & 150.0 \\
Capital account & 326 & 326 & 47.0 & -259.2 \\
Direct foreign investment & 256 & 181 & 592.4 & 968.0 \\
Other long-term capital & -53 & 718 & $1,731.7$ & 658.3 \\
Short-term capital & 123 & -573 & $-2,277.1$ & $-1,886.6$ \\
Errors and omissions & -197 & -324 & 494.4 & 73.1 \\
Changes in reserves $^{b}$ & -569 & 1,102 & -897.9 & -709.2 \\
\hline
\end{tabular}

a January-September 1992.

${ }^{b}$ Negative value means increase of reserves.

Source: State Bank of Czechoslovakia.

once the domestic recovery is under way, the surplus on non-trade flows can be expected to continue to balance the current account at least for a while.

\section{Possibilities of a foreign trade-led recovery}

During the period from 1990 to 1992 , the inflation and balance of payments records were two domains where the results achieved in the former CSFR were highly satisfactory. In the trade sphere, a major reorientation of trade toward the OECD (to the EC countries, in particular) had been accomplished, with exports to the OECD rising in 1990 and 1991 by 18 percent and 35 percent, respectively. Since 1991 export demand and export flows have been developing more favorably than domestic sales, contributing thus to lessening the implied fall in the GDP.

Viewed from the demand side, the recovery of transition economies could be fostered through the expansion of either domestic-demand components or foreign demand. While the possibilities of an across-the-board promotion of domestic demand appear to be rather constrained under current terms, the prospects of foreign-demand expansion seem to be more promising.

In the case of the Czech Republic there is certainly an opportunity for revival of trade in the former CMEA area, with neighboring Hungary and Poland in particular. At the same time there are still unused opportunities 
to expand also "non-sensitive" exports to the OECD area, especially when the present recession in the main OECD countries is over.

\section{"Wrong" type of exports}

The developmental impact of export flows appears, however, in reality rather "devalued" due to its composition. As discussed above, Czechoslovak exports to the world market were increasingly shifted toward relatively lower valueadded products.

As shown in a study by Bohatá and Fischer (1992), although the total export volume fell in 1990 and 1991, the stabilized and even increasing exports were those of iron metallurgy and of basic chemicals. This occurred despite their rather high energy and material inputs, the supply of which, moreover, was subject to increasing uncertainties and constraints.

These industries were also at the top in relative export performance expressed as the volume of exports per employee and/or firm.

\section{The Role of Foreign Exchange Rate Regime}

The strategy that the CSFR government followed in the trade sphere initially relied almost entirely on the exchange rate adjustment only, leaving aside policies of export promotion, the instruments of commercial and industrial policies in particular. The reasoning behind this strategy was to put everybody on "equal footing" and to avoid any "administrative" interference in the production and trade patterns.

The three consecutive devaluations of CSK in 1990 were in accordance with this reasoning; they aimed at creating conditions for sustainable trade liberalization and limited currency convertibility by providing a "flat" basis for export expansion.

The devaluation-type approach is expected to lead to an improvement in price and cost competitiveness, given satisfactory price elasticities and provided that the effects of devaluation are not quickly eroded by the followup increases in incomes.

Apart from the qualification that these conditions need not be $a$ priori satisfied, the export stimulus of devaluation applies to those items where the cost and price dimensions of competition are substantial, if not dominant. The non-price factors, on the other hand, tend to be more important with nonhomogeneous products, more sophisticated and higher value-added 
ones, where goodwill, reliability, advertising and marketing, prompt delivery, after-sales service, and meeting of individualized demands are crucial.

This qualification to the devaluation's export stimulus are relevant under the conditions of the transition economies. The legacy of the past development and the rigidities of the existing markets, of labor and financial markets in particular, severely constrain the reallocation of resources and the supply response to changing price and exchange rate ratios. Even more important, the lack of established contacts with the world markets, the lack of distribution networks, underdeveloped marketing, and deficient related services substantially diminish the impact of price advantages implied by a devaluation, in particular in the sphere of nonhomogeneous, higher value-added products.

Consequently, as could be expected, the response to the devaluations effected in the CSFR in 1990 was rather unequal across individual branches. As a rule, with some notable exceptions, raw materials, intermediate products, and construction materials could find new export markets relatively more easily. ${ }^{11}$

\section{Short-term Gains Versus Medium- and Long-term Costs} of the Devaluation-Type Approach

Under the environment created by the devaluations at the start of transition, the implied comparative advantages of Czechoslovak exporters were increasingly based on cost advantages, conditioned particularly by the depreciated labor costs in foreign exchange terms. ${ }^{12}$

The impact of this type of development appears rather controversial. To its credit could be claimed that it secured the following:

- Trade balance and current account surplus at a time when the internal convertibility on current account transaction and trade liberalization were implemented; foreign exchange reserves were rather low; and sustained export growth to convertible-currency markets was crucial to

\footnotetext{
${ }^{11}$ An export "boom" in steel and rolled material on the EC markets has already led to countermeasures by the EC countries, involving antidumping procedure.

${ }^{12}$ Though the former rather equalized level of wages and salaries have begun to differentiate substantially recently, the "average" wage of a qualified worker - when expressed in foreign exchange terms - still amounted to less than US\$200 per month in early 1992, a rather low level among comparable countries in Western Europe and apparently even lower than in neighboring Hungary and Poland.
} 
offset, at least partially, the sharp contraction of trade to the former CMEA.

- More attractive conditions for foreign investors who were ready to exploit the opportunities provided by low labor costs (particularly since the labor force is relatively well educated and qualified), along with prospective capital gains.

On the other hand, the consequences in the medium and long run are hardly favorable:

- Data on recent trends seem to confirm that the incentives derived from an undervalued currency and "cheap labor," accentuated the long-run trends to "regressive specialization."

- The negative implications of moving to lower value-added products include the risk of a brain-drain and an increasing gap in the technological standards in the world economy. By contrast, the successful examples of revitalization elsewhere in the world were based on narrowing this gap. In addition, a cost disadvantage compared to the parallel products of low-income countries and the continued clashes of interest in the "sensitive sectors" with the EC countries make the "devaluation-type" approach risky. ${ }^{13}$

- Under the conditions in the transition economies the "soft" exchange rate regime is fostering the already strong traditional pattern of characterizing decision making in the enterprises. To reverse inertia of past trends, enterprises must be induced to make all possible effort to innovate, to develop, and to market new products of a higher quality and technical standard, to catch up in the marketing and sale services. "Devaluation-type" policies, however, provide for a continuation in the "traditional" behavior pattern and expectations. Given the underdeveloped financial and labor markets and existing institutional rigidities, there is an implied inertia in the "given" allocation of resources. While in the past the preferences were mostly given to heavy industry branches, the devaluation-type policies gave a further impetus to their comparatively high "profitability" and "export orientation." As a result, the comparative advantages are distorted, i.e., favoring materialand energy-intensive branches, in the course of resource allocation.

${ }^{13}$ Their share was estimated at over 50 percent of total Czechoslovak exports to the EC markets in 1990, including agricultural products 8.1 percent, textiles 11.5 percent, iron and steel 16.3 percent, coal 2.5 percent, and products with tariff ceilings and quotas 19.2 percent (Rollo and Stern, 1992). 
A conclusion follows that the "devaluation-type" approach was able to secure competitiveness of the Czechoslovak exports in the short run. At the same time, however, due both to the type of signals to economic agents and to the generated pattern of resource allocation it worked in fact against their competitiveness in the medium and long run.

\section{An Alternative Exchange Rate Regime for the Czech Republic}

Taking into account the special institutional arrangement in the first stage of the transition, the question arises whether there is another option of an exchange rate regime that would be more conducive to restructuring in the microsphere without, however, imposing intolerable macroeconomic costs? And if the answer is positive, under what conditions?

The challenge of the Czech Republic's development in the medium run is to reverse the downgrading trends of its production and export structures which dominated in the past. Increasing shares of low value-added branches and products produced and traded depressed the economic potential of the country relative to the outside world, constraining the scope for productivity increases. Consequently, real incomes were doomed to fall in relative terms, which really materialized in the long run.

If this trend continues in the medium and long run, a kind of vicious circle would develop. Under the terms of an open economy, the increasing productivity gap with respect to the trade partners would further diminish gains from trade and feed the repeated waves of inflation and devaluation. Such an outcome, widening - instead of narrowing - productivity and income gaps, would imply a further peripherization of the Czech Republic, and not only in the European context. Instead, any sustained recovery and revival of economic growth requires moving upward on the value-added scale.

\section{Policies to cope with microeconomic and structural defects}

An alternative to exchange rate policies accommodating ex post to domestic cost and price increases via repeated devaluations is the "hard currency" option. It implies nominal exchange rate being a policy target. Its most demanding version is an irrevocably fixed nominal rate, pegged to a lowinflation "pilot" national or composite (ECU) currency. 
The main argument for such an approach to fixing the nominal exchange rate is the traditional one: disciplining effects on economic agents. In the case of the Czech Republic as an economy undergoing transition, these effects should contribute to the entire overhaul and reorientation of their behavioral pattern and expectations.

In the Czech case, a wide margin for productivity increases is available, provided the changed regime and reoriented incentives and expectations begin to bite. As a legacy of the past, there is still an accumulated potential of efficiency gains in the existing wasteful methods of using inputs and equipment, "organizational slack," overstaffing, outmoded routines. Even more important are potential gains in a dynamic setting, as the centralized framework failed particularly in introducing new products and technologies.

Once the policy of nominal exchange rate target is made credible (i.e., after the authorities pass several "tests" of their policies and proceed differently from what could otherwise be expected), and the enterprises learn that they could not rely any more on "traditional" depreciations of the domestic currency as a way out from reoccurring pressures of inflating domestic costs, the microeconomic advantages of the fixed exchange rate approach should begin to materialize. The experience from elsewhere, notably from Austrian development, seems to support this assumption (Marin, 1985).

It does not follow, however, that the nominal exchange rate anchor could be powerful enough to do "the job"; other instruments must be applied in a consistent and comprehensive way to make the regime change in the microsphere effective (Portes, 1990).

Along with the microeconomic impact, the policies adopted should be capable of coping with the structural defects of the Czech economy. As argued above, rather unequal starting conditions across branches and industries resulted from the past development. Consequently, the policy relying on unified exchange rate only and on its changes, aiming at "equal footing," worked in reality in a discriminatory way. It favored heavy industry branches that were preferred in the past, at the cost of most manufacturing sectors.

To correct this trend and to achieve a real "leveling of the grounds" would require a transitional arrangement, combining exchange rate policies with promotion schemes for those "disfavored," i.e., mostly for industries with higher value-added products.

There seems to be a legitimate case for such forms of "industrial policies" which - not attempting to pick up winners and losers - would contribute to the development of infrastructure, telecommunications, business, trade, and 
banking services, to the increased mobility of labor, and to the upgrading of human capital. The flaws just in these spheres placed firms in sophisticated manufacturing branches to rather less favorable conditions with respect to both foreign competitors and domestic producers of basic, low value-added products as well.

At the same time the export promotion schemes appear to be warranted to correct for the implied disadvantages of domestic exporters of higher valueadded products. These schemes should:

- Enable enterprises to carry the costs of export reallocation and of penetration to the world market (the extra cost of developing marketing, goodwill, distributional networks, and the additional risk implied).

- Provide "breathing space" for adjustment and restructuring to those which are likely to be viable producers and exporters in the medium run.

These arguments, developing along the infant-industry reasoning, could be baptized "revitalizing industries" arguments.

There are, of course, well-known qualifications and difficulties with the infant-industry argument for protection (Baldwin, 1969; and Hillman, 1991). In the context of transition economies, several issues appear to be especially relevant:

- The protection once extended may be only temporary.

- Even if only temporary, protection incurs costs.

- As the whole manufacturing sector cannot be assisted, the selection implies moral hazard problems.

- Infant-industry protection may more or less eliminate foreign competition which, given the absence of workable domestic competition, is the only factor capable of providing effective incentives for restructuring.

The "revitalizing" protection may work in just the opposite direction of the hoped-for disciplining effects of a fixed exchange rate.

Nevertheless, unlike in the "traditional" infant-industry reasoning, the core of this approach is not in the protective measures against foreign competition. Rather, it addresses the constraining factors and disadvantages experienced by the domestic producers, due mostly to the legacy of the centrally planned economy. 


\section{The potential role of foreign competition}

In the transition scenarios, the incentive and disciplining impact of foreign competition has been attributed a key role in developing a competitive environment. It was recognized that the reforming countries of Central and Eastern Europe - unlike, e.g., Japan - cannot rely on "workable" and "contestable" competition to be created within the domestic economy only.

However persuasive and unambiguous this claim may appear, judging from the Czechoslovak experience the "revitalizing" impact of foreign competition on domestic firms in the first stage of the transition has been far less than expected and, moreover, it was also controversial (Hrnčír, 1993).

Along with the still mostly lacking capacity of the domestic producers to adjust, the main causal factors for this disappointment were related to the adopted policies. These policies relied on "nondiscriminatory" exchange rate's changes only, despite the inherently unequal conditions for individual industries and branches.

At the start of the transition, the substantial devaluations effectively eliminated foreign competition to most industries. The exceptions were only the least efficient ones, including Czechoslovak consumer electronics.

The existing conditions present a dilemma. On the one hand, a more intensive impact of foreign competition would be highly desirable as a driving force for restructuring of domestic firms. On the other hand, however, any profound flat increase in exposure to foreign competition is likely to threaten the very existence of more sophisticated, relatively high value-added branches, while leaving mostly unaffected the material- and energy-intensive basic industries.

Unlike the policies adopted at the start of transition, the strategy combining the fixed exchange rate target concept with the schemes of industrial and export promotion policies could also allow for a more intensive role of foreign competition.

Under the hard currency approach, the pressure of foreign competition would squeeze the profits across all industries. Contrary to the past, however, the support via the industrial policy and an export promotion scheme would compensate manufacturing firms for their relative disadvantages, enabling those viable in the medium run to survive and to expand.

The export promotion schemes should be based on ex ante established rules to avoid administrative discretion and moral hazard problem as much as possible: the support should be extended only to those who qualify. Experience from elsewhere (including Far East Asian countries) suggests the 
feasibility of such schemes, rewarding volume and/or increasing rates of export sales. Unlike the schemes in the past, in this type of promotion scheme the support is oriented to the relatively successful and prospective ones. Consequently, the success in keeping it as a temporary device only is more likely.

In summary, while the case for a unified exchange rate is preferred to trade policy measures, under the given distorted conditions a transitory "corrective" departure appears to be desirable. Along this reasoning McKinnon (1991) argued for "cascading" tariffs rather than lowering the exchange rate. Our approach, however, is not based on a differentiated protection. Rather, it aims at improving the general business environment and at providing selective assistance to those who qualify, demonstrating their capacity to survive, to expand, and to export.

\section{Conditions for fixed exchange rate regime to be viable}

The microeconomic advantages of the fixed nominal exchange rate policy must, however, be compared with the macroeconomic constraints and costs implied. However attractive its disciplining and behavior effects might be in the environment of transition economies, it does not follow that the "hard currency" policy of fixed exchange rate could be reasonably resorted to under any conditions and at any time. It would be neither viable nor sensible, if its costs in terms of lost output, increased unemployment, and social hardship were likely to outweigh microeconomic and structural benefits.

In the postwar period, a number of European economies (e.g., Nordic countries) adopted a different strategy: promoting macroeconomic developments via low interest rates, while repeated adjustments of exchange rates were used to accommodate for domestic costs pressures and to reestablish a strong competitive position. They mostly shifted to the policy of fixed rates only at a more mature and stabilized phase.

If in a "strict" version, i.e., when irrevocably fixed, the exchange rate is "lost" as a policy instrument. It implies, the other instruments must be used, and must be capable of securing competitiveness.

In the course of development, however, cyclical changes and various external and domestic shocks are arising which must be accommodated as well. It follows then that the policy of fixed exchange rate is highly demanding of 
the mechanisms of domestic adjustment: they must be sufficiently effective and flexible as for both trends and short-run developments.

When assessing the chances of fixed exchange rate policy in a transition economy, what matters most is the potential development of the real exchange rate. Providing that the prospective inflation differential with respect to the anchor country would be either zero or negative, the given nominal exchange rate is likely to be sustained.

The changes in the real exchange rate are related to the change in the nominal exchange rate and to relative changes in wage levels, profit rate, and productivity with respect to the anchor countries. The key variable appears to be relative change in productivity. If favorable, i.e., higher or at least matching the increases in the partner countries, wages and profits may rise accordingly, without causing the appreciation of the real rate. This type of favorable constellation materialized, e.g., in postwar Germany. It may be also a challenge for transition economies: Can they use the chance of starting at a rather low level and achieve relatively higher productivity increases while catching up?

The structural and institutional properties of the given economy are evidently decisive in this respect, in particular the degree of effectiveness and flexibility in the functioning of labor and financial markets. It matters whether the disposable savings are increasingly channeled to the "right" users. In a parallel way, a flexible functioning of the labor market is apparently crucial, if the competitiveness is to be maintained via domestic adjustments instead of nominal exchange rate changes. The positive experience of social corporatism and voluntary incomes policies in a number of small European economies at the early stage of their development could be good examples for the Czech Republic to follow (Pekkarinen et al., 1992).

Even with appreciating real exchange rate, however, the given nominal rate could successfully be maintained, provided that the counterbalancing effects of the improving non-price factors of competition exist. Particularly it is hoped that these effects will result from the hard currency policy. The Austrian example suggests their feasibility:

Austria has increased her real market share in the OECD area from 0.9 percent in 1970 to 1.08 percent in 1980 . This 20 percent increase in Austrian market share took place despite an 18 percent revaluation of the real exchange rate of the schilling vis-à-vis her trading partners in the same period. [Marin, 1985, p. 479] 


\section{Conclusion}

However unrealistic the fixed exchange rate regime may appear under present conditions of the transition economies, we suggest that its benefits and costs should be seriously scrutinized, taking into account the specific conditions of each country. In the case of the Czech economy, we believe, it could be a desirable option in the future.

The timing of its possible adoption is, however, a controversial issue. Referring to our earlier arguments in this paper, it is evidently not viable in the next one to two years, taking into account all the institutional and systemic changes under way and the uncertainties involved.

On the other hand, a number of factors would call for avoiding any unnecessary delay in the policy shift mentioned:

- One of the lessons from the development of open market economies is that it takes time to build the credibility of the strategy, and it must be "earned" (Hochreiter and Knöbl, 1991). Implementing the change discussed becomes increasingly demanding, the more embedded the existing expectations are in the behavior of firms, trade unions, and various pressure groups. A comparison between Austria and the Nordic countries is of particular interest in this respect. Along this reasoning, there is a difference between forward- and backward-looking expectations in inflationary tendencies (Barro and Gordon, 1983), and in the resulting conditions to be coped with by fixed exchange rate regime.

- While the capital account flows remain mostly regulated, the "complicating" role of interest rate parity and of speculative capital flows is diminished compared with open market economies of Western Europe. It seems, therefore, advantageous to go through the process of learning under the conditions when the "fundamentals matter."

A reasonably early move to the policy of nominal exchange rate anchor could, therefore, create a more favorable environment for the future development stages.

Despite all the barriers, the Czech Republic has relatively good prospects of succeeding with the fixed exchange rate strategy. Along with the comprehensive privatization program and inflow of foreign direct investment, there is a tradition of industrial development and, moreover, of prudent monetary and fiscal policies in this country aiming at a stabilized currency. This tradition dates back to the period after World War I, when the newly created Czechoslovak Republic adopted conservative fiscal and monetary policies 
and, as a result, avoided the hyperinflation experienced by all its neighbors, including Germany, Austria, Hungary, and Poland (Sargent, 1986).

The hypothesis is that under the given conditions, the policy of the hard currency - instead of devaluations as implied in the conventional wisdom - should contribute to a sustained recovery of the Czech economy in the medium run.

\section{References}

Balassa, B. (1964) "The purchasing power doctrine: A reappraisal," Journal of Political Economy, December.

Baldwin, R. (1969) "The case against infant-industry tariff protection," Journal of Political Economy.

Barro, R.J., and Gordon, D.B. (1983) "Rules, discretion and reputation in a model of monetary policy," Journal of Monetary Economics.

Bofinger, P. (1990) The Role of Monetary Policy in the Process of Economic Reform in Eastern Europe, CEPR Discussion Paper No. 457 (London: Center for Economic Policy Research).

Bohatá, M., and Fischer, M. (1992) Analýza vývoje výkonnosti prümyslu v prüběhu transformačního procesu (Prague: ÚÚNV).

Dornbusch, R. (1990) From Stabilization to Growth, NBER Working Paper No. 3302 (Cambridge, MA: National Bureau of Economic Research).

Facts on Czechoslovak Foreign Trade (1991) (Prague: Czechoslovak Chamber of Commerce and Industry).

Fry, M.J. (1992) Monetary and Exchange Rate Policies in Poland and Other Eastern European Countries: Some Lessons from Further East (Birmingham, UK: University of Birmingham, International Finance Group).

Fry, M.J., and Nuti, D.M. (1992) "Monetary and exchange rate policies during Eastern Europe's transition," Oxford Review of Economic Policy, Spring.

Herr, H., Tober, S., and Westphal, S. (1991) "A strategy for economic transformation and development in Eastern Europe," De Pecunia, No. 3, December.

Hillman, A.L. (1991) "International trade policy in the transition from socialism," Conference "Whither Socialist Society? Economic and Social Transformation in the Soviet Union and Eastern Europe," April 8-10, Jerusalem, in M. Keren and G. Ofer (eds.), Trials of Transition: Economic Reform in the Former Communist Bloc (Boulder, San Francisco, Oxford: Westview Press).

Hochreiter, E., and Knöbl, A. (1991) Exchange Rate Policy of Austria and Finland: Two Examples of a Peg, Discussion Papers, 191, No. 12 (Helsinki: Bank of Finland).

Hrnciír, M. (1993) "The roles of foreign competition and of financial intermediation in revitalising the Czechoslovak economy," in C.T. Summers (ed.), The Role of Competition in Economic Transition (New York: St. Martin's Press in association with the Vienna Institute for Comparative Economic Studies). 
Hughes, G., and Hare, P.G. (1992) "Industrial policy and restructuring in Eastern Europe," Oxford Review of Economic Policy, No. 1.

Kolanda, M. (1989) Export Performance of Czechoslovak Manufacturing Firms

(Prague: Institute of Foreign Trade).

Kolanda, M., and Kubišta, V. (1990) Costs, Performance and Behavior of the Czechoslovak Manufacturing Enterprises on the World Markets in the 1980 s (Prague: Institute of Forecasting).

Kornai, J. (1986) "The soft budget constraint," Kyklos.

Landesmann, M. (1991) "Industrial restructuring and the reorientation of trade in Czechoslovakia," European Economy, Special Edition No. 2.

Lepännen, S. (1992) "Finland and Austria: Two different economic policy strategies" (Helsinki: Government Institute for Economic Research).

MacDonald, R., and Taylor, P.M. (1992) "Exchange rate economics," IMF Staff Papers, No. 1.

McKinnon, R. (1991) "Liberalising trade in a socialist economy," in J. Williamson (ed.) Currency Convertibility in Eastern Europe (Washington, DC: Institute of International Economics).

Marin, D. (1985) "Structural change through exchange rate policy," Weltwirtschaftliches Archiv, No. 3.

Mundell, R.A. (1962) "The appropriate use of monetary and fiscal policy for internal and external stability," IMF Staff Papers.

National Economic Development Office (1977) International Price Competitiveness, Non-Price Factors and Export Performance (London: National Economic Development Office).

Nurkse, R. (1950) "Conditions of international monetary equilibrium," in H.S. Ellis and L.S. Metzler (eds.) Readings in the Theory of International Trade (Philadelphia, Toronto: Blakiston Company).

Nuti, D.M. (1990) "Internal and international aspects of monetary disequilibrium in Poland," European Economy, Special Issue, Economic Transformation in Hungary and Poland, March, No. 43.

Pekkarinen, J., Pohjola, M., and Rowthorn, B. (1992) Social Corporatism: A Superior Economic System? (Oxford: Clarendon Press).

Pick, M. (1990) Productivity, Purchasing Power Parity, Exchange Rate (Prague: Institute of Forecasting).

PlanEcon (1992), PlanEcon Report, Nos. 16-18 (Washington, DC: PlanEcon).

Portes, R. (1990) "Introduction," European Economy, Economic Transformation in Hungary and Poland, March, No. 43.

Rollo, J.M.C., and Stern, J. (1992) Growth and Trade Prospects for Central and Eastern Europe (London: National Economic Research Associates).

Sargent, T.J. (1986) Rational Expectations and Inflation (New York: Harper \& Row).

Summers, R., and Heston, A. (1988) "A new set of international comparisons of real product and prices: Estimates for 130 countries," Review of Income and Wealth, No. 1. 
Wihlborg, C.G., and Willett, T.D. (1991) "Optimal currency areas revisited," in C.G. Wihlborg, M. Fratianni, and T.D. Willett (eds.) Financial Regulation and Monetary Arrangements after 1992 (Amsterdam: Elsevier).

Williamson, J. (1991) The economic opening of Eastern Europe," in J. Williamson, (ed.) Currency Convertibility in Eastern Europe (Washington, DC: Institute for International Economics). 



\section{Chapter 4}

\section{The Birth and Childhood of a Currency: The Experience of Slovenia}

Jože Mencinger*

\section{Introduction}

On June 26, 1991, Slovenia proclaimed its independence from Yugoslavia. The proclamation coincided with unresolved disputes over customs duties. When the Yugoslav federal authorities attempted to grab control of the borders, they were extremely surprised by the resistance. They gave up within a week, and an agreement was reached: the army would withdraw if Slovenia postponed the implementation of independence for three months. On 8 October 1991 Slovenia became "fully independent" and introduced its own currency - the Slovene tolar. In early 1992 , the country was recognized as an independent state by the EC. In May 1992, it became a member of the UN.

The events described above put an end to the tense and uncertain political and economic developments of the 1980s and early 1990s. This chapter begins by highlighting the economic and political environment that inspired

\footnotetext{
*This paper was prepared at the International Center for Economic Research in Torino, Italy. The financial support provided is gratefully acknowledged. I would like to thank Enrico Colombatto for helpful comments on a previous draft.
} 
the de-coupling of Slovenia. An overview of the debates that preceded the creation of the new monetary system, dealing with the conversion process, the proper starting exchange rate, and the dilemmas of fixed versus flexible exchange rate systems, follows. The paper then describes the creation of the system that was at odds with the advice of foreign financial experts. The chapter ends with a description of the foreign exchange market and an explanation of the developments that appear to diverge from forecasts and from what is in the literature.

\section{The Failure of Transition and Stabilization in Yugoslavia}

The political vacuum after Tito's death, the rise of oil prices, the tightening of the world financial markets, and the breakdown of the so-called contractual socialism ${ }^{1}$ had given first impulses for what, in the early 1980 s, developed into deep economic, social, and political crises. This prompted attempts at new economic reform. However, for the first time, and despite the proven ability to adapt systems, revaluate Marxism, and redefine socialism to daily needs, Yugoslavia found it difficult to move in any new direction. The country had apparently reached the point at which an economic reform, unaccompanied by a political reform, could only increase the inconsistencies between the economic system and the political system. A radical economic reform would have required, above all, a separation of the political and the economic power, while political considerations permitted only modest changes. The reform attempt in 1982, therefore, produced a long-lasting stalemate.

\footnotetext{
${ }^{1}$ Since 1945 , four distinct socialisms, related to the changes in the formal allocation of decision making in the economy, could be distinguished: administrative socialism (19451952), administrative market socialism (1953-1962), market socialism (1963-1973), and contractual socialism (1974-1988). Contractual socialism rejected the market as the basic mechanism for resource allocation, and macroeconomic policy as the means of indirect regulation of economic activities. Instead, it insisted that these were to be replaced, to the greatest extent possible, by mechanisms of social contracts, self-management agreements, and social planning. However, the concept was never operative; the statutes regulating the behavior of economic units in accordance with the concept were explicitly or implicitly abolished soon after they appeared or remained irrelevant to the actual functioning of the economy.
} 
Finally, in 1988, when party ideologists and economists persisted in speculating on new types of socialism, the federal government, realizing that it was impossible to solve economic problems within the existing system, launched a new reform. It began with the premise that the system of property rights was the basic cause of economic problems, and urged abandonment of the so-called non-property philosophy of social property. The Enterprise Act passed in December 1988 also formally abrogated socialism; the self-management relationships were replaced by capital relationships. A year later, in December 1989, the federal government launched a shock-therapy stabilization program. A fixed exchange rate, tight monetary policy, and wage controls were to be the pillars. However, an overvaluation of the dinar, weak wage controls, and fiscal overhang existed from the very beginning.

In the first two quarters of 1990 economic performance was satisfactory; in April 1990 the rate of inflation was even negative. In June, fatal mistakes were added to those of December 1989. Policy makers started to pump money through selective credits to the agricultural sector and nearly doubled the salaries of federal employees. This triggered a general race of wages. The program was thus left without nominal anchors in the middle of 1990; the burden remained solely on a fixed exchange rate. Private- and public-sector spending increased dramatically during the summer and stayed high, while economic activity plummeted. This made price stability unsustainable; in the third quarter of 1990 prices escalated. Severe monetary restrictions imposed during the last quarter pushed the economy into critical illiquidity, large-scale bartering, and a recession without deflation. Exports dropped, imports grew, and the trade deficit soared. In October, the run on banks to withdraw deposits in foreign exchange began, and foreign exchange reserves - the last resort of the stabilization program - decreased dramatically.

In autumn 1990, the country began to disintegrate. All attempts by the federal government to halt the deterioration of the economy and halt political developments were blocked by the republics. Yugoslavia ceased to exist as a functioning economic entity; taxes were not collected; money was "printed" elsewhere; special duties were charged for "imports" from other republics. In addition, the republics framed their own economic systems that differed considerably. 
Table 4.1. The Slovene economy at the outset of independence. ${ }^{a}$

\begin{tabular}{lrlr}
\hline General data & \multicolumn{3}{c}{$\begin{array}{l}\text { Output and demand in } 1990 \\
\text { In US\$ million }\end{array}$} \\
\hline Area (in 1,000 km ${ }^{2}$ ) & 20.2 & GDP at market prices & 11,778 \\
Population (in 1,000s) & 1,996 & Exports & 5,826 \\
Employment (in 1,000s) & 823 & Imports $^{b}$ & 5,269 \\
Unemployment (in 1,000s) & 85 & Total consumption & 7,562 \\
GPD/capita (in US\$) & 5,900 & Private & 6,019 \\
External debt & & General government & 1,543 \\
Long term (in US\$1,000) & 1,814 & Gross domestic investments & 2,992 \\
Short term (in US $\$ 1,000)$ & 141 & Fixed assets & 2,238 \\
Debt/Export ratio & 0.31 & Change in inventories & 754 \\
Debt/GDP ratio & 0.15 & & \\
\hline
\end{tabular}

${ }^{a}$ Export and import data refer to trade with the world outside the former Yugoslavia.

${ }^{b}$ Goods and nonfactor services.

Source: Statisticni Letopis Slovenije, 1991.

\section{The Creation of the Tolar}

\section{Uncertainties and disputes}

The economic policy of the Slovene government installed after general elections in May 1990 has been described elsewhere (Mencinger, 1991). In short, the Slovene government believed that the prospects of transition to a market economy within Yugoslavia were worsening; the economic policies of the federal government were full of mistakes; the existing economic system was unsuitable; and the federation was facing political turmoil. Consequently, the government focused on pragmatic adjustments to unknown future political decisions and policy measures of the federal government. These were accompanied by a gradual construction of a normal economic system and acquisitions of policy tools. This policy proved successful; in a year, Slovenia increased its relative competitiveness to the rest of Yugoslavia, established sovereignity in the fiscal and foreign exchange systems, and prepared institutional settings for a new country (Table \&.1).

The search for monetary independence began in mid-1990 and concentrated on three issues: the consequences of unilateral decisions for the functioning of the financial system and for the relations with other countries and international institutions; the possibilities of a monetary system in a confederation that was at a time still considered a viable solution; and the prospects of eventual monetary independence. After the Serbian raid on the 
monetary system in December 1990 , the discussions shifted to the name, the pattern, and the $\mathrm{mr}$ it appropriate moment for the introduction of the Slovene currency. ${ }^{2}$

Establishing a monetary system involved a choice between a fixed exchange rate and a floating exchange rate: the former surrenders the control of money supply and the latter surrenders the control of the exchange rate. Economic theory does not provide an answer as to which is preferable; however, most experts support the view that the fixed exchange rate system suits countries in transition better (Meltzer, 1992) or propose a crawling peg as a possibility (Bomhoff, 1992). Following an abrupt drop of foreign exchange reserves in October 1990, Slovenia, contrary to these beliefs, opted for the floating rate system. The drop simply revealed that the fixed exchange rate could not be defended in the future. The debates on the proper exchange rate system nevertheless continued, encompassing major theoretical quandaries known from the debates on the optimum currency area (Ishijama, 1975). Two issues - the relationship between the real exchange rate and macroeconomic stability and the anchoring role of the nominal exchange rate - divided the participants. Theoretical pros and cons were used to defend different positions, while much less attention was given to arrangements in other countries (Aghevli et al., 1991).

Practical preparations continued as well; before the end of 1990 , for example, provisional notes were printed. At the same time, temporary solutions to handle the repercussions of a fixed overvalued dinar and to cope with advancing hyperinflation were explored and introduced if found suitable. These efforts are best illustrated by the Law on the Introduction of a Parallel Currency drafted on February 4, 1991. It envisaged a parallel monetary unit pegged to the Austrian schilling; the new unit would have entered circulation through foreign transactions and would have floated against the dinar. However, the concept of parallel currency was abandoned in favor of "the certificate of import privileges" that was much simpler and less risky; it did not expose Slovene banks to the likely angry reactions of the federal authorities. The system functioned in the following manner: an exporter who, for example, sold foreign exchange to a bank at the official exchange rate, acquired a certificate that was salable and would allow its buyer access to foreign exchange. The fixed rate plus the price of the certificate made up

\footnotetext{
${ }^{2}$ In the beginning of 1991, similar ideas appeared in other Yugoslav republics, notably Croatia which, at that time, favored a monetary union of Bosnia and Hercegovina, Croatia, and Slovenia. The ideas of establishing a Yugoslav currency board also circulated (Hanke and Schuler, 1991).
} 
the flexible rate. The black market for foreign exchange in fact disappeared by its de facto legalization. Finally, the Slovene ECU, a measure of account to which the parties in economic transactions could adhere, was introduced in May 1991, less than two months before the proclamation of independence. Its value was to be determined by the average weekly price of the certificate on the Ljubljana stock exchange. Slovenia thus indirectly established an independent currency area with a floating exchange rate within the Yugoslav monetary system based on the fixed exchange rate.

Government document P2, dated April 15, 1991, treated the macroeconomic issues of independence and was the breaking point in the creation of the new currency. It had contemplated most of the settings that were later applied: a rapid conversion (three to five days) of dinars to the new currency, a one-to-one conversion rate, and a floating rate. ${ }^{3}$ Different solutions were later proposed in the documents that were prepared during the summer of 1991. ${ }^{4}$ They proposed a ten-to-one conversion rate of the dinar to a new currency and a pegged exchange rate regime. The changes were described in a document entitled A Program for Economic Sovereignty and Restructuring of Slovenia, dated March 21, 1991. This document, drawn up by the Sachs group, proposed pegging to the German mark, ECU, or a basket to assure a nominal anchor for a shock-therapy stabilization program..$^{\mathbf{5}}$

The pegging-versus-floating issue reflected two opposite general approaches to the transition in Slovenia: a radical approach and a gradual approach. The former suggested a formal shock-therapy macroeconomic stabilization program encompassing the fixed exchange rate as an anchor, the monetary policy that would support it, a balanced budget, foreign financial assistance, and restructuring of manufacturing and banking by the government. The latter approach suggested that economic policy remains founded on a gradual construction of market institutions. There would be no formal stabilization program and the government would have only an indirect role in the restructuring of the economy. The economic policy instruments of this approach should include a firm but flexible wage policy; very restrictive government spending enhanced by the fiscal deficit, if required; monetary

\footnotetext{
${ }^{3}$ The possibility of future pegging would, according to the document, depend upon the existence of foreign exchange reserves and the settlement of Yugoslav foreign and domestic debt issues.

'I wrote document $\mathrm{P} 2$ while I was the deputy prime minister. I resigned from that post in May 1991.

${ }^{5}$ The Sachs group changed its views in favor of unrestricted floating in a memorandum on October 8, 1991, when the floating exchange rate system was already introduced.
} 
policy enabling tolerable liquidity; a flexible exchange rate; reliance on foreign equity capital; and concessions for investments in infrastructure.

The linkage between the monetary and the exchange rate system was ultimately defined by the Law on the Foreign Exchange System and by the Law on the Bank of Slovenia. These laws instituted the independence of the monetary authorities and envisaged the supply of money as an exogenous variable determined by the central bank. The exchange rate would consequently be endogenous. Slovenia thus established a managed floating system exercised mainly by the developed market economies. The experiences that followed proved that floating was the right solution. Fixing the new monetary unit to a monetary unit of a country with low inflation would have ensured financial discipline only if this exchange rate had "never" changed. This would have turned out to be illusionary because the basic conditions for the exchange rate stability were not met. They simply didn't exist.

First, the central bank had no foreign exchange reserves to defend the fixed rate.

Second, monthly (not annual) inflation in October 1991 was 21.5 percent. A moderate initial devaluation would therefore have been overridden by inflation immediately, while a large devaluation would have stimulated inflation and again endangered the fixed rate. By sticking to it, prices of nontradables could only have been adjusted to prices of tradables through an unrealistic fiscal contraction mechanism prolonging and deepening recession. Successive devaluations and/or restrictions on exchange rate transactions and imports would have been the most likely outcome. The presumed advantage of the fixed exchange rate - enhancing confidence - would have become the disadvantage of a crawling peg approach; Slovenia would have found itself in the worst of both worlds (Walters, 1990, p. 15).

Third, the question emerged: What would be the nominal fixed rate that assured equilibrium real exchange rate? Would it be $27,32,42,50$, or 65 tolars per German mark? The experiences of different shock-therapy programs, the one in the former Yugoslavia included, have proved that $e x$ ante determination of the equilibrium exchange rate is impossible. It would be even more futile to determine such an equilibrium exchange rate in a new country; the calculations based on past developments would soon prove to be misleading because structural features of a new country have differed from those in the past.

Fourth, the transition and, particularly, the loss of the traditional market in former Yugoslavia have most strongly affected the volume of trade 
and trade patterns. As a small country, Slovenia should in a short period more than double its share of foreign trade in GDP. Pegging would, in such circumstances, hinder accommodations of the equilibrium real exchange rate to a newly required volume of trade and trade patterns.

\section{The creation of the monetary system}

The Bank of Slovenia (BS) was formally created on June 25, 1991, when the Law on the Bank of Slovenia was passed. The BS that was to replace the National Bank of Slovenia (NBS), a subsidiary of the National Bank of Yugoslavia (NBY), declared that it would continue to operate within the uniform Yugoslav monetary system. The NBY, however, excluded Slovenia from the Yugoslav monetary system by halting the supply of notes and coins to Slovenia, denying refinancing facilities and purchases of foreign exchange from the NBY, and prohibiting new borrowing arrangements abroad. On October 8, 1991, when the three months' moratorium on all actions toward independence agreed upon in the Brioni agreement had passed, the Slovene monetary system was also functionally established.

The BS assumed the functions of a central bank determined by law: regulation of the money supply, issuing of notes and coins, prudential regulation and supervision of financial institutions, and control of payments to the rest of the world. To separate and insulate the new monetary system from the rest of Yugoslavia, the BS substituted the National Bank of Yugoslavia for the bankers' bank by assuming existing liabilities and claims and transferring them to its own balance sheet. It also immediately adopted a series of measures to wipe out excess liquidity of the banks and to normalize reserve requirements. These measures included: a mutual cancellation of selective credits to commercial banks and their mandatory deposits, a reduction of minimum reserve requirements from 20 percent to 7 percent, revocation of automatic availability of rediscount facility, fixation of rediscount rate at 25 percent per annum, reduction of the rediscount quota, and a credit freeze from October 8 to October 31. While interest rates for new loan commitments were left free, the BS requested that for one month banks linearly align interests on existing loans and deposits to the new rediscount rate, according to the given conversion table. This was hoped to be a shock device for lowering inflationary expectations. It failed.

A new monetary unit - the Slovene tolar - was created by converting dinars to tolars at the one-to-one conversion rate, to minimize technical problems. All balances on the accounts were automatically converted; the 
existing dinar notes and coins were to be physically converted in three days at all banks and Social Accounting Service (SDK) offices. The conversion process took place very smoothly; few people came to a bank. Instead, they spent cash balances through routine purchases of goods and services. The uncertain future of the tolar deterred speculative inflows of dinars from other parts of Yugoslavia. Some controls on conversions were nevertheless stipulated to prevent abuses. Conversions up to 20,000 dinars (approximately twice the average monthly salary) were unconstrained, the amounts between 20,000 and 100,000 dinars had to be transferred to the owners' accounts, and the amounts exceeding 100,000 dinars could only be converted at a major SDK office. Very few cases of conversions exceeding the 20,000 dinars limit were reported.

The one-to-one conversion was also meant to prevent a rounding up of prices that would have most likely occurred if another conversion rate were chosen. More important, the one-to-one conversion was to abate the suspicion of the population recalling previous conversions (after World War I and at the beginning and after World War II), when many lost their financial wealth. The existing structure and the rather bad quality of the new notes that had been printed nearly a year earlier also decisively inspired the oneto-one conversion. ${ }^{6}$ A small purchasing power of even the most valuable note was meant to moderate appetites for counterfeiting. The arguments that a ten-to-one rate would strengthen the faith of the population in a new monetary unit and lessen inflationary expectations were rejected as irrelevant. So were the arguments that a proper currency reform includes different conversion rates depending on the owner, form, and value of an asset converted.

Only 8.57 billion dinars were converted in cash, less than anticipated by the BS (which had projected up to 13 billions), and far less than the amount of cash that had entered circulation through the National Bank of Slovenia ( 27 billions). The difference can be explained by a steady outflow of cash from Slovenia; by guest workers from other republics of former Yugoslavia supporting their families at home; by tourists buying dinars at the borders and spending them on the Adriatic coast; and by the legalization of the

${ }^{6}$ The provisional notes-coupons were secretly printed during the last months of 1990 by the Ministry of Finance. Their value structure resembled the structure of dinars in circulation. They were nameless; the name was chosen by the parliament from among competitive alternatives (lipa, krona, klas, karant, slovenski dinar) the very last night before conversion. 
black market in the spring of 1991 , attracting foreign exchange from other republics.

The German mark was chosen as the currency of reference, and the rate of 32 tolars to the mark was the starting exchange rate for assets and liabilities in foreign currencies. Frankfurt cross exchange rates determined other rates. The tolar was to float on two separate markets: one for current account transactions and one for capital account transactions. Consequently, there had to be two different market rates: the current account transactions exchange rate (CUREX) and the capital account transactions exchange rate (CAPEX). In fact, the delineation of the two markets went along with the distinction between the market for the business sector, the participants being companies, banks, and the BS, on the one hand, and the market for individuals, the participants being individuals, banks, and new private foreign exchange offices, on the other.

Exchange controls were few. There were no repatriation requirements and no restrictions regarding purposes for which foreign exchange might be bought by residents, both individuals and firms. The foreign exchange accounts of the firms were abolished. Firms that repatriated foreign exchange were free to dispose of it within two days, but had to sell the rest to a commercial bank afterward at an agreed upon rate, with the exception of 30 percent of the foreign exchange that had to be surrendered for the socalled common needs (servicing the external debt, payments for essential imports such as medical supplies and oil) at the official exchange rate. This requirement was abolished in December 1991.

The frozen foreign exchange deposits with the banks (the so-called old foreign currency accounts) were the main reason for a separate market for capital account transactions. The BS would not intervene on this market and participating banks were obliged to equalize demand and supply each month, a restriction abolished in April, 1992. The reason for a few restrictions on the amount of tolars in cash transferable to foreign countries was to lessen the danger of counterfeiting.

The official exchange rate (OEX) was devised as a moving-parity rate obtained from CUREX by moving averages over a span of 60 days with descending daily weights. The speed of descent would depend on the rate of inflation: the higher the inflation rate, the faster the descent. At 0 inflation, all 60 days would have equal weight. The OEX had been used for settling customs duty payments, and was, until December 1991, also used for the surrender of 30 percent of foreign exchange for common needs and for the 
conversion of the frozen deposits in foreign exchange held by individuals to tolars.

\section{The "Miraculous" Strength of the Tolar}

\section{The foreign exchange market}

The initial nominal exchange rate of 32 tolars per mark was set rather arbitrarily. It was intended to match its real exchange rate to the real exchange rate of the dinar back in April 1988, that is, the rate that had enabled partial convertibility of the dinar as well as the growth of the foreign exchange reserves of Yugoslavia during 1988 and 1989. It implied a 16 percent real depreciation if compared to the rate in December, 1989, when Markovic's shock-therapy stabilization program was enacted, and a 15 percent real depreciation of the existing flexible exchange rate determined by the price of the certificates. Despite the real depreciation embodied in the initial exchange rate of 32 tolars per mark, the nominal exchange rate immediately jumped to about 42 tolars per mark on both markets, the main causes being expectations and high liquidity of the banks. The BS did not possess reserves to intervene, ${ }^{7}$ while tightening liquidity of the banks was a matter of trial and error; behavioral relations in the new Slovene economy were simply unknown.

Three months of stability followed. In mid-January 1992, rumors of an "inevitable devaluation," combined with speculations related to the privatization of apartments, pushed CAPEX to 52 tolars per mark. CUREX followed. The BS decided not to intervene, though it would have been possible, as it had already accumulated sufficient reserves. The tolar was already overly strong, given the high inflation rates at the end of 1991. In February, 1992 , the rates stabilized again, at a level slightly over 50 tolars per mark. In mid-April, CAPEX suddenly rose to 62 tolars per mark; CUREX did not follow and CAPEX dropped back to 52. The BS used the opportunity to abandon the provision that banks should equalize demand and supply on the capital account market each month; thus the two markets colluded. The forward market transactions remained banned.

In the period observed, the average of CAPEX exceeded the average of CUREX by 3 percent, while the difference fluctuated between -5 percent (in

\footnotetext{
${ }^{7}$ Upon the assumption of independence, foreign exchange reserves consisted of operating balances of commercial banks only, and amounted to $\$ 190$ millions.
} 
Table 4.2. The daily foreign exchange market, current account transactions, 1 December 1991 to 31 August 1992.

\begin{tabular}{|c|c|c|c|c|}
\hline & $\begin{array}{l}\text { Number } \\
\text { of trans- } \\
\text { actions }\end{array}$ & $\begin{array}{l}\text { Value } \\
\text { in } \\
\text { DM } 1,000\end{array}$ & $\begin{array}{l}\text { Average } \\
\text { transactions } \\
\text { in DM }\end{array}$ & $\begin{array}{l}\text { Exchange } \\
\text { rate } \\
\text { tolar/mark }\end{array}$ \\
\hline Bank $\rightarrow$ Bank (BB) & 2 & 2,016 & $1,080,000$ & 49.55 \\
\hline Bank $\rightarrow$ Enterprise (BP) & 130 & 8,170 & 109,558 & 50.76 \\
\hline Enterprise $\rightarrow$ Bank (PB) & 142 & 12,751 & 94,683 & 49.95 \\
\hline Enterprise $\rightarrow$ Enterprise (PP) & 51 & 1,741 & 34,790 & 50.30 \\
\hline All transactions & 325 & 24,679 & 82,999 & 50.23 \\
\hline
\end{tabular}

Source: The Bank of Slovenia.

the first week of December 1991) and +18 percent (in mid-April 1992) and then gradually narrowed.

There are four different types of transactions on the current account transactions market: direct sales and purchases of foreign exchange between enterprises, exporters and importers ( $\mathrm{PP}$ ); sales of foreign exchange by exporters to banks (PB); purchases of importers from banks (BP); and sales and purchases among banks (BB). The number of transactions per trading day (there were 188 trading days between December 1, 1991, and August $31,1992)$, the value, the average value of a transaction, and the average exchange rate are presented in Table 4.2.

Two major changes characterized the foreign exchange market structure during the period from December 1991 to August 1992; PP transactions that had amounted to 17 percent in December 1991 nearly disappeared and the differences between the average exchange rates of different transactions narrowed considerably.

The data enable us to determine supply and demand. The quantity supplied consists of sales of foreign exchange by enterprises to banks, enterprises to enterprises, and banks to banks, while the quantity demanded equals the purchases of foreign exchange by enterprises from enterprises and banks and by banks from banks. Thus, the foreign exchange supply (S) equals

$$
\mathrm{S}=\mathrm{PB}+\mathrm{PP}+\mathrm{BB}
$$

the foreign exchange demand (D) equals

$$
\mathrm{D}=\mathrm{BP}+\mathrm{PP}+\mathrm{BB}
$$


Table 4.3. Weekly supply and demand for foreign exchange, in millions of German marks, 1 December 1991 to 31 August 1992.

\begin{tabular}{lcccc} 
& Average & $\begin{array}{l}\text { Standard } \\
\text { deviation }\end{array}$ & Minimum & Maximum \\
\hline Demand & 57.2 & 14.8 & 23.7 & 90.1 \\
Supply & 79.3 & 24.6 & 25.7 & 136.1 \\
Excess supply & 22.1 & 20.0 & -20.7 & 71.7 \\
Relative excess supply & 1.41 & 0.38 & 0.61 & 2.16 \\
\hline
\end{tabular}

Source: Bank of Slovenia.

and the excess supply (SS) equals

$$
\mathrm{SS}=\mathrm{S}-\mathrm{D}=\mathrm{PB}-\mathrm{BP}
$$

The basic characteristics of the weekly market are presented in Table 4.3 and Figure 4.1.

With regard to the evolution of the exchange rate, the first events were the two sharp rises of the nominal rates, in October 1991 (from 32 to 42 tolars per mark) and in January 1992 (up to slightly above 52 tolars per mark) that had pushed the real exchange rate above the initial real exchange rate (real depreciation). This was followed by a very slow growth of the nominal rate. Consequently, the real exchange rate, given the growth of prices, fell by a third of its initial value until June (real appreciation) though at a decreasing rate. During the whole period, the tolar was overvalued on the average by 18 percent. The overvalued tolar was accompanied by a surplus in foreign trade and a constant growth of foreign exchange reserves. These reserves reached $\$ 1.25$ billion ( 120 billion tolars) at the end of A ugust 1992, a high figure given the size of the economy and the corresponding transaction money, $\mathrm{M}_{1}$ ( 56 billion tolars). The strength of the tolar, coupled with the gradual abolition of foreign exchange restrictions and the growth of foreign exchange reserves, increasingly appeared to be a "miracle" that repudiated forecasts of experts and contradicted theoretical findings. The miracle can, however, be rather easily explained by the lags in responses to the real exchange rate changes, shifts in the conditions of supply and demand, and the monetary policy.

Figure 4.2 presents the movements of the real exchange rate of the tolar around its "equilibrium" real exchange rate of 8 October 1991. It is calculated by dividing the ratios of the daily CUREX and the initial exchange rate by the ratios of the daily retail sale price index and retail sale price 


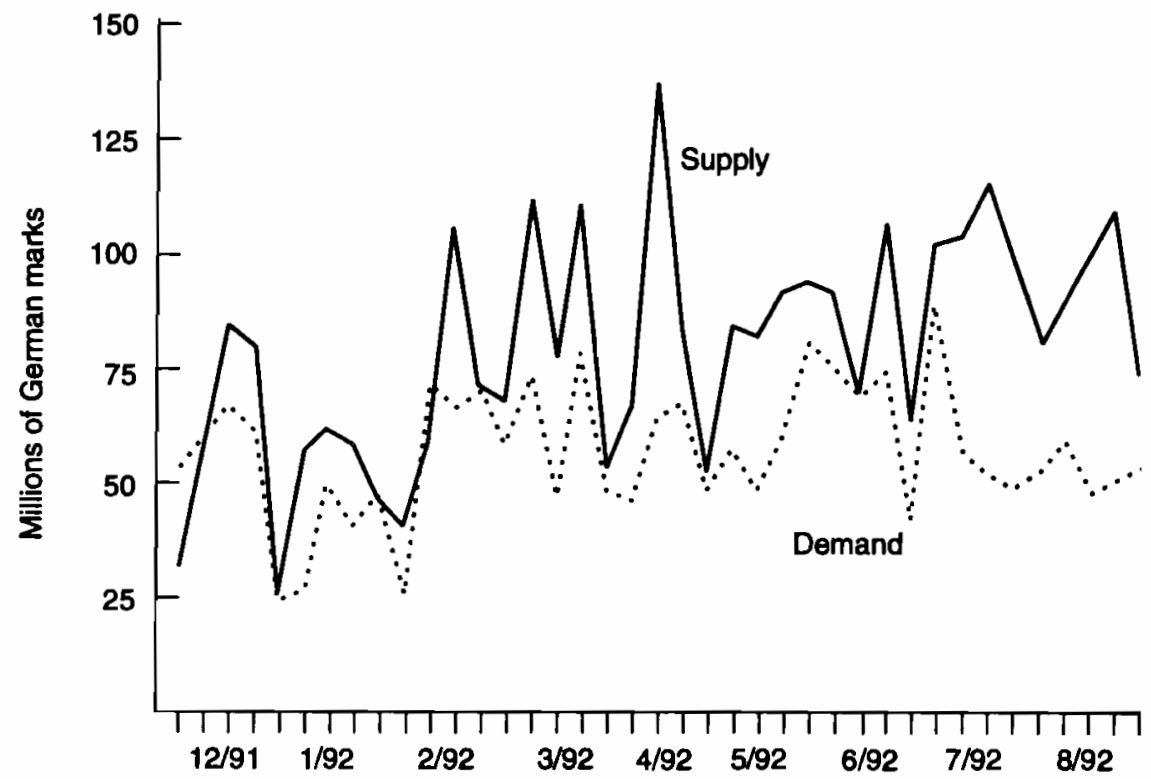

Figure 4.1. The foreign exchange market, December 1991 to A ugust 1992, weekly values.

index on October $8,1991 .^{8}$ The daily price indices are linear interpolations of monthly price indices reported on the 20 th of each month.

Lags in responses to the changes of the real exchange rate offer an explanation for the trade surplus; considerable real depreciations during the period of certificates were augmented by the additional initial real depreciation of the tolar. This might have contributed to favorable trade flows in 1992; a too strong tolar would correspondingly bite in 1993.

Changes in the characteristics of demand and supply of foreign exchange seem to be the best explanation for the coexistence of the overvalued tolar and excess supply of foreign exchange. These changes shifted the equilibrium real exchange rate downward by increasing supply, reducing demand, or moving both. Some of these changes might be considered permanent, others temporary. Most of these changes can be derived from the secession of Slovenia and from the economic collapse of the rest of Yugoslavia. Some are

\footnotetext{
${ }^{8}$ This calculation does not take into account inflation in Slovenia's trading partners; accordingly, the result is not a conventional real exchange rate. Nevertheless, given the great difference between inflation in Slovenia and in its trading partners (dominated by Germany), the simplified calculation should not cause too much distortion.
} 


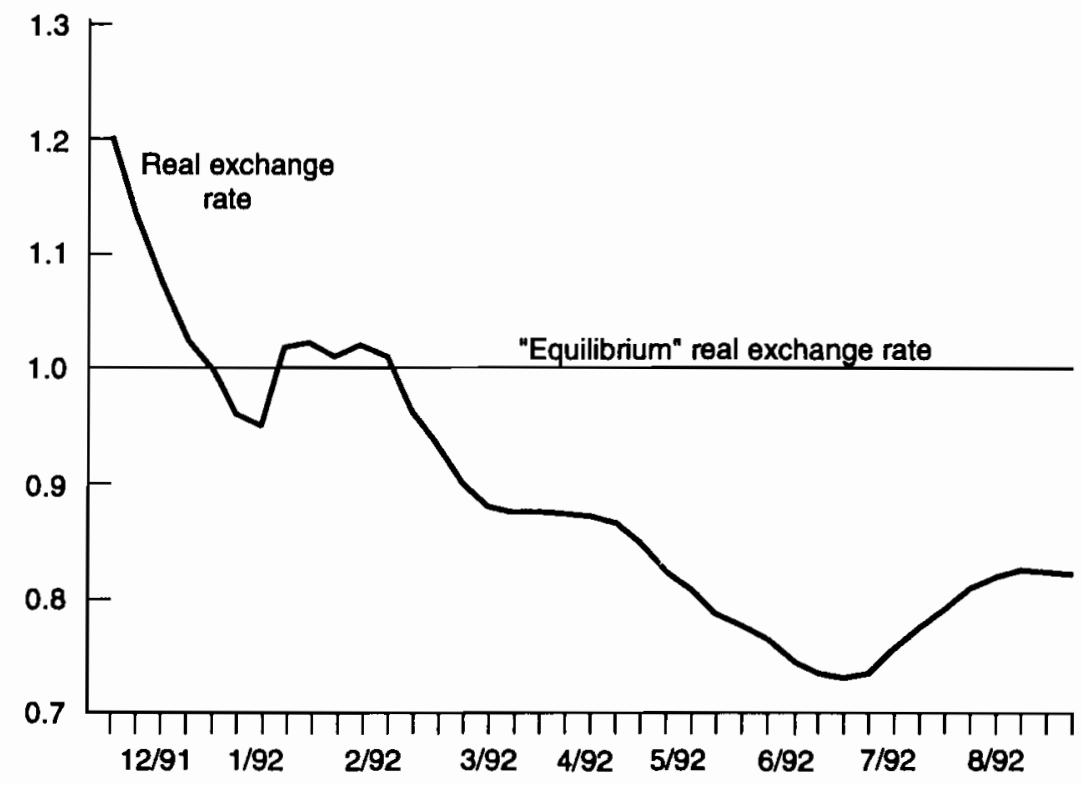

Figure 4.2. The real exchange rate, December 1991 to August 1992 (a downward movement indicates a real appreciation).

related to transition: the privatization of the apartments ${ }^{9}$ and, to a limited extent, the sales of a few enterprises to foreign owners. The supply of foreign exchange increased because producers tried to substitute exports for sales in the former Yugoslav market (in 1990, sales in the rest of Yugoslavia surpassed sales in foreign market "proper" by 33 percent). The supply also increased because the Slovene population sold much of its foreign exchange balances to moderate the drop in the standard of living. At the same time, the demand for foreign exchange plummeted with the contraction in domestic demand and vanishing links with the rest of Yugoslavia, both reducing imports of raw materials. Finally, the drop in real incomes also reduced savings and demand for foreign exchange, a traditional form of financial assets.

The shifts in demand and supply also indicate that the former highly protected Yugoslav market provided Slovenia with an equilibrium real exchange rate that a small domestic market cannot assure. This is particularly

\footnotetext{
${ }^{9}$ The privatization started in November 1991, with approximately 100,000 apartments privatized at very low prices; additional high discounts were extended to those who paid in cash. The privatization brought $\$ 200-300$ million in foreign exchange, heretofore kept in foreign banks in neighboring countries or under mattresses.
} 
so because the demand patterns on the domestic market differ substantially from the supply patterns fitted to the Yugoslav market. Consequently, the sales to the former Yugoslav market can only be replaced by exports, however, at prices much lower than the prices on the protected Yugoslav market. This implies lower real wages, both in the sector producing tradables and in the sector producing nontradables.

\section{The monetary policy}

Through the option for the floating exchange rate system, the supply of money became an exogenous variable and the exchange rate endogenous. The role of the monetary authorities in the miracle cannot, thus, be overlooked. The BS, despite being constantly urged to remove all foreign exchange restrictions and to devalue, reacted sensibly by removing restrictions only when appropriate conditions prevailed, and intervened only to prevent substantial nominal appreciations. Only in July and August 1992, when inflation fell to 2 and 1.4 percent per month, respectively, did the BS deliberately weaken the tolar by slowly pushing its nominal rate to 60 tolars per mark.

The potentials of the BS to regulate the exchange rate at will by sales and purchases of foreign exchange, through supply and demand, should not be overstated. An asset market model of foreign exchange determination used to simulate the links between the monetary policy and exchange rate (Mencinger, 1992) illustrates convincingly the detrimental but, at the same time, limited scope of the monetary policy; realistic changes of the monetary policy could lower or raise the exchange rate by as much as 10 percent. Largescale monetization of foreign exchange would produce monetary overhang and speed inflation back to hyperinflationary levels, due particularly to the small currency area (Bole, 1992).

A summary of monetary policy presented in Table 4.4 indicates that monetary policy was highly restrictive in the first half of 1992; real money supply decreased by 40 percent between October 1991 and June 1992. Foreign currency transactions became the only channel of money creation; the ratio of foreign exchange reserves of the $\mathrm{BS}$ and high-powered money increased from 0.04 to 1.70 ; and the ratio of total reserves and $M_{1}$ increased from 0.31 to 1.35 . The regulation of money supply and the banks' liquidity shifted from the manipulation of reserve requirements to open market operations and prudential regulations; the share of required reserves in the total banks' reserves decreased from 0.71 to 0.08 . The money multiplier that rose 
Table 4.4. Monetary policy between October 1991 and August 1992, at the end of the period, in millions of tolars.

\begin{tabular}{|c|c|c|c|c|c|c|}
\hline & & Oct. 91 & Dec. 91 & Mar. 92 & May 92 & Aug. 92 \\
\hline (1) & High-powered money & 18,489 & 16,463 & 19,374 & 27,600 & 30,175 \\
\hline (2) & Notes in circulation & 8,117 & 9,026 & 10,587 & 16,474 & 18,101 \\
\hline (3) & Banks' reserves & 10,372 & 6,669 & 6,596 & 9,004 & 8,238 \\
\hline (3a) & Banks' cash in vaults & 476 & 617 & 668 & 1,200 & 1,084 \\
\hline$(3 \mathrm{~b})$ & Banks' deposits & 2,472 & 583 & 832 & 4,002 & 6,515 \\
\hline (3c) & $\begin{array}{l}\text { Banks' obligatory } \\
\text { reserves }\end{array}$ & 7,411 & 5,494 & 5,096 & 3,669 & 639 \\
\hline (3d) & $\begin{array}{l}\text { Non-bank deposits } \\
\text { with BS }\end{array}$ & 13 & 0 & 2,191 & 2,256 & 3,837 \\
\hline (4) & Money $\mathbf{M}_{1}$ & 36,104 & 38,912 & 44,153 & 52,131 & 62,976 \\
\hline (5) & Demand deposits & 27,987 & 29,760 & 33,566 & 35,657 & 43,046 \\
\hline (6) & $\begin{array}{l}\text { Passbook savings } \\
\text { deposits }\end{array}$ & 6,812 & 15,952 & 14,649 & 19,136 & 23,382 \\
\hline$(6 a)$ & $\begin{array}{l}\text { Time and restricted } \\
\text { deposits }\end{array}$ & 18,587 & 21,898 & 43,344 & 52,740 & 65,260 \\
\hline (7) & $\begin{array}{l}\text { Foreign exchange } \\
\text { deposits }\end{array}$ & 47,751 & 55,398 & 77,787 & 83,888 & 95,404 \\
\hline (8) & $\begin{array}{l}\text { Foreign currency } \\
\text { reserves in US\$ }\end{array}$ & 237 & 401 & 548 & 703 & 1,065 \\
\hline (9) & $\begin{array}{l}\text { Banks' operating } \\
\text { reserves }\end{array}$ & 221 & 282 & 341 & 423 & 435 \\
\hline (10) & BS reserves & $\begin{array}{r}16 \\
752\end{array}$ & $\begin{array}{r}119 \\
6,867\end{array}$ & $\begin{array}{r}207 \\
17,016\end{array}$ & $\begin{array}{r}280 \\
23,380\end{array}$ & $\begin{array}{r}659 \\
51,271\end{array}$ \\
\hline (11) & $\begin{array}{l}\text { Prices } \\
(\text { Oct. } 8,1991)=1\end{array}$ & 1.06 & 1.53 & 2.11 & 2.36 & 2.61 \\
\hline (12) & $\begin{array}{l}\text { Exchange rate } \\
(\text { Oct. } 8,1991)=1\end{array}$ & 1.20 & 1.32 & 1.64 & 1.66 & 1.89 \\
\hline \multicolumn{2}{|c|}{$(4) /(1)$} & 1.95 & 2.36 & 2.27 & 1.88 & 2.09 \\
\hline \multicolumn{2}{|c|}{$(2) /(5)$} & 0.29 & 0.30 & 0.32 & 0.46 & 0.42 \\
\hline \multicolumn{2}{|c|}{$(6) /(4)$} & 0.19 & 0.41 & 0.33 & 0.37 & 0.37 \\
\hline \multicolumn{2}{|c|}{$(8) /(4)$} & 0.31 & 0.59 & 1.02 & 1.13 & 1.35 \\
\hline \multicolumn{2}{|c|}{$(10) /(1)$} & 0.04 & 0.42 & 0.88 & 0.85 & 1.70 \\
\hline \multicolumn{2}{|c|}{$(3 c) /(3)$} & 0.71 & 0.82 & 0.77 & 0.41 & 0.08 \\
\hline \multirow{2}{*}{\multicolumn{2}{|c|}{$\begin{array}{l}\text { (12) } /(11) \text { Real exchange rate } \\
(4) /((11) / 36,104)\end{array}$}} & 1.13 & 0.86 & 0.78 & 0.70 & 0.72 \\
\hline & & 1.00 & 0.71 & 0.58 & 0.61 & 0.67 \\
\hline
\end{tabular}

Source: Bank of Slovenia. 
between October 1991 and March 1992 was later blocked by the increased ratio of currency to deposits.

The miracle cannot persist. The responses to real depreciations of the currency that prevailed in 1991 will eventually be followed by responses to real appreciations prevailing in 1992. The effects of the temporary shifts in supply and demand that preserved the mixture of a strong tolar and the growth of foreign exchange reserves with a mixture of inflation, plummeting production, and rising unemployment will disappear. Monetary policy that was conceived to first lower and then keep inflation under control and to preserve a real exchange rate at a level that makes exports competitive will also be trapped in conflicting goals. The only result of future large nominal depreciations, if not supported by measures to reduce real wages and budget expenditures, would be the pushing up of inflation while doing nothing to increase competitiveness except in the very short run. When currency depreciates, import prices rise, followed by domestic prices and wages. Only a sluggish adjustment of these domestic rates could temporarily help the exporting sector. But, after many years of experiencing high inflation, the illusion concerning a longer time lag has disappeared and adjustments have become quick, preventing gains from depreciation to last. A more lasting miracle requires the reduction of costs per unit of output, including modest public expenditures, wage restraints, and administrative price controls of nontradables provided by monopolies.

\section{References}

Aghevli, B.B., Khan, M.S., and Montiel, P.S. (1991) Exchange Rate Policy in Developing Countries: Some Analytical Issues, IMF Occasional Paper No. 78 (Washington, DC: International Monetary Fund).

Bole, V. (1992) "Inflacija in ekonomskopoliticne alternative" (Inflation and economic policy alternatives), Gospodarska Gibanja, Vol. 226, March, 35-49.

Bomhoff, E.J. (1992) "Monetary reform in Eastern Europe," European Economic Review, Vol. 36, April, 454-458.

Hanke, S.H., and Schuler, K. (1991) Monetary Reform and the Development of a Yugoslav Market Economy, Center for Research into Communist Economies, New Series 3.

IMF (1991) Exchange Arrangements and Exchange Restrictions, Annual Report 1991 (Washington, DC: International Monetary Fund).

Ishijama, Y. (1975) "The theory of optimum currency areas: A survey," IMF Staff Papers, No. 2. 
Meltzer, A.H. (1992) "Prices and wages in transition to a market economy," Paper presented at the 19th Karl Brunner Symposium on Liberty, Analysis, and Ideology, Interlaken, Switzerland, June 8-12.

Mencinger, J. (1991) "From socialism to capitalism and from dependence to independence: Double transition of Slovenia," Est-Ouest, Vol. 22, December, 57-92.

Mencinger, J. (1992) "Oblikovanje tečaja tolarja," Gospodarska gibanja, October, $23-39$.

Walters, A. (1990) Sterling in Danger (London: Fontana Paperbacks). 



\section{Part II}

\section{Trade Liberalization and Emerging Trade Patterns}





\section{Chapter 5}

\section{Trade Liberalization in the CSFR, Hungary, and Poland: Rush and Reconsideration}

János Gács

\section{Introduction}

In the rich literature on attempts at liberalizing trade there is ample evidence that for less developed economies trade liberalization usually takes a long period of time. The opening up of economies has successive phases of progress, reversals, and even serious regressions. Taking an overly restrictive trade regime as a starting point, the whole process of liberalization may last for two to three decades on average. ${ }^{1}$ The chance of success of a zealous move for trade liberalization depends on many factors: the position of the economy in the international distribution of labor; the tendency of balance of payments, external indebtedness, and foreign aid; the accompanying package of macroeconomic policies; the stage the economy achieved in

\footnotetext{
${ }^{1}$ Compare the analyses in the latest extensive project of the World Bank (Michaely et al., 1991) and the project of the National Bureau of Economic Research (Bhagwati, 1978; and Krueger, 1978).
} 

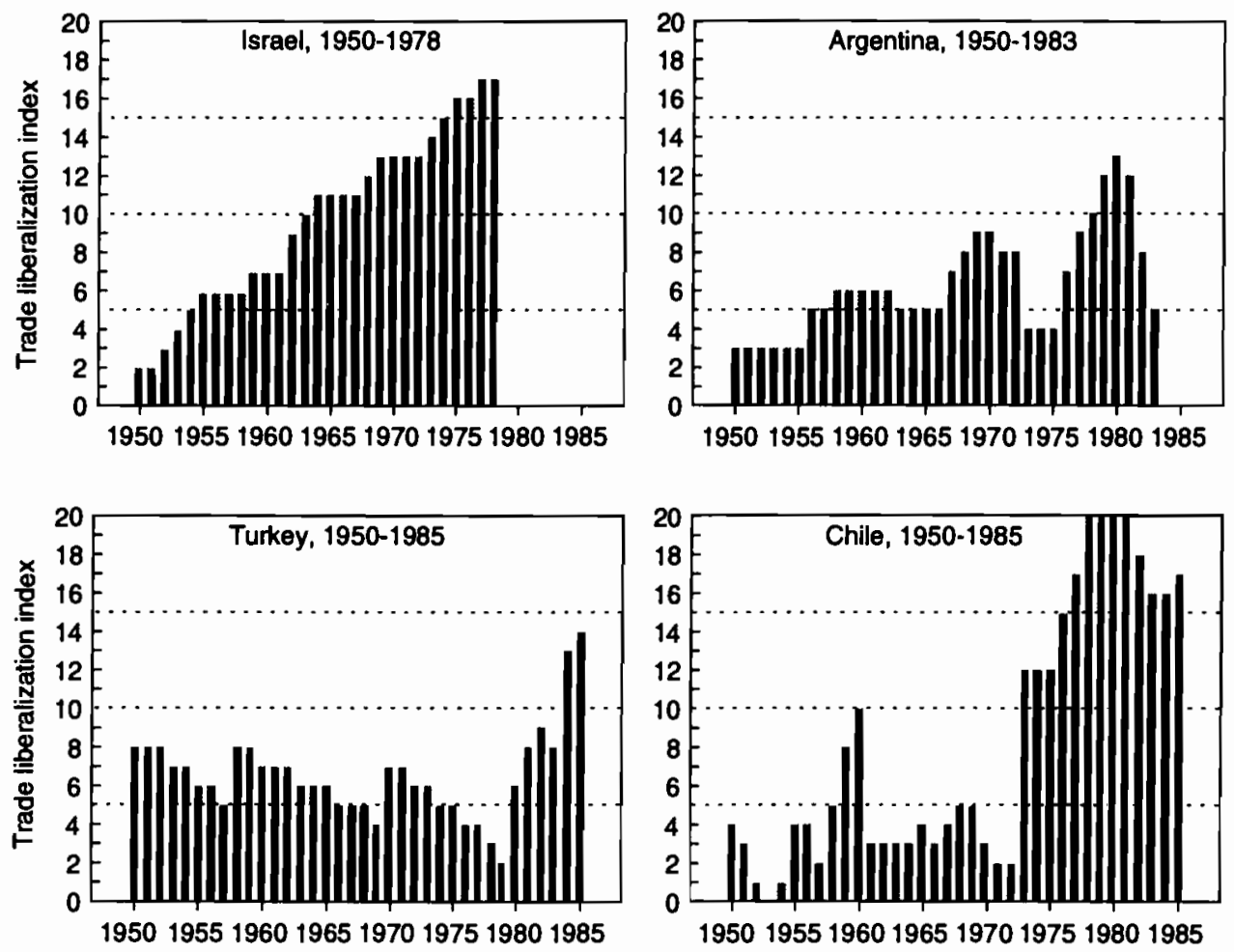

Figure 5.1. Characteristic patterns of trade liberalization in Israel, Argentina, Turkey, and Chile. Source: Michaely et al., 1991.

establishing modern institutions of a market economy; the efficiency of its political institutions; the power of pressure groups, and so on.

In Figure 5.1 the graphic presentation of progress of trade liberalization in some representative countries are reproduced from the latest World Bank comparative analysis of trade liberalization. The index of trade liberalization used by the authors of that project is a composite index of a diversity of measures concerning tariff and nontariff barriers, interventions in trade, and general economic activity, such as export subsidies and price control. It is also an ordinal index that varies from 1 (the theoretically most restrictive, interventionist regime) to 20 (the theoretically most liberalized one). Different patterns of trade liberalization are well exemplified by the economies in the following four countries: Israel, slow and gradual progress 

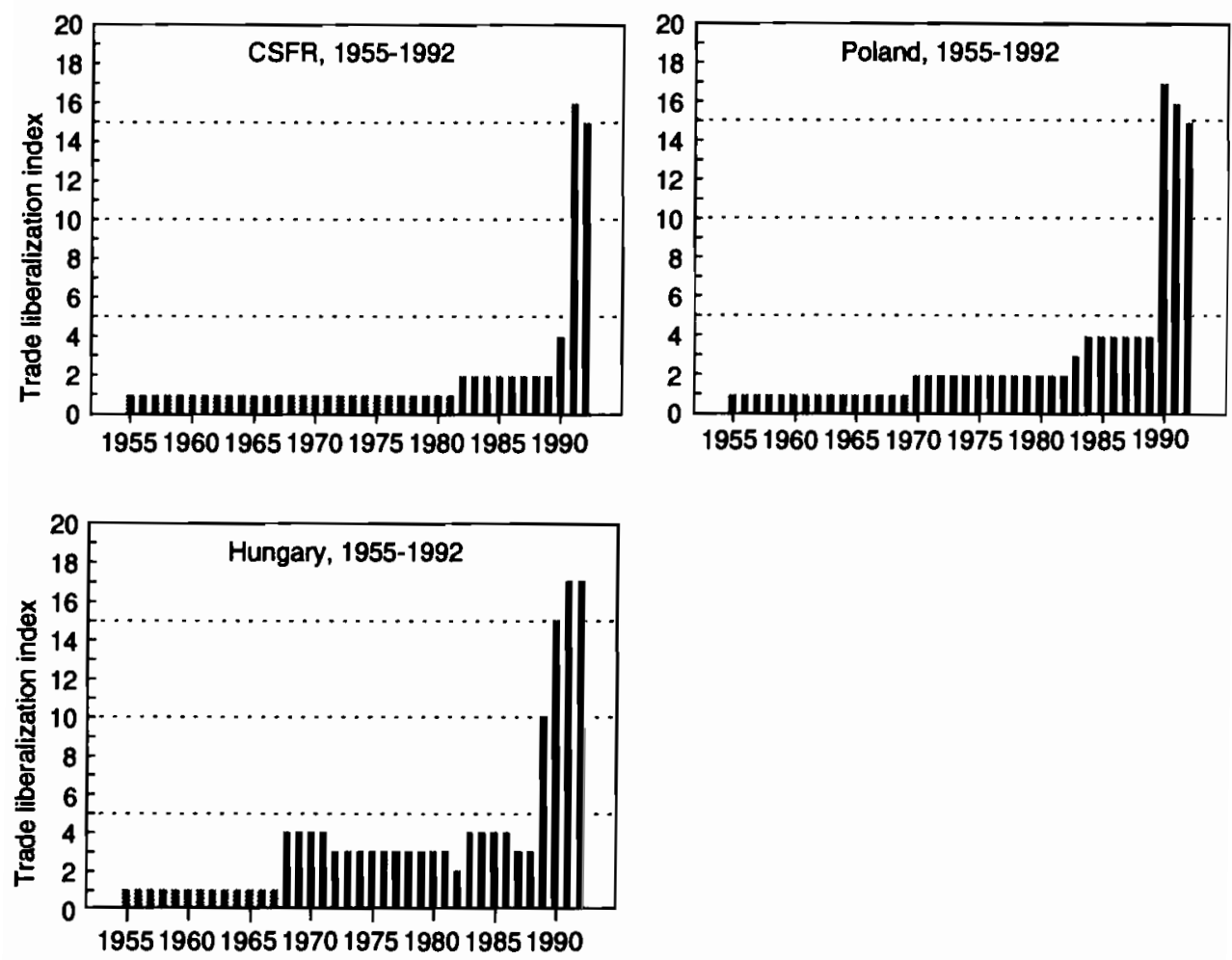

Figure 5.2. Trade liberalization indices for the CSFR, Hungary, and Poland, 1955-1992. Source: Author's calculations.

of liberalization; Argentina, periods of gradual progress followed by gradual reversals; Turkey, jumps and ensuing reversals; Chile, the champion in terms of the speed to achieve and maintain a high level of liberalization.

In the light of the experiences of developing countries, trade liberalization in Eastern Europe was of a unique kind. ${ }^{2}$ After 1989 a nearly complete trade liberalization was accomplished in Eastern Europe at an unprecedented

\footnotetext{
${ }^{2}$ In this case the phrase "trade liberalization" means a significant reduction of nontariff trade barriers, including the easier acquisition of foreign exchange for import purposes, the reduction of the average rate and the variation of tariffs, the reduction of export-related subsidies and taxes, and the reduction of the influence of central authorities in controlling microeconomic decisions of enterprises related to trade. Liberalization of trading activity (i.e., providing the opportunity to conduct trade for all business units) is considered part of trade liberalization.
} 
speed. Figure 5.2 illustrates the stylized patterns of trade liberalization in the CSFR, Hungary, and Poland. ${ }^{3}$

Naturally, there are differences among the three countries in terms of the speed of liberalization. Hungary's progress was more gradual than the other two in two respects: it had already gradually liberalized trade to some extent even before 1989, and the program of trade liberalization commenced in 1989 followed a four-year schedule. It is remarkable that even in the case of Hungary an extremely fast pace of liberalization was accomplished. The speediest among the three was the CSFR.

One can appraise the rapid pace of liberalization in the region either as promising or as risky. On the one hand, we can take into account that the unique opportunity of systemic change in policy making and the economy helped policy makers in these countries to evade the series of stumbling blocks that usually halt the introduction and extension of liberalization measures in traditionally protected economies. In this respect the great leap forward may pay off. On the other hand, the unparalleled breakthrough may bring about tensions and counterattacks of equal strength. A serious reversal of liberalization would impede the evolution of further liberalization for a long time. In the latter scenario the record speed is not going to be seen as an accomplishment. Trade liberalization is beneficial in the course of transition for several reasons (enhancing adjustment, calibrating prices, and encouraging competition); but if import competition were to magnify the impact of other shocks (like the loss of traditional CMEA markets, contraction of domestic demand), its drawbacks may outweigh its benefits.

Major questions are emerging from the process of trade liberalization: Will the expected favorable impacts evolve? Will imbalances, like an unexpected trade deficit due to a rapid growth of imports or domestic shortages due to an unexpected outflow of exports, accompany trade liberalization? Can domestic production respond to the challenge of import competition? Can the process of liberalization (in the light of these or unrelated factors) be sustained?

The following review of trade liberalization in Eastern Europe gives early answers to these questions using available evidence. More data are cited for

\footnotetext{
${ }^{3}$ Since I did not have the opportunity to attune the rules of constructing the index with the authors of the World Bank book series, I made my estimations based on my own intuitive weights. In fact, even the participants of that project had to rely on ad hoc approaches and intuition to make assessments for the values of the index of liberalization in their respective studies. The authors of the World Bank project did not intend to use the index of liberalization for socialist economies (Michaely et al., 1991, p. 18, footnote 8).
} 
Hungary, the country I am most familiar with and where experiences and analyses are relatively more abundant.

\section{Conditions and Timing of Liberalization in Eastern Europe}

Trade liberalization is not a completely new phenomenon for Eastern Europe's formerly centrally planned economies. For instance, the long history of gradual reforms in the Hungarian economy since 1968 is also the history of sometimes ill-fated, but not completely unsuccessful, attempts at reforming and liberalizing trade (see Gács, 1990 and 1991). However, the scope of trade liberalization in the late 1980s and early 1990s in Eastern Europe is incomparable to the earlier attempts. The immanent autark nature of centrally planned economies, the rigid system of distribution of labor in the framework of the CMEA, the lack of means to deal with competition, as well as the political constraints, all had impeded any bold attempt at trade liberalization.

Transition in each of the formerly centrally planned economies entails three major interrelated economic processes: stabilization, marketization, and restructuring. In the economies of Eastern Europe, trade liberalization has been assigned a prominent role in the processes of both marketization and restructuring; in Poland it has also been assigned a crucial function in the process of macroeconomic stabilization. Trade liberalization and establishing de jure currency convertibility have been related to stabilization less in the CSFR and even less in Hungary.

In late 1989 Poland's inflation reached hyperinflational dimensions. The stabilization package introduced on 1 January 1990 used the establishment of currency convertibility of the zloty and its pegged rate to the US dollar as major instruments to curb further increases in prices. The introduction of currency convertibility and the role of the exchange rate as a nominal anchor made sense only if foreign trade flows were to be permitted to change relatively freely and to help in restoring balance on product markets. Accordingly, the Polish government had virtually abolished all its licensing activity in non-ruble-accounted trade. As for exports, in early 1990 temporary export restrictions were introduced on 24 items with the aim of preventing an outflow of essential goods in the time of widespread shortages. As a consequence of the excessive devaluation of the zloty, the worry about an outflow 
of goods was so pronounced that other administrative methods were also used to keep the level of exports under control.

In the CSFR most of the reform measures were introduced in January 1991; this was also the starting point of trade liberalization. In 1990 the domestic currency experienced three substantial devaluations, and in January 1991 it became - although with limitations - internally convertible (for current account transactions and for registered business units).

While inflation increased in 1990 (from 1.4 percent in 1989 to 10.1 percent in 1990), this acceleration was not very rapid and was under control. Also there was neither an excessive monetary overhang nor a serious disequilibrium on the market of consumer or industrial goods. Accordingly, price liberalization and trade liberalization were not needed to overcome these types of disequilibria. The purpose of early trade liberalization cum establishing internal convertibility was more closely related to the evolution of a new structure of prices and incentives and "importing" competition than to stabilizing existing imbalances. ${ }^{4}$

The architects of the reform in the CSFR also realized that the Czechoslovak economy was more separated from the changes in the world market than other small centrally planned economies, like the Polish and Hungarian economies. Trade liberalization seemed an appropriate tool to facilitate catching up with competitors and to enhance adjustment to the price as well as demand and supply relations in the world market.

In January 1991 only four categories of products in the CSFR remained subject to import licensing (crude oil, natural gas, narcotics, and arms and ammunition), while 20 percent of merchandise exports remained to be controlled by licensing.

Of the three countries, Hungary was the first to make the political decision to start trade liberalization, in the summer of 1988. The program entailed a schedule of fast, but gradual liberalization. Non-ruble-accounted imports were planned to be liberalized in the course of four years, from 1989 to 1992 , in steps ranging from 20 to 35 percent, and there were no plans to declare any kind of convertibility of the domestic currency as a part of the liberalization package. Partly under pressure from the IMF and the World Bank, and partly based on early favorable experiences, the program was

\footnotetext{
${ }^{4}$ See Hrnćíi and Klacek (1991). However, after Czechoslovak reformers decided to introduce currency convertibility and embark on a policy of bold trade liberalization, the extent of devaluation of the koruna reflected the will to prevent an anticipated dangerous trade deficit. See Williamson (1991).
} 
sped up and implemented in three years. In 1992 about 90 percent of imports were liberalized, and about 70 percent of domestic production had to face import competition. The remaining restricted items were mostly food products and consumer goods.

In Hungary the state of imbalances provided a mixed picture on the eve of trade liberalization. There were no serious disequilibria on product markets; however, increasing budget deficits, external indebtedness, and trade deficits were subject to serious concern. Inflation, while accelerating in the late 1980s, did not necessitate the "big bang" approach, like the one applied in Poland in 1990. While stabilization measures were at the center of government's policy since 1988, after much debate it was decided that the introduction of the convertibility of the Hungarian currency and the use of the exchange rate as a nominal anchor for curbing inflation would not be used as a means of anti-inflationary policy. As a matter of fact, the government adhered to this rule to the extent that the package of trade liberalization was not accompanied by any serious concept of devaluation or exchange rate management. Despite the lack of actions for deliberately establishing de jure currency convertibility, through the progress of liberalization and other seemingly unrelated measures, the de facto current account convertibility of the forint, however, has essentially been achieved in the last four years.

\section{First Experiences}

Trade liberalization was not the only or the main element of economic reform in any of the countries at the time liberalization was introduced. Liberalization was part of a package for stabilization and reform..$^{5}$ The well-known elements of these packages - liberalization of prices, reduction of subsidies, introduction of restrictive macropolicies, and institutional changes to enhance private ownership and competition - had far-reaching consequences on the development of the economy and trade. These changes were accompanied by other impacts, exogenous from the point of view of national reforms, like the demise of the CMEA, the collapse of the Soviet Union, and recession in the world economy. It is extremely difficult to distinguish between consequences of trade liberalization and other simultaneous changes. The complication of separating the effects of different impacts might have been the cause for the astounding lack of analyses concerning the effects of trade liberalization in these three countries. As of this writing, the end of 1992,

\footnotetext{
${ }^{5}$ This was less obvious, though, in Hungary than in the CSFR and Poland.
} 
we still have only a limited amount of information on the experience of trade liberalization in these three countries and most of the evidence is fractional or anecdotal.

The expected positive impacts of trade liberalization were the following: the incentive system would be more neutral than before in respect to import substitution and exports; enterprises would familiarize themselves with foreign markets, prices, demand, and standards (this would both force and enable them to make adjustments); domestic competition would be induced by import competition (less state intervention would be needed for antitrust purposes); the prices that had been liberalized would follow the pattern of world market prices, rather than the pattern dictated by domestic monopolies; production would have access to cheap imports and efficiency would be enhanced, while consumer access to a wide range of imported goods, many of them relatively cheaper than domestic ones, would give additional incentives to contain inflation; through export liberalization and access to imports, exports would be enhanced and scale efficiency could be better utilized.

The most spectacular reaction on measures of trade liberalization was the explosive increase in the number of business units engaged in foreign trade. Earlier the number of enterprises having licenses to carry out exports and imports was in the hundreds, but for the overwhelming majority of these firms the scope of activity was strictly limited. After liberalization this number jumped to tens of thousands in each country. This development was a reflection of several factors: the serious distrust in the efficiency of traditional foreign trade enterprises; the growing interest in discovering foreign markets and carrying out international transactions; the determination of earning windfall profits in connection with the still prevailing shortages and price differentials; the utilization of legal or illegal personal benefits for those directly involved in this business (exchange and transfer of foreign exchange, under- and over-invoicing, organizing trips abroad, and so on).

Producers in Eastern European economies had been isolated from Western markets for a long time because access to foreign exchange was blocked. The eventual decision to select the direction of purchase (and in some countries that of the sale) was not delegated to them, and even access to information about foreign markets, suppliers, prices, and other parameters were only accessible to a limited extent. Consumers were isolated in a similar manner; their chances to choose imported products for purchase were determined eventually by central bureaucracies. There were significant differences, however, between the three countries concerned. Through 
a sophisticated systems of regulation, Hungarian and Polish producers had more access to Western markets, at least in the 1980s, than CSFR producers; in addition, the more mobile Polish and Hungarian citizens had more chances than their Czechoslovak counterparts to learn about the characteristics of supply of Western goods through tourism or business trips.

After this long isolation and with the enterprise budget constraint still not hard enough, it seemed obvious that easy access to the "forbidden fruit" would tempt Eastern European firms and consumers to taste them. Authorities in the three countries feared an attack on imports and purposefully introduced new barriers or brakes to curb the growth of imports. The import surcharge on a wide range of goods in the CSFR, the requirement to use trade credits for payments of certain categories of imports also in the CSFR, the gradual approach followed in Hungary, the substantial devaluations in Poland and the CSFR, the introduction of import deposit (or in other words, 100 percent prefinancing requirement) in Hungary all served this target, as others too, like restrictive monetary and fiscal policies carried out at the time when trade liberalizations commenced.

Foreign trade data indicate that none of the three countries experienced a surge in their aggregate imports in the first year of import liberalization. Total imports changed by -20 percent, 1 percent, and -27 percent in the CSFR, Hungary, and Poland, respectively, in the first year following trade liberalization (Mladek, 1992; Central Statistical Office, 1992; and International Financial Statistics, No. 9, 1992). Naturally, there was a large variance among the growth rates of different products and different categories of goods.

Pent-up consumer demand was high in each country. This was the case even in Hungary, the best-supplied centrally planned economy, following a year in which Hungarian tourists could import duty-free an enormous volume of consumer goods for their own purpose. In the first year of the liberalized regime in Hungary, the import of some products rocketed in as high as 2- to 12 -fold of their previous level. ${ }^{6}$

In some cases, the saturation of the market was achieved in the very first year: in Hungary the imports of building materials increased 6-fold in 1989, while the value of imports of the next year was hardly more than half the 1989 value. The demand for many other kinds of imported consumer goods, however, continued to be high.

${ }^{6}$ The favorite items purchased were deep freezers (12-fold growth), tiles and floor tiles (4- to 7-fold growth), and color TV sets (60 percent growth). 
Table 5.1. Distribution of manufactured industrial products imported from the EC, in percent.

\begin{tabular}{lrrrrrr}
\hline & 1980 & 1985 & 1988 & 1989 & 1990 & 1991 \\
\hline Czechoslovakia & & & & & & \\
Materials & 46.75 & 41.19 & 33.78 & 33.99 & 30.49 & 28.31 \\
Machinery & 40.93 & 43.48 & 50.26 & 49.50 & 53.19 & 53.53 \\
Consumer goods & 5.81 & 5.53 & 5.40 & 5.18 & 7.40 & 9.81 \\
Food products & 5.23 & 6.68 & 7.21 & 7.53 & 5.37 & 5.25 \\
Other products & 1.27 & 3.12 & 3.35 & 3.80 & 3.56 & 3.10 \\
Total & 100.00 & 100.00 & 100.00 & 100.00 & 100.00 & 100.00 \\
Consumer goods+vehicles & 7.07 & 6.61 & 6.53 & 6.53 & 9.38 & 13.97 \\
Hungary & & & & & & \\
Materials & 55.37 & 50.44 & 47.69 & 42.95 & 40.26 & 38.51 \\
Machinery & 33.18 & 34.63 & 35.82 & 39.01 & 39.35 & 40.53 \\
Consumer goods & 5.66 & 7.73 & 8.78 & 10.30 & 13.13 & 14.18 \\
Food products & 4.07 & 3.78 & 3.76 & 3.34 & 3.07 & 3.03 \\
Other products & 1.72 & 3.42 & 3.95 & 4.40 & 4.20 & 3.76 \\
Total & 100.00 & 100.00 & 100.00 & 100.00 & 100.00 & 100.00 \\
Consumer goods+vehicles & 6.28 & 8.91 & 10.67 & 14.08 & 16.68 & 20.63 \\
Poland & & & & & & \\
Materials & 48.82 & 45.47 & 42.97 & 37.27 & 33.32 & 29.19 \\
Machinery & 39.05 & 34.04 & 35.92 & 37.22 & 40.80 & 40.42 \\
Consumer goods & 4.55 & 8.48 & 7.76 & 9.24 & 13.89 & 15.24 \\
Food products & 6.21 & 9.23 & 9.60 & 12.44 & 8.70 & 11.36 \\
Other products & 1.37 & 2.78 & 3.75 & 3.83 & 3.29 & 3.79 \\
Total & 100.00 & 100.00 & 100.00 & 100.00 & 100.00 & 100.00 \\
Consumer goods+vehicles & 6.10 & 11.03 & 9.45 & 11.23 & 16.33 & 21.53 \\
\hline Sourc: Gas, & & & & & &
\end{tabular}

Source: Gács, 1992.

As Table 5.1 indicates (on the example of imports from EC economies), consumers have continuously shown an increasing preference for goods imported from the West. The share of consumer goods has steadily grown in all three countries in recent years, no doubt partly as a consequence of trade liberalization that brought the opportunity of free choice. We list the share of consumer goods and motor vehicles separately because a significant and growing ratio of vehicle imports were passenger cars imports, the favorite target of consumer purchases in these years. The consolidated share 
of consumer goods and vehicle imports is showing an even more spectacular growth.

As far as license-free importation and exportation by business units is concerned, enterprises, when acting as buyers, realized almost all the advantages of liberalization that were previously envisaged. In fact they adjusted to the changes as easily as households do after an automatic washing machine is put into use, or as university professors adapt to the use of copying machines and transparencies: no doubt these devices make life much easier and without them normal operation would be unimaginable, but after a very short period of time one tends to forget the enormous advantages brought about by these changes.

Industrial case studies about the impact of trade liberalization in Hungary give numerous examples for the most visible general effect of liberalization - that is, as a consequence of a better supply of goods from imports, domestic producers started to pay more attention to their customers, improved conditions of supply, and gave up their earlier practice of raising prices mechanically in line with the inflation (Nagy, 1991).

In all three countries import liberalization contributed the most to the containment and even reduction of prices of passenger cars and consumer electronics. Liberalization and/or increasing of import quotas for these goods lead to enthusiastic consumers, who spent much of their savings on better and cheaper electronic products and (mostly used) Western cars. In a later section we discuss how respective domestic producers reacted to this event.

\section{How Much Crowding Out of Domestic Production?}

The less attractive side of trade liberalization is the impact of competing imports on the sustainability of domestic production. Before the act of liberalization, there were already major concerns about whether the allegedly rigid, unresponsive state enterprises would be able to meet the challenge of import competition. We have seen that, at the outset of liberalization, each government took measures to curb imports, and through this gave some protection to domestic industries. The radical devaluations of the domestic currency and some complementary measures (import surcharge) or substitutes (import deposit, financing requirements) were operational in this respect. Note again that in Hungary trade liberalization was not accompanied by any substantial devaluation of the currency. 
Data on real effective exchange rates (see, for instance, the figures presented in Chapter 1 by Oblath) show, however, that in all three countries the start of the liberalization was followed by a long period of appreciation of the domestic currency. In the CSFR and in Poland experts found this development mostly justified, partly because the magnitude of the initial devaluations counted with the inflationary effects of price liberalization (and the ensuing real appreciation) and partly because, according to many analysts, the initial devaluation in fact implied an overshooting. Without going into details we must note that the pursuance of the policy of real appreciation of the domestic currency has been strongly criticized in Hungary for several years, and became the subject of disputes in the CSFR and Poland recently.

One of the arguments against the current pro-appreciation policies of Eastern European governments is strongly supported by the author: in the peculiar position of Eastern European producers in 1989-1992, neither the good export performance nor acceptable balance of payments position is a good measure for the evaluation of the level of real exchange rate. Industries with exceptionally good export performance may export at a loss and as a result may accrue high debts and face a series of bankruptcy procedures as well as the liquidation of their leading enterprises. Because of the extreme vulnerability of Eastern European industries, governments must provide a cushion for the most viable ones in different ways during the period of restructuring. One policy option that should not be excluded, and this is the experience of almost all successful liberalizations in developing economies, is depreciating the exchange rate.

It is a peculiar feature of trade liberalization in the three countries that, contrary to international experiences, the abolishment of quantitative restrictions on imports was not combined with an increase in tariff protection. None of the governments realized the importance of tariff protection at the time of dismantling nontariff barriers, or, if realized, they overemphasized the reluctance of international organizations, like GATT and the EC, to accept tariff increases that would replace the quantitative restrictions.

In the special Hungarian case the new, democratically elected government did not realize the chance to dissociate itself from the lies of previous Hungarian governments concerning alleged automatic licensing of imports in Hungary since 1968. Accordingly, the breakthrough of import liberalization, which commenced in 1989, was played down and was not used as grounds for renegotiating tariffs with trade partners (Oblath, 1991a). 
While in Hungary the free flow of imports met with an average tariff level of 16 percent, at the start of liberalization the average Polish tariff was about 12 percent, and tariffs in the CSFR averaged at a paltry 5 percent.

In the first year of liberalization, in each of the three countries domestic enterprises usually enjoyed the benefits of trade liberalization and, except for some producers of consumer goods, did not express any difficulties in meeting the challenge of import competition. One reason for this was the shelter that the devalued currencies in the CSFR and Poland provided for domestic producers. Another explanation is related to the phenomenon that can be called "the dominant effect."

Enterprises clearly sense if after a long period of strong protection they are being forced to face competition. However, for enterprises in Eastern Europe the hardships of import competition were hardly noticeable compared to the impact of other more dominant shocks. In this respect one has to refer to the collapse of trade with the economies of the CMEA, the effects of restrictive policies resulting in, inter alia, the decline of domestic demand and in the difficulties in obtaining credits for financing everyday operation, the hardships of adjustment to liberalized prices, and the threat of privatization to the old management of the enterprises. Under the conditions of these shocks, the challenge of import competition was comparatively negligible for the enterprises, at least at the outset of trade liberalization.

Responses to the detrimental effects of trade liberalization became laudable usually one year after the liberalization started. One complaint was concerned with the rapid penetration of cheap Western imports into the domestic markets, the danger of crowding out indigenous producers from their traditional markets.

Unfortunately problems of collecting the necessary statistical data for trade and production do not make it easy to check the validity of these complaints. Still, a calculation was made for Hungary to analyze the shifts in the sources of domestic supply in 1988-1990, and through this one can follow the pattern of import penetration in the first two years of liberalization. ${ }^{7}$ Table 5.2 shows the results of this calculation for the sectors that showed the most rapid pace of import penetration.

\footnotetext{
${ }^{7}$ Unfortunately, because of the changes in the accounting of foreign trade flows in Hungarian statistics in 1991, the calculations could not be carried out for 1991 and 1992. Calculations on penetration are usually rudimentary means of analysis because they are subject to strong and sometimes unrealistic assumptions. Therefore, the reader should consider these results with caution.
} 
Table 5.2. Sources of domestic supply in Hungary for selected product groups from 1988 to 1990 , in percent.

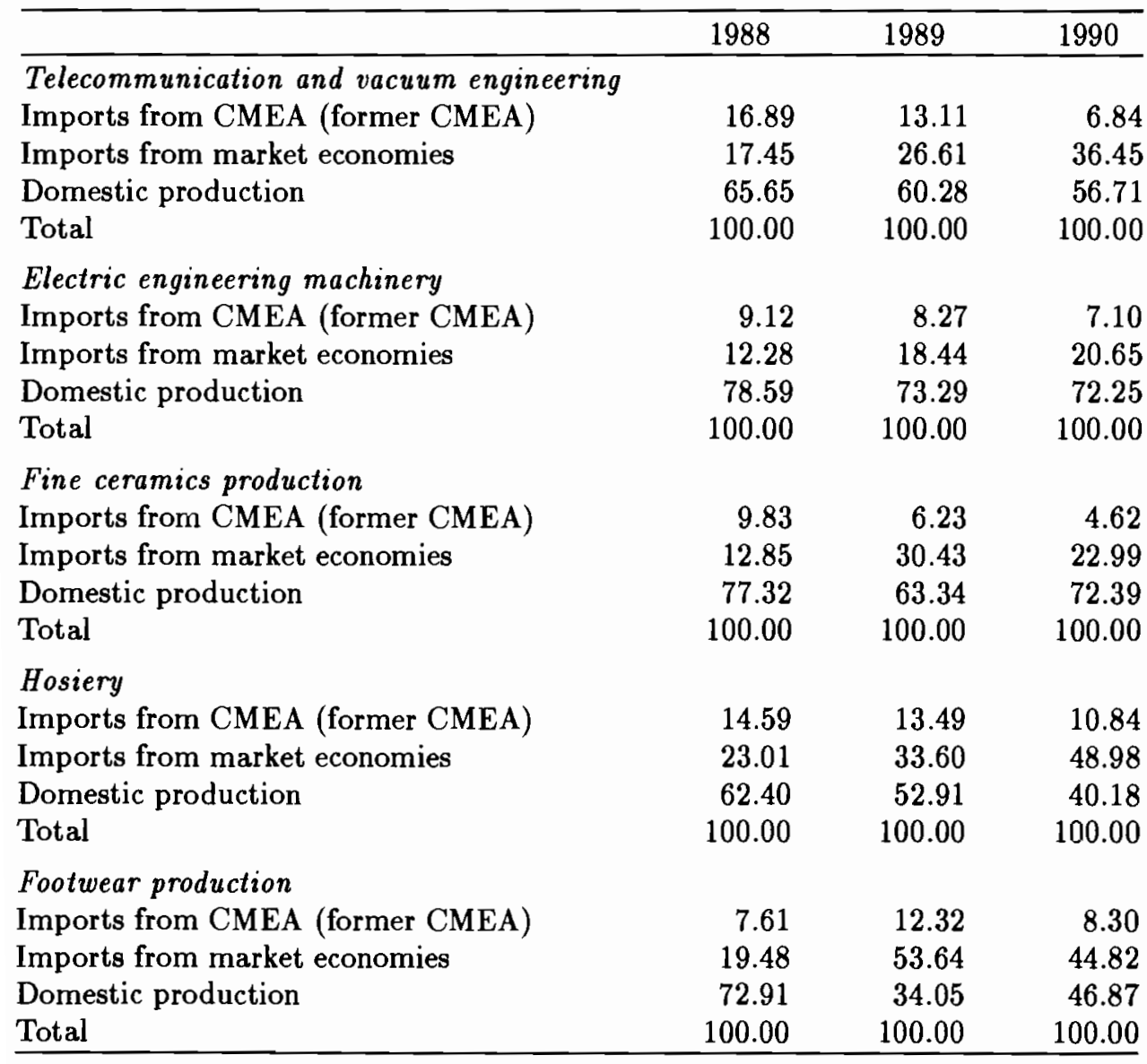

Sources: KOPINT-DATORG data base; Magyar Statisztikai Évkönyv (Statistical Yearbook of Hungary), Central Statistical Office, Budapest, various issues; Külkereskedelmi Statisztikai Evkönyv (Statistical Yearbook of Foreign Trade), Central Statistical Office, Budapest, various issues.

The first conclusion one can draw from the table is that Western imports have penetrated the market; they have replaced not only domestic production, but also former CMEA imports. Another interesting finding is that, of the five product groups listed in Table 5.2, hosiery and footwear products had the fastest penetration; these imports were hardly liberalized between 1989 and 1990. In fact, the faster inflow of certain goods was not necessarily the consequence of liberalization (or geographical reorientation). As one can 
see in Table 5.1, in both the CSFR and Poland the sharp increase in the share of consumer goods imports started one year before trade liberalization commenced.

None of the above-mentioned remarks are intended to belittle the importance of penetration of imports in Hungary or in Eastern Europe. In fact, domestic production could have been further reduced in 1991 and 1992, since the level of protection of the domestic market and the ability of many enterprises to face the challenge of imports must have diminished over the course of this time. ${ }^{8}$ It is also fully understandable that for industries that have suffered a 30 to 60 percent decline of output in the past four years - and this is the case with almost all the industries in the three countries - a further loss of even a small part of the domestic market is increasingly painful.

\section{The Lack of Strong Pressure Groups}

According to the literature of comparative trade liberalization in developing economies, the success and sustainability of liberalization are usually jeopardized the most by pressure groups. Organizations of employers or employees try to block the evolution of the process of liberalization when they feel they will lose much from dismantling old trade barriers. Many successful episodes of liberalization benefited from the fact that a major move to liberalization was carried out in a period when the respective pressure groups were emasculated and old connections of lobbying and rent-seeking groups were cut. The successful moves toward liberalization in Korea in the mid-1960s, in Indonesia after 1965, in Chile after 1973, and in Turkey after 1980 were connected with this kind of political shift. In all these cases, however, the shift could clearly be identified with a turn to an authoritarian, mostly dictatorial political system, following the events of terror.

In contrast to the political shifts in these countries, the systemic changes in the CSFR, Hungary, and Poland between 1989 and 1990 involved dismantling the authoritarian regimes, embarkation on the road to democracy, carried out in a peaceful way. As evidence of the acceptance of the ensuing economic hardships in these societies, the usual pressure groups resisting economic reforms were either nonexistent or virtually ineffective.

In these centrally planned economies the functions of the employer were distributed among the party, the state, the managers, and different - mostly puppet - organizations of the employees. After the changes in 1989, the

\footnotetext{
${ }^{8}$ This is, in fact, testified by KOPINT-DATORG (1993, pp. 113 and 117).
} 
party-state did not exist and the behavior of the state (including the branch ministries) was dominated by pro-liberalization policies of the government. Earlier managers had traditionally derived their power from their close relation to the communist party. With the disappearance of this situation, most managers felt themselves discredited and, for the sake of their survival in their old positions, they did not make any noise, even when the interest of their enterprises was seriously endangered. Old trade unions were also discredited, and the new ones were either supporters of the new governments (like the Solidarity in Poland in 1990) or were too new to act effectively.

\section{The Emergence of Resistance}

The first reaction to liberalization of trade was unanimous satisfaction both in businesses and in the civil society. The universal welcome of consumers to the long-awaited inflow of import products and the disappearance of chronic shortages also determined the general positive mood of the society toward trade liberalization.

The enterprises awaking the earliest were newly established joint ventures. Investing with concrete business targets, more skilled in lobbying, and possessing the means for blackmailing domestic authorities, they were fast, aggressive, and efficient. Many foreign investors targeted their sales neither to Western markets nor to Eastern countries, but to capture domestic demand. They also wanted to make use of the monopolistic structures inherited from the period of central planning. For instance, the Hungarian industries that were most quickly and completely privatized (and almost exclusively by foreign investors) were the sugar, distilled spirits, tobacco, brewing, and paper and pulp industries; none of them being especially export oriented.

Apart from foreign investors, the most responsive to the risks of liberalization were producers of farm products. Losing many kinds of subsidies and still facing high protection policies in Western countries, they were not enthusiastic about trade liberalization, even if a substantial part of the items still under import control were food and agricultural products. In September 1991 farmers in the CSFR agreed with their government to put some crucial agricultural and food products under quantitative control again. Polish farmers pushed their government to achieve a faster liberalization in order for their produce to penetrate the EC and other Western markets, and, at the same time, they pleaded for extra duties on "well advertised, attractively packaged products" pouring into Poland (Marsh, 1992). 
The voices concerning the willingness of governments to assist domestic producers by locking out competition of foreign imports come from very different levels of the administration. It is never clear whether alleged support against imports is taken seriously or is simply used to pacify producers and employees endangered by the decline of domestic production.

President Walesa continuously attacks Western firms that, instead of investing into Poland, take advantage of the low custom duties and flood his country with cheap mass-produced merchandise. ${ }^{9}$ The state secretary of the Hungarian Ministry of Finance asserts that more emphasis should be put on the protection of domestic market and calls upon Hungarian consumers to consume primarily Hungarian goods rather than purchase foreign products. ${ }^{10}$ The Hungarian state secretary of the Ministry of Agriculture has initiated the elaboration of a law that would protect Hungarian agriculture against cheap liberalized imports, even if the whole idea is contrary to the stand of the rivaling Ministry of Foreign Economic Relations. ${ }^{11}$

These actions are not easy to evaluate. One could cite as many statements in praise of the process of liberalization as warnings against hasty interventions. Also pro-protectionist statements may serve as substitutes for protectionist actions. While a general turn against trade liberalization cannot yet be seen in the three countries, there are numerous signs of a recent reconsideration of the virtues of record-fast liberalization.

\section{New quotas}

In the case of simple, homogeneous products, and where visible demonstration of the arresting of inflow of imports is needed, the reintroduction of quotas is the most popular method. Endangered Hungarian coal miners successfully pressed their government to introduce an annual quota of 14 million metric tons of domestic coal that should be purchased by the national electricity trust for use in the power stations. Imported coal that is usually cheaper and of better quality can be purchased only after the Hungarian quota is exhausted. We have seen above that the CSFR government used quotas to limit the imports of some important agricultural products. The Association of Hungarian Light Industry urged the Hungarian government to introduce new quotas for the protection of domestic textile and clothing

\footnotetext{
9 "Cautious investors in Poland," Napi (Daily) 23 April 1992.

10 "Buy Hungarian!" Napi (Daily) 19 October 1992.

11 "The law for protection against agrarian imports is in preparation," Napi (Daily) 15 May 1992.
} 
markets from imports. As a result, the number of quotas used in textile and clothing increased from three to six. In many cases the reference of proposals for quotas is either Southeast Asia or the EC, where many quotas are still in use in respect to sensitive industries. ${ }^{12}$

A special feature of new protectionism in Eastern Europe is that many of the protectionist barriers are erected against the allegedly damaging trade flows coming from former allies in ex-CMEA. Transition is simultaneous in these countries, although not completely similar. Soon after the bold measures of trade liberalization were put into force, accusations of market disruption and dumping were made in the Eastern European countries. A telling example was Hungary's move in which beginning in March 1992 annual quotas were introduced for the importation of 15 different steel products from the CSFR and the successor states of the USSR. The process was initiated in early 1991, not long after the main reforms were introduced in the CSFR and much before the reforms were introduced in the successor states of the USSR. Protective measures were made at the request of the employers' association of the Hungarian iron and steel industry, which substantiated its request by referring to the sustained subsidization of the price of energy (one of the basic inputs of metallurgy) in the countries concerned and the fast growth of metallurgical imports in Hungary. ${ }^{13}$

A similar process was initiated by the association of the Hungarian cement producers' association which resulted in a 9 percent supplementary tariff on cement imports from the same countries.

According to market disruption processes initiated in Western Europe at the same time, not only Hungarian producers were sensitive to Eastern European steel and cement exports. Following the cry of alarm from French, Italian, and other Western steel producers EUROFER (the European steel producers' association) initiated antidumping penalties and quotas against CSFR steel exports to Western Europe. ${ }^{14}$ Similar complaints of Austrian

\footnotetext{
${ }^{12}$ For example, "The wreck-lobby won of," Napi (Daily) 11 February 1992.

13 “Import quotas for 15 steel products," Napi (Daily) 3 March 1992; and Külkereskedelmi Tájékoztató (Bulletin of Foreign Trade) 7 April 1992. In Hungary the import of metallurgical products was liberalized in 1990. Domestic demand for metallurgical products declined by 12 percent in that year; imports, however, surged by 12 percent. As a consequence, penetration of the imports increased from previous year's 25 percent to 32 percent. See Ár-piac (Price-market), Hungarian Ministry of Finance, December 1991.

${ }^{14}$ The complaint followed a 126 percent rise in CSFR steel exports to Western Europe in the first four months of 1992 ("Slovak steel-makers find success has a price," Financial Times, 16 June 1992).
} 
cement producers prompted the Austrian government to introduce quotas for CSFR cement imports in August 1991.

\section{The behavior of foreign investors}

Eastern European governments and businessmen are docile students of the market economy. When setting up market institutions, wording new legislation, and elaborating government policies, they tend to believe textbooks, foreign advisers, and respectable international organizations. It did not take much time, though, for them to become disillusioned, if not with the idea of free market, then with their "professors." One lesson they learned fast is that the rapid opening of their markets is not followed by a comparable pace of getting access to Western markets, which are really crucial from the point of view of their exports (Kupka et al., 1992). Another bitter experience is connected with the behavior of Western investors. These businessmen, after setting up their business (mostly joint venture) or having taken over some existing state enterprise in the course of privatization, immediately forgot the sermon they had preached about the virtues of free trade and the evils of government intervention. They soon became stronger and more innovative lobbyists of trade protection than experienced managers of the old regime could have ever become.

It is clear that their sensitivity to fluctuations to expected profitability is high (or in other words, their budget constraint is harder than the average domestic business). After all this is why experts of trade liberalization could not imagine a successful liberalization in Eastern Europe without a fast process of privatization (Havrylyshyn and Tarr, 1991). Western businessmen, however, are also extremely experienced in presenting their case, and in finding ways to blackmail host governments. Each Eastern European country has stories of aggressive or invisible interventions by Western investors trying to erect specific trade barriers for their own purpose.

The Korean Samsung company, even before signing the contract for its joint venture in Hungary for manufacturing television sets, started lobbying for higher tariff barriers for color TVs (from 15 percent to 25 percent tariff rate) and zero tariff rate for components of color TV sets. The Hungarian authorities were very flexible, and tariffs on components were cut back to 5 percent. After several months, Samsung started its fight again for zero tariff on components, and now for a $\mathbf{3 0}$ percent tariff on the import of the final product. The Korean businessmen even organized all the other Hungarian producers of TV sets to lobby jointly and to threaten the authorities with the 
closing of TV manufacturing plants in Hungary unless the demanded changes were implemented. The authorities first granted specific tariff exemptions on components to Samsung, then, after some negotiations, tariff rates on TV sets were raised to 25 percent. A few days after this tariff increase was accepted by GATT, a domestic price rise of domestically manufactured TV sets was announced (Borszéki, 1991).

Another example is the current case of an Austrian businessman who has invested about US $\$ 10$ million in three Hungarian enterprises producing paper sheets for printing and copying. In 1992, two years after his initial investment, he started to complain about the anomalies of paper tariffs: for the importation of the raw materials for paper production one has to pay tariffs of 5 to 10 percent, while the import of processed paper products enjoys a 0 percent tariff rate. In addition, raw materials for paper products have to be imported because they are not available in Hungary. After realizing his failure with tardy Hungarian authorities to achieve an adjustment in tariffs, the businessman turned extremely aggressive. He started to give critical interviews in international newspapers on the worsening Hungarian business environment and irresponsible government policies. He explicitly dissuaded foreign investors from starting businesses in Hungary. He also threatened to close down his Hungarian factories, unless his demand for tariff adjustments or introduction of quotas for processed paper products were seriously considered. Hungarian authorities were reluctant to change tariffs, but at last they offered a market disruption case. It had some ground, since the import of processed paper products (with 0 percent tariff) increased 2- to 4-fold in 1992. In November 1992 the respective ministry introduced annual quotas for imports of five groups of processed papers from all countries except Finland and the EC. This decision does not seem to have been satisfactory for the businessman; since the introduction of the new quotas (in fact, most of additional imports come from Finland), he has closed down one of his paper factories. ${ }^{15}$

Of all the foreign investors in Eastern Europe, carmakers are the most aggressive ones in pushing host governments to introduce or reintroduce protective measures. Table 5.3 gives an overview of some recent results of car lobbyists in the CSFR, Hungary, and Poland. One reason for their

\footnotetext{
${ }^{15}$ Prinzhorn, "Hungary was the No. 1 favorite," Napi (Daily), 28 September and 22 October 1992; HVG (World Economy Weekly) 7 November 1992.
} 
Table 5.3. Major car lobbyists in the CSFR, Hungary, and Poland.

\begin{tabular}{lll}
\hline Country & Company & Results achieved \\
\hline CSFR & Volkswagen-Skoda & $\begin{array}{l}\text { Increased import duty on imported cars. } \\
\text { Slashed turnover taxes on cars manufactured } \\
\text { domestically. }\end{array}$ \\
Hungary & Suzuki, GM-Opel & $\begin{array}{l}\text { For passenger cars an annual import quota } \\
\text { introduced to replace licensing. Licensed } \\
\text { imports slashed from 200,000 to 140,000 in } \\
\text { 1992. Restrictions most effective for } \\
\text { commercial importers of used cars. Stricter } \\
\text { restrictions planned for used cars in 1993. }\end{array}$ \\
& & $\begin{array}{l}\text { The quota of 30,000 duty-free cars and 100 } \\
\text { trucks to be imported a year allotted to the } \\
\text { new joint ventures (normal duty is 35 } \\
\text { percent). Tariffs and turnover taxes for cars } \\
\text { increased several times in the course of the } \\
\text { last three years. }\end{array}$ \\
\hline
\end{tabular}

Source: Various newspaper reports.

strength is the sheer magnitude of their investments and the promises they make for further investments. ${ }^{16}$

\section{Active tariff policy: The new tool}

As referred to in a previous section, the three countries did not start their trade liberalization with a conscious adjustment of their tariff rates.

For most governments it took some time to realize that, after the disappearance of central planning and their formal and informal opportunities for assigning quantitative restrictions, they were left with only a few tools to control the inflow of imports - tools that had been sporadically used by them in the past. Tariffs had been used earlier more as a means to centralize revenue for the budget and to achieve tariff concessions from trade partners, than as a way to protect the domestic market or some domestic industry. At the outset of their transition most of the European centrally planned economies considered it better if their tariff level and structure were closer to the standard accepted by international organizations (GATT, EC), and

\footnotetext{
${ }^{16}$ The investments are usually in the order of hundreds of millions or billions of US dollars.
} 
did not intend to use it as a tool of protection or some kind of an industrial policy.

In the CSFR a new tariff bill and a new tariff table were introduced in February 1991, but the new tariff could not be considered a protective one, since its average 4.7 percent rate was extremely low, comparable with that of most developed economies only. As a complement the CSFR government temporarily introduced a special import surcharge of 20 percent for virtually all goods excluding raw materials (Charap et al., 1992). The level of the surcharge was in fact slashed five times in 1991 to the level of 10 percent for legal persons and 15 percent for natural ones. Also the coverage of the surcharge was reduced.

Realizing the importance of tariffs as a protective tool, the CSFR government prepared a major modification in the structure of tariffs for 1992 . The changes covered 23 percent of all tariff items and involved both a perspective restructuring (like establishing a vertical progression of tariffs) and obvious protective intents (like higher protection for food, agriculture and sensitive products, textiles and clothing, electric equipments, and machinery). While the average tariff rate did not increase by more than 1 percent, if calculated on more recent structure of trade (and not for 1988), tariff protection was much higher than that. ${ }^{17}$ GATT was notified that most of the tariff increases would only be temporary. ${ }^{18}$

The pre-reform average tariff rate in Hungary was 16 percent, and the 1 percent cut in the year 1989 had nothing to do with the adjustment to the liberalization measures. ${ }^{19}$ Currently a new customs law is being prepared with the aim of replacing the obsolete one. This is why the Hungarian authorities did not make any serious conceptual modifications in the system of tariffs in recent years. The pressure of domestic enterprises (and sometimes of the organizations and/or ministries representing them) has built up since the start of trade liberalization. They have aimed for corrections of unreasonable relative tariff rates and for apparent protection of domestic production. These moves for increasing tariff protection did not result in

${ }^{17}$ This note, however, implies that numbers for the CSFR average tariff protection are most probably weighted averages, while those usually quoted for Hungary are unweighted ones. The weighted average for Hungary for 1992 should be about 6 percent. See "The system of market cannot be disrupted in a one-sided way," Napi (Daily) 13 February 1992.

18 "New tariff rates in Czechoslovakia," Napi (Daily) 29 January 1992; and personal communication with Vit Barta.

${ }^{19}$ It was a cut accomplished in compliance with a schedule Hungary had to keep according to agreements based on the Tokyo Round. 
a substantial increase of the average rate of protection, but have achieved some increase in the tariff protection of specific products like color TV sets, passenger cars, lysine, and aniline oil (Borszéki, 1991).

In fact, domestic producers did not intend to increase tariff rates on competing imports only, but many times they demanded tariff reductions on their own in puts. The reasons for this were that comparative tariff rates of their inputs in other countries were allegedly much lower or simply that actual hardships in their activity should have been compensated by cheaper imported inputs. Examples of this kind of tariff reductions are raw materials used for the production of artificial fibers, tinned steel plate, and components of TV sets and of passenger cars.

Since the actual Hungarian tariff code is very much outdated, one cannot exclude the possibility that many applications for tariff modifications were justified. What is important here is that in recent years producers in Hungary and in the other two countries have habitually prepared a case for tariff modification for their own benefit and have applied and lobbied for it with increasing strength. In many cases the sentiments of the public are also put into motion to protect viable industries, technological cultures, and, what is most important, domestic employment.

In Poland the average tariff rate was 12 percent when the main reforms were introduced. Contrary to expectations, after the first months of trade liberalization the Polish government started to cut back or suspend many of its tariff rates. The intention was to correct the combined excessive effect of a radically devalued currency and other instruments (a 20 percent turnover tax and a 10 percent import deposit). The amendments introduced in the first six months of 1990 covered about half of all tariff positions. These suspensions of tariff rates were carried into the first half of 1991. As an outcome of the reduction of tariff rates, imports to Poland had a 10.9 percent average tariff in the first half of 1990 , an 8.1 percent average tariff in the third quarter, and a 5.2 percent average tariff in the fourth quarter (Foreign Trade Research Institute, 1991).

With the gradual appreciation of the zloty in 1990 and in 1991, the necessity to raise the level of existing tariff protection emerged as an imminent task for Polish policy makers. In 1991 the Polish government issued 15 regulations concerning changes in tariff rates or customs duties. An important additional tool in the hands of the authorities was the turnover tax that was collected at the border beginning on 2 March 1991. Total protection rate in Poland (including tariffs and turnover taxes) in the period between January 
and April 1991 was 19 percent as opposed to 7.7 percent in the same period in 1990 (Foreign Trade Research Institute, 1992). In many cases additional protection was achieved by altering turnover taxes (characteristic examples are imported cars and consumer electronics) (Rosati, 1991).

The importance attached to tariffs as a tool of trade policy and a more systematic move to tariff protection in Poland became manifested by the amendments to the customs law introduced in mid-1991. These amendments included, among others, clauses to protect the domestic market from importation of goods posing a threat to the economic interests of domestic manufacturers. As a consequence of the introduction of new tariff rates and the reduction of earlier suspensions, average tariff rates in Poland were raised to 13.6 percent in 1991 from the average rate of 8.6 percent in 1990 .

The continuing pressure from domestic producers to raise tariffs for protective purposes was reflected by the fact that at the beginning of 1992 the Polish government decided to raise the tariff of a series of important manufactures again; examples include personal computers (from 5 percent to 20 percent), televisions and audio and video equipment (from 20 percent to 30 percent), and motor vehicles (including passenger cars, trucks, and buses from 10 percent to 35 percent). ${ }^{20}$ Additional protection was provided for domestically produced passenger cars in the course of turnover tax modifications in May 1992. The changes implied that the sale of any car over the value of 120 million zlotys (approximately US\$8,300) would be penalized with a 50 percent turnover tax. ${ }^{21}$

One could not close a survey of renewed Polish efforts for using tariffs better than by referring to a recent move of the Polish parliament to temporarily introduce a 6 percent import surcharge on all imports. While the initiators of the proposal intended to provide relief for the national budget, experts of the Polish economy tend to think that this measure was equally supported by those who were dissatisfied by the "too weak" protection of domestic producers in Poland. ${ }^{22}$

\footnotetext{
${ }^{20}$ According to the plans, the tariff rates on motor vehicles will be reduced to 0 percent in the course of the next 10 years. See "Higher tariff also in Poland," Napi (Daily) 10 February 1992.

21 "Warsaw: Tax increase for traders only?" Napi (Daily), 4 May 1992.

${ }^{22}$ And the process continues in other areas. In a similar vein as in Poland, the newly established Slovak Republic introduced an across-the-board 20 percent tariff surcharge on imports in early 1993.
} 


\section{The need for more intricate methods of protection}

In the absence of the opportunity to use the traditional means of protection, more and more emphasis is being given to the more sophisticated kinds of protection. These are usually applied after the goods have crossed the border. Some call them procedural or administrative protection, others prefer to speak about the third and fourth line of protection of industries (Török, 1992).

The most customary of these methods are antidumping and market disruption procedures. Each country has set up its own agency to deal with well-prepared complaints of domestic enterprises against the flow of foreign goods that cause damage to domestic firms. Governments encourage domestic enterprises to start such procedures, rather than to lobby authorities for traditional measures of protection, like quotas and higher tariffs. To launch procedures like these, however, special expertise, requiring much preparation, is needed, and the process is time consuming. In addition, proving the damage is extremely difficult. The complaint of Hungarian metallurgical firms that imports from the CSFR and the former USSR are too cheap (referred to above) resulted in a decision after more than a year. In Poland, in 1991 only two such cases were initiated (one against butter and vegetable oils imports, the other against beef imports from EC economies). Both cases were discontinued because of the difficulties in proving the damage to Polish producers (Foreign Trade Research Institute, 1992). Polish and Hungarian analysts alike refer to the lack of experience in preparing and carrying out such procedures in Eastern European countries.

Other kinds of procedural protection recommended as new measures of protection are the enforcement of special quality requirements and health and environmental standards. In Hungary this idea was supported by both scholars (Török, 1992) and responsible officials of the administration. ${ }^{23}$

\section{Summary and Conclusions}

Trade liberalization in Eastern Europe has been accomplished with record speed in comparative perspective; this is true even in Hungary, which applied

\footnotetext{
${ }^{23}$ "Quotas based on quality in the imports? - The market should not be broken," Napi (Daily), 20 February 1992.
} 
a more gradual approach. Liberalization of foreign trade has been an integral part of the comprehensive reform packages: the targets of rapid marketization, stabilization, and structural adjustment could not be consistently pursued without the bold steps to open the closed economies of Eastern Europe. It has been justifiably accepted that benefits of trade liberalization will be greater in European transition economies than in other countries around the world (c.f. Havrylyshyn and Tarr, 1991).

The usual stumbling blocks of social resistance to liberalize trade were absent in Eastern Europe partly because of the legacy of the shortage economy, and partly due to the complete disorganization of traditional pressure groups of earlier political and economic structures. While the reorganization of new interest groups has not been prevented by authoritarian forces, it has proceeded at a relatively slow speed.

In the first month and even in the first year of change, the impact of liberalization was either contained or was dominated by its advantages. Targeted temporary brakes and restrictive macroeconomic policies prevented an expected attack on imports and were successful in moderating abrupt oscillations of trade flows. The impact of trade liberalization was also overshadowed by the effect of a multitude of other shocks, like the collapse of trade with the economies of CMEA, the decline of domestic demand, the difficulties of financing current operations, and the economic and personal uncertainties related to privatization.

Recent experiences indicate that the honeymoon of trade liberalization is over. It has become apparent that liberalizations were not well prepared. The lack of tariff adjustments to compensate for the abandonment of quantitative restrictions turned out to be not a virtue but a deficiency. Currently each country is attempting to fill in the gaps of a system that lacks moderate and reasonable tariff protection. The international conditions, however, are less favorable for this task today than they were several years ago. The commitments of Eastern European countries to GATT and to the EC are more binding than before, and Western countries are more sensitive to changes in the level of protection in Eastern European economies.

Another deficiency of liberalization policies is that exchange rate management was not planned for the medium and long term. Too little attention was paid to the role the exchange rate can play in cushioning domestic producers in an intermediate period of restructuring. The protection of domestic markets has become more pronounced recently as crucial CMEA markets disappeared and the enterprises lost most of their strength in the 
transition shocks. With their domestic currency continuously appreciating (in real terms), enterprises are unable to achieve adequate profitability in their exports to Western markets and, as a consequence, they lose prospects in each of their three markets (ex-CMEA, domestic, and Western).

None of the three governments embarked on trade liberalization with a well-elaborated industrial policy. It is peculiar, however, that after years of experience, governments still do not dare (or are unable) to draw up even the outline of an industrial policy. Their activity in this respect is limited to easing the most acute tensions. They either temporarily rescue the largest enterprises from going under (the recent "industrial policy" of Hungary) or help to defer the unraveling of the collapse of a large number of business (for example, the decisions of the former CSFR government to postpone, in fact several times, putting into force the adopted bankruptcy regulations).

Public disappointment with unfavorable effects of trade liberalization is slowly, but continuously growing. The fractional account about the resistance to current forms of trade regulations given in this chapter has not brought extremely bad news. Attempts at modifying the existing rules for the protection or benefit of particular groups are normal events in a civil society. The interest groups involved are so far not very strong (excluding the largest foreign investors), and governments in the three countries are committed to supporting free trade. However, the number of signs of resistance is growing; populist and protectionist slogans may be welcomed by a broader group of the disappointed population. And governments in Eastern Europe are becoming vulnerable too. It seems better to reconsider the structure of policies related to trade liberalization now, and make the necessary corrections to achieve an endurable pace of restructuring, than to face the threat of major reversals in the process of liberalization later.

\section{References}

Aghevli, B.B., Borensztein, E., and van der Willigen, T. (1992) Stabilization and Structural Reform in the CSFR: An Assessment of the First Stage, IMF Working Paper (Washington, DC: International Monetary Fund).

Asselain, J. (1991) "Convertibility and economic transformation," European Economy, No. 2.

Bhagwati, J.N. (1978) Anatomy and Consequences of Exchange Control Regimes, Ballinger for the National Bureau of Economic Research (Cambridge, MA: Ballinger).

Borszéki, Zs. (1991) Tariff Bargaining 1990-1991 (in Hungarian), Mimeo (Budapest: Institute of Economics, Hungarian Academy of Sciences). 
Borszéki, Zs., Fölsz, A., Jánszky, Á., and Oblath, G. (1992) The System of Institutions and Control of Hungarian Foreign Trade in Relation to the EC Association Agreement: Facts, Possibilities and Tasks (in Hungarian) (Budapest: Association of Unified Europe).

Central Statistical Office (1992) Magyar Statisztikai Zsebkönyv 1991 (Pocketbook of Hungarian Statistics 1991) (Budapest: Central Statistical Office).

Charap, J., Dyba, K., and Kupka, M. (1992) "The reform process in the CSFR: An assessment of recent developments and prospects for the future," Communist Economies and Economic Transition, Vol. 4, No. 1.

Foreign Trade Research Institute (1991) Polish Foreign Trade in 1990 - Annual Report (Warsaw: Foreign Trade Research Institute).

Foreign Trade Research Institute (1992) Polish Foreign Trade in 1991 - Annual Report (Warsaw: Foreign Trade Research Institute).

Gács, J. (1980) Import Constraints, Shortages and Enterprise Adjustment (in Hungarian) (Budapest: Institute for Economic and Market Research).

Gács, J. (1990) "Liberalization of trade in reformed centrally planned economies: the case of Hungary," Paper Presented at the Fifth Annual Congress of the European Economic Association, Lisbon, 31 August-2 September 1990.

Gács, J. (1991) "Foreign trade liberalization (1968-1990): Hungary's experiences and policy options," in A. Köves and P. Marer (eds.) Foreign Economic Liberalization: Transformations in Socialist and Market Economies (Boulder, CO: Westview).

Gács, J. (1992) "Trade penetration between Hungary and the European Communities," Paper prepared for the Commission of the European Communities (IIASA: Laxenburg, Austria).

Havrylyshyn, O., and Tarr, D. (1991) "Trade liberalization," in P. Marer and S. Zecchini (eds.) The Transition to a Market Economy - Special Issues (Paris: OECD).

Hrnčír, M., and Klacek, J. (1991) "Stabilization policies and currency convertibility in the CSFR," European Economy, Special Edition, No. 2.

Klacek, J. et al. (1991) Economic Reform in the CSFR - Current Evaluation (Prague: Institute of Economics of the Czechoslovak Academy of Sciences).

KOPINT-DATORG (1993) Konjunktúrajelentés (Report on Business Tendencies) (Budapest: Institute for Economic and Market Research and Informatics).

Köves, A., and Marer, P. (eds.) (1991) Foreign Economic Liberalization: Transformations in Socialist and Market Economies (Boulder, CO: Westview).

Krueger, A.O. (1978) Liberalization Attempts and Consequences, Ballinger for the National Bureau of Economic Research (Cambridge, MA: Ballinger).

Kupka, M., Tuma, Z., and Zielenec, J. (1992) Macroeconomic Developments in East-Central Europe: Czechoslovak Survey (Prague: The Center for Economic Research and Graduate Education).

Marsh, D. (1992) "Central Europe surveys an imperfect pact," Financial Times, 11 May. 
Michaely, M., Papageorgiou, D., and Choksi, A.M. (eds.) (1991) Liberalizing Foreign Trade: Lessons of Experience in the Developing World, Vols. 1-7 (Cambridge, MA: Blackwell).

Mladek, J. (1992) Survey of the CSFR Economy in 1991, Manuscript (Prague: Ministry of the Economy).

Nagy, A. (1991) The Methods and Impact of Import Liberalization: A Summary (in Hungarian) (Budapest: Institute of Economics, Hungarian Academy of Sciences).

Oblath, G. (1991a) "Trade policy recommendations: Hungary's experiences and policy options," in A. Köves and P. Marer (eds.) Foreign Economic Liberalization: Transformations in Socialist and Market Economies (Boulder, CO: Westview).

Oblath, G. (1991b) "Limits, success and questions marks of the Hungarian import liberalization," (in Hungarian) Külgazdaság, No. 5.

OECD (1991) Czech and Slovak Republic: OECD Economic Surveys, Center for Co-operation with European Economies in Transition (Paris: OECD).

Rosati, D. (1991) "Institutional and policy framework for foreign economic relations in Poland," in M. Kaser and A.M. Vacic (eds.) Reforms in Foreign Economic Relations of Eastern Europe and the Soviet Union, Economic Commission for Europe (New York: United Nations).

Szamuely, L. (ed.) (1989) Opening to the World Economy: A Turn in the Economic Policy and a Reform of the Institutional Setup (in Hungarian) (Budapest: Közgazdasági és Jogi Könyvkiadó).

Török, Á. (1992) "Means of industrial protection in structural adaptation" (in Hungarian), Külgazdaság, Nos. 3-4.

UN ECE (1991) Economic Bulletin for Europe, Vol. 43 (New York: United Nations).

UN ECE (1992) Economic Survey of Europe in 1991-1992 (New York: United Nations).

Williamson, J. (1991) The Economic Opening of Eastern Europe (Washington, DC: Institute for International Economics). 


\section{Comments on János Gács's Paper}

\section{Giovanni Graziani}

The paper addresses a very interesting topic and highlights often neglected problems. The author does not deal with the much-debated question of the proper sequencing of reforms and the correct place of it in trade liberalization. He seems to imply that trade openness is a good thing and outward-oriented policies are in the long run positively connected with growth.

The objective of the investigation is the process of trade liberalization per se, its main features, and its effects on the domestic economy of the CSFR, Hungary, and Poland. This last undertaking is particularly difficult, given the limited time span since the inception of the process.

The gist of the argument is the following. The liberalization process was undertaken at a much speedier pace in these countries than in many less developed countries (LDCs). In the first year, positive effects seemed to prevail, although import penetration caused a certain displacement of domestic production. Since then a growing disappointment has started to set in, causing inter alia new requests from domestic and foreign investors alike for protection. According to Gács, the whole process was not well planned. There was first a lack of tariff adjustment to compensate for the abandonment of quantitative restrictions. Furthermore, exchange rate management was planned only for the short term, not cushioning the effects of the real.appreciation of the currencies in the ensuing period. Finally none of the governments embarked with a well-elaborated industrial policy. Let me take briefly each point in turn, before evaluating his conclusions.

As for the impact of trade liberalization and import penetration on domestic production, it is certainly very hard to calculate exactly these effects, especially in periods when other factors like restrictive policies and the collapse of the CMEA market are at work. The author presents in Table 5.2 some calculations on the shifts between the sources of domestic supply of five Hungarian industrial sectors which showed the most rapid pace of import penetration. The results are contradictory. In the first year (1989) the share of domestic production actually decreases together with the share of imports from the former CMEA (with the exception of footwear in the latter case). This does not happen for three of the sectors in the second year (1990), but there is a generalized contraction of imports from former CMEA countries. The evidence seems then to go beyond the author's own conclusions. Import penetration from the West appears to have crowded out imports from the former CMEA more than domestic production. Coupled with other available evidence from the other two countries, one could conclude that trade liberalization and import competition were only a concurrent cause, and probably not the main one, in the drop of domestic production and its crowding out. One could also suppose that the fall of production in the net importing sectors was compensated by the expansion of the net exporting sectors. Paradoxically, however, import penetration might become a more important factor in displacing industrial subsectors, now that 
some of the shocks at work, like the collapse of the CMEA, have elapsed and the fall of GDP seems to have halted.

As for the lack of tariff adjustment, there is a point here. But there is even more to it. Not only were the levels of tariffs right after the liberalization not exceedingly high, taking into account the extremely fast process of dismantling quantitative restrictions, but also there existed an inequality of protection between the three countries and their main partner, the EC. Weighted average tariffs in 1991 were actually higher in the EC, in the case of both the CSFR (6.8 percent compared with 4.7 percent) and Hungary ( 7.3 percent compared with 6 percent). Only Poland presented an average tariff rate well above the EC one (13.6 percent compared with 6.3 percent). But even this gap is more than compensated by the huge weight of nontariff measures (NTM) characterizing the EC at that time, especially in the most sensitive sectors. Let us just recall that the share of imports into the EC covered by NTM was 39.7 percent from Hungary, 32.5 percent from the CSFR, and 26.6 percent from Poland.

This missed opportunity for using import liberalization as grounds for renegotiating tariffs with trade partners, coupled with insufficient exchange rate management in the light of the real appreciation of the currencies, is largely responsible, according to the author, for the resurgence of activity of pressure groups demanding increasing protection. Here many interesting examples are provided, coming from both domestic and foreign producers operating in loco.

Some final words on the question of industrial policy, the lack of which, according to the author, would also be responsible for the ill-preparedness of the trade liberalization path. We all know that the phrase "industrial policy" has many meanings, so the concept might become rather elusive. In the case of the transitional economies, we are not talking very seemingly of picking up the strategic industries, even admitting that this were possible. What is at stake is probably trying to save those sectors which, for various reasons, are unprofitable at world prices, but still produce a positive value added, while letting go bankrupt those that present a negative value added. One should, however, remember that even the picking-up of the viable industries presents the well-known problems of arbitrariness, political intervention, lobbyism, and the like. The only thing one can safely say is that, were a support scheme decided upon, this should be preferred to nontariff measures. Naturally this kind of temporary protection would not be effective if there was not an active policy in the field of education, $R \& D$, infrastructure, and worker retraining. But on the whole it remains true, as the author says, that the governments should think about these issues in a clearer and more attentive way now, instead of running after the wishes of the different pressure groups in a chaotic way which might endanger the very process of liberalization. 



\section{Chapter 6}

\section{Changing Trade Patterns and Industrial Policy: The Case of Poland}

Dariusz K. Rosati*

\section{Introduction}

Transformation and reforms in East European countries in transition (CIT) have brought about profound changes in the trade and industrial structures of these economies. Trade with traditional partners within the CMEA grouping declined sharply, while trade with developed market economies expanded. Many industrial sectors and branches, specializing for decades in exports to the former Soviet Union and other socialist countries, have seen their traditional markets shrinking rapidly. At the same time, reorientation of trade toward the West appears to be more difficult and more painful than initially expected. In this context, the governments in transition countries have been faced by important policy dilemmas concerning ways and means of intervention in the process of structural change, in order to minimize costs of adjustment.

*The author wishes to acknowledge helpful comments received on earlier drafts from János Gács, Miroslav Hrnčíí, and Mario Nuti. 
This paper discusses four broad groups of issues. Firstly, it looks into the changes in the trade pattern of Poland and presents early results of trade and industrial restructuring over the period from 1989 to 1991. Secondly, it discusses the limitations of liberal trade regimes in countries in transition. Thirdly, the paper draws lessons from the Polish experience in rapid trade liberalization. In the last section it offers some general observations on the optimal pattern of trade policies in the transition from central planning to a market system.

\section{Change in the Trade Pattern}

\section{Internal and external shocks}

European economies in transition have remained in deep recession since 1990, with output levels falling steeply and unemployment levels rising. The recession is generally considered to be an outcome of a confluence of many external and internal factors, with stabilization programs, systemic reforms, and various, mostly unfavorable international developments being responsible for most of the fall.

Economic reform programs undertaken in CIT in 1990 and 1991 included two broad initiatives. First, and typically, a stabilization package was introduced at the outset of the reform, aimed at stopping inflation and restoring macroeconomic equilibrium, chiefly through drastic cuts in budget expenditures, monetary and credit restraint, incomes controls, and devaluation of the domestic currency. This was accompanied by institutional reforms, aimed at replacing the central planning system by a market system, through sweeping price and foreign trade liberalization, large-scale privatization, and the revamping of legal frameworks for economic activities. Both initiatives had strong contractionary effects, because they sharply reduced real incomes and expenditures and changed domestic price structures, thus rendering many economic activities unviable.

Among the external factors, the demise of CMEA trade and payments arrangements and the collapse of the Soviet economy are commonly cited as most important. The negative impact of the collapse of the CMEA foreign trade of East European countries was certainly not unexpected, although the magnitude of such a fall in trade had not been foreseen. It was widely assumed that the change of the trade system would immediately result in a sharp increase of the relative prices of commodities, such as energy, fuels, and raw materials, and a sharp decline of trade in industrial goods within the 
CMEA. The Soviet Union, as the only large net exporter of commodities in the region, was supposed to be the main gainer (and perhaps the only one), while other countries were expected to incur large trade deficits vis-à-vis the Soviet Union. Of course, the economic rationale for the reform was that, in the long run, all countries involved were to gain from a better allocation of resources and mutually beneficial trade based on principles of comparative advantage. In the short run, however, substantial transition costs were expected, raising serious concern about the ability of East European economies to adjust to the new external environment.

The fall of Eastern trade resulting from the demise of the CMEA worked through three main mechanisms. First, the deterioration of East European terms-of-trade led to a decline of imports from the Soviet Union. Second, the shift to convertible currencies and elimination of ruble-clearing reduced sharply trade possibilities because of the acute shortage of convertible currencies in the region. Third, decentralization and liberalization of foreign trade regimes opened much wider possibilities for trade diversion from East to West.

But apparently even more important than the demise of the CMEA have been the consequences of the economic and political disintegration of the Soviet Union. The Soviet economy has been deteriorating for several years, and the recession was accelerated by the precipitate dismantling of central controls which were not replaced by any efficient market mechanism. Inconsistent and hesitant reforms were unable to stop inflation and alleviate massive shortages. The shift to convertible currency settlements in trade with former CMEA members came at the time when Soviet foreign balance worsened substantially, and the access of Soviet enterprises to hard currencies became more and more difficult. Limited payments possibilities, a chaotic system of foreign exchange allocation, falling output, and the opening up of new trade opportunities with the West all produced a sharp decline of imports from East European countries.

Because of numerous statistical and data problems, Eastern trade developments have always been a slippery area for trade analysts. The year 1992 was no exception in this respect: even though the elimination of the transferable ruble from mutual trade settlements and the shift to world market prices in 1991 liquidated the most pervasive distortions which were characteristic for previous periods, new problems have emerged, connected mainly to the formation of new states and with changes in systems of statistical reporting in transition countries. As a result, trade statistics for 1991 and 
1992 are incomplete and difficult to interpret. ${ }^{1}$ Nevertheless, the massive fall of trade appears unquestionable, and may range from 50 to 60 percent in volume terms over 1991 and 1992 (UN ECE, 1992).

\section{Structural change: Statistical evidence}

Policy-induced and exogenous shocks experienced by CIT between 1990 and 1992 have had a strong impact, not only on the aggregate trade levels, but also on the territorial and commodity composition of trade flows. Generally, domestic recession reduced import demand and contributed to export expansion, as domestic producers sought new outlets abroad. Sharp devaluations of domestic currencies against convertible currencies provided strong incentives for increasing export sales to Western markets. The demise of CMEA arrangements eliminated preferences for Eastern trade, and worked as a customs union mechanism $\dot{a}$ rebours, producing trade contraction within the region and trade diversion to the outside world. The collapse of Soviet markets further exacerbated the need for East European firms to restructure trade toward the West. In sum, one would expect a sharp fall of trade among CIT, an expansion of trade with market economies, and an important change in the commodity composition of trade.

Data on the territorial structure of Polish trade generally confirm this observation. A pronounced shift in the territorial structure of Polish manufactured trade in favor of Western countries has been documented. ${ }^{2}$ The share of OECD countries in Polish manufactured exports increased from 42.4 percent in 1988 to 73.9 percent in 1991 , while the share of CMEA countries diminished from 41.1 percent to 16.7 percent, respectively. The shift in the territorial structure of manufactured imports was equally substantial: the OECD share in Polish imports rose from 50.5 percent in 1988 to 78.9 percent in 1991 , and the CMEA share declined from 35.6 percent to 10.8 percent.

\footnotetext{
${ }^{1}$ Problems with aggregation of ruble- and dollar-trade flows plagued statistical analysis of intra-CMEA trade in 1991. In 1992, many countries stopped publishing data on the territorial structure of trade, being unable, apparently, to cover appropriately trade transactions carried out by the rapidly growing private sector. The introduction of SAD (single administrative document) as the only source of statistical information on trade has come only with great difficulties, and many errors in reporting have been signaled by statistical services in the countries concerned (Poland, Czechoslovakia). More important, the shifts in statistical reporting rules have inevitably reduced the comparability of 1992 figures with data from previous periods, while endless revisions and corrections made by statistical services in transition countries in the course of 1991 and 1992 suggest that the possibility of errors remains imminent.
}

${ }^{2}$ The following discussion concentrates on Polish trade in manufactures. 
Also, the share of the rest of world (ROW) diminished from 16.4 percent to 9.5 percent in exports and from 13.9 percent to 10.3 percent in imports between 1988 and 1991. The dominating position in Polish trade has now been assumed by the EC countries, with their share in Polish exports having increased from 28.1 percent to 55.2 percent, and in Polish imports from 32.7 percent to 57.9 percent between 1988 and 1991 .

The pattern of change is, however, less clear in the case of commodity structure. Data on the evolution of industrial structure of the Polish economy during the transition from central planning to a market system reveal that a major structural adjustment has been under way. Changes in sectoral shares of output and employment have been assessed at NACE 2-digit aggregation level (21 sectors of manufacturing industry). (NACE is the system of statistical classification of economic activities in the European Community.) The main "losers" were electro-engineering, textile, clothing, leather, and footwear industries (NACE groups 31-37, 43-45), while the "winners" included such sectors as metal-processing, food-processing, wood, and paper industries (NACE groups 41/42,21, 24-25). Generally, the shift away from heavy and engineering industries to industries based on natural resources could be observed.

The evolution of the industrial structure has largely been reflected by the corresponding changes in the structure of trade with CMEA countries. As shown in Tables 6.1 and 6.2, engineering products, which had accounted for more than half of Polish exports to CMEA countries, were particularly affected: the share of mechanical engineering (NACE 32) declined from 31.1 percent to 18.4 percent, the share of electrical engineering (NACE 34) declined from 12.9 percent to 8.3 percent, the share of office machines and data processing (NACE 33) declined from 6 percent to 3.6 percent, and that of instrument engineering (NACE 37) declined from 4.1 percent to 1.7 percent. Very similar was the pattern of change in manufactured imports: the combined share of NACE groups 32-37 dropped from 58.5 percent to 42.5 percent, and if transport means are excluded (NACE 35), the fall was even more dramatic (from 50 percent to 29.5 percent).

Among the sectors which significantly increased their shares in exports to CMEA were mostly chemical industries (NACE 25, from 10 percent to 20.9 percent) and food processing (NACE 41/42, from 2.6 percent to 8.6 percent); but in absolute terms exports from these sectors also declined, although at a slower pace than exports of electro-engineering products. 


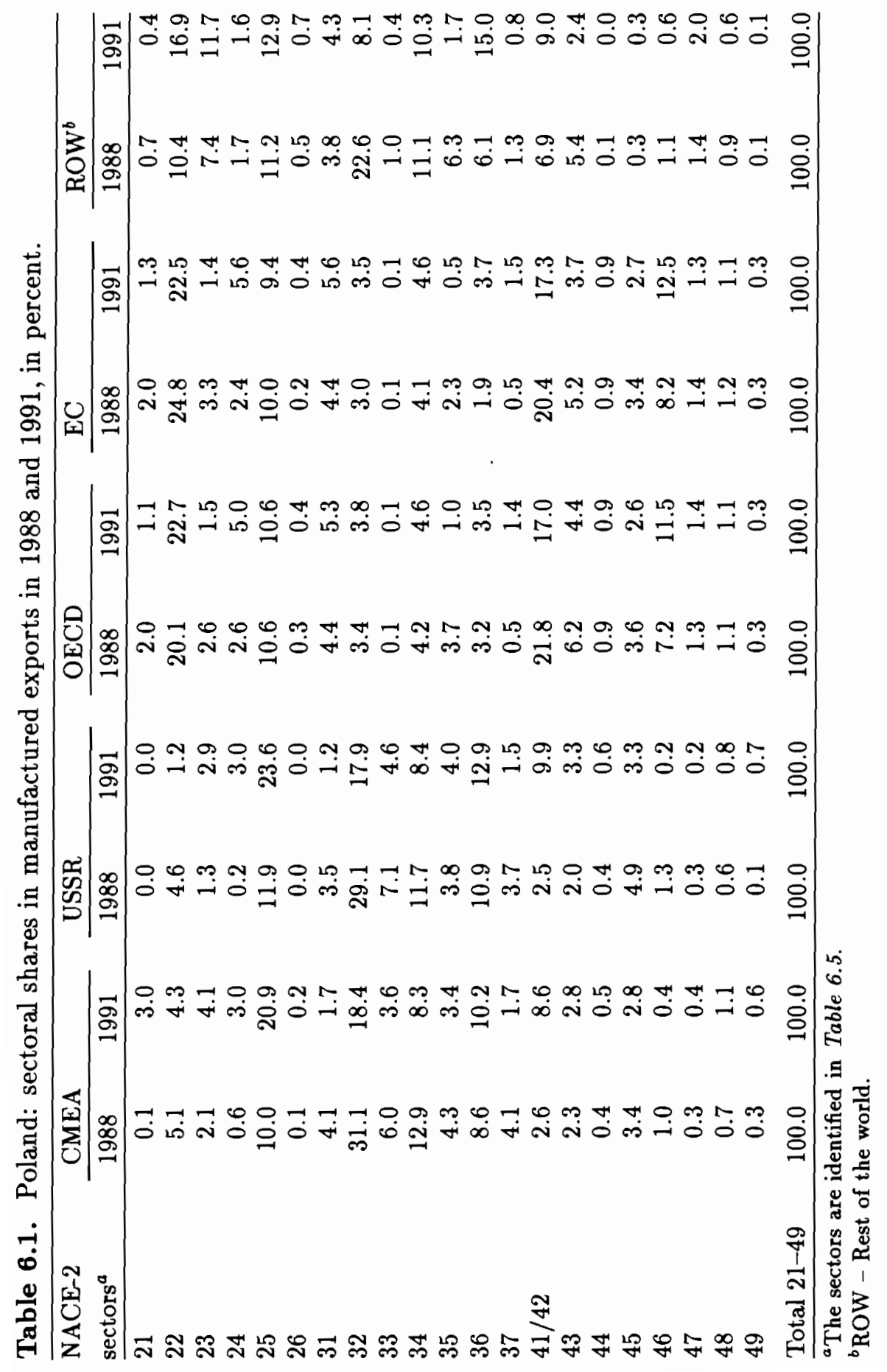




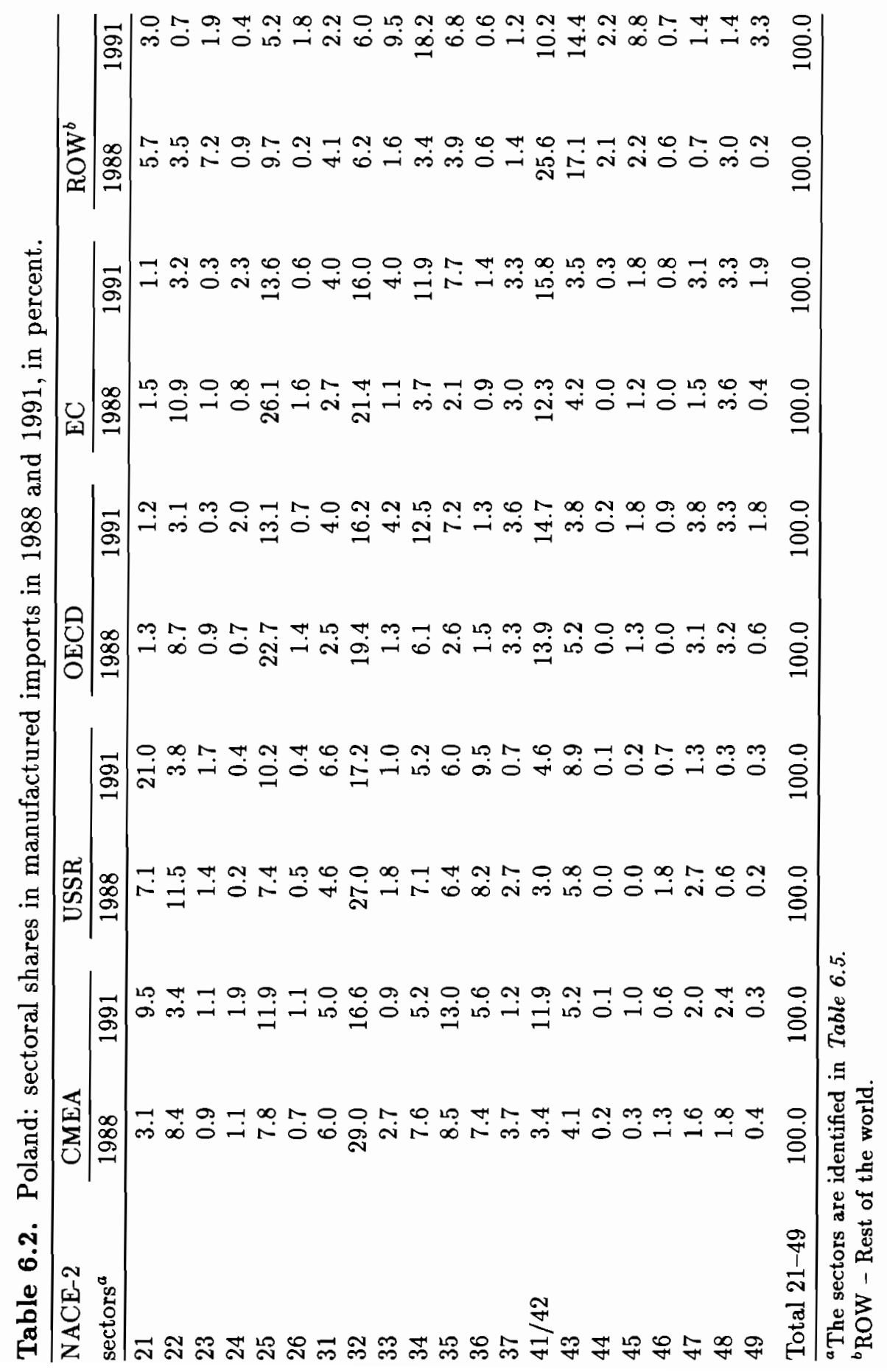


Table 6.3. Poland: correlation coefficients between the industrial structure and the export structure.

\begin{tabular}{llllll}
\hline & \multicolumn{2}{c}{ Exports to CMEA } & & \multicolumn{2}{c}{ Exports to OECD } \\
\cline { 2 - 3 } \cline { 5 - 6 } & 1988 & 1991 & & 1988 & 1991 \\
\hline Output shares in 1988 & 0.2486 & - & & 0.9014 & - \\
Output shares in 1991 & - & 0.3608 & & - & 0.7948 \\
\hline
\end{tabular}

Source: Own calculation, based on data from the Central Statistical Office of Poland.

By contrast, the changes in the commodity structure of trade with the OECD have largely been uncorrelated with the evolution of Polish industrial structure. As can be seen from Table 6.3, the commodity composition of exports to the CMEA changed in the same direction as the output structure (correlation coefficient between the two structures increased between 1988 and 1991), but the commodity composition of exports to the OECD seems to have moved in the opposite direction (correlation coefficient declined). An interesting observation which can be derived from Table 6.3 is that the OECD export structure was much more similar to the Polish industrial output structure than the CMEA export structure. This may suggest that exports to the CMEA were coming primarily from a few specialized sectors rather than from the economy as a whole, and that large areas of the Polish industry were integrated with CMEA markets only to a small degree.

It is interesting to see how the trade pattern with OECD countries has changed in recent years. A closer look at the statistics reveals that while Polish export expansion was indeed remarkable, the growth was essentially of an across-the-board character, with all industrial sectors increasing their sales to the West at broadly similar rates. In fact, the commodity structure of Polish exports to OECD countries changed only marginally during the period from 1988 to 1991. Regression of trade structures for 1988 and 1991 for particular trading areas revealed a much higher stability of OECD-oriented exports than CMEA-oriented exports (see Table 6.4). As in the past, the highest shares were taken by metal products, processed food, various chemicals, and timber and wood products, followed by textiles, clothing, and footwear. This observation is interesting and somewhat puzzling, because it suggests that neither the economic reforms nor external shocks have exerted any significant impact on the commodity composition of Polish exports to OECD countries. One possible explanation may be that trade with the West, being based on competitive market rules, always reflected the "true" comparative advantage of the Polish economy. At the same time, it may 
Table 6.4. Poland: correlation coefficients between the commodity structures of Polish exports in 1988 and in 1991, by trading areas.

\begin{tabular}{ll}
\hline Trading area & Correlation coefficient \\
\hline OECD, 1988/1991 & 0.9510 \\
EC, 1988/1991 & 0.9643 \\
CMEA, 1988/1991 & 0.7831 \\
USSR, 1988/1991 & 0.7847 \\
ROW, 1988/1991 & 0.6880 \\
\hline
\end{tabular}

Source: Own calculation.

also indicate that no significant trade diversion from the East to the West has taken place so far.

The pattern of specialization in trade between Poland and OECD countries has been examined with the use of trade coverage ratios, defined as the proportion of the country's imports of a given sector covered by the country's exports of the same sector (that is, the ratio of exports to imports). Sectors with the highest trade coverage ratios are assumed to be the areas of the country's revealed comparative advantage. The results of this exercise are shown in Table 6.5.

In exports to CMEA markets, Poland's specialization has remained strong in footwear and clothing, leather goods, and some branches of engineering (electrical and office machinery, ships, and instruments), while it has been further strengthened in mineral products. The pattern of specialization in trade with the OECD countries is clearly different; in fact, the two patterns do not display any similarity (the correlation coefficients between the two vectors of trade coverage ratios for 1988 and 1991 are -0.0426 and 0.0836 , respectively). Wide differences in coverage ratios for trade with the CMEA and the OECD suggest that there have been significant departures from Poland's pattern of comparative advantage in trade with CMEA, and cases of wrong specialization may have been common.

In trade with OECD countries, Poland tends to specialize in two broad categories of products: natural resource-based products, such as metals, wood products, minerals, building materials, foodstuffs, and coke, on the one hand, and low-technology manufactures, such as clothing, footwear, and leather products, on the other. Both categories have some common characteristics: their output is relatively unprocessed, they rely on traditional technologies, demand for their output is relatively income-inelastic, and they face strong competition from developing countries. As a result, the manufacture value-added potential of these sectors is limited. An important 
Table 6.5. Poland: trade coverage ratios, in trade with CMEA and OECD countries, by industrial sectors, 1988 and 1991 (NACE-2 classification).

\begin{tabular}{|c|c|c|c|c|}
\hline \multirow{2}{*}{$\begin{array}{l}\text { NACE-2 } \\
\text { sector }\end{array}$} & \multicolumn{2}{|c|}{ CMEA } & \multicolumn{2}{|l|}{ OECD } \\
\hline & 1988 & 1991 & 1988 & 1991 \\
\hline 21 Metalliferous ores & 0.05 & 0.42 & 1.39 & 0.74 \\
\hline 22 Production and processing of metals & 0.75 & 1.70 & 2.08 & 6.03 \\
\hline 23 Minerals (except fuel and metals) & 2.82 & 4.94 & 2.70 & 3.82 \\
\hline 24 Manufacture of nonmetallic minerals & 0.68 & 2.16 & 3.19 & 1.99 \\
\hline 25 Chemical industry & 1.58 & 2.37 & 0.42 & 0.66 \\
\hline 26 Synthetic fibers & 0.25 & 0.24 & 0.16 & 0.40 \\
\hline 31 Manufacture of metal articles & 0.84 & 0.45 & 1.60 & 1.09 \\
\hline 32 Mechanical engineering & 1.33 & 1.50 & 0.16 & 0.19 \\
\hline 33 Office machinery, data processing & 2.78 & 5.24 & 0.07 & 0.02 \\
\hline 34 Electrical engineering & 2.10 & 2.14 & 0.62 & 0.30 \\
\hline 35 Motor vehicles and parts & 0.62 & 0.35 & 1.25 & 0.11 \\
\hline 36 Other means of transport & 1.44 & 2.44 & 1.94 & 2.14 \\
\hline 37 Instrument engineering & 1.38 & 1.85 & 0.15 & 0.31 \\
\hline 41/42 Food, drinks, and tobacco & 0.96 & 0.98 & 1.41 & 0.94 \\
\hline 43 Textile industry & 0.69 & 0.72 & 1.07 & 0.95 \\
\hline 44 Leather and leather products & 2.44 & 5.98 & 27.18 & 2.87 \\
\hline 45 Footwear and clothing & 13.22 & 3.74 & 2.42 & 1.19 \\
\hline 46 Timber and wood & 0.97 & 0.87 & 137.73 & 10.08 \\
\hline 47 Paper products & 0.22 & 0.30 & 0.37 & 0.31 \\
\hline 48 Rubber and plastics & 0.47 & 0.60 & 0.31 & 0.26 \\
\hline 49 Other manufactures & 0.92 & 2.61 & 0.49 & 0.13 \\
\hline
\end{tabular}

Source: Own calculations, based on data of the Central Statistical Office of Poland.

implication of this characteristic is that, ceteris paribus, growth based on such an economic structure may be expected to be slower than in OECD countries. Moreover, the evolution of this pattern of exports may also be of some concern, if one takes into account the gradual decline of exports of such higher-technology goods as precision instruments, office and data-processing machinery, transport vehicles, and electrical machinery.

\section{Reorientation of trade from CMEA to OECD}

Expanding shares of trade with OECD countries and declining shares of trade with former CMEA countries would suggest that a strong trade diversion is taking place. If this is the case, it could be assumed that the production and skill potential accumulated in traditional CMEA-oriented sectors (mostly electro-engineering) will not simply be lost, but rather will be adapted to new 
markets. Unfortunately, the available statistical evidence does not support this hypothesis.

Empirical analysis of trade reorientation is an inherently difficult task, not only because of aggregation problems, but also because a method must be found to eliminate the "leakages" of exportables into the domestic market. One possible approach is to apply the so-called similarity coefficients, defined as the difference between unity and the sum of squared differences between sectoral export shares on two export markets. ${ }^{3}$ The numerical values of trade similarity coefficients are given in Table 6.6.

The results show a moderate increase of similarity between trade structures with the CMEA and the OECD countries between 1988 and 1991, and a small decline of similarity between CMEA countries and the rest of the world. However, the changes are small and the structural convergence seems to be very limited. Moreover, it should be noted that trade similarity coefficients are only indicators of structural convergence, not of the actual diversion of trade. Even if in most cases the two phenomena are linked together, there may be exceptions (if trade diversion takes place in sectors with a low relative share in exports, the similarity coefficient would decline, thus failing to reflect the actual diversion).

For this reason yet another measure of structural similarity has been used. It could be assumed that if export diversion takes place, the share in OECD-oriented exports of those sectors which dominated the commodity structure of CMEA exports in the past should subsequently increase. A correlation has been calculated between the vector of ratios of sectoral shares of exports to CMEA and OECD in 1988 and the vector of ratios of sectoral shares of exports to OECD countries in 1991 and $1988 .{ }^{4}$

${ }^{3}$ Analytically, the trade similarity index (TS) can be expressed as follows:

$$
T S=1-\sum_{i}[e(i, k)-e(i, l)]^{2}
$$

where $e(i, k)$ and $e(i, l)$ are shares of sector $i$ in total exports to markets $k$ and $l$, respectively. The index takes values between -1 and 1 , negative values only for extremely disparate structures.

"Analytically, the correlation between the following series has been computed:

$\frac{e[i(C), 8 B]}{e[i(O), 8 B]}$, and $\frac{e[i(O), 91]}{e[i(O), 88]}$

where $e[i(C),],. e[i(O),$.$] stand for export shares of sector i$ in total exports to the CMEA and the $O E C D$, respectively, for a given year. 
Table 6.6. Trade similarity coefficients for sectoral composition of exports, by main trading areas, in 1988 and 1991 .

\begin{tabular}{lll}
\hline Relationship & 1988 & 1991 \\
\hline CMEA and OECD & 0.8425 & 0.9038 \\
CMEA and EC & 0.8256 & 0.8979 \\
CMEA and ROW & 0.9783 & 0.9553 \\
\hline
\end{tabular}

Source: Own calculations.

However, no correlation has been found (correlation coefficient of 0.0016 ) between the two vectors, which may indicate that there is no "rapprochement" of trade structures of exports to CMEA countries in 1988 and to OECD countries in 1991. The results confirm that trade reorientation from CMEA countries to OECD countries has been weak, if at all.

The following conclusions can be drawn from the analysis of structural change. First, the change in industrial structure displays strong similarities with changes in the trade structure with CMEA countries. Second, the emerging comparative advantage of Poland seems to be located in the areas of traditional industries and natural-resource-based industries. Third, higher technology sectors, geared mostly to CMEA markets in the past, diminish their exports, both because of the collapse of Eastern markets and because of the lack of reorientation to Western markets. This pattern of "spontaneous" structural change may be the result, to a large extent, of the absence of stronger industrial and trade policies in the transition. This outcome does not have to be considered optimal, if the market mechanism is distorted or inefficient or externalities involved in vanishing sectors are large compared with costs of restructuring. If this is true, then there is a case for more active government policies.

\section{Liberal Trade Policy and Its Limitations}

\section{The "New Liberal Orthodoxy" and its roots}

A radical liberalization policy course adopted in Poland, as well as in some other CIT, is a direct outcome of an important evolution in mainstream economic thinking observed over the past 10 to 15 years. A new free market orthodoxy emerged in the early 1980s, resulting from dissatisfaction and critique of traditional economic policies, that for several decades were based on fundamental Keynesian ideas. 
On the theoretical front, the new orthodoxy was buttressed by the revival of monetarism, the theory of rational expectations and profit-maximizing agents, and, above all, by the theory of the second-best and the theory of domestic distortions. The last theory provided strong arguments against clumsy interventionism of politically motivated governments and for liberal economic policies.

The new ideas were quickly absorbed by international financial institutions (which also actively contributed to the new intellectual trend). The involvement of the IMF and the World Bank in supporting economic stabilization and guiding reform programs in developing countries in the $1980 \mathrm{~s}$ was based essentially on three main pillars: macroeconomic discipline, microeconomic deregulation and liberalization, and outward orientation. When asked for assistance to combat internal and external imbalances, the IMF invariably suggested drastic cuts in government spending in order to achieve fiscal and monetary balance, extensive price decontrol, devaluation of domestic currencies, and foreign trade liberalization (Williamson, 1992). These "orthodox" programs were in some cases supplemented by less-orthodox measures, such as wage controls or credit ceilings, if they were deemed to work in favor of macroeconomic stabilization.

It is not the purpose of this paper to make a comprehensive evaluation of the IMF-supported adjustment and stabilization programs. Suffice it to say that they were based on a solid economic logic and, in principle, their efficiency in bringing macroeconomic situations under control is undisputed. But it should also be noted that they probably suffered from excessive "shorttermism" and from not paying enough attention to structural impediments and sociopolitical conditions. Moreover, some crucial assumptions underlying the standard model of financial programming are increasingly seen as problematic (e.g., the constant velocity of money circulation or stable function of demand for money balances). This is probably why these programs, although conceptually sound and internally consistent, were aborted or failed in so many countries.

It was quite natural that essentially similar stabilization-cum-reform programs have been adopted in the CIT. Not only did the mainstream economic policy thinking and the unquestionable reputation of the IMF play an important role, but the programs also fitted perfectly well into the social and political reality of the East European countries. Disastrous experience with central planning led to a generalized critique and wholesale rejection of government involvement in the economy, while high welfare levels achieved in 
developed Western economies provided a persuasive demonstration of the efficiency of the market mechanism. Finally, there was not so much choice after all: external financial assistance for CIT hinged on the adoption of the IMF-supported reform programs by these countries.

\section{Important qualifications}

A liberal trade regime is not an aim in itself, but rather is considered an important tool used to promote economic development. But should it be taken for granted that trade liberalization is always and everywhere a good thing? There seems to be a consensus among experts in economics that higher and more equitable economic growth tends to be associated with a higher growth of exports, and that more outward-oriented trade policy gives better trade performance in terms of export expansion and external balance (see, e.g., Krueger, 1978; and Edwards, 1989). There is also wide agreement that transparent measures are generally more effective than administrative, discretionary policies. But there are continuous controversies about whether the neutrality of incentives should be achieved through import liberalization, i.e., reduction of protection measures, or be done instead via compensatory export-promotion measures (Havrylyshyn and Tarr, 1991). Similarly, the issues of the optimum sequencing of trade liberalization are not entirely clear. While it is relatively simple to establish theoretical links between liberal trade regimes and improved economic performance, it is more difficult to support these links with consistent empirical evidence that demonstrates beyond a doubt the causal relationship existing between trade liberalization and economic growth. ${ }^{5}$

While the benefits of free trade have strong theoretical underpinnings, empirical evidence is less sanguine. Extensive studies, made mainly under the aegis of the World Bank, confirm many of the theoretical conclusions; and yet, many countries which started liberal reforms, failed to improve economic performance and eventually retreated from the reform track (Balassa, 1971; Krueger, 1978; Papageorgiou et al., 1990). This may suggest that while trade liberalization as a general policy orientation is most probably a good thing, the ways and means of its implementation are not as universal as

\footnotetext{
${ }^{5}$ It should be noted, however, that a vast body of empirical literature supports the view of the existence of a close causal relationship between trade liberalization and the rate of economic development. But these conclusions are typically drawn on the basis of large samples of liberalization episodes observed in various countries during various periods and have a stochastic rather than a deterministic character.
} 
many believe, and should differ according to specific conditions in individual countries.

The recognition of the significance of different local conditions means, however, that the theoretical validity of the obtained conclusions may also be limited. It is not the logic of the free-trade argument which comes into question, but rather the standard assumptions underlying the theoretical analysis of gains from trade, and especially the general equilibrium model, which has been the main driving force behind normative thinking in the area of economic policy. Three assumptions seem to be of special importance in this regard, because they are very unlikely to be fulfilled in the context of the economies of the CIT. First, the assumption of competitive markets with profit-maximizing agents and perfect information is clearly much further from reality in CIT than in Western countries. Second, externalities are significant, and should not be ignored. Third, the income distribution aspect is an important self-imposed constraint on the speed and scope of reforms in CIT.

Perhaps the most important assumption is the competitive markets postulate. How does it affect the analysis of trade liberalization effects? Take the simplest case of the removal of a tariff. The ensuing price effect reduces profitability of import-substitution activities and drives out the least efficient producers. Released resources are assumed to shift to export sectors, where profitability increases. This is simply a structural adjustment, evoked by a combination of demand and supply factors.

But for this adjustment to take place, several things have to happen. First, output has to decrease and unemployment must increase in importsubstitution sectors. This should be accompanied by a fall of real factor incomes in these sectors, which would induce factor owners to move to other sectors. But the redeployment can be done, in principle, only through new investment, which may be quite substantial if the reallocation is on a massive scale. For the new investment to materialize, capital resources have to be transferred because self-financing would be insufficient. For the capital to be transferred, not only future prospects of profits have to be attractive enough, i.e., the net present value of new projects must be substantially positive after allowing for the risk factor, but also reasonably efficient capital markets have to be in operation. In the meantime, the work force would have to be reallocated, which would require a reasonably flexible labor market. Moreover, unemployment effects have to be contained through an efficient social safety net. In short, for the adjustment mechanism to work efficiently 
three things are needed: time, money, and market institutions. But none of them are in sufficient supply in CIT.

\section{Specific conditions in the CIT}

The scope of the transformation in Eastern Europe obviously goes above and beyond any reform attempts in the postwar world history. Latin American experience, so influential in shaping the new liberal orthodoxy, has been limited mostly to macroeconomic stabilization, market deregulation, and reduction of the public sector. Similarly, the celebrated German reform of the late 1940s consisted essentially of removing widespread distortions from the economy, but its institutional dimension was relatively limited. Nevertheless, it took years for these changes to yield expected results.

Emerging from the socialist era, CIT differed from other reforming nonsocialist economies in many important respects. They differed even more from developed market economies. Their most fundamental differences concerned structural and institutional characteristics.

Unlike in the Western countries, the private sector in the CIT was almost nonexistent. The share of the private sector in GDP in the mid-1980s varied from some 20 percent in Poland (where the bulk of it was in agriculture) to less than 3 percent in the USSR, Bulgaria, and Czechoslovakia, and its share in industrial output was generally even lower. The domination of state firms in industry resulted in a distorted structure of incentives and, subsequently, in a distorted and perverse pattern of responding to market signals and macroeconomic policy measures. Specifically, state firms' behavior has not been of a profit-maximizing character, but rather has been driven by employment and wage considerations. Under such conditions, adjustment is sluggish and not necessarily economically efficient.

Industrial structure in CIT was geared for many years to the needs of the huge and uncompetitive Soviet market. It was also shaped by specific priorities in economic policy, concentrated in military and heavy industry sectors. At the same time, the service sector in CIT was weak and underdeveloped. The key implication of this structural bias is that the scope of required reallocation of physical and human resources is much larger than in other reforming countries. This means that for the necessary adjustment to take place in CIT more funds and more time are needed.

The well-known feature of Soviet-type economies is their high degree of monopolization - a direct consequence of central planning. The response of 
monopolistic firms to market signals is typically perverse, and possibilities of breaking up the monopolies and establishing competitive markets from "within" are limited in the short run.

Finally, marketing and management skills, necessary to operate in a market environment, are in short supply in the former centrally planned economies; while they can eventually be acquired either through imports of managers and/or foreign firms or by a "learning-by-doing" process, neither can be done overnight. Coincidentally, once the economy opens up to international markets, a large part of the human capital accumulated in industrial sectors becomes obsolete and needs to be retrained.

Institutional differences are no less important. Price structures in centrally planned economies, being a result of widespread price controls and continuous isolation from international markets, displayed many distortions and differed considerably from relative prices prevailing in market economies. The relative price shock, resulting from general price liberalization and realignment, drastically changes patterns of profitability in the economy. A legal framework for market mechanism is only in statu nascendi in such essential areas as property rights, enforcement of private contracts, bankruptcy laws, banking system, taxes, and customs control. Capital and labor markets are rudimentary and in most CIT have to be built from first principles. This is a major impediment to resource mobility, which in turn is absolutely necessary for structural adjustment. Important, too, are the different habits and mentality of East European societies, which were, for decades, accustomed to job security, egalitarian income structure, and generally slack work discipline. The transformations, however, require exactly the opposite: jobs may be lost, large income and wealth inequalities are inevitable, work effort and productivity will have to increase. To change this "socialist" (or Homo sovieticus) mentality will take some time, and the process of acquiring new ethical and work standards may cause continuous social unrest.

This sketchy review is not meant to give the full characteristics of the "distorted world of Soviet-type economies" (as expressed by J. Winiecki); it simply intends to recall that the real situation in CIT is quite different from those in market economies. The necessary adjustments may be expected to assume considerably larger proportions because the change in relative prices is indeed dramatic, and the structural distortions inherited from the communist past must be considered significant.

New investments on the scale required will be difficult to obtain, because of limited amounts of capital in those countries. Restrictive macroeconomic 
policies followed in CIT in 1990 and 1991 reduced the levels of domestic demand, thus diminishing prospects for future profits and business confidence. They also made domestic credit relatively expensive and difficult to obtain. Furthermore, capital markets are underdeveloped and an efficient mechanism for transferring even the limited savings to the production sector has not yet been developed. Most important, however, is the risk factor: not only are the economic prospects of these countries uncertain, but the social and political situations are becoming less and less stable. ${ }^{6}$

This is clearly a market failure case: under such conditions, necessary capital transfers would simply not materialize. Not only will the time span needed for the adjustment have to be extended, but the adjustment costs will be much higher. Sectors, which could potentially be viable under efficient markets, will probably disappear altogether. A large proportion of physical and human capital resources, which otherwise would be effectively redeployed, will be irrevocably lost. The costs will be particularly substantial in manufacturing (and especially high-technology) industries, where the need for restructuring is greatest and where massive and prolonged unemployment may lead to an irreparable loss of skills through the "hysteresis" effect. These are important externalities, which so far tend to be disregarded or belittled in the designing of economic policies in CIT.

\section{Implications for trade policy}

Limitations of the traditional model of gains from trade and the specific, unfavorable conditions of CIT call for a more careful application of liberal policies in Eastern Europe. While these observations do not generally question the need for transparency and neutrality of trade policies, they suggest that the opening of the economy should perhaps not be too abrupt, because adjustment possibilities in CIT are much more limited than in market economies. If this is the case, then active trade policies should not be totally forsaken, but rather should be applied - in a limited scope - to achieve a strengthening of the market mechanism wherever it is too weak and to correct it wherever it is significantly distorted.

\footnotetext{
${ }^{6}$ Social instability and fragility of political structures have been repeatedly demonstrated in such countries as Poland, Romania, Bulgaria, and Russia. In Czechoslovakia, where the transformation had started in a climate of remarkable national unity, the split into two separate states was largely prompted by unexpectedly high costs of economic reforms and the uneven distribution of these costs between the two republics. Even in Hungary the political situation deteriorated in 1992 .
} 
Of course, the possibility of government failure cannot be excluded either. With still-distorted prices in the CIT it is difficult to determine a priori the areas of comparative advantage and to pick up "winners" in terms of sectors, branches, or individual firms; besides, the danger of favoritism, corruption, and rent seeking is still considerable in CIT. At the same time, however, democratically appointed governments may be assumed to be less prone to these dangers than were totalitarian governments. A suggested solution would be to avoid a highly differentiated, made-to-measure protection structure, and to start rather with a uniform, moderate tariff on manufactures, lower (or zero) tariff on production inputs, and perhaps no quantitative restrictions. Ideally, this tariff structure should be accompanied by uniform export subsidies; but government budget constraints may make this option unfeasible. In any case, a competitive exchange rate and a large scope of current account convertibility are necessary conditions for a successful trade reform.

It is important to note that the conditions of CIT call for a "specific" package of trade liberalization measures. While enormous price distortions, monopolization, and market shortages provide clear arguments for an early opening to international trade, especially to imports, other factors such as the required scope of structural adjustments, low competitiveness, lack of market institutions, and high uncertainty provide arguments for temporary protection. It is, however, essential for the adjustment mechanism to be set in motion as early and as efficiently as possible; hence, market signals should be strong and undistorted from the very beginning of transformation. But undistorted prices and competition cannot be established internally overnight, because of high monopolization, weakness of domestic markets, and sluggish response of the state sector. The only possibility is, therefore, to "import" correct relative prices and competition from abroad. This requires the replacement of quotas and administrative restrictions by tariff measures, because the tariffs do not blunt the spur of competition, and the removal of the notorious import-substitution bias in the structure of protection. This also means the elimination of most binding restrictions on currency convertibility and the introduction of a transparent (i.e., marketbased) system of foreign exchange allocation, coupled with a neutral (i.e., neither undervalued nor overvalued) exchange rate.

By contrast, the opening of the economy - in terms of lowering import tariffs and export subsidies - will probably take some time. Large initial price differentials as compared with international markets and inherently 
slow adjustment responses in CIT call for a gradual removal of protection. A too-abrupt opening would result in a deep contraction and large-scale unemployment, and whole (potentially viable) industrial sectors would be wiped out of the economy.

Of course, the level of initial protection should not be too high either. After starting with broadly uniform (i.e., limited to a few rates) tariffs, ${ }^{7}$ the rates should gradually be scaled down within a predetermined schedule, which extends over five to seven years. ${ }^{8}$ Together with the competitive real exchange rate, this policy would provide incentives for export-oriented restructuring, and help in avoiding unnecessary adjustment costs. ${ }^{9}$

\section{Possible Lessons from the Polish Experience}

The analysis of the trade liberalization episode in Poland in 1990 and 1991 offers some interesting insights into the risks and benefits connected with radical liberalization. The evidence generally supports the view that trade liberalization is a necessary and important step in reforming the economies and has to be carried out at an early stage. However, it also highlights the risks if the wrong sequence of liberalization is instituted. The main lessons stemming from the Polish experience are summarized below.

First, contrary to earlier beliefs, the post-socialist economy displays a considerable degree of elasticity with regard to initial export expansion, if incentives are strong enough and the deregulation sufficiently large. The 40 percent growth of convertible currency exports in the year 1990 is a remarkable achievement by any standard. The export expansion continued in 1991, although its pace was much slower due to the collapse of CMEA markets and the appreciation of the zloty. Nevertheless, exports to nonCMEA markets increased in 1991 by 13 percent at current dollar prices, broadly offsetting the 60 percent drop of CMEA exports (in volume terms). Data for 1992 indicate that exports increased by 10 percent.

Second, the Polish experience demonstrates how rapidly a sustainable equilibrium can be achieved in the foreign exchange market after currency

\footnotetext{
${ }^{7}$ A specific system of agricultural protection would also probably be put in place, depending on local conditions.

${ }^{8}$ It is important to make this scheme credible and independent from the changing political environment. Corden (1992) speaks in this context about a "hard tariff path."

${ }^{9}$ This general scheme would have to include some exceptions. For social reasons, some special "protecting" measures cannot be avoided in case of some big enterprises which are the only employers for certain cities or regions.
} 
convertibility is introduced, provided the initial devaluation margin is large enough and the macroeconomic policy sufficiently restrictive. This is one of the most spectacular results of the early liberalization stage. It also suggests that the apparent "dollar shortage," so characteristic for a centrally planned economy, may have been rooted in administrative restrictions and inflationary financial policies, which could be removed fairly quickly, albeit at some cost.

Generally, the foreign trade sector has been one of the brightest points in the otherwise somber picture of the Polish economy, even though it suffered heavily from the CMEA shock in 1991. Official international reserves increased from US $\$ 2.0$ billion at the end of 1989 to US\$5.1 billion at the end of June 1992.

Other lessons highlight errors and mistakes made during the initial stage of liberalization. Therefore, the third lesson is that it is tempting to "overshoot" the initial devaluation, if trade liberalization is introduced as part of a broader stabilization-cum-reform program. The pervasive "shortage syndrome" inherited from the central planning era led policy makers to believe that only a very sharp devaluation could be effective in dampening the apparently unsaturated demand for foreign currencies. However, as soon as monetary and fiscal restrictions are introduced in the form of a comprehensive and credible package, the inflationary expectations subdue and the demand curve for foreign currency shifts downward. The real income effect is thus further exacerbated by the portfolio (expectations) effect, and the demand for convertible currencies falls faster than anticipated. To be sure, some initial "overshooting" is probably necessary in order to achieve the reversal in expectations, and therefore the initial devaluation has to push up the exchange rate over and above the level corresponding to the equilibrium rate in a balanced economy. While it is difficult to determine the degree required of the initial "overshooting," it seems that in the Polish case it proved to be excessive.

Fourth, under the conditions of transition and price liberalization, the "anchoring" of the nominal exchange rate may be a good anti-inflationary measure only for a short period of time. Both the initial price liberalization and the devaluation itself push up the general price level, and the resulting "corrective" inflation continues for some time. The initial depreciation margin disappears quickly, and the domestic currency appreciates in real terms. In Poland, the official exchange rate was kept constant from January 
1990 to May 1991, i.e., for more than 16 months, but consumer prices increased over that period by 350 percent, i.e., the real zloty rate appreciated more than four times. Moreover, when the exchange rate becomes clearly overvalued, expectations of a new devaluation build up and economic policy loses its credibility. It is clear that maintaining the fixed rate for too long had damaging effects on trade and output levels. In the end, inflation cannot be controlled either, since unit costs of production tend to rise due to lower capacity utilization, and expectations of future devaluation destroy the confidence of business.

The Polish government devalued the zloty in May 1991 by 17 percent, and pegged it to a basket of convertible currencies in an attempt to make it less dependent on fluctuations of the dollar. Later, the crawling peg was introduced. Once more a devaluation took place at the end of February, 1992 (for details see Chapter 2 by Jasiński). All these measures notwithstanding, the real appreciation of the zloty continued, albeit at much slower pace.

Fifth, the Tinbergen principle in applying the most efficient economic policy instruments to achieve specific policy goals should not be violated. The exchange rate devaluation cannot bear the entire burden of adjustment and competitiveness realignment. Not only would the required fall in real wages be politically and socially unacceptable, but, in the case of industries yielding negative value added, devaluation cannot help. Thus, there is a basis for transitory protection. Customs tariffs should be treated as an instrument of structural policies and therefore should not be changed constantly in pursuance of short-term policy goals, such as the current account equilibrium, or budgetary equilibrium.

Sixth, the policy of trade liberalization should follow a clear course, and erratic moves back and forth should be avoided. In Poland, the tariffs were raised in January 1990, then they were partly reduced and partly suspended as part of the government's efforts to stimulate economic recovery, and in August 1991 they were raised again to levels generally much higher than the initial rates. As a result, the Polish economy started with relatively high protection, which quickly disappeared due to the real rate appreciation and various tariff reductions. Such sharp and erratic fluctuations of nominal protection send misleading signals to economic agents and increase uncertainty.

This leads us to the seventh lesson, and this is that political resistance builds up quickly in the course of trade liberalization. Exposed to unrestricted foreign competition in late 1990 and in 1991, Polish industrial and 
agricultural lobbies put increasing pressure on the government to abandon its liberal policy course and to restore some protection. They indeed managed not only to reimpose high tariffs in August 1991, but also to obtain additional protection in the form of minimum prices for selected agricultural goods, additional tariffs and taxes for some industrial goods (cars, electronics), and new import licenses (alcoholic beverages, tobacco products, and fuels).

Finally, trade liberalization should not put too much competitive pressure on too many. If, under a given exchange rate and tariff levels, one-third of domestic industry operates at a loss and structural adjustment is hindered by tight monetary policy and underdeveloped capital markets, social and political problems, which inevitably emerge, may put the whole reform process in jeopardy. Thus, if a massive structural adjustment is necessary, the better policy would be to impose temporary protection, gradually scaled down within the preannounced credible program.

\section{The Optimum Pattern of Trade Policy in Transition Economies}

The preceding section should have made clear that, while trade liberalization is both necessary and beneficial, it should be designed with care and due attention to possible negative side effects during the transitional period. In particular, the specific initial conditions in CIT should be taken into consideration in trying to secure an optimal path of trade liberalization.

In principle, there is no argument against transparency and neutrality of trade policies. They can and should be established right from the beginning of the reform process. Replacing the old, administrative trade regime by a tariff-based, transparent regime results in immediate efficiency gains, and does not have to be in any way destructive to domestic producers (within a transparent system, policy makers may choose the desired level of protection). An essential component of the transparent trade system is currency convertibility for current account transactions. Similarly, broad neutrality can best be achieved by establishing a competitive exchange rate, supplemented, if necessary, by moderate tariffs and export incentives.

On the basis of a transparent system, the main trade policy instrument to be used during transition would be a tariff. Quotas are acceptable, and sometimes even necessary, only insofar as they reflect external obligations 
connected with trade restrictions imposed by other countries. For domestic policy reasons, quotas are, in all cases, inferior to tariffs. ${ }^{10}$

In the former Soviet Union, the case of energy exports has sometimes been used as an argument for quantitative restriction on exports. But in this case also, an export tax is preferable for a number of reasons.

While an opening toward international markets is an essential element of the transformation, it does not mean that tariffs should necessarily be eliminated or drastically reduced, as was the case in Poland in 1990. There are important reasons for the tariffs to be maintained at "moderate" levels (i.e., not lower than levels of protection, including nontariff barriers, which prevail in industrialized countries) for at least several years. There are several arguments in favor of such a tariff policy.

The most controversial position is the argument in favor of the need for transitional protection. Because the production sector in CIT is inefficient and structurally distorted, it cannot compete internationally, and thus has to be protected for some time in order to allow for necessary adjustments to take place. Once the restructuring is made and industries of the CIT become competitive, the protection can be removed. This is the core of the argument for transitional tariff protection.

This reasoning has been attacked on many grounds. One argument is that the exchange rate policy can be used instead: in principle, if the exchange rate is sufficiently devalued, it can make most of the loss-making industries efficient. But this may not be feasible. Not only would it lead to an excessive reduction of real wages throughout the economy, but, because of large disparities in the profitability of individual enterprises, the currency would have to be depreciated to absurdly low levels. It should be remembered that prior to price liberalization and reform, enterprises in CIT had a fairly uniform profitability distribution; after the reform the distribution became much more irregular and differentiated.

But the most important argument against using the exchange rate to deal with structural deficiencies is the presence of "value-added subtractors." Under new relative prices some activities may yield negative value added, especially in energy-intensive sectors (McKinnon, 1991). In such situations, devaluation alone clearly cannot help, and these activities would have to be discontinued.

\footnotetext{
${ }^{10}$ Except for situations where a total ban on trade is desirable (e.g., drugs and nuclear armaments),
} 
Another argument against temporary protection draws on the experiences of developing countries. Protection offered to infant industries in those countries very rarely resulted in an increase of international competitiveness and did not lead to the eventual removal of protection. As a result, the "infant industries" have never matured. It should be added that the ability of the government to determine a priori potentially efficient sectors and firms is widely disputed.

Actually, the case of CIT is not protection of "infant industries" but rather protection of "senile industries" (Williamson, 1992). These industries exist already, but they have to be restructured if they are to survive. They cannot receive credits for restructuring because of the weakness of capital markets, general lack of capital, and the high sociopolitical risks in CIT. These industries may, however, offer important externalities, which should be taken into consideration - especially in manufacturing. Therefore, the best policy would be a direct subsidy to production. However, subsidies may be unfeasible for budgetary reasons; they also are prone to rent-seeking. A second best solution would therefore be a transitional tariff protection.

Transitional tariff protection has disadvantages which are well known; protection of one industry is always at the expense of the other industries. Moreover, it introduces a significant price distortion. These costs should be weighted against current and future benefits.

One has to be skeptical, however, about the possibility of establishing sector-specific or even product-specific protection structures, with tariff rates varying according to the value-added contents (this approach has been suggested by McKinnon, 1991). First, under distorted prices and costs it is difficult to determine a priori areas of comparative advantage and to pick up "winners" in terms of sectors or branches. Second, a widespread tariff differentiation opens up practically unlimited possibilities for rent-seeking. This solution would also be administratively cumbersome and rigid. One is thus left with a less ambitious but probably more realistic option of imposing a uniform, moderate tariff on all manufacturing industries. Together with the competitive real exchange rate and a minimum number of quantitative restrictions, the system can provide strong incentives for export-oriented restructuring and avoid unnecessary adjustment costs.

Trade taxes are used sometimes to deal with externalities in consumption. But, as in the case of production, trade policy offers only a second best solution to this problem. An excessive consumption of luxuries should be 
countered rather with sales or consumer taxes, which attack the distortion at the source and do not affect relative prices for producers. ${ }^{11}$

Trade taxes are also very important sources of government revenues. This aspect should not be forgotten, because the fiscal systems in CIT are generally obsolete and inefficient, and sooner or later result, typically, in a fiscal crisis. Since the traditional tax base shrinks because of the prolonged recession and widespread tax evasions, alternative sources of budget revenues have to be sought. Trade taxes are easier to collect and to enforce than income-based taxes, and for this reason should not be abandoned. Theoretically, a tax on imports is an equivalent of a tax on exports (Lerner's symmetry theorem); but in practice, export taxes should be used only in special situations (e.g., exports of underpriced energy and fuels) because they have a strong disincentive effect.

By contrast, tariffs (and other trade policy measures) should not be used in order to ensure a targeted balance of payments. The external equilibrium is better assured with a competitive exchange rate and prudent financial policies. Tariffs should remain instruments of structural policies, independent of current stabilization goals.

\section{References}

Balassa, B. (1978) "Export incentives and export performance in developing economies," Weltwirtschaftliches Archiv, 114.

Balassa, B., et al. (1971) The Structure of Protection in Developing Countries (Baltimore, MD: Johns Hopkins University Press).

Berg, A., and Sachs, J. (1992) "Structural adjustment and international trade in Eastern Europe: The case of Poland," Economic Policy, No. 14.

Corden, W.M. (1992) "Trade policy and exchange rate issues in the former Soviet Union," Working Papers, WPS 915, May (Washington, DC: World Bank).

Dornbusch, R. (1990) Policies to Move from Stabilization to Growth, Discussion Paper Series, No. 456 (London: Center for Economic Policy Research).

Edwards, S. (1989) Openness, Outward Orientation, Trade Liberalization, and Economic Performance in Developing Countries, Working Paper, June (Washington, DC: World Bank).

Fairlamb, D. (1990) "The convertibility conundrum," Institutional Investor, April. Gomulka, S. (1992) "Polish economic reform 1990-1991: Principles, policies and outcomes," Cambridge Journal of Economics, No. 3, September.

Havrylyshyn, O. (ed.) (1990) Poland: Policies for Export Promotion, UNDP/World Bank (Washington, DC: World Bank).

\footnotetext{
${ }^{11}$ In other words, they do not discourage domestic producers from exports of luxury goods.
} 
Havrylyshyn, O., and Tarr, D. (1991) Trade Liberalization and the Transition to a Market Economy, Working Papers, WPS 700, July (Washington, DC: World Bank).

Krueger, A. (1978) Foreign Trade Regimes and Economic Development: Liberalization Attempts and Consequences, Ballinger for the National Bureau of Economic Research (Cambridge, MA: Ballinger).

McKinnon, R. (1991) The Order of Economic Liberalization: Financial Control in the Transition to a Market Economy, (Baltimore, MD: Johns Hopkins University Press).

Nuti, D.M. (1991) "Progress in trade reforms, missing links, convertibility: A discussion," in M. Kaser and A.M. Vacic (eds.) Reforms in Foreign Economic Relations of Eastern Europe and the Soviet Union, Economic Commission for Europe (New York: United Nations).

Nuti, D.M. (1992) Economic Inertia in the Transitional Economies of Eastern Europe, Mimeo (Florence: European University Institute).

Papageorgiou, D., Choksi, A.M., and Michaely, M. (1990) Liberalizing Foreign Trade in Developing Countries: The Lessons of Experience (Washington, DC: World Bank).

Portes, R. (1991a) The Transition to Convertibility for Eastern Europe and the USSR, CEPR Discussion Paper, No. 500, January (London: Center for Economic Policy Research).

Portes, R. (1991b) "The path of reform in Central and Eastern Europe: Introduction," European Economy, Special Edition No. 2.

Rosati, D.K. (1991) "Institutional and policy framework for foreign economic relations in Poland," in M. Kaser and A.M. Vacic (eds.) Reforms in Foreign Economic Relations of Eastern Europe and the Soviet Union, Economic Commission for Europe (New York: United Nations).

Rosati, D.K. (1992) "Trade policies in Poland," in D. Salvatore (ed.) National Trade Policies, Vol. 2 (New York: Greenwood Press).

Rosati, D.K., and Mizsei, K. (1989) Adjustment Through Opening of Socialist Countries, WIDER Working Papers, No. 52, January (Helsinki: World Institute for Development Economics Research).

UN ECE (1992) Economic Bulletin for Europe, Vol. 44, Economic Commission for Europe (New York: United Nations).

Williamson, J. (1992) The Eastern Transition to a Market Economy: A Global Perspective, Occasional Paper No. 2, March (London: Center for Economic Performance). 



\section{Chapter 7}

\section{Life Without CMEA: Foreign Trade in Eastern and Central Europe}

Sándor Richter

\section{Introduction}

Since the fall of the Soviet Union the answer to the question, "What comes after the CMEA?" has become even more complicated than it was in June 1991 when the CMEA officially ceased to exist. ${ }^{1}$ An analysis of economic relations within and between major post-CMEA blocs (such as Czechoslovakia, Hungary, and Poland often called the Visegrád Group; the latecomers Bulgaria and Romania; the three Baltic states; the CIS states excluding Russia; the regions in Russia; the separate Czech and Slovak republics) is far beyond the scope of this paper. Its purpose is, first, to investigate the recent development of the mutual economic relations of the five Eastern European economies (Bulgaria, Czechoslovakia, Hungary, Poland, and Romania, referred to as the EE5), with a special emphasis on the Visegrád Group

${ }^{1}$ CMEA (Council for Mutual Economic Assistance, also known as Comecon, the economic organization of Eastern European countries and the Soviet Union) was set up in 1949 to enhance the development of the member countries on a complementary basis. In the 1960 s and 1970 s other centrally planned economies, like Mongolia, Cuba, and North Vietnam, joined the organization. 
economies, ${ }^{2}$ and, second, to deal with the motives for and viable forms of intra-regional economic cooperation in Central and Eastern Europe.

The dissolution of the CMEA in the summer of 1991 meant no less than recognition of the failure of the basic principles of economic cooperation among the centrally planned economies in the last four decades. The introduction of hard currency payments and of prices following the actual trends in the world economy in January 1991 broke the back of the traditional system of economic cooperation in the region.

Over the last decades external economic relations of the former CMEA members were characterized by a peculiar duality: the "rules of the game," relevant to the trade among CMEA countries differed from those for the rest of the world (OECD and developing countries).

Trade among the CMEA countries had traditionally been based on four pillars: bilateral clearing and its accounting unit, namely, the transferable ruble; a peculiar price formation system; a determining role for government institutions in all respects of trade; and, finally, decision-making based on predominantly political rather than economic considerations (Rácz and Richter, 1989; Richter, 1989, p. 49).

In the trading with the West, these peculiar features of CMEA cooperation were missing: contract prices followed actual tendencies on the world market and payments were in convertible currencies. Government intervention was of a different nature; all foreign trade deals with Western firms needed the approval and license of the respective Ministry of Foreign Trade. Conducting foreign trade was the privilege of a couple of specialized firms and a limited number of major producers. The trading firms' activity was delimited by the so-called "profile monopoly" which strictly prohibited competition among participants in foreign trade by designating exclusive rights to trade with certain groups of commodities to individual foreign trade organizations. Licensing was the main instrument for the control of imports whose allowed level was determined by the current account situation and other considerations.

For the five Eastern European economies (Bulgaria, the CSFR, Hungary, Poland, and Romania) not only did the duality in the external economic relations (CMEA versus rest of the world) cease to exist in 1991, but the transition from the planned to the market economy necessitated a new setup

\footnotetext{
${ }^{2}$ This is because there is a relatively abundant amount of data on these three countries, contrary to Bulgaria and Romania, and also because the Visegrád Group economies have already taken steps to set up intra-regional economic cooperation.
} 
in trade with the non-CMEA economies. More or less simultaneously with the replacement of the peculiar conditions in trade with the CMEA partners, trade with the rest of the world underwent fundamental changes. Participation in trading activities was completely liberalized, allowing market entry for thousands of firms. Strict administrative control of imports was either abolished or confined to a small segment of the foreign trade in the Visegrád Group countries and Bulgaria, and partially liberalized in Romania.

The homogenization of the main features of external economic relations in a principally market compatible framework put mutual trade of the EE5 countries into a new context. Prior to 1991, mutual economic relations of the EE5 countries was one of the two subsystems within the CMEA, where the bilateral relations of individual EE5 countries with the Soviet Union had always been more important than their bilateral relations with one another. With the fall of the CMEA, intra-Eastern European economic cooperation is no longer a subsystem of secondary importance within the "quasi-preferential" CMEA system.

\section{1: The Beginning of a New Era}

Before beginning any discussion on the future of the mutual trade of the five Eastern European economies a review of the situation in 1991 and 1992 must be undertaken. The first year after the homogenization of external economic relations in the countries concerned has seen important new developments in intra-regional trade.

\section{Declining trade volumes}

Although many associate the collapse of intra-CMEA and intra-Visegrád Group trade with the shift to a hard currency settlement of payments in January 1991, the decline of intra-CMEA trade in fact began much earlier. According to the data presented in Table 7.1, in the period between 1985 and 1990 , i.e., in the last five years of the old system, the trade of the Visegrád Group countries at constant prices with non-CMEA economies grew substantially faster than that with CMEA countries. ${ }^{3}$ With respect to exports, the difference between trade with East and West was the biggest in Hungary, where exports to the CMEA dropped by one-quarter, while deliveries to the rest of the world rose by nearly one-third. The tendency was similar in the

\footnotetext{
${ }^{3}$ The respective data for Romania and Bulgaria are not available.
} 
Table 7.1. Development of trade with centrally planned economies and market economies between 1985 and 1990 at constant prices, in percent, $1985=100$.

\begin{tabular}{|c|c|c|c|c|c|c|}
\hline \multirow[b]{2}{*}{ Partner region } & \multicolumn{3}{|c|}{ Exports in 1990} & \multicolumn{3}{|c|}{ Imports in 1990} \\
\hline & CSFR & Hungary & Poland & CSFR & Hungary & Poland \\
\hline $\begin{array}{l}\text { Centrally planned } \\
\text { economies and countries } \\
\text { in transition }\end{array}$ & 81.6 & 75.1 & $106.7^{a}$ & 105.5 & 87.2 & $72.0^{a}$ \\
\hline Market economies & 116.0 & 130.8 & $164.9^{b}$ & 151.0 & 110.9 & $132.1^{b}$ \\
\hline
\end{tabular}

${ }^{a}$ Trade in nonconvertible currencies.

${ }^{b}$ Trade in convertible currencies.

Sources: Jahrbuch des Außenhandels der Tschechoslowakei, 1991; Külkereskedelemi Statisztikai Évkönyv, 1990; Rocznyk Statystyczny, 1991; and Handel Zagraniczny, 1991.

CSFR while in Poland the volume of exports to both regions increased in the period concerned, but to the rest of the world expansion was substantially stronger ( 7 percent and 65 percent, respectively).

In the case of Hungary and Poland imports from the CMEA declined while imports from the rest of the world expanded. In the case of the CSFR, imports increased from both regions, but by strikingly different amounts (from CMEA 6 percent, from rest of the world 51 percent).

\section{Changing geographical distribution of trade}

The relative significance, i.e., the share of trade of the Visegrád economies with (former) CMEA partners in their total trade over the period from 1985 to 1991 is presented in Tables 7.2 to 7.4. In 1985, in a still "peaceful" year in the CMEA, trade with the CMEA made up nearly two-thirds of the CSFR's total trade, and nearly half of Poland's and Hungary's total trade. Compared with Hungary and Poland, the CSFR's relatively more intensive engagement in trade with the CMEA partners prevailed until after the shift to a hard currency settlement. In 1991 the CSFR's trade with former CMEA countries amounted to more than one-third of total trade, while in Poland and Hungary this share was approximately one-fifth. For the CSFR the relative significance of the former CMEA is close to twice as large as for Poland and Hungary.

The share of intra-Visegrád Group trade in the total trade of each Visegrád country was not especially high in 1985 . It was less than 10 percent in both exports and imports for Poland and Hungary, and 12 percent and 14 


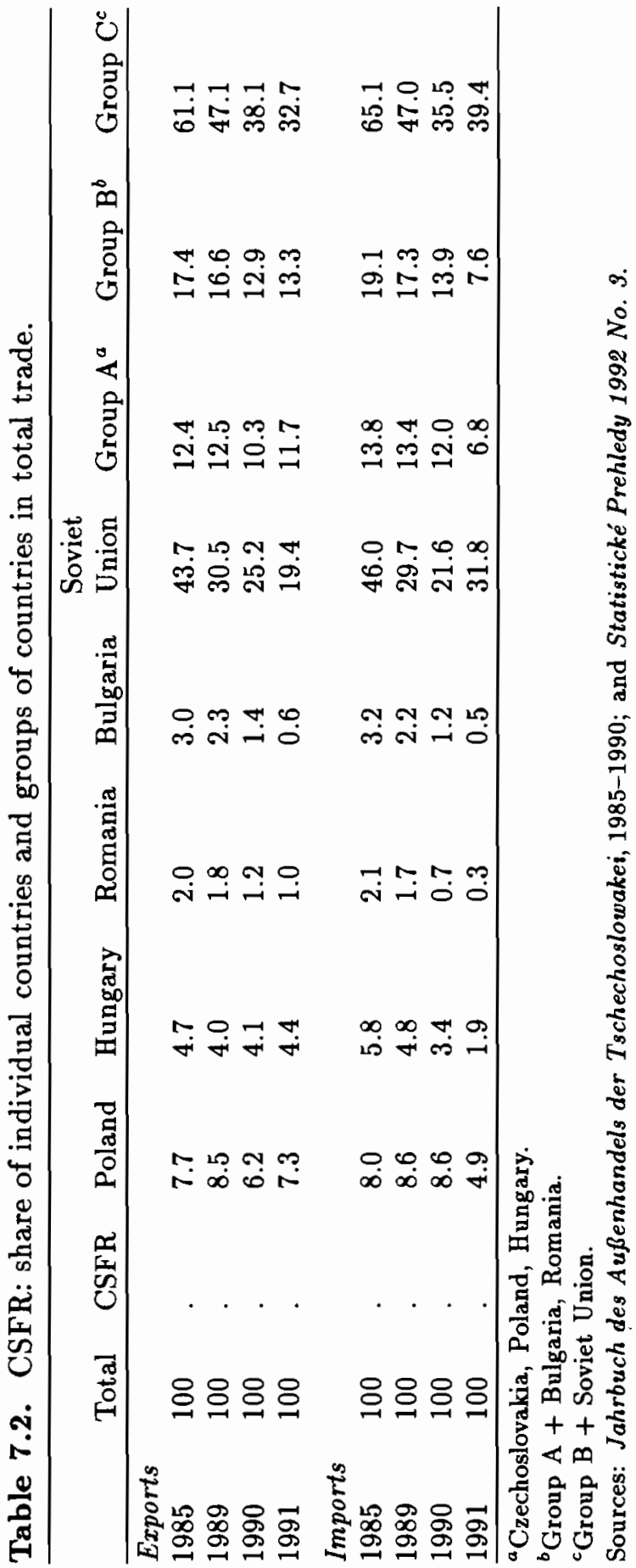




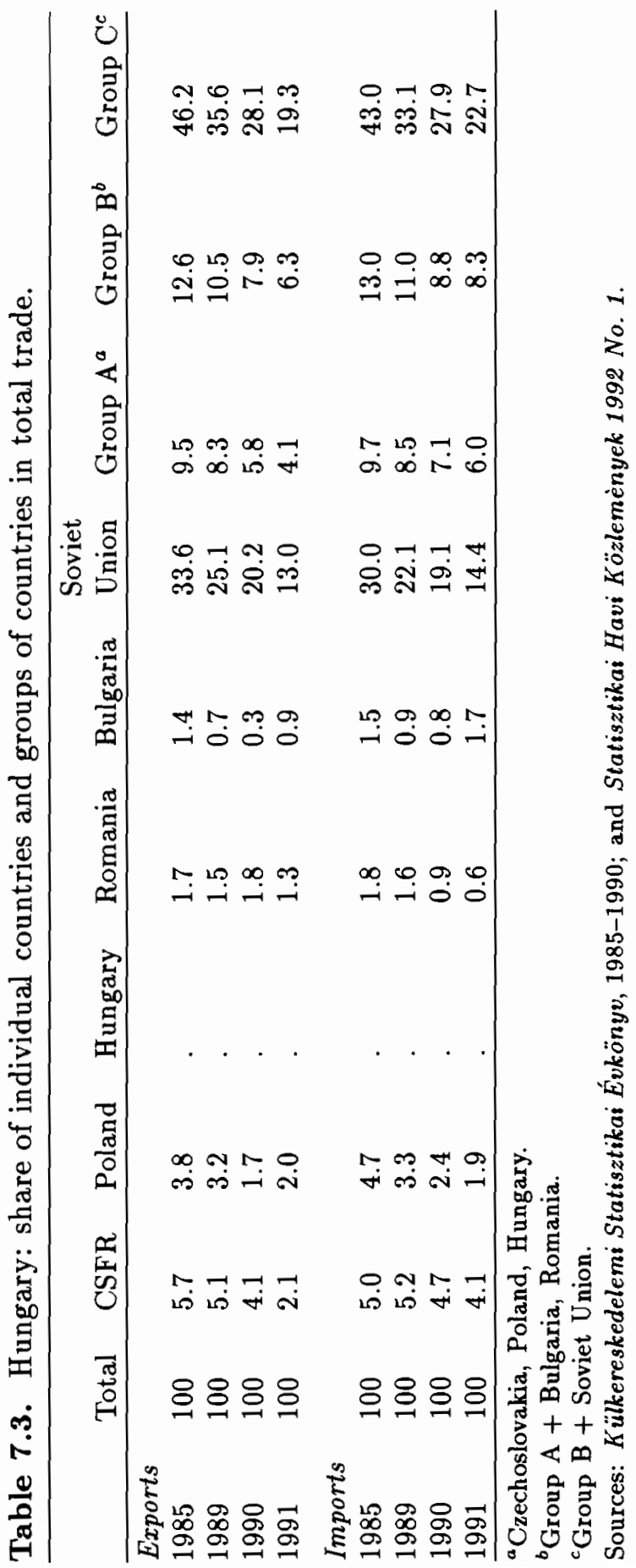




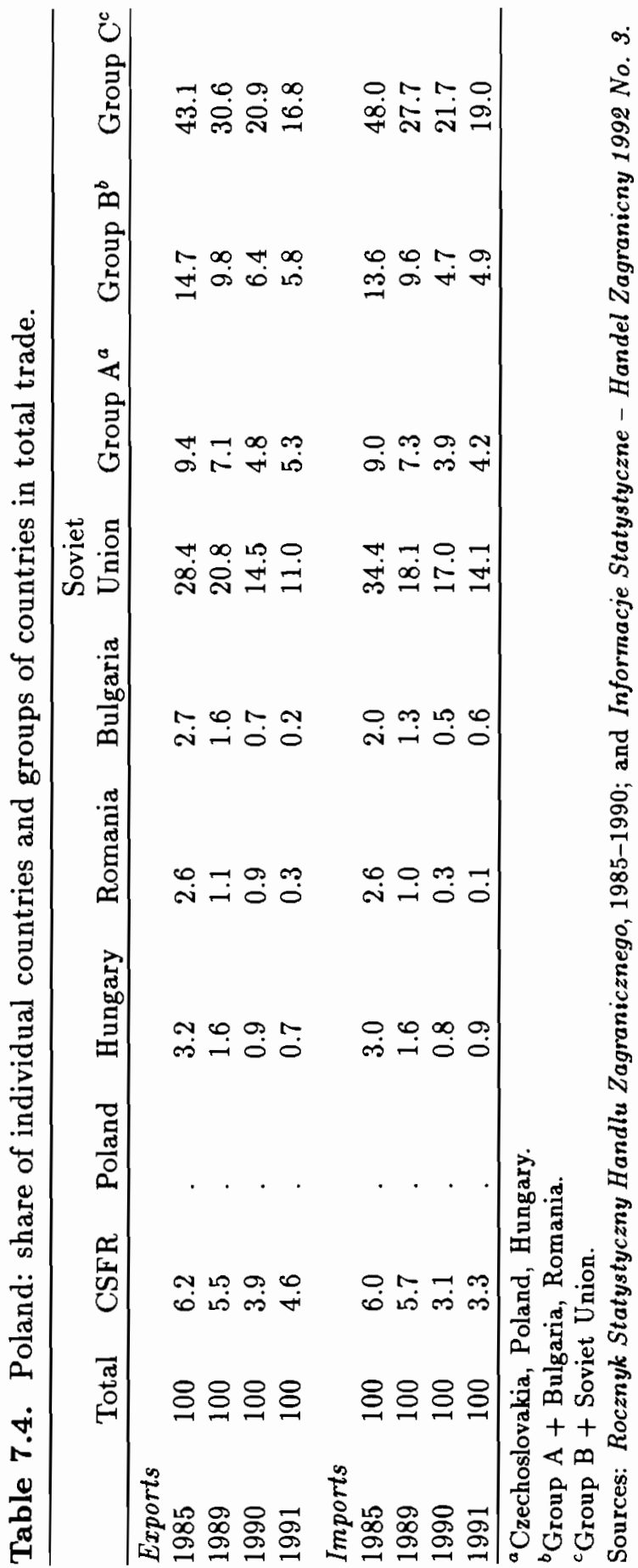


percent, for exports and imports for the CSFR. By 1991 the share of intraVisegrád Group trade was approximately half of the 1985 level for Hungary and Poland in total trade and for the CSFR in imports; the respective share in CSFR's exports remained nearly as high as the 1985 level.

In the case of Poland and Hungary the share of the Soviet Union shrank by nearly the same rate as the share of the Visegrád Group partners. Thus trade shares with the Soviet Union, in both exports and imports, were two to three times higher than the Visegrád Group partners combined in 1985 and in 1991. In the case of Czechoslovak imports, the Soviet share was more than three times higher in 1985 and more than four times higher in 1991 than the share of the Visegrád Group partners. In exports this relation changed significantly over time. Whereas in 1985 the ratio of exports to the Soviet Union to exports to the Visegrád Group was approximately four to one, by 1991 it had dropped to less than two to one.

Where was the decline of trade stronger: with the Soviet Union or with the EE5 (i.e., the Visegrád Group plus Bulgaria and Romania)? A comparison of respective shares in exports and imports demonstrates that in Poland nearly two-thirds of the 1985 shares were lost by 1991 in both directions. In Hungary the shrinkage of shares was stronger with the EE5 than with the Soviet Union in both exports and imports. For the CSFR's exports twothirds of the Soviet share was lost, while only one-quarter of the EE5 share was lost. In imports it was just the contrary: with the Soviet Union less than one-third of the 1985 share vanished by 1991; in trade with the EE5, nearly two-thirds.

Within the Visegrád Group, Hungary has been a relative outsider. Poland's trade share with the CSFR was nearly twice as big as its share with Hungary, in both 1985 and 1991 . The same pattern held for the CSFR, whose share was also approximately twice as big with Poland than with Hungary. For Hungary in 1985 the CSFR was a somewhat more important trading partner than Poland. In 1991 this was still true for exports while in imports the relative significance of trade with the CSFR was twice as high as that with Poland.

The rearrangement of the geographical composition of foreign trade had peculiar features in Bulgaria and Romania. Data for Bulgaria show that in both, exports and imports, the Soviet Union preserved its dominating position with close to half of the turnover, and this share is not much lower than in 1985 and 1990. The share of the EE5 dropped from the 12 percent level in 1985-1990 in both, exports and imports, to less than half by 1991. 
The trade share of the EE5 also decreased by half in Romania, amounting to 6 percent to 7 percent of total trade in 1991. The drop of the Soviet share, however, was much less dramatic in Romania than in the Visegrád Group countries. True, the Soviet share was traditionally lower in Romania's foreign trade than in that of the Visegrád Group countries.

\section{Soviet statistics}

Reviewing the rearrangement of the Soviet foreign trade from 1985 to 1991 ( Table 7.5) we can see that the share of the EE5 economies in 1991 dropped nearly to the half of the 1990 indicator in both exports and imports. In imports this applies more or less to each EE5 economy except for Romania where the shrinkage of the trade share was less strong, nevertheless it was the lowest in trade with the EE5 countries. Concerning Romania the same applies to the exports. The drop in trade shares of Soviet exports to other EE5 countries was the smallest with the CSFR and the largest with Bulgaria.

\section{Changing trade structure}

Data on the change of commodity patterns following the shift to a hard currency settlement of payments are available only for the CSFR and Hungary. ${ }^{4}$ In Hungary's exports all "hard goods" to the CSFR increased, especially food and livestock, raw materials, and chemicals. At the same time the share of "soft goods" (machinery and industrial consumer goods) contracted sharply (the former from 46 percent to 33 percent, the latter from 16 percent to 9 percent). In the CSFR's exports to Hungary the same tendency was observed, with a much more drastic reduction of the share of machinery from 42 percent to 22 percent, and a milder contraction in the case of industrial consumer goods, from 10 percent to 5 percent.

Poland is only a passive participant in this analysis as data on its trade patterns with the Visegrád Group partners are available only from statistics of the partner countries. In Hungary's exports to Poland the share of machinery dropped from 37 percent to 14 percent, while the relative significance of agricultural products doubled. In imports, the decrease of the share of machinery was even more drastic, from 39 percent to 9 percent. The

\footnotetext{
${ }^{4}$ In trade between Hungary and the CSFR, where data were already reported by both countries, the patterns in corresponding trade flows are not identical as they would be if statistics were perfect, nevertheless they are quite similar. Here we refer to the data collected from Hungarian statistics.
} 


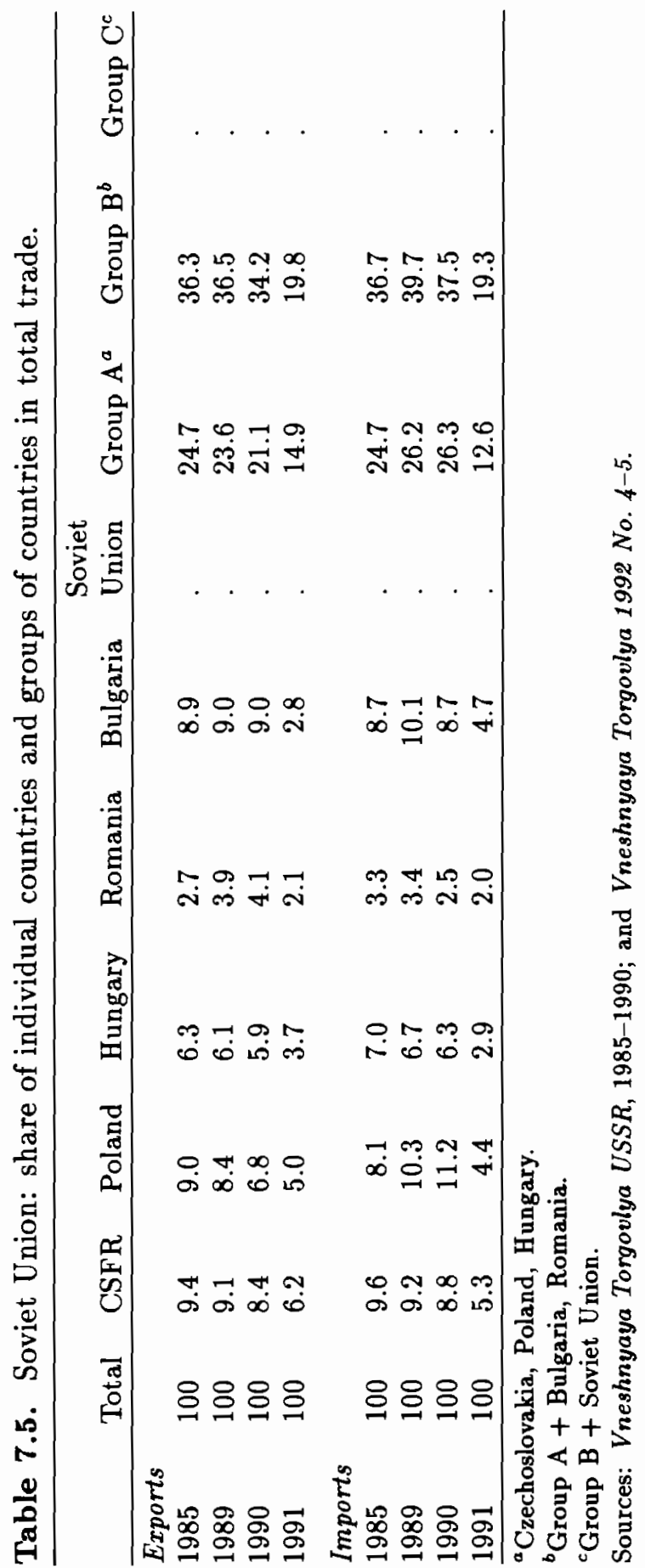


Table 7.6. CSFR's trade with the Soviet Union by commodity groups, 1990 and 1991, in percent.

\begin{tabular}{|c|c|c|c|c|}
\hline \multirow{2}{*}{$\begin{array}{l}\text { Commodity groups } \\
\text { SITC }\end{array}$} & \multicolumn{2}{|c|}{ Exports } & \multicolumn{2}{|c|}{ Imports } \\
\hline & 1990 & 1991 & 1990 & 1991 \\
\hline 0 Food and livestock & 1.3 & 4.3 & 0.7 & 0.3 \\
\hline 1 Beverage and tobacco & 0.1 & 0.2 & 0.3 & 0.2 \\
\hline 2 Raw materials (except fuels) & 2.6 & 0.4 & 7.7 & 10.8 \\
\hline 3 Fuels and lubricants & 2.3 & 1.5 & 56.3 & 76.5 \\
\hline 4 Animal and vegetable fats and oils & - & - & - & - \\
\hline 5 Chemicals & 4.1 & 8.3 & 3.0 & 2.6 \\
\hline 6 Manufactured goods (classified by materials) & 9.3 & 24.6 & 7.3 & 4.4 \\
\hline 7 Machinery and transport equipment & 60.8 & 43.8 & 22.0 & 4.6 \\
\hline 8 Miscellaneous manufactures & 17.5 & 16.9 & 1.2 & 0.6 \\
\hline 9 Other commodities and transactions & 2.0 & - & 1.5 & - \\
\hline Total & 100.0 & 100.0 & 100.0 & 100.0 \\
\hline
\end{tabular}

Source: CSFR in International Economy, Research Institute for Foreign Economic Relations, March 1992.

"winners" in Hungary's imports were fuels and semifinished products, with respectively two and three times higher shares in 1991 than in 1990.

In exports from the CSFR to Poland, machinery made up two-thirds of deliveries in 1990. After the introduction of the hard currency payments in 1991 this share shrank dramatically, nevertheless it still remained by far the most important individual commodity group in the CSFR's exports. The relative significance of semifinished products and chemicals increased substantially. 'The CSFR's imports of machinery from Poland dropped from 39 percent to 19 percent, that of the industrial consumer goods from 15 percent to 3 percent, while the share of fuels increased from 3 percent to 36 percent.

The change of the CSFR's and Hungary's patterns in exports to the Soviet Union from 1990 to 1991 followed roughly the developments observed in intra-Visegrád Group trade (Tables 7.6 and 7.7). The biggest "loser" was the commodity group of machinery and transport equipment in both cases, although its share remained very high in the exports from the CSFR (1990, 61 percent; 1991, 44 percent). In case of Hungary machinery became the second most important commodity group (1990, 42 percent; 1991, 31 percent) after food and livestock. Industrial consumer goods (group 8) maintained their 1990 position in the CSFR's exports but dropped to half of their share in Hungary's exports. In case of the CSFR's exports the share of semifinished 
Table 7.7. Hungary's trade with the Soviet Union by commodity groups, 1990 and 1991 , in percent.

\begin{tabular}{lrrrrr}
\hline Commodity groups & \multicolumn{3}{c}{ Exports } & & \multicolumn{2}{c}{ Imports } \\
\cline { 2 - 3 } \cline { 6 - 7 } SITC & \multicolumn{1}{c}{1990} & 1991 & & 1990 & 1991 \\
\hline 0 Food and livestock & 21.8 & 35.9 & & 0.7 & 1.1 \\
1 Beverage and tobacco & 2.8 & 1.1 & & 0.2 & 0.3 \\
2 Raw materials (except fuels) & 2.9 & 8.5 & 9.8 & 8.1 \\
3 Fuels and lubricants & 0.3 & - & 48.7 & 66.3 \\
4 Animal and vegetable fats and oils & 0.1 & 0.1 & - & - \\
5 Chemicals & 11.4 & 7.7 & 9.3 & 6.3 \\
6 Manufactured goods (classified by materials) & 5.1 & 9.1 & 14.6 & 10.4 \\
7 Machinery and transport equipment & 41.8 & 30.5 & 16.1 & 6.8 \\
8 Miscellaneous manufactures & 13.3 & 6.9 & 0.5 & 0.5 \\
9 Other commodities and transactions & 0.5 & 0.2 & 0.1 & 0.2 \\
Total & 100.0 & 100.0 & 100.0 & 100.0 \\
\hline
\end{tabular}

Sources: Statistical Yearbook of the Hungarian Foreign Trade, 1990; and Information from the Central Statistical Office, 1991.

products (group 6) and chemicals grew substantially; that of food products, modestly. In Hungary's export to the Soviet Union, the share of food and livestock, raw materials, and semifinished products increased significantly.

In the change in the composition of imports from the Soviet Union, the dominance of energy became stronger than ever, making up two-thirds of Soviet deliveries to Hungary and no less than three-quarters of those to the CSFR. The share of machinery, in 1990 still making up 22 percent for the CSFR and 16 percent for Hungary, dropped to one-fifth and one-half, respectively, of the 1985 level.

Although 1991 was the first year after the introduction of hard currency payments and world market prices, the emerging trade patterns presented above do not reflect the structural rearrangement to its full extent. In 1991 a part of the mutual trade of the former CMEA countries was still conducted in transferable rubles. These deliveries were primarily designed to balance the clearing payments system where trade imbalances had emerged in 1990. Besides this, in the case of 1991 deliveries for contracts signed in 1990 transferable ruble payments were still allowed. Data on the share of the turnover settled in transferable rubles are available only for the CSFR (Table 7.8). All data reported in this paper also include that part of the trade which was settled in transferable rubles. Therefore, trade pattern data are biased to some extent. This has special significance since we intend to analyze the 
Table 7.8. Foreign trade of the CSFR with selected former CMEA countries by currency of payments in 1990 and 1991, in percent.

\begin{tabular}{|c|c|c|c|c|}
\hline & & Total & $\begin{array}{l}\text { In transferable } \\
\text { rubles }\end{array}$ & $\begin{array}{l}\text { In convertible } \\
\text { currencies }\end{array}$ \\
\hline \multicolumn{5}{|l|}{ Exports to } \\
\hline \multirow[t]{2}{*}{ Poland } & 1990 & 100.0 & 95.5 & 4.5 \\
\hline & 1991 & 100.0 & 6.6 & 93.4 \\
\hline \multirow[t]{2}{*}{ Hungary } & 1990 & 100.0 & 96.0 & 4.0 \\
\hline & 1991 & 100.0 & 14.6 & 85.4 \\
\hline \multirow{2}{*}{ Soviet Union } & 1990 & 100.0 & 96.7 & 3.3 \\
\hline & 1991 & 100.0 & 12.2 & 87.8 \\
\hline \multicolumn{5}{|l|}{ Imports from } \\
\hline \multirow[t]{2}{*}{ Poland } & 1990 & 100.0 & 90.8 & 9.2 \\
\hline & 1991 & 100.0 & 7.2 & 92.8 \\
\hline \multirow[t]{2}{*}{ Hungary } & 1990 & 100.0 & 98.0 & 2.0 \\
\hline & 1991 & 100.0 & 26.3 & 73.7 \\
\hline \multirow[t]{2}{*}{ Soviet Union } & 1990 & 100.0 & 85.3 & 14.7 \\
\hline & 1991 & 100.0 & 4.1 & 95.9 \\
\hline
\end{tabular}

Source: CSFR in International Economy, Research Institute for Foreign Economic Relations, March 1992.

effects of the shift to a hard currency settlement of payments by comparing patterns of trade in 1990 and 1991. In addition, a part of intra-Visegrád Group trade had already been settled in hard currency prior to the fundamental change in the payments system in 1991 (see again Table 7.8 for the CSFR).

Nevertheless, it can safely be assumed that the shrinkage of the share of machinery and industrial consumer goods in mutual trade would have been even stronger if 1990 trade data net of deliveries settled in hard currencies and 1991 trade data net of deliveries in transferable rubles could be compared.

\section{The Future}

\section{The Visegrád Countries: Should they cooperate?}

The future of economic relations between the CSFR (respectively its successor states), Hungary, and Poland should be analyzed in economic and political context. It is true that the three countries have many common features in their history. It is also true that all three countries were forced to 
leave their path of social and economic development at the same time after the Second World War, and had the same Soviet-type socioeconomic model forced upon them, with similar consequences. Moreover, each country had a more or less simultaneous opportunity for leaving the Soviet bloc. ${ }^{5}$ These important facts, however, cannot alone provide the basis of future economic cooperation. Future cooperation in the sense of unfettered flows of goods and services, joint projects, can only be based on strong, identifiable common interests. Once such interests are identified, supporting policy measures and an appropriate framework are needed to derive advantage from intra-regional cooperation.

\section{Priority for relations with the EC}

Do interests for intra-regional cooperation exist? The starting point when trying to answer this question is that the main goal of each country, pushing into the background any other considerations, is full membership in the European Community as soon as possible. This vehement endeavor to achieve full membership in the EC is perhaps not easily understandable for Western Europeans. Besides the easily perceived mere economic reasons (such as free access to a huge market, substantial contribution to the modernization of the economy through transfers from the EC budget), one has to take into consideration other, exclusively Eastern-Europe-specific psychological motivation: the fear of a reversal of the Russian retreat from the region, the population's (perhaps partly illusionary) identification of welfare, and civilized public life with the "European values" where Europe means the European Community. The Visegrád Group countries' endeavor to achieve full membership is all the more remarkable as their intention has been received by the EC with restraint and, according to the present state of affairs, the probability of a quick accession of the three economies to the EC is very low. The asymmetry is obvious: while the EC can easily imagine its future without the Visegrád Group countries' membership, Poland, the successor states of the CSFR, and Hungary are completely at the EC's mercy, since as a long-term strategy these countries have no alternative to EC membership (this is discussed later in this chapter in the section titled "Can future trade

\footnotetext{
${ }^{5}$ For more on the historical precedent of the economic cooperation among the three countries, see Illés et al. (1991).
} 
flows be predicted?"). Neither a close cooperation of the three countries, nor any kind of revitalization of the late CMEA, nor EFTA membership, nor former President Bush's idea of a free-trade agreement with the USA is considered an alternative.

Relations to the EC make up only one, albeit the most important, element of the political and economic context in which the intra-Visegrád Group relations are embedded. Another important element is the three countries' controversial attitude toward Bulgaria, Romania, and the successor states of the former Soviet Union. Their intention to emphasize the difference between the state of affairs in the Visegrád Group countries and in Bulgaria, Romania, and the former USSR is clear. Nevertheless the peculiar mixture of mistrust of and superiority to the non-Visegrád Group former socialist countries also appears, although with lower intensity, in each Visegrád Group state vis-à-vis the other two. Most probably the political elite in each of the three countries is convinced that for various historical, political, and economic reasons its country is predestinated to join "Europe" first, and a coordinated approach toward negotiations with the other two countries on the modalities of their "Europe" policy would only narrow its country's options.

Taking into consideration these political aspects of intra-Visegrád Group relations the question must again be raised, what are the interests on which economic cooperation of the three countries can be based?

\section{The image of maturity}

First it is worth mentioning that each country's fundamental interest is to demonstrate that it is "mature" for EC membership. Maturity has certainly various political and economic criteria, but - justified or not - some kind of formalized political and economic cooperation among the three countries seems to be a sine qua non of the "mature for Europe" image of these countries in the West. (If they cannot come to terms with each other, then how can they participate in the sophisticated, interest-reconciliation processes within the EC?) The bloc approach toward the West obviously survived the blocs themselves, which, paradoxically, is inducing the Visegrád Group countries to reconstruct (at least formally) a part of the former Eastern bloc (see Ilés et al., 1991, pp. 41-42). 


\section{Trade diversion versus trade creation}

It is relevant to ask, whether a recovery of intra-Visegrád Group trade would be characterized by trade diversion or trade creation. Taking into consideration the marginal position of the three countries in the world economy and the low technological level of the manufactured products of the three economies, any form of regional cooperation which might lead to artificially induced trade diversion favoring intra-Visegrád Group trade and discriminating against trade with the rest of the world would result in a misallocation of resources. This means that regional cooperation based on trade diversion is not in the interest of the three countries (see Csaba, 1992, pp. 14-24).

Trade creation generated by regional economic cooperation, contrary to cooperation characterized by trade diversion, would result in better resource allocation in the participating countries with beneficial effects in the long run. Trade can be created in a bilateral relation or in mutual trade of a group of countries by mutual elimination of the quantitative and tariff barriers of trade. The process of the gradual elimination of trade barriers eventually comes to an end: efforts to create more trade by this strategy make no sense once all barriers are removed. This triviality has special significance, as the Visegrád Group countries have agreements with the EC and the EFTA to achieve free trade in industrial products in the course of a ten-year-long transitional process. Therefore, the efforts to boost intra-Visegrád Group trade by reducing barriers have a perspective of ten (better to say, already only nine) years, since, if things work out according to plan, conditions of trade for each country in the Visegrád Group vis-à-vis the other two and with Western Europe will be the same (except for agricultural products). The intra-Visegrád Group cooperation may "compete" with its cooperation with EC and EFTA countries first by envisaging a shorter period of transition from the present state of affairs to free trade of industrial products and, second, by including agricultural products in free trade.

\section{Discrimination against neighboring countries}

It may seem strange that the strongest motive for setting up intra-Visegrád Group cooperation is a defensive one. Without establishing free trade within the Visegrád Group, mutual negative discrimination of the Visegrád Group partners vis-à-vis trade with the EC will automatically emerge as the stipulations of the agreements on free trade with the EC come into force. Mutual negative discrimination against neighboring countries' trade would lead to 
misallocation of resources and unnecessary trade diversion, implying higher import prices and lost opportunities for stepping up exports, especially of commodities with high transport costs. Furthermore, once an agreement on free trade between the Visegrád Group countries comes into force, the EC probably applies a less restrictive regulation of origin for products containing components produced in more than one Visegrád Group countries.

\section{The launching of free trade in Central Eastern Europe}

The multilateral agreement on establishing free trade among the Visegrád Group countries was eventually signed on 21 December 1992 by the Czech Republic, Hungary, Poland, and Slovakia.

Why did the birth of the Central European Free Trade Association (CEFTA) last so long? In 1992 the euphoria about the hastily concluded bilateral agreements with the EC envisaging free trade was gone, and voices from the Visegrád Group countries criticizing the quick liberalization of imports and demanding more protection for domestic producers grew louder. The governments concerned, after the conclusion of the EC agreements and under increasing pressure from competing EC imports, needed great courage to step up pressure on suppliers of the domestic market by allowing additional competing imports when introducing free trade with the Visegrád Group partners. True, each government concerned might have pointed to the increasing export opportunities that would follow the conclusion of the free trade arrangements. At the time of the negotiations with the EC, increased export opportunities were the main concern of Visegrád Group negotiators. But in view of the much deeper than expected recession in 1991, the delayed recovery in 1992, and the rapid rise in unemployment, it seems that a more protectionist attitude to intra-Visegrád Group trade was hardly avoidable.

In the free trade agreement the four countries undertook to abolish gradually all tariffs and quantitative restrictions of industrial products in mutual trade in the period from 1 March 1993 to 1 January 2001, in three stages. In the first stage no tariffs are to be imposed for goods on List A. These are commodities making up, for instance, 38 percent of the exports of the Hungarian industrial products to the Czech Republic and Slovakia and 48 percent of those to Poland. Some 19 percent of Poland's industrial exports to Hungary and from 23 percent to 24 percent of the Czech Republic's and Slovakia's exports to Hungary are free of tariffs from March 1993. Commodities in List B can be delivered free of tariffs beginning in January 1997. 
Finally, free trade will apply to sensitive products (textiles, clothing, metallurgical products, and vehicles in List C) beginning in January 2001. For agricultural products, free trade is not envisaged, but mutual concessions will be made. In the first two years tariffs will be decreased by 20 percent, and within five years by 50 percent [Figyelö (Spectator), 23 December 1992].

\section{Can trade between the Visegrád Group countries recover?}

The separation of the market into two segments may help in addressing this question. The share of one segment of the pre-1991 mutual trade flows comprising goods of low quality has already shrunk radically after the introduction of hard currency payments and world market prices. These commodities were mainly machinery and industrial consumer goods, produced primarily by big state-owned industries which had specialized in the CMEA markets. Without the protective umbrella of the clearing system, the artificial prices, and strict administrative control to keep out Western imports, these commodities are not competitive and thus have no future in intraVisegrád Group trade.

This, however, does not necessarily mean that mutual trade is doomed to decline or even stagnate. In the three countries the transformation of the economy is taking place relatively more quickly and with more success in the foreign trade sector than in other sectors. Thousands of new participants have entered the market. Recent successes in exports to the West indicate that the products offered to the OECD markets are more competitive than they were under the old trade regime. There is no reason for assuming that the new (and after restructuring also the streamlined old) producers and trading firms entering the external markets with new, competitive products will not try to use every business opportunity provided by the Visegrád Group partners. This as yet not well-defined group of products and businesses comprises the other more prospective segment of the the Visegrád Group countries. Within a few years probably very few traditional participants and traditionally traded manufactured products will remain in the intra-Visegrád Group exchange of goods. A clear indication of fundamental changes in this field is that in 1991 no less than half of the Hungarian exports to Poland was supplied by private firms, while the respective share for the Polish exports was 30 percent [Magyar Hirlap (Hungarian News), 11 April 1992].

Can anything be said about the likely future composition of the mutual trade flows? Most probably high-technology products will be rather rare 
in the mutual trade of the three countries, since apart from exceptional cases such products will be imported from the OECD region. Second, it also seems likely that the commodities whose competitiveness is based on cheap and relatively well-skilled labor will compete with each other on third markets rather than make up a dynamic part of the intra-Visegrád Group trade flows. Nevertheless intra-industry trade, characterizing the exchange of goods among highly developed industrial nations, may increase in the intra-Visegrád Group trade flows. This can easily occur if multinational firms establish their outlets in more than one Visegrád Group country with the intention of bringing about intensive cross-border cooperation.

\section{Intra-regional trade in the light of other experiences}

The question of whether the anticipated, mainly newly "created" mutual trade will ever attain the relative importance (shares in total trade) of the "good old" days of the CMEA can certainly not be answered today (Tóth, 1992). Looking for references for regional cooperations in the world economy, one example is obvious from the past. The Austro-Hungarian monarchy embraced, among others, territories of the present-day Visegrád Group economies, i.e., Hungary, the former CSFR, and southern Poland. However, this comparison may be misleading as the motivating force of that historical cooperation, Austria, is not a member of the Visegrád Group. Furthermore, it is important to note that in the monarchy the whole modernization and industrialization process took off within what was practically a single economy; the economic relations among firms in different parts of the empire were not then thought to be, and probably should not now be analyzed as, foreign trade (Good, 1984, pp. 96-124).

Looking for comparable cases in today's world economy, where neighboring economies at medium levels of development maintain intensive mutual trade relations, the findings are surprisingly disappointing. In the following the result of the analysis of three cases are to be summarized: the intraregional trade of the four South Asian Tigers, the bilateral trade of the two countries in the Iberian peninsula, and the intra-regional trade of four member countries of the Latin American Integration Association.

In the case of the four South Asian Tigers (Taiwan, South Korea, Singapore, and Hong Kong) the share of the other three Tigers in total export and import of each country was not especially significant (see Table 7.9). In none of the selected years did the combined trade share of the other three countries reach 20 percent, and, in two-thirds of the cases (years) analyzed, 
Table 7.9. The share of mutual trade flows in foreign trade of Taiwan, South Korea, Singapore, and Hong Kong, in selected years.

\section{Three}

South Singa- Hong countries

Taiwan Korea pore Kong together World

Share of individual countries (regions) of destination in total exports Exporting countries

\begin{tabular}{lllllrrr} 
Taiwan & 1960 & $\times$ & 3.7 & 2.3 & 12.6 & 18.6 & 100.0 \\
& 1970 & $\times$ & 1.9 & 2.4 & 9.2 & 13.5 & 100.0 \\
\multirow{5}{*}{ South Korea } & 1980 & $\times$ & 1.3 & 2.8 & 7.8 & 11.9 & 100.0 \\
& 1987 & $\times$ & 1.2 & 2.5 & 7.7 & 11.4 & 100.0 \\
& 1960 & 1.2 & $\times$ & 1.2 & 8.2 & 10.6 & 100.0 \\
\multirow{5}{*}{ Singapore } & 1980 & $1.8^{a}$ & $\times$ & 1.3 & 3.3 & 6.4 & 100.0 \\
& 1987 & $1.1^{a}$ & $\times$ & 1.5 & 4.7 & 7.4 & 100.0 \\
& 1960 & 0.2 & 0.7 & $\times$ & 1.7 & 7.8 & 100.0 \\
\multirow{5}{*}{ Hong Kong } & 1970 & $0.3^{a}$ & 0.7 & $\times$ & 4.1 & 2.6 & 100.0 \\
& 1980 & 1.7 & 1.5 & $\times$ & 7.7 & 10.9 & 100.0 \\
& 1987 & 2.7 & 1.7 & $\times$ & 6.3 & 10.7 & 100.0 \\
& 1960 & 1.9 & 0.9 & $4.3^{a}$ & $\times$ & 7.1 & 100.0 \\
& 1970 & $1.1^{a}$ & 0.7 & 4.0 & $\times$ & 5.8 & 100.0 \\
& 1980 & $1.3^{a}$ & 1.2 & 4.4 & $\times$ & 6.9 & 100.0 \\
& 1987 & 3.2 & 2.6 & 2.7 & $\times$ & 8.5 & 100.0
\end{tabular}

Share of individual countries (regions) of origin in total imports Importing countries

\begin{tabular}{llllllll} 
Taiwan & 1960 & $\times$ & 0.1 & 0.4 & 1.6 & 2.1 & 100.0 \\
& 1970 & $\times$ & 1.0 & 0.3 & 1.8 & 3.1 & 100.0 \\
& 1980 & $\times$ & 1.1 & 1.1 & 1.3 & 3.5 & 100.0 \\
South Korea & 1987 & $\times$ & 1.5 & 1.5 & 2.2 & 5.2 & 100.0 \\
& 1960 & 1.6 & $\times$ & 0.0 & 0.4 & 2.0 & 100.0 \\
& 1970 & $1.4^{a}$ & $\times$ & 0.7 & 0.8 & 2.9 & 100.0 \\
\multirow{5}{*}{ Singapore } & 1980 & $1.2^{a}$ & $\times$ & 0.7 & 0.4 & 2.3 & 100.0 \\
& 1987 & $1.3^{a}$ & $\times$ & 0.9 & 0.8 & 3.0 & 100.0 \\
& 1960 & 0.5 & 0.0 & $\times$ & 2.2 & 2.7 & 100.0 \\
& 1970 & $1.5^{a}$ & 0.5 & $\times$ & 2.5 & 4.5 & 100.0 \\
Hong Kong & 1980 & 2.4 & 1.2 & $\times$ & 2.1 & 5.7 & 100.0 \\
& 1987 & 4.6 & 2.7 & $\times$ & 3.7 & 11.0 & 100.0 \\
& 1960 & 2.1 & 0.3 & $1.9^{a}$ & $\times$ & 4.3 & 100.0 \\
& 1970 & $4.7^{a}$ & 0.9 & 2.0 & $\times$ & 7.6 & 100.0 \\
& 1980 & $6.9^{a}$ & 3.5 & 5.0 & $\times$ & 15.4 & 100.0 \\
& 1987 & 8.8 & 4.5 & 3.8 & $\times$ & 17.1 & 100.0 \\
\hline
\end{tabular}

${ }^{a}$ Calculated from import and export data, respectively, of partner countries.

Sources: International Trade Statistical Yearbook, United Nations; Yearbook of Statistics, Singapore, 1989; Taiwan Trade Information. 
they did not reach even a 10 percent share. There is no unambiguous answer to the question whether, parallel to the rapid export-led economic growth experienced in these economies, the relative significance of mutual trade increased or decreased. Of the 24 one-way bilateral trade relations (12 export and 12 import relations) in the selected years, the share of the individual partner countries increased unambiguously in nine cases, decreased in three cases, and in the rest of the cases, i.e., in half of all cases, the changes had no clear direction.

In the bilateral relations between Spain and Portugal the relative significance of mutual trade (measured by shares in total trade in selected years in the period from 1960 to 1988) increased substantially, true, from an unbelievably low base. Even so Portugal's share in the foreign trade of Spain was still quite modest in 1987, 2 percent in imports and 6 percent in exports. Spain's role in Portugal's foreign trade has been substantially larger; nevertheless in 1988 Spain's share of Portugal's export and import was under 15 percent.

In the third region analyzed (Brazil, Argentina, Uruguay, and Chile), ${ }^{6}$ with the exception of Uruguay, the share of trade with the region's economies was well under 20 percent in selected years between 1960 and $1987 .{ }^{7}$ Of the 24 bilateral relations in the selected years, 14 failed to show an unambiguous direction in the change of the relative significance (share in total trade) of the bilateral relation concerned. In nine cases the relative significance increased, and in one case it decreased.

What could regional economic cooperation groupings and integration blocs of the less developed countries achieve in enhancing intra-group trade? As data in Table 7.10 demonstrate the share of intra-group trade was well under or in a few cases close to 10 percent, except for the Central American Common Market (CACM) and the Association of South East Asian Nations (ASEAN) and, generally, it did not increase between 1981 and 1988 (UNCTAD, 1990, pp. 2-5). Reviewing the development of seven Third World integration groupings with a history of at least 25 years, the researchers of UNCTAD point out that although trade liberalization has led to an initial rapid growth in mutual trade, it did not prove to be sufficient to ensure that the expansion in intra-group trade was sustained. In most integration blocs

\footnotetext{
${ }^{6}$ Each country is a member of the Latin American Integration Association (ALADI), a successor of the Latin American Free Trade Association.

${ }^{7}$ Except for Chile's import in 1970.
} 
Table 7.10. Economic integration groupings of developing countries: intragroup trade as a percentage of total exports of each group.

\begin{tabular}{lrrrrrr}
\hline & 1981 & 1985 & 1986 & 1987 & 1988 & 1989 \\
\hline Africa & & & & & & \\
CEAO & 10.1 & 7.1 & 6.5 & 8.4 & 10.5 & n.a. \\
CEEAC & 2.4 & 1.4 & 2.8 & 2.9 & 3.7 & n.a. \\
CEPGL & 0.2 & 0.8 & 0.6 & 0.7 & 0.7 & n.a. \\
ECOWAS & 4.6 & 2.5 & 3.2 & 4.0 & 4.9 & n.a. \\
MRU & 0.1 & 0.4 & 0.4 & 0.5 & 0.6 & n.a. \\
PTA & 9.0 & 7.5 & 6.9 & 8.9 & 8.0 & 7.8 \\
SADCC & 5.7 & 4.9 & 5.9 & 6.1 & 5.0 & n.a. \\
UDEAC & 3.0 & 2.0 & 3.0 & 3.2 & 3.6 & n.a. \\
America & & & & & & \\
ALADI & 12.6 & 9.6 & 11.5 & 10.9 & 10.7 & 10.6 \\
Andean Group & 3.4 & 3.1 & 3.3 & 5.5 & 5.2 & 3.9 \\
CACM & 20.7 & 15.9 & 17.7 & 13.2 & 14.4 & n.a. \\
CARICOM & 7.4 & 5.5 & 5.4 & 3.0 & 3.3 & n.a. \\
Asia & & & & & & \\
ASEAN & 18.9 & 17.9 & 16.7 & 17.6 & 17.5 & n.a. \\
Bangkok Agreement & 1.9 & 2.5 & 2.2 & 1.7 & 1.4 & n.a. \\
ECO & 4.2 & 10.0 & 9.1 & 6.1 & 4.5 & n.a. \\
GCC & 3.4 & 4.6 & 5.8 & 5.6 & 5.4 & n.a. \\
\hline
\end{tabular}

Not all country groups have extended and implemented mutual trade preferences.

CEAO (West African Economic Community)

CEEAC (Economic Community of Central African States)

CEPGL (Economic Community of the Great Lakes Countries)

ECOWAS (Economic Community of West African States)

MRU (Mano River Union)

PTA (Preferential Trade Area for Eastern and Southern African States)

SADCC (Southern African Development Co-ordination Conference)

UDEAC (Central African Customs and Economic Union)

ALADI (Latin American Integration Association)

CACM (Central American Common Market)

CARICOM (Caribbean Community)

ASEAN (Association of South East Asian Nations)

ECO (Economic Co-operation Organization)

GCC (Co-operation Council for the Arab States of the Gulf)

Source: UNCTAD, 1990, p. 5.

the initial growth in mutual trade had soon reached a peak after which the volume of mutual trade either stagnated or declined (UNCTAD, 1990, p. 3). 


\section{Can future trade flows be predicted?}

Under the peculiar conditions of CMEA trade the member countries were, to a significant extent, isolated from the main stream world economy. It was obvious to everyone that the introduction of hard currency payments and world market prices, and the dissolution of the CMEA itself would bring about a rearrangement in the geographical composition of the EE5 foreign trade. It was also obvious that intra-CMEA trade, artificially inflated in the last decades, would play a less important role after the changeover to the new trade regime. Well-founded assumptions of future trade flows, however, would be of vital importance for elaborating feasible foreign trade strategies and applicable trade policy recommendations. A few recent publications have made predictions on future trade flows.

In an article published in 1989 , before the fundamental political changes in Eastern Europe, Nagy (1989) calculated trade intensity indicators which reflect the deviations of actual trade flows from hypothetical "normal" trade flows. Nagy's trade intensity indicator shows the ratio between the share of a given country's exports in total imports of a partner country and the share of this country's total exports in world trade. For example, in 1980 the share of the Soviet Union's exports to the CMEA made up no less than 39 percent of total imports of the CMEA, while total Soviet exports amounted to only 3.6 percent of total world trade. The ratio, i.e., the trade intensity, is 10.8 , implying that actual trade in that year was more than 10 times higher than normal trade. The comparison of actual trade flows of the CMEA countries with their hypothetical normal trade flows in selected years between 1960 and 1980 shows that actual trade between the six small European CMEA countries and the Soviet Union was 9 to 13 times higher than it would have been in the normal case defined by the share of the Soviet Union in the world trade. The intensity of the mutual trade of the six small CMEA countries was only half that of their trade with the Soviet Union; nevertheless the actual trade flows were still five to six times higher than the normal ones. Nagy's research on trade intensity of other regions and countries in the world economy proved that trade between strongly integrated countries/regions was characterized by an intensity two to three times higher than normal trade. According to his calculations if the intensity in mutual trade of the CMEA countries dropped, as a consequence of an opening toward the world economy, from the earlier extremely high level to three times the normal intensity, the share of mutual trade in total trade of these countries would 
Table 7.11. Geographical composition of trade of the CSFR, Hungary, and Poland in 1928, 1989, and predicted, percentages of total.

\begin{tabular}{|c|c|c|c|c|c|c|}
\hline \multirow[b]{2}{*}{ Country and partner } & \multicolumn{3}{|c|}{ Imports } & \multicolumn{3}{|c|}{ Exports } \\
\hline & 1928 & 1989 & Predicted & 1928 & 1989 & Predicted \\
\hline \multicolumn{7}{|l|}{$\overline{C S F R}$} \\
\hline EC & 54.79 & 15.37 & 55.02 & 43.92 & 16.46 & 46.28 \\
\hline United States & 5.94 & 0.32 & 3.48 & 5.56 & 0.56 & 4.73 \\
\hline Japan & 0.07 & 0.33 & 3.95 & 0.19 & 0.76 & 1.55 \\
\hline Eastern Europe & 16.67 & 16.66 & 7.69 & 20.55 & 16.45 & 10.77 \\
\hline Soviet Union & 1.04 & 45.58 & 10.20 & 1.32 & 43.14 & 14.28 \\
\hline Other & 21.49 & 21.74 & 19.66 & 28.46 & 22.64 & 22.40 \\
\hline \multicolumn{7}{|l|}{ Hungary } \\
\hline EC & 32.40 & 30.93 & 47.07 & 25.00 & 24.15 & 37.16 \\
\hline United States & 3.63 & 1.60 & 2.78 & 0.82 & 2.83 & 2.77 \\
\hline Japan & 0.00 & 1.21 & 3.72 & 0.00 & 1.15 & 1.40 \\
\hline Eastern Europe & 40.22 & 14.25 & 12.47 & 33.61 & 14.41 & 15.03 \\
\hline Soviet Union & 0.28 & 24.28 & 14.94 & 0.41 & 28.29 & 18.01 \\
\hline Other & 23.46 & 27.74 & 19.02 & 40.16 & 29.17 & 25.62 \\
\hline \multicolumn{7}{|l|}{ Poland } \\
\hline EC & 54.39 & 27.73 & 55.69 & 55.88 & 30.45 & 51.18 \\
\hline United States & 13.95 & 1.78 & 5.43 & 0.84 & 2.73 & 2.94 \\
\hline Japan & 0.00 & 1.41 & 3.99 & 0.29 & 0.97 & 1.59 \\
\hline Eastern Europe & 9.09 & 13.46 & 6.00 & 16.60 & 14.13 & 9.31 \\
\hline Soviet Union & 1.10 & 26.11 & 8.96 & 1.68 & 24.96 & 13.89 \\
\hline Other & 21.47 & 29.50 & 19.93 & 24.71 & 26.77 & 21.09 \\
\hline
\end{tabular}

Source: Collins and Rodrik, 1991, pp. 39-40.

fall to one-half or one-third of the 1986 level. Nagy proved to be prophetic: exactly that happened between 1990 and 1991 .

Recently further attempts have been made to predict future trade flows of the former CMEA countries. In their model Collins and Rodrik worked under the dual assumption that the Eastern European countries had never become socialist and that their trade would have developed after 1928 in parallel with the "average" pattern exhibited in six other countries - Austria, Finland, Germany, Italy, Portugal, and Spain (Collins and Rodrik, 1991, p. 43). Their estimation also adjusted for the special position the Soviet Union had in 1928. The authors implicitly assumed that the Soviet Union and Eastern Europe (SUEE) had generally unhindered access to the markets of Western countries, and to those of the EC, in particular. Their predictions on 
Table 7.12. Developments of EE5 trade with the EC, between 1985 and 1992.

\begin{tabular}{lrrrr} 
& \multicolumn{2}{l}{ EC's share in total trade } & & \\
\cline { 2 - 3 } & 1985 & 1990 & 1991 & 1992 \\
\hline Export & & & & \\
Bulgaria & 6.4 & 5.0 & 15.7 & 30.8 \\
CSFR & 9.1 & 26.9 & 40.7 & 49.4 \\
Hungary & 15.8 & 32.2 & 46.8 & 49.8 \\
Poland & 22.4 & 47.2 & 55.6 & 58.0 \\
Romania & 25.4 & $31.5^{a}$ & 34.5 & 32.5 \\
Import & & & & \\
Bulgaria & 9.4 & 9.6 & 20.7 & 32.6 \\
CSFR & 8.6 & 24.0 & 34.6 & 42.1 \\
Hungary & 21.2 & 31.0 & 42.2 & 42.8 \\
Poland & 20.1 & 45.6 & 49.9 & 33.2 \\
Romania & 10.3 & $19.7^{a}$ & 25.2 & 37.5 \\
\hline
\end{tabular}

${ }^{a}$ Including trade with the former GDR.

Source: National statistics.

the geographical breakdown of SUEE foreign trade presented in Table 7.11 can be interpreted as a likely final outcome of foreign trade development and reorientation following the transition of the countries to a market economy. The authors predict, compared with 1989 actual trade flows, a dramatic reorientation toward the West: first of all toward the EC and Germany in particular. Their prediction coincides with actual developments after 1990 (see Table 7.12). Collins and Rodrik (1991, p. 67) finally come to the conclusion that the natural trade partners of SUEE are the advanced industrial countries of Europe, rather than one another.

In their gravity model Hamilton and Winters (1992) try to determine how the SUEE economies may behave (concerning foreign trade flows) once they become market economies. In their model the ultimate determinants of potential trade flows are GNP, population of exporting and importing countries, and distance. The authors focused first of all on trade volumes. They conclude that, taking into consideration actual trade flows of the year 1985, "SUEE trade with market economies falls dramatically short of its potential" (Hamilton and Winters, 1992, p. 81). Havrylyshyn and Pritchett (1991, cited by Steinherr, 1992) also use a gravity model to predict geographical rearrangement in foreign trade of the SUEE. Their findings also suggest that Eastern European countries will increase their trade with Western Europe 
dramatically. As a consequence, in most Eastern European countries, the share of this trade will exceed 70 percent. In contrast, the share of trade among themselves (including the former USSR) is expected to decline dramatically, to less than 25 percent for most Eastern European countries. The results of their computations make it clear that very little is left over for trade with non-European countries, suggesting that the economies of Eastern Europe need to organize their foreign trade and financial systems in view of their dominant trade relationship with Western Europe (Steinherr, 1992, p. 4).

\section{Conclusions}

The introduction of convertible currency payments and world market prices in early 1991, coupled with the liberalization of imports from the rest of the world and the growing chaos in the Soviet Union/CIS, accelerated the decline of mutual trade among the former CMEA economies. The available data on the composition of trade show a fundamental rearrangement. The share of sophisticated manufactures, primarily machinery, decreased dramatically in mutual trade of the Visegrád Group economies; the share of exports of machinery from the CSFR and Hungary to the Soviet Union has, however, remained high, despite the decline compared with the pre-1991 era.

The issue of regional economic cooperation among the former five Eastern European economies is treated as being subordinate to their relations with the EC. This attitude is a result of well-founded economic and political considerations but also of illusions about the "European values" and of mistrust of one another.

Various recently published research results suggest that the Eastern European countries have huge potential for trade expansion with Western Europe while this potential in their mutual trade is fairly limited. An analysis of development of intra-regional trade of neighboring countries in Southeast Asia, Southern Europe, and Latin America and a review of experiences of attempts to enhance economic integration in various groups of less developed countries show that mutual trade of economies at medium or low levels of economic development cannot replace trade with the highly industrialized "core" of the world economy. This has a clear foreign trade strategy implication for Eastern Europe: there is no modernization and sustainable economic growth without intensive trade with the OECD, particularly with the EC. 
This necessitates the greatest efforts for Eastern European governments to create the optimal conditions for export expansion to Western Europe.

The EC, which has let more trade barriers prevail vis-à-vis the Visegrád countries than really justified, has to be aware that there is neither political nor economic stability on its eastern borders without the reintegration of Eastern Europe into "Europe."

Justified priority for relations with the EC, however, does not mean that the potential, even if limited, for intra-regional cooperation in Central and Eastern Europe should not be exploited. The low level of mutual trade in 1991 and 1992 surely lags behind this potential.

Since forced trade diversion to boost intra-regional relations would lead to a similar misallocation of resources as it did in the former CMEA, and as it would contradict valid and forthcoming trade agreements with the $\mathrm{EC}$ and the EFTA, it should be avoided. Consequently there are basically three scenarios for a framework for mutual trade among the EE5 economies. ${ }^{8}$ First, that mutual trade remains on the basis of most favored nation treatment. Second, quantitative and tariff barriers in mutual trade are removed more or less simultaneously with the gradual elimination of these barriers to imports from the EC. The third option calls for the establishment of free trade with one another substantially quicker than with the EC.

The first option leads to unnecessary trade diversion and to misallocation of resources, thus it can be regarded as a worst case scenario. The second and third scenarios create equal or better conditions for intra-regional trade than for trade with the EC. But the third scenario gives Eastern European producers a couple of years' lead in various groups of commodities.

The agreement on the establishment of free trade among the successor states of the former CSFR, Hungary, and Poland makes it likely that the second scenario will be implemented, at least for three of the former EE5 countries, while in the case of Bulgaria and Romania the worst case scenario will prevail.

At present there are no plans for an extension of regional cooperation with new members. It seems that any enlargement would need clear signals from Brussels that the EC is ready to renounce the bloc approach and that the Visegrád Group countries will have no reason to worry that an enlargement would have a negative impact on their bargaining position with the EC in future negotiations about their accession.

\footnotetext{
${ }^{8}$ With the separation of the Czech Republic and Slovakia the category EE5 does not apply any longer; here it is used for the sake of simplicity.
} 


\section{References}

Collins, S.M., and Rodrik, D. (1991) Eastern Europe and the Soviet Union in the World Economy (Washington, DC: Institute for International Economics).

Csaba, L. (1992) Economic Consequences of Soviet Disintegration for Hungary, Discussion Papers No. 2 (Budapest: KOPINT-DATORG).

Good, D.F. (1984) The Economic Rise of the Habsburg Empire 1750-1914 (Berkeley, CA: University of California Press).

Hamilton, B.C., and Winters, L.A. (1992) "Opening up international trade with Eastern Europe," Economic Policy, April.

Havrylyshyn, O., and Pritchett, L. (1991) European Trade Patterns after the Transition, Working Paper WP5748 (Washington, DC: World Bank).

Illés, I., Mizsei, K., and Szegvári, I. (1991) "Válaszúton a közép-európai gazdasági együttmüködés" (Central and Eastern European economic cooperation at a crossroad), Európa Fórum, October.

Nagy, A. (1989) "Külkereskedelmi orientáció váltást!" (The orientation of foreign trade must be changed), Közgazdasági Szemle (Economic Review), September.

Rácz, M., and Richter, S. (1989) Some Aspects of the Hungarian-Soviet Economic Relations in 1971-1985, Research Report No. 153 (Vienna: Vienna Institute for Comparative Economic Studies).

Richter, S. (1989) The Economic Relations of Austria, Finland, Yugoslavia, and Hungary with the Soviet Union, Research Report No. 161 (Vienna: Vienna Institute for Comparative Economics Studies).

Steinherr, A. (1992) "The evolution of East-West trade and the role of the ECU in Eastern Europe," Moct-Most, September.

Tóth, G.L. (1992) "The dubious unity of the Visegrád Group countries," Figyelo" (Spectator), July 5.

UNCTAD (1990) Economic Integration among Developing Countries: Trade Cooperation, Monetary and Fiscal Co-operation and Review of Recent Developments in Major Economic Co-operation and Integration Groupings of Developing Countries, TD/B/C.7/AC.3/10 (Geneva: UNCTAD). 


\section{Chapter 8}

\section{Trade Patterns and Comparative Advantages of Central Eastern Europe with EC Countries*}

Giovanni Graziani

\section{Introduction}

Good export performance in Western markets by Hungary, Poland, the CSFR, and Bulgaria in 1990 and 1991, coupled with the new climate of trade liberalization on both sides, is sometimes described as the bright spots in an otherwise dim economic picture due to the mounting difficulties of the transition process (UN ECE, 1991). At the same time, some see the possibility of an export-led economic recovery for these Central and Eastern European countries (CEECs). Predictions of huge, long-run increases in trade with the West add to the optimism (Collins and Rodrik, 1991; Wang and Winters, 1991; and Hamilton and Winters, 1992). However, the path to recovery is not as smooth as it appears, even on the trade front. Some of the obstacles can best be understood by making first a structural analysis of the basic features of the EC-CEEC trade flows.

\footnotetext{
*Some sections are reprinted from Graziani (1993), by permission of the publisher.
} 
Table 8.1. Market shares in EC imports, in percent.

\begin{tabular}{lll}
\hline Countries & 1980 & 1991 \\
\hline Bulgaria & 0.10 & 0.06 \\
CSFR & 0.28 & 0.35 \\
Hungary & 0.26 & 0.32 \\
Poland & 0.45 & 0.53 \\
Romania & 0.34 & 0.13 \\
Total CEECs & 1.43 & 1.38 \\
Hong Kong & 0.67 & 0.72 \\
Korea, Republic of & 0.38 & 0.68 \\
Singapore & 0.27 & 0.49 \\
Taiwan & 0.41 & 0.96 \\
Indonesia & 0.22 & 0.30 \\
Malaysia & 0.34 & 0.41 \\
Thailand & 0.24 & 0.43 \\
\hline
\end{tabular}

Source: Calculated from UN, Comtrade.

Strong structural asymmetries characterize the EC-CEEC trade flows. The first is the different relative importance of reciprocal trade. The EC is by far more important to the CEECs than the CEECs are to the EC. From the 1970s until 1985, the EC's share in the total CEECs' trade was roughly 14 percent, while the CEECs' share in the EC's total trade was just over 2 percent (Graziani, 1985, 1987). This asymmetry was enhanced in the late 1980s, and there has been a real upsurge in the first two years of the 1990s. By 1991, the shares of total exports from the CEECs to EC countries were the following: Bulgaria (16 percent), the CSFR (41 percent), Hungary (46 percent), Poland ( 56 percent), and Romania ( 36 percent). The EC was also of paramount importance as a supplier of the CEECs' imports: 21 percent, 33 percent, 41 percent, 50 percent, and 25 percent, respectively. In addition, the EC constitutes a major outlet for Eastern European exports to the OECD: roughly three-quarters since German unification took place. Germany is by far the main outlet within the EC; Italy, France, and the UK follow somewhat behind. On the other side, the CEECs accounted for only 1.38 percent of the EC's total imports in the same year (Table 8.1) and for roughly the same amount of its exports. This enormous discrepancy, which cannot be explained merely by the different relative sizes of the two regions, is a basic fact that must be kept in mind when assessing the possible impact of any EC trade liberalization process. 
In addition to being relatively low, the CEECs' total market shares in the EC slowly declined up to 1980 , followed by a slight increase and stabilization until 1985, at which time a steady loss continued until the late 1980s. In this last period, Hungary and Poland were the only countries which were able to keep their position stable. Since 1990, a recovery of market shares has taken place in all CEECs, except Romania. Altogether, the CEECs' market share in the EC in 1991 was still lower than a decade before (1.38 percent as compared with 1.43 percent); however, the CSFR, Hungary, and Poland have slightly improved their positions (Table 8.1). By contrast, all the main competitors from the Far East have substantially increased their shares in the market - in the case of Taiwan more than doubling it. In 1991, the combined share of the "Four Tigers" (Singapore, Hong Kong, the Republic of Korea, and Taiwan) was 2.85 percent (up from 1.74 percent in 1980), i.e., just over twice the CEECs' value. Rapidly developing fast exporters, like Thailand, Malaysia, and Indonesia, are now accounting for shares of the EC market comparable to the better-performing CEECs.

\section{The EC Import Structure with Regard to the CEECs}

Trends in global trade can be understood better by analyzing the commodity structures and the relative balances by product groups.

The EC import structure in relation to the CEECs is rather diversified, although for a long time primary products have accounted for the largest relative share. Within the primary products sector the biggest role used to be played by fuels, the leading single category in the early 1980 s (here shares in import ranged between 5 percent and 43 percent; see Table 8.2). Particularly visible was the importance of this group in Bulgaria, Romania, and Poland. It should not be forgotten, however, that not all these mineral fuels are raw materials. If one excludes Polish and possibly some Czech coal, the rest consisted mainly of petroleum products that CEECs processed on the basis of Soviet and OPEC oil. The generally cheaper Soviet oil, which was not paid for in hard currency, represented for the CEECs substantial windfall gains, which have vanished since the establishment in 1991 of world market prices within the CMEA and the subsequent collapse of its trade. In 1991 fuels represented only between 2 percent and 13 percent of CEECs' exports, the latter share referring to Romania. Ores and metals accounted for between 


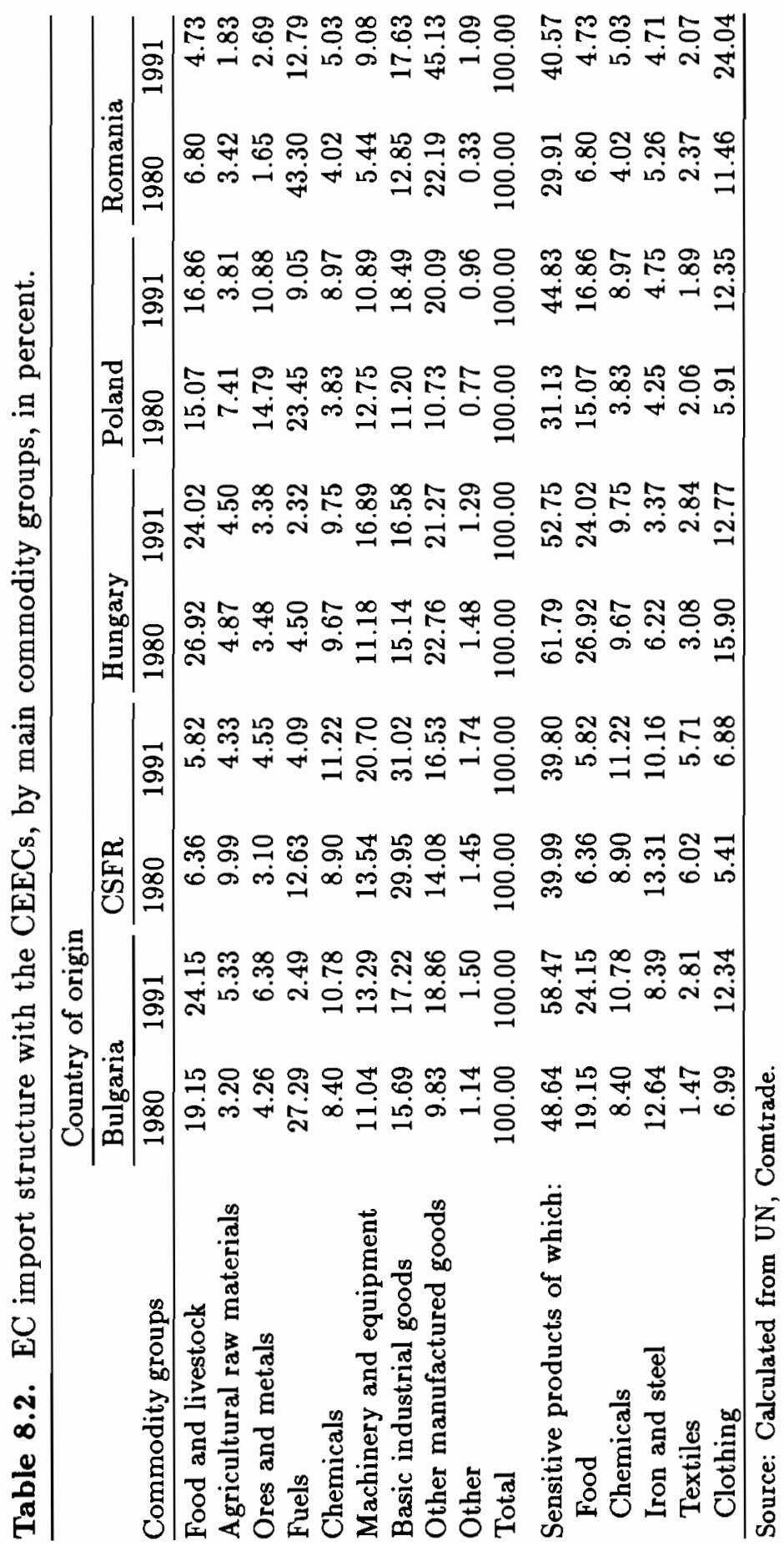


3 percent and 11 percent. Finally between 7 percent and 29 percent of the CEECs' exports to the EC were foodstuffs, livestock, and agricultural raw materials. This share was the highest in the case of Hungary (29 percent), Bulgaria (29 percent), and Poland (21 percent). These three countries are naturally bound to especially suffer from the Common Agricultural Policy. All in all, food and raw materials (SITC 0-4) occupied a rather large place in EC imports from the CEECs, certainly larger than in the equivalent flows from the world or the newly industrialized countries (NICs). The overall balance for primary products has always been negative for the EC.

Intermediate products represent another important category. Twothirds of them are accounted for by basic industrial goods (SITC 6 minus SITC 68), iron and steel and textile yarns and fabrics make up almost half ( 9 percent of total imports on average, but 16 percent for the CSFR). The EC countries, more than other more industrialized countries which are geographically so far away, like the USA or Japan, are natural markets for products which require high transport costs. However, their share for these products has been decreasing since 1977 for two main reasons: EC import restrictions, and growing competition from the NICs (Graziani, 1987). The balance is negative for the $\mathrm{EC}$ in intermediate products at large, but always positive for textiles.

The share of chemical products has generally been increasing since the early 1970 s, and reached 9 percent in 1991 on the average, with the CSFR, Bulgaria, and Hungary having a slightly higher share. The industrial cooperation agreements as a trade promoter between the two areas seem to have been particularly important in this sector. Here too, the balance has been positive for the EC.

The sector of finished manufactured goods is composed of two broad categories which exhibit different weights and patterns. Machinery and equipment, which has exhibited an increasingly negative balance for the CEECs, represents a relatively small share in EC imports, much smaller than in EC trade with the world ( 15 percent as compared with 34 percent). Its relative weight follows more or less the ranking of development within the CEECs: more important for the CSFR (21 percent) and Hungary (17 percent), at an intermediate level for Bulgaria (13 percent) and Poland (11 percent), and well under the average for Romania ( 9 percent). In some instances, these trade flows are the by-products of past intra-CMEA specialization, which made some of the CEECs able to exploit economies of scale: i.e., the CSFR in machine tools used for metal processing; Poland in ships, automobiles, 
and tractors; Hungary in buses and household appliances; Bulgaria in nonelectrical machinery; Romania in ball bearings and motor vehicle parts. The loss of market shares up to 1990 and the present very low level (0.6 percent of EC imports) seem to point to increasing difficulties in penetrating Western European markets. Apart from international competition, a further element of competition derives from the fact that the CEECs compete among themselves, especially in some manufactured products in the EC market. Some examples are the CSFR's competition with Hungary in polyethylene and PVC; with Poland in electric motors; and with Bulgaria in metal-working machine tools. The fundamental reason for this competition is the heritage of the so-called parallelism of the industrial structures, which results in the tendency to export similar products (Graziani, 1982). Enterprises from the CEECs are also increasingly competing for a globally reduced market share. Other negative factors include weak marketing strategies, lack of spare parts and after-sales services, poor infrastructure and financial services, apart from the well-known technological lag.

There is, however, a bright spot: the miscellaneous manufactured goods (SITC 8), which account for 22 percent of total exports from the CEECs to the EC, the highest values being 45 percent for Romania and 21 percent for Hungary (Graziani, 1993). Clothing, footwear, furniture, and traditionally labor-intensive industries have positively contributed to the trade balance of the CEECs, although EC tariff and nontariff measures coupled with increased competition from the developing countries seem to have limited possible further expansion.

If we look at a more disaggregated level (3-digit SITC) of the manufactures exported by each CEEC, only in a few instances is the share of total exports carried out by a single sector higher than the 2 percent of $\mathrm{EC}$ imports from the given country. Such is the case for manufactured fertilizers (Bulgaria and Poland), iron and steel ingots and universals (Bulgaria and the CSFR), mechanical-handling equipment and ships and boats (Bulgaria), outer garments (all CEECs), undergarments, refined petroleum products, and cement (Romania), polymerized products (the CSFR and Hungary), glassware and passenger cars (the CSFR), furniture (all CEECs except Bulgaria), and finally footwear (all except Bulgaria and Poland). In categories pertaining to the same division, the share is often higher of those products which are less refined or have less value added. Such is the case, for instance, of organic versus inorganic chemicals and of plastics in primary rather than in nonprimary forms. 
The importance of the EC trade policy with respect to CEECs can indirectly be gauged by the weight of the so-called sensitive sectors in the CEECs' export structures toward the EC. This is exactly where tariff and especially nontariff barriers were, and still are, relatively stronger. Food and agricultural materials, chemicals, iron and steel, and textiles and clothing represent 58 percent of total exports for Bulgaria, 53 percent for Hungary, 45 percent for Poland, 41 percent for Romania, and 40 percent for the CSFR. In the case of Bulgaria, Poland, and Romania, this share has even grown over the last decade (Table 8.2). In contrast, the same group of products accounts for less than one-third of EC imports from the world.

In short, the place of primary products in the export structure of the CEECs to the EC has been greatly reduced since the early 1980 s, thanks mainly to the decline of the supplies of fuels. Among the general advance of manufactures, only iron and steel suffered substantial losses on the average, with the exception of Poland.

\section{Resource Dependence, Factor Intensity, and Technological Level of the CEECs' Manufacturing Exports}

In this section we focus on the trade of manufacturing products. Following a procedure adopted in Graziani (1989), we have distinguished "resourcebased" from "non-resource-based" manufacturing exports. Further distinctions have been made for non-resource-based manufactures: whether they were characterized by low- or high-skill-intensive processes, or by low or high rates of development, or by labor- or capital-intensive processes. Finally, the same products have also been classified according to technology intensity and import demand growth. The analysis is based on UN Comtrade SITC data at the 3-digit level.

The picture emerging from Table 8.3 indicates that by 1991 all the CEECs had succeeded in reducing their share of resource-based exports to much less than half of their exports to the EC, whereas in 1980 three of them were well above 50 percent. This is a rather general phenomenon characterizing countries which climb the ladder of economic development. However, some of the main competitors of the CEECs seem to have done much better. On average, the share of resource-based exports from the world declined to 26 percent, as did the share of some of the newly emerging exporters (NECs) like Thailand and Malaysia. The newly industrialized countries' 
Table 8.3. Share of EC imports of manufactures classified according to resource dependence, in percent, rounded figures.

\begin{tabular}{llllll}
\hline \multirow{2}{*}{$\begin{array}{l}\text { Exporting } \\
\text { countries }\end{array}$} & \multicolumn{2}{l}{ Resource-based } & & \multicolumn{2}{c}{ Non-resource-based } \\
\cline { 2 - 3 } \cline { 5 - 6 } Bulgaria & 1980 & 1991 & & 1980 & 1991 \\
CSFR & 67 & 41 & & 33 & 59 \\
Hungary & 38 & 23 & & 62 & 77 \\
Poland & 42 & 35 & & 58 & 65 \\
Romania & 52 & 38 & & 48 & 62 \\
Total CEECs & 72 & 34 & & 28 & 66 \\
NECs $^{a}$ & 56 & 33 & & 44 & 67 \\
NICs $^{b}$ & 69 & 26 & & 31 & 74 \\
World & 8 & 3 & & 92 & 97 \\
\hline
\end{tabular}

${ }^{a}$ Indonesia, Malaysia, Philippines, Thailand.

${ }^{b}$ Hong Kong, Singapore, Republic of Korea, Taiwan.

Source: Calculated from UN, Comtrade. For the methodology see Graziani, 1989.

(NICs') share, already extremely low, plummeted to a mere 3 percent. By comparison, only the CSFR succeeded in reducing this amount to 23 percent, just under the world average, while the shares for the other four CEECs range between 34 percent and 41 percent. All in all, the CEECs' exports. are still more concentrated in resource-based manufactures, if compared to the world average and especially to their most important competitors in the EC markets. Apart from the situation with regard to processed agricultural products, such a bias is rather questionable for relatively resource-scarce countries like the CEECs.

The analysis of non-resource-based manufactures adds new dimensions to the present difficulties of CEECs' exports. First a distinction was made between the low and high level of skill intensity characterizing the different industries, as measured by the share of skilled labor employed. According to the relevant version of the product-cycle concept, one could call those industries that require low degrees of skill "mature" and those characterized by a high degree of skill intensity "new." Table 8.4 clearly shows that exports from CEECs are relatively much more concentrated in mature industries, as compared with both the world average and their competitors. For all of them, the share is equal to or higher than 65 percent. What is more, this percentage has even increased over the last decade for Poland and Romania, while remaining stable for Bulgaria. The importance of low-skill-intensive exports to the EC has diminished only in the case of Hungary and the CSFR. 


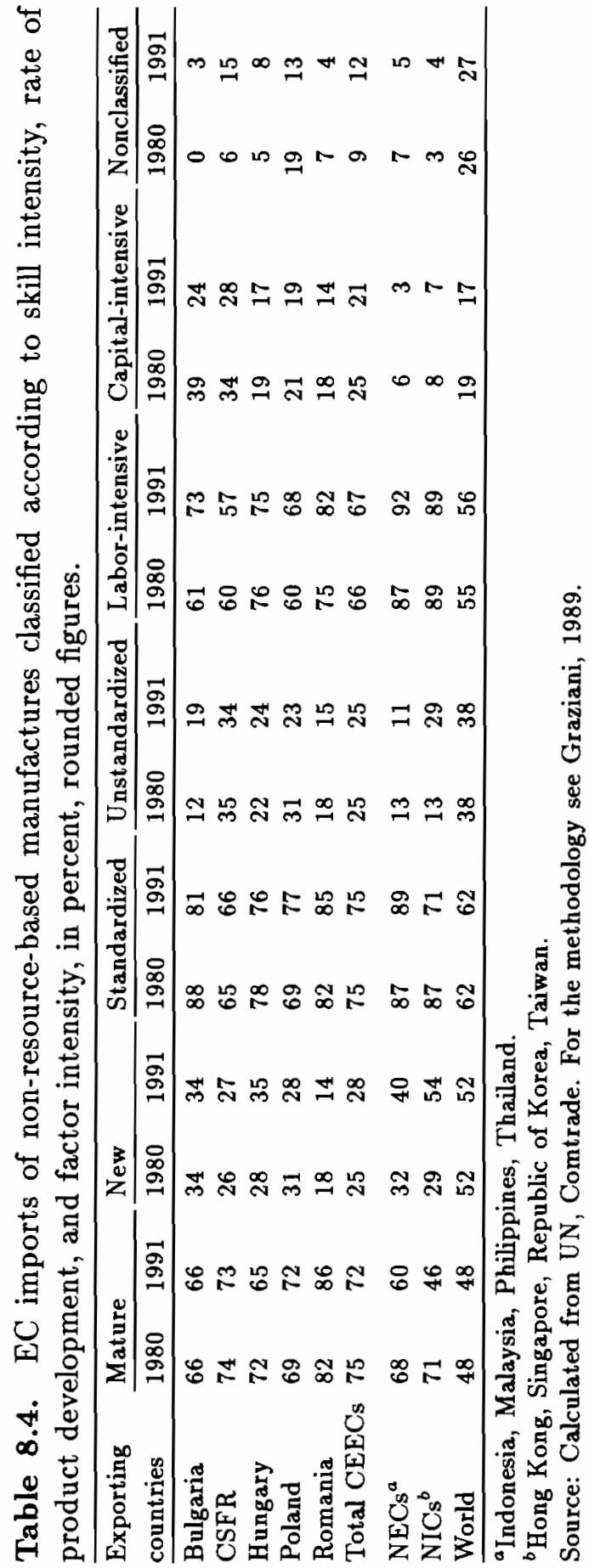


If we apply another interpretation of the product cycle in international trade, we can classify the industries according to their low or high rates of product development (measured by the number of items that appear or disappear over a period, as a share of the total number of items in the SITC group). Manufactures will then be called "standardized" in the first case, and "unstandardized" in the latter. From this point of view, quite a few differences exist between the CEECs and the rest of the world. Table 8.4 shows that the majority of import flows into the EC is represented by standardized products. However, the average share for the world (62 percent) is lower than for any of the CEECs. The CSFR is the only CEEC that shows a favorable ratio when compared with the world average (+4 percent) and the NICs ( -5 percent). Hungary and Poland, with roughly three-quarters of standardized products, have a higher share than the NICs, while Bulgaria and especially Romania come closer to the new Asian exporters (NECs), which show, on average, the highest figure ( 89 percent). As in the case of mature industries, Poland and Romania have increased their shares over the decade, while the CSFR has maintained the same level and the others have exhibited decreases. On the whole, then, standard manufactures appear to be at the core of intensive present and potential competition between the CEECs and their competitors on the EC market.

If, finally, non-resource-based manufactures are classified according to the well-known concept of factor proportions, labor-intensive products, on average, seem by far to dominate ( 67 percent, with peaks of 82 percent for Romania and 75 percent for Hungary), as against 21 percent of capitalintensive and 12 percent of nonclassified goods. By comparison, the shares for the NICs are 89 percent, 7 percent, and 4 percent, respectively, while the same for the other Asian exporters are 92 percent, 3 percent, and 5 percent, respectively. It is worth noting that the CEECs are, by consequence, relatively more concentrated on capital-intensive exports than their competitors. In addition, traditional labor-intensive industries like clothing, footwear, and furniture prevail over nontraditional ones, such as engineering.

Looking at the results it is interesting to see what changes occurred over the period from 1980 to 1991 within each homogeneous category. Considering the standardized, labor-intensive product groups, among the mature industries clothing, furniture, and glassware have increased their shares, while the shares of footwear have decreased. Among the new industries, other machinery, household equipment, and electrical machinery have improved their positions. Within the unstandardized, but mature, industries only the 
Table 8.5. Share of EC imports classified according to technology level, in percent, rounded figures.

\begin{tabular}{|c|c|c|c|c|c|c|}
\hline \multirow{2}{*}{$\begin{array}{l}\text { Exporting } \\
\text { countries }\end{array}$} & \multicolumn{2}{|c|}{ High technology } & \multicolumn{2}{|c|}{ Medium technology } & \multicolumn{2}{|c|}{ Low technology } \\
\hline & 1980 & 1991 & 1980 & 1991 & 1980 & 1991 \\
\hline Bulgaria & 3 & 5 & 20 & 30 & 77 & 65 \\
\hline CSFR & 6 & 9 & 24 & 33 & 70 & 58 \\
\hline Hungary & 5 & 10 & 26 & 26 & 69 & 64 \\
\hline Poland & 4 & 6 & 37 & 29 & 59 & 65 \\
\hline Romania & 2 & 3 & 11 & 16 & 87 & 81 \\
\hline $\mathrm{NECs}^{a}$ & 8 & 17 & 22 & 22 & 70 & 61 \\
\hline $\mathrm{NICs}^{b}$ & 14 & 29 & 29 & 36 & 57 & 35 \\
\hline World & 14 & 19 & 40 & 44 & 46 & 37 \\
\hline
\end{tabular}

${ }^{a}$ Indonesia, Malaysia, Philippines, Thailand.

${ }^{b}$ Hong Kong, Singapore, Republic of Korea, Taiwan.

Source: Calculated from UN, Comtrade. For the methodology see Graziani, 1989.

percent of textile articles has increased somewhat among the labor-intensive products, and the percent of motor vehicles and plastic materials has increased among the non-labor-intensive products.

Another interesting insight into the technological level of exports of manufactures can be gained by ranking them according to their $R \& D$ content, although the usual caveats should be applied to such types of classifications (Table 8.5). Low-technology sectors appear to dominate exports from CEECs, although their share has decreased over the decade, with the exception of Poland. What is striking, however, is that in all instances the percentage of low-tech products appears to be much larger than in the case of most Asian competitors (almost twice as much as in the exports of the NICs, and well above that of Malaysia, for instance). As a mirror image, the CEECs exhibit the lowest share of the high-technology sectors among all competitors. As a share of the CEECs' exports to the EC, high-technology sectors have grown substantially over the years, although the swift increase in 1991 data may be partly due to the inclusion of the former GDR in the EC total. Still, the gap between the CEECs and the NICs is considerably wide. Hungary and the CSFR were clearly the leaders among the CEECs, followed by Poland, Bulgaria, and Romania. A common general feature for all the CEECs seems to be the dominance of products in the lower end of the hightechnology spectrum (electrical and nonelectrical machinery and high-grade chemicals), in contrast to their competitors' export, which is dominated by 
electronic components, telecom equipment, and scientific instruments. Hungary is the only country in which these latter sectors have increased as a share of its high-tech exports.

Finally, non-resource-based manufactures are mostly concentrated (69 percent) in sectors characterized by a slower than average import demand growth into the EC. This is true also for the world exports to the EC at large; however, the share in the world export ( 59 percent) is still lower (Graziani, 1993).

In summary, some general features seem to emerge from our analysis so far. The CEECs' export structure toward the EC seems to be relatively biased in favor of resource-based products. Many of these productive processes require substantial amounts of capital. If we add this fact to the share of capital-intensive manufactures, one could argue that CEECs' exports seem to be particularly biased for exports characterized by heavy use of natural resources and capital outlays. Given that the former is generally not plentiful in the region and the latter is also relatively scarce, this pattern could only be the result of the far-reaching misallocation of resources caused by the well-known irrational system of prices and other features of the past regime. Moreover, non-resource-based manufactures are concentrated in mature, standardized, labor-intensive, low-technology-intensive, and relatively slowly expanding sectors, where the competition of NICs and EC protection is strong.

\section{Identifying the Competitive Sectors of Central Eastern European Economies}

Trying to identify the CEECs' products that are most suitable candidates for competition in international markets is obviously a very difficult task in a period of rapid redirection of trade flows and of sweeping internal transformations. The best one can do is to show where the region's comparative advantages with the EC seem to lie up to now, then discuss whether these sectors are viable at all, and, finally, compare these results with the factor endowments existing there.

For the analysis of revealed comparative advantages, in this section I use the export specialization index calculated for EC-CEECs relations. The index was calculated for each CEEC in the EC market at the SITC 3-digit level, for both 1980 and 1991. The ratio indicates the weight of the product in the EC import structure from the CEECs, relative to the weight of the 
same product in the EC imports from the world. A value higher than one indicates a relative specialization. In Table 8.6, only the top 20 products are shown for each CEEC, plus the total number of products for which each country shows a value higher than one.

A first remark concerns the degree of concentration of the specialization pattern (memo item at the bottom of the table). The CSFR appears specialized in the largest number of products and Romania in the smallest number (half as much as the former). Hungary, Poland, and Bulgaria are ranked in between. Considering now only the top 20 products in 1991, it should be noted that, on average, one-fifth of them had an index indicating, in fact, despecialization (a value lower than one) a decade before. This share is slightly lower in the case of Hungary, most likely reflecting the fact that this country has tended to consolidate its already acquired well-performing positions relatively more than the other CEECs.

The detailed analysis of the specialization indices broadly confirms some of the previous findings. Raw materials, food, and agricultural products are among the best performing sectors, together with resource-based manufactured products. These three categories represent, generally, half of the top 20 products. They are slightly less important for the CSFR and, for different reasons, for Romania. As for the non-resource-based manufactures, specialization is mostly concentrated in mature, standardized, and labor-intensive industries. There are, however, some notable exceptions. Examples of skill-intensive products can be found for all the CEECs. For instance, mechanical-handling equipment and ships for Bulgaria; tractors, power-generating machinery, and steam boilers for the CSFR; agricultural machinery and equipment for electrical distribution for Hungary; steam boilers for Poland; and, finally, rotating electrical plants and household equipment for Romania. Examples of unstandardized products are represented by leather manufactures (except the CSFR), textile articles (Bulgaria and the CSFR), rubber articles (Bulgaria), rails (the CSFR and Poland), and iron and steel bars (the CSFR).

The list would certainly be longer if we considered all the products in which the CEECs exhibit a relative specialization index (not shown in the table). It does not, however, include many products from the machinery and equipment division ( 3 for Bulgaria; 13 for the CSFR and Hungary each; 6 for Poland; and 9 for Romania). Moreover, in these instances the indices are often very low and are accompanied by particularly negative exportimport balances. One should also note that on average low specialization 


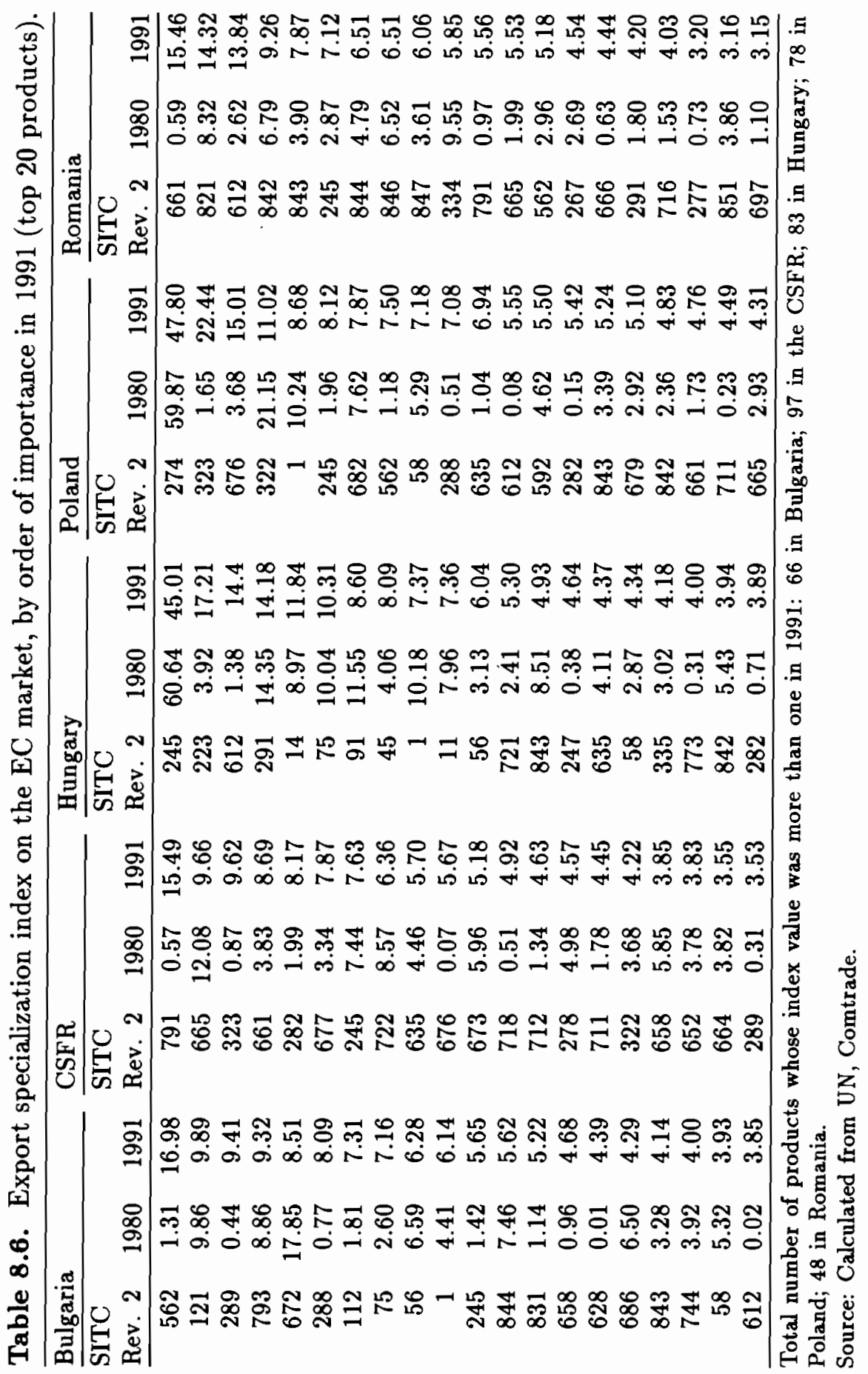


is characterizing this commodity group more than the other groups. No CEEC shows a specialization index higher than one in the most dynamic and high-tech sectors, like office and automatic data-processing machines, telecom equipment, scientific instruments, photographic apparatuses, and optical goods. In all these groups balances are generally negative.

All in all, the previous analysis shows that the apparent specialization of the CEECs manifests itself mostly in those same types of goods that constitute the bulk of their exports: resource-based products and standard labor-intensive and low-skill manufactures. One can nevertheless detect a few differences among individual CEECs. As expected, the CSFR is still relatively more advanced in the higher-technology-intensive products among the CEECs, followed by Hungary, Poland, Bulgaria, and Romania. The last three countries are also relatively more specialized in resource-based goods; Hungary is more specialized in labor-intensive manufactures and the CSFR in capital-intensive manufactures.

Export specialization indices, as revealed by actual trade, cannot tell us more about the underlying comparative advantages supposedly pertaining to a country. Certainly, in the case of a substantial misallocation of resources, the chance is that the two sets might differ in various cases. The question is even more complicated as far as the future pattern of specialization is concerned, since the very rapid and far-reaching transition process is bound to have a notable impact on the general economic structure of the countries involved. For example, a general redistribution of employment away from agriculture and industry and toward the service sector, as well as an industrial restructuring, foreseeable in the near future, might substantially also change the trade structure.

Interesting insights into the matter can be derived from a study by Hughes and Hare (1991). By calculating the value added by each industry at world prices and thus the domestic resource costs of production, the authors were able to identify the branches which make the greatest contribution to national income relative to the capital and labor they require. They also identified the sectors which, on the contrary, generate a negative value added at world prices, because they actually reduce the net resources of the country by using inputs the value of which exceeds the value of the output they produce. In such a way they find that for the CSFR, Hungary, and Poland 20 percent to 25 percent of manufacturing output is produced by branches that operate with negative value added, if measured at world prices. Among these the food industry is first, followed by various energy-intensive branches. 
Placing these findings and our previous results on export specialization for manufactured sectors side by side, we can see that for Bulgaria and the CSFR the industries with negative value added at world prices do not include many of the sectors that show an apparent export specialization. The contrary is true in the case of Hungary, where parts of the food industry and iron and steel, which show a negative value added, reveal a certain specialization. The same can be said for some negative value-adding Polish industries, namely, food and nonferrous metals production.

\section{Current Versus Future Specialization Patterns: The Question of Human Capital}

What are the implications for future specialization in these CEECs? Here one should distinguish between the short-medium term and the long term.

In the first instance, the CEECs apparently will have to cope with their present factor endowment, the established pattern of specialization, and the necessity to solve the problems encountered in the sectors indicated above. Our previous analysis of the CEECs' trade commodity structure quite clearly reveals that the export-oriented sectors in these countries consume much energy. It is well known that this is a general feature of CEECs. Energy consumption per capita is, on average, the same as for Northern EC countries, while their consumption per unit of output is roughly double. Accordingly energy-intensive industries are certainly among the first to require drastic restructuring. In many instances, this might imply a substantial contraction of previous exports, as their profitability will fall even lower, due to the ending of the epoch when cheap raw materials were supplied on barter terms by the former USSR. Such is the case, for instance, of petrol processing and the petrochemical and metallurgical industries, based essentially on crude and high-grade iron ore. The choice now is between paying world prices in convertible currencies (when bartering is not resumed) or using lower-metal-content ores when they are available, thus inevitably raising production costs substantially. In some instances, however, it might be rash to simply do away with entire sectors that could be viable. Such is the case, for example, for Bulgarian oil-processing capacities, which have undergone intensive renovation and might be used, on a compensation basis, for processing petrol belonging to foreign companies and paying them back with petroleum products. Or, even more likely, this might be the case of Hungarian energy-intensive industries, which already in the last decade had 
to pay the full world market price for Soviet oil (the balance over the lower price paid to the USSR went into the national budget). In general, however, one could perhaps safely assume that the energy-intensive manufacturing exports are bound to start losing ground soon in the CEECs' export structures toward the EC.

As for agriculture, the pressure to earn foreign currency might immediately increase the exports of this sector. If this were the case export potentials might rise also because of per capita productivity gains due to a substantial release of the labor force and a swift positive reaction to liberalization measures in the countryside. Past experiences show that this is a possible outcome (Anderson, 1992). As an example of the CEECs' productivity lag, the United States Department of Agriculture (USDA) reports that in 1990 the level of cereal production was roughly half of that in similar areas in Western Europe (Senior Nello, 1991). The most suitable candidates for an export boost could be gauged from the ratio of per capita production in the CEECs and the same for the world. In this respect, cereals, sunflowers, meat, milk, canned meat/fruits/vegetables, beer, and refined sugar would seem to have, on the average, the greatest potentials (Collins and Rodrik, 1991).

Our results so far seem to point to a reshuffling of the CEECs' export structure within the resource-based product groups in favor of agriculture and against more energy-intensive goods. Whether resource-based exports will contract as a whole as a share of global exports to the EC will very much depend on the development of non-resource-based manufacturing products. Among the latter, will the standardized labor-intensive goods continue to prevail? According to some analysts (CEPR, 1990), data on factor endowments in human capital point to a possible relatively higher growth of the CEECs' exports of more sophisticated, skill-intensive products. In this sense, they would not be competing with the EC-South.

The analysis of the data reveals, however, some problems. Such is the case, for instance, of the occupational breakdown of employed labor force. According to experts, the CEECs' average share of the work force engaged in professional, technical, and related occupations is 15 percent, which would put it somewhere in between the EC-North and the EC-South. However, this average is heavily biased by Bulgaria's reported share of 26 percent. Statistical foundations on this subject are very shaky. The 1991 International Labor Organization's Yearbook of Labor Statistics shows data only for Poland (ILO, 1991). On the basis of calculations from these data, Poland would be 
roughly on a par with the EC-North, while the low shares of administrative, managerial, clerical, sales, and service workers would lag far behind even the EC-South and NICs.

Possible hints at the future pattern of trade may be drawn from the statistics on education and $R \& D$, if we accept any reasonable relationship between educational and $R \& D$ flows, on the one hand, and the availability of skilled workers, on the other. For this purpose, we present a series of country-by-country data taken or calculated from UNESCO (Table 8.7). In addition to the CEECs and the EC countries, we have included a few developing countries for comparison.

The picture that unfolds is quite composite and reveals some notable differences among the individual CEECs. As for gross enrollment ratios, the share of students reaching the second level of education is, on average, lower for the CEECs than for the EC and comparable to the best-performing LDCs. This feature is accentuated if we look at the third level of education. Apart from Bulgaria, whose inflated data, although still lower than the EC, seem to be dubious, Romania has a lower share than any of the LDCs presented in the table, while the rest of the CEECs can only compare with Portugal in the EC and with average LDCs, like Egypt, Mexico, or Thailand. Countries like Argentina and Korea seem to fare much better.

But, even accepting these data at face value, how do we know that the CEECs' educational standards are comparable to their Western counterparts? Statistics on quality comparisons are almost nil. One of the few studies of this problem was undertaken by the International Association for the Evaluation of Educational Achievement in the mid-1980s (as reported in Hamilton and Winters, 1992). The data collected for a certain range of developed and developing countries, including Hungary and Poland, show the scores obtained by students on a standardized science test. Hungary is first in the secondary level (14- and 15-year-old students) and the third level (final years of schooling), while Poland compares favorably with the lessperforming developed countries. On the basis of admittedly rough positive correlations between scientific skills at the secondary level of education and the comparative advantages in mid-tech goods in the West, Hamilton and Winters conclude that Hungary is a particularly good candidate to become an exporter of sophisticated goods.

Another often-considered input measure is total education expenditures as a share of the GNP. The table shows that here the CEECs are roughly on 


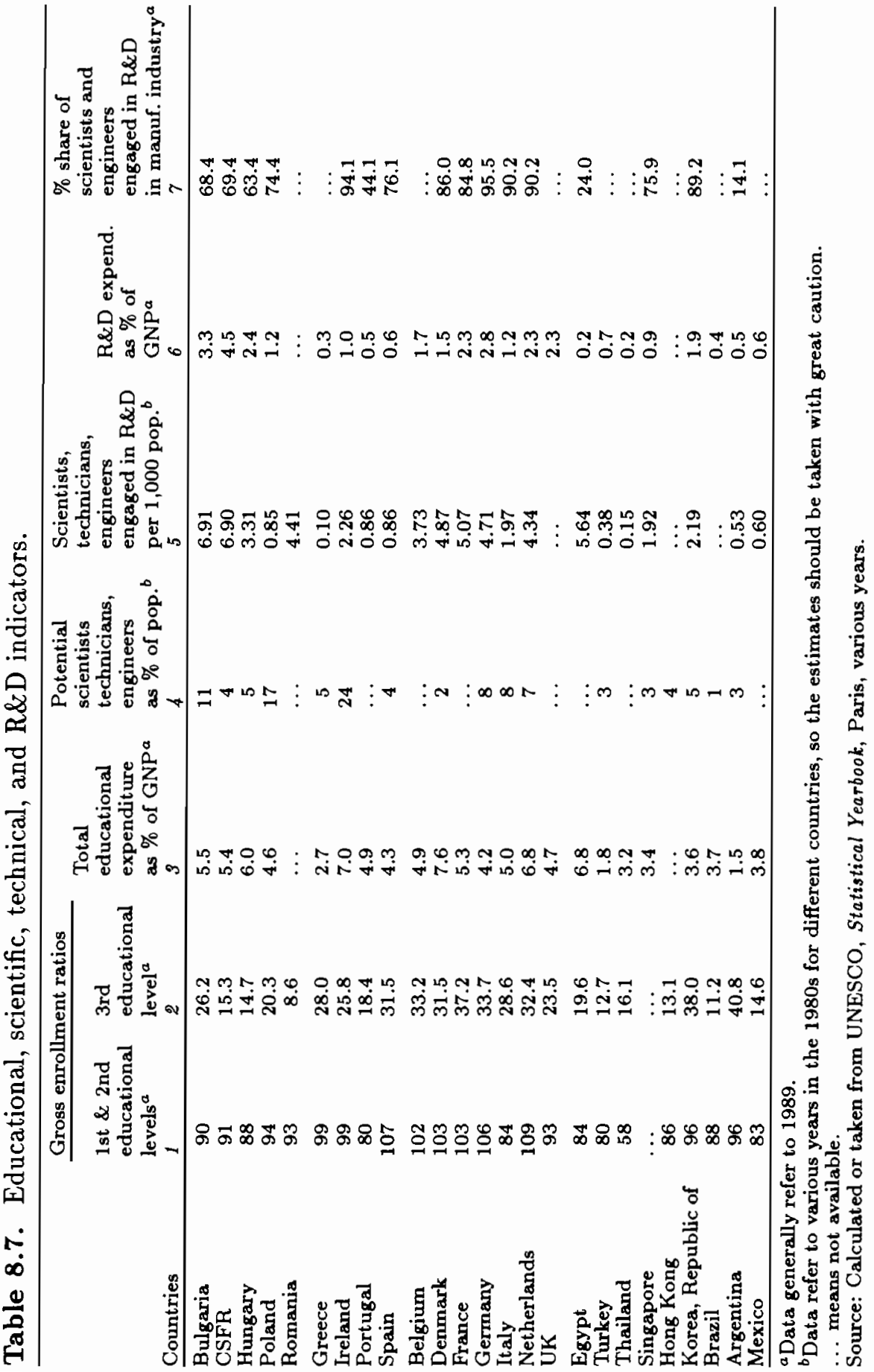


a par with the EC countries and spend relatively more than most LDCs, indicating very likely rather widespread inefficiencies in the educational systems and/or differences in recording expenditures.

Some of the CEECs seem to have strong points in scientific and technical personnel. The fourth column shows the share of potential scientists, engineers, and technicians in the total population. This is meant to be economically active qualified labor either engaged or actively seeking work in any branch of the economy. Here the data would suggest Poland is in a leading position, followed by the EC-North; the CSFR and Hungary being on a par with the EC-South and the Asian NICs. A similar picture emerges from the analysis of the fifth column, where the share of scientists, engineers, and technicians engaged in research and experimental development are calculated, again within the total population. Bulgaria and the CSFR appear to be leading, followed by the EC-North. Hungary and Romania would be somewhere in the middle, with the NICs, EC-South, and finally Poland following suit. Were the share calculated as a percentage of the total labor force, most of the CEECs would compare favorably with the best-performing Western countries.

If we look at column six, we can see that the CEECs seem to devote a considerable share of their national incomes to $\mathrm{R} \& \mathrm{D}$. Although the data are not exactly comparable (because they are calculated as a share of net material product, which is lower than GNP), the much higher figure obtained in the case of the CSFR, Bulgaria, and Hungary than in the EC-North appears to imply a substantial difference. Poland and Romania look more like the better-performing EC-Southern countries.

A few factors, however, might reveal some doubts on the exact value of $R \& D$ efforts of the CEECs relative to other countries. First, one should not forget that in the West a substantial amount of research is conducted by private firms. Consequently, official data underestimate the national research efforts in the West. Second, Eastern European scientists and engineers are much less concentrated than their Western counterparts in manufacturing industry, which apparently does not bode well for the future of that sector (column seven).

In summary, the situation does not seem to be uniform for the various CEECs and among the different types of education, scientific and technical personnel, and $R \& D$ efforts. Data on $R \& D$ should be taken with great caution and most likely inflate the CEECs' real research effort. A certain relative abundance of scientists, engineers, and technicians does seem to 
exist in some CEECs. Apart from the reliability of data, however, it is not at all clear whether education, as well as the skills of the labor force, can correspond in the near future to the new tasks of a full-fledged market economy. For a long time researchers and technicians have been isolated in their work from the international milieu and have rarely had access to the most updated equipment. The same can be said about the labor force. At present, many qualified workers are leaving industry to find better-paying jobs in services and trade, if not migrating abroad. The remaining employees need intensive retraining, but some evidence seems to point to a collapse of training centers in the CEECs. Finally, even if the skill potentials are there, a lot of capital to make these skills usable is needed, in this case in the form of direct foreign investment.

All in all, the arguments presented above do not seem to indicate relevant opportunities for the export potential of skill-intensive goods in the short run. This seems also to be the perception of foreign investors. In a survey of large firms in various Western countries, the 54 respondents, 36 percent of which are primarily engaged in manufacturing, did not perceive the skills of the labor force as a major attraction for investment in the former CMEA countries (Collins and Rodrik, 1991). In fact, skills ranked only fifth, after the perspective of new and expanding markets, the possibility of beating out competitors, the proximity of the EC markets, and the low labor costs. Of course, these principles do not imply that foreign investment and transfer of technology in substantial amounts might not considerably change the situation in the long term and help to fully utilize the potential existing in the CEECs. In this respect Hungary seems for the moment the most suitable candidate. Some examples already exist in this direction, such as the Hungarian software company Graphisoft, which created a popular program for computer-aided design and is a successful exporter.

Meanwhile, the CEECs will be obliged to go on concentrating on laborintensive manufactures. Cheap labor is still a reality of the CEECs. In 1989, Poland, Hungary, and the CSFR still had very competitive wage levels. Their average hourly earnings in manufacturing were, respectively, 1.5 percent, 7.3 percent, and 9.5 percent of the US level and, in the highest case (the CSFR) just over 10 percent of the EC-North, 15 percent of Spain, and still behind Latin American and Asian NICs (Graziani, 1993).

This low competitive level of wages in Eastern European countries may not hold out forever. Recent macroeconomic policies characterized by strong devaluations of the home currency and the ensuing surge of inflation have 
started to erode the competitive edge of these countries. By September 1991 Polish wages in dollars had increased by about five times with respect to the 1989 level and the Hungarian wages had increased by 20 percent. Apparently, the CSFR was the only successful CEEC, not only in keeping wages in dollars under control, but even in lowering them.

In the first period of transition, there has been a realignment of wages toward equalization of wage competitiveness in dollars for the three CEECs involved. On the other side, it should be remembered that, for the future, unemployment might exert a downward pressure at the wage level. As we know, unemployment rates have already surpassed the 10 percent threshold in many CEECs and will presumably go on increasing. Labor will be relatively even more abundant because of less employment in agriculture, widespread bankruptcies, and/or reduced employment in factories which for a long time have practiced overemployment.

The second reason why data on wages have to be analyzed cautiously when measuring competitiveness lies in the well-known fact that wages are not synonymous to labor costs. Since reliable comparable statistics do not exist even for Western countries, we can only give here a few qualitative remarks. It has been a tradition of the Eastern European state enterprises to generously provide their employees with food and other payments in kind, like housing, social security, vocational training, welfare services, transport, and work clothes. A reasonable guess is that these items played a much larger role in the CEECs than in their Western counterparts. Moreover, some of these benefits might not be provided any more in the near future, especially if the privatization process proceeds rapidly. This would have a wage-push effect, the consequences of which are not readily quantifiable.

Finally, labor cost is only one side of the coin related to competition. Labor productivity has to be taken into account as well. Here too, we run into the usual difficulties in international comparisons. It is a well-known fact that productivity levels are very low in the economies of CEECs. A Polish study has compared the output per employee for 16 products in Poland and the EC in the late 1980s (Burzynski et al., 1991). In only three cases does Polish productivity approach the level of EC productivity: in the production of animal feed, leather, and railway rolling stock. The narrowest productivity gaps were found for labor-intensive and resource-based industries. Moreover, the higher the degree of processing, the larger the productivity gap appeared to be. A more detailed comparison with Germany shows that the latter has a productivity that is 13 times higher in certain industries, like wood 
and paper. Making a comparison of productivity and labor costs between Poland and Germany in 28 industries, the authors conclude that in most cases lower labor costs do not pay off for even lower labor productivity. The only exceptions were found to be in the production of iron and steel, cable and wire, synthetic plastics, ceramic, and pottery. As shown previously, most of these revealed a specialization index higher than one for Poland.

This situation seems to indicate that substantial productivity gains could be obtained by either letting firms go bankrupt or restructuring those that are deemed viable. This process almost inevitably involves shedding excessive labor force. How fast and far this process can be carried out without engendering social tensions is still an open question.

\section{Trade Liberalization and the Future International Division of Labor Between the EC and the CEECs}

The pattern of CEECs' specialization in the EC market is not likely to witness a dramatic change among its main component parts in the near future. Some rearrangement may take place within the resource-based exports, where agricultural products tend to a greater weight in comparison to energy-intensive goods. Keeping in mind that labor is bound to be relatively more abundant than natural resources, mature labor-intensive manufactures will go on being the most viable export earner, especially if reinforced by a favorable exchange rate policy. In the long term, the results of the restructuring process and the expected inflow of foreign investment and technology might allow these countries to concentrate on more sophisticated exports, for which some countries seem to have the right factor endowments.

What type of international division of labor derives from such an analysis? Commercial relations between the EC and the CEECs are clearly relations between developed countries, on one side, and countries at an intermediate level of development, on the other. A trade structure, which is in some sectors largely substitutive and not complementary, creates problems of competition, when it cannot give way to intra-sectoral trade flows. To this must be added the place of the EC in the world division of labor. In the 1980 s the USA and Japan underwent a process of specialization in sectors characterized by strong and average international demand, while the EC did not follow this path, but rather tended to specialize in the weak demand products. As the previous analysis has shown in detail, the CEECs' relative specialization often expresses itself in those very sectors where international 
demand is weaker; NICs' competition is stronger; competitive phenomena appear among CEECs themselves; some of the EC countries tend also to concentrate their exports on the other industrialized countries; an increasing overproduction and/or unemployment exists in the EC; and pressures are greater toward protection.

Until 1989 the EC's attitude was characterized by strong discrimination against the CEECs (Olechowski and Yeats, 1982; Messerlin, 1991; and OECD, 1991). Since then, it has promoted a process of progressive trade liberalization. In an earlier paper I have shown, however, that the CEECs are still facing a disproportionate burden of EC trade protection (Graziani, 1992). The possible benefits of tariff lowering under the General System of Preference Scheme (GSP) are limited by the exclusion of steel products and, for Poland, fishery products. Moreover, they apply only to a very minor part of the eligible goods. But above all, nontariff measures (NTMs) coverage, although decreasing for the last few years, is still both very high absolutely and relatively to other regions of the world.

A new step forward to better access to EC markets seems to be represented by the new Europe Agreements (or association agreements), which regulate the future EC relations with Hungary, Poland, and the successor states of the CSFR. In March 1992, all tariffs and quantitative restrictions on EC imports were abolished, with the exception of the sensitive sectors. In agriculture, liberalization is strictly limited to a few commodities and to certain quantities within the boundaries of quotas that are allowed to grow by 10 percent a year. Over a three-year period variable levies can reach a 60 percent decline at most. Naturally, all tariffs and levies beyond the quota limits have to be paid. In textile and clothing that are covered by multi-fiber agreements, tariffs should be reduced in six steps and eliminated by 1998 , while quantitative restrictions should disappear within a period of time equal to half the period to be decided in the Uruguay Round but no sooner than 1998. For iron and steel products other than those covered by the European Coal and Steel Community, nontariff protection should be eliminated immediately and tariffs within six years. For other products, like wooden and metal furniture, footwear, glass, cement, and polyvinyl chloride, protection would be maintained for five to six years. All in all, tariff reductions are lower and the period envisaged for their elimination longer, depending on the degree of importance of the sensitive sectors in each country's exports. Furthermore, the agreements offer new opportunities for the EC members to initiate and carry out antidumping actions, by authorizing them to look 
outside of the exporting country for a fair-price calculation. Finally, they add to the "grey" area of NTMs by allowing safeguard measures in those cases in which increased imports "cause or threaten to cause serious injury" to domestic producers (Schumacher and Möbius, 1992).

UN Comtrade data for 1990 and 1991 imports into EC countries show that the liberalizing measures already taken have not succeeded in reversing other negative factors at work for some of the sectors involved. In fact, 1991 was a worse year than 1990. On average, in all sensitive sectors the export growth decelerated, despite an uplift of quotas and a lowering of tariff barriers. Iron and steel imports even decreased absolutely from all CEECs, except the CSFR. Poland fared the worst: the growth rate of exports of all subsectors contracted and was negative for food as well. Absolute falls were also recorded for textiles from Hungary and Romania and for clothing from Romania. The sectors that increased their growth rates were chemicals for the CSFR, Bulgaria, and Romania (from an earlier negative rate); food for Hungary, the CSFR, and Romania (again from a negative rate); and clothing for the CSFR. Clothing showed the fastest growth rate in both years: above 30 percent on average, with a peak of 88 percent from the CSFR and a trough of -3 percent from Romania in 1991. It should be noted, however, that a large part of the CEECs' clothing exports to the EC have been carried out under the Outward Processing Traffic (OPT) scheme. Through this scheme EC producers were exporting fabrics to the CEECs and reimporting clothing, paying tariffs only on the value added by the processing country. In 1991, the share of OPT in total imports of clothing was 75 percent for Poland, 74 percent for Hungary, 44 percent for the CSFR and Romania, and 33 percent for Bulgaria. From this perspective, the very high growth rates exhibited by these CEECs' exports are not to be regarded as much as a positive reaction to trade liberalization, but are to be regarded largely as strategic imports, i.e., as part of a strategy of EC producers redeploying some of the productive processes to lower-cost countries.

Finally, apart from the slow liberalization process in the sensitive sectors, there is a danger that protectionist pressures might be mounting in the CEECs themselves, as well as from foreign investors active in these countries, thus reversing the very fast trade liberalization in the CEECs applied until now.

All the foreseeable impediments notwithstanding, over the next few years a rapid constant removal of EC trade restrictions would allow the countries 
of Central and Eastern Europe to reap the full benefits of a deeper integration into the world economy. But this, of course would imply also needed structural adjustment policies in the EC countries which until now have been delayed.

\section{References}

Anderson, K. (1992) Intersectoral Changes in Transforming Socialist Economies: Distinguishing Initial from Longer Term Responses, Mimeo, May (Siena: University of Siena).

Burzynski, W., Sadowska-Cieslak, E., and Zbytniewski, D. (1991) Polish Export Capabilities in the 90s, CCET/TD(91)93 (Paris: OECD).

CEPR (1990) Monitoring European Integration - The Impact of Eastern Europe (London: Center for Economic Policy Research).

Collins, S.M., and Rodrik, D. (1991) Eastern Europe and the Soviet Union in the World Economy (Washington, DC: Institute for International Economics).

Graziani, G. (1982) Comecon, domination et dependances (Paris: Maspero).

Graziani, G. (1985) "Complementarities in foreign trade between the EEC and the CMEA countries," Paper Presented to the Conference on East-West Trade and Financial Relations, 4-6 June (Florence: European University Institute).

Graziani, G. (1987) "La CEE e il Comecon: concorrenza e complementarietà," in R. Parboni and I. Wallerstein (eds.), L'Europa e l'economia politica del sistema mondo (Milan: Franco Angeli).

Graziani, G. (1989) "Influence and policy implications of the major factors in intersystems trade, especially the East-South trade," Study Prepared for the UNCTAD Secretariat, ITP/TSC/6 (Geneva: UNCTAD).

Graziani, G. (1993) "Specialization for Eastern Europe and access to EC markets," in van Brabant (ed.) The New Eastern Europe and the World Economy (Boulder, CO: Westview).

Hamilton, C.B., and Winters, L.A. (1992) "Opening up international trade with Eastern Europe," Economic Policy, 14 April.

Hughes, G., and Hare, P. (1991) "Competitiveness and industrial restructuring in the CSFR, Hungary and Poland," European Economy, No. 2.

ILO (1991) Yearbook of Labor Statistics (ILO: Geneva).

Messerlin, P.A. (1991) Trade Barriers Affecting Central and Eastern European Countries on the Western Market, TD/TC/WP(91)22/ADD1 (Paris: OECD).

OECD (various years) Foreign Trade by Commodities (Paris: OECD).

OECD (1991) Trade Barriers Affecting Central and Eastern European Countries on the Western Market: A Preliminary Appraisal, TD/TC/WP(91)22 (Paris: OECD).

Olechowski, A., and Yeats, A. (1982) "The incidence for nontariff barriers on socialist country exports," Economia Internazionale, Vol. 35, No. 2, May. 
Schumacher, D., and Möbius, U. (1992) Community Trade Barriers Facing Central and Eastern European Countries: Impact of the Europe Agreements, Mimeo (Berlin: DIW).

Senior Nello, S. (1991) The New Europe: Changing Economic Relations between East and West (London: Harvester Wheatsheaf).

UNCTAD (1990) Protectionism and Structural Adjustment, TD/B/1282 (Geneva: UNCTAD).

UN ECE (1991) Economic Bulletin for Europe, Vol. 43 (New York: United Nations). UNESCO (various years) Statistical Yearbook (Paris: UNESCO).

Wang, Z.K., and Winters, L.A. (1991) The Trading Potential of Eastern Europe, Discussion Paper Series, No. 610 (London: Center for Economic Policy Research). 


\section{Comments on Giovanni Graziani's Paper}

\section{Elhanan Helpman}

This most interesting paper contains a wealth of information about a number of newly emerging European economies: Bulgaria, the CSFR, Hungary, Poland, and Romania. The author devotes much effort to the preparation of detailed data that bear on these countries' trade and specialization patterns. And these data have been organized in a convenient way that supports the analysis.

The main findings are that in these countries exports are mainly concentrated on mature, low-skill labor-intensive products; some capital-intensive products (due to the legacy of the past); and low-technology products for the most part, but also some medium-technology products. The disaggregated analysis provides some additional insights. It identifies, for example, some exports of high-skill laborintensive products, which have the potential to expand their market. And it also identifies some negative value-added sectors whose elimination will not only raise income but also may affect foreign trade in a major way. Not surprisingly, some of these exports are energy intensive, mostly in resource-based industries. They too are candidates for adjustment programs.

The data on factor endowments are also revealing. These countries have a relatively well-educated labor force, and they have relatively large spending shares on education and $R \& D$ and a large fraction of scientists and engineers in the labor force. These data suggest that their comparative advantage is in high-skill, hightech products, rather than in the low-skill, low-technology products in which they specialize. Looking at it in this way one would predict that with the integration of these countries into the world economy their patterns of specialization and trade will shift toward high-skill, high-tech products (it would be nice, in fact, to predict this pattern from Leamer-type regressions, by placing the countries on the regression line). There are good reasons for believing, however, that these simple predictions require major qualifications.

First, the R\&D data of these countries are probably not very reliable. The data may also be contaminated to a larger degree for these countries than for OECD countries because of the lack of a sharp distinction between civilian and military R\&D. Second, the education data tell only a partial story. On this one can learn from the experience of Israel that has absorbed a large population of emigrants from the former Soviet Union. This experience shows that many skills acquired in the former Soviet Union are not readily applicable in a market economy. Some of these skills are too specific to the type of planned economy in which they operated, and they do not fit into the organization and manufacturing structure of a Western-style economy.

It therefore appears that in order to form an opinion about the most likely changes in the patterns of specialization and trade of these countries, we need to take into account the following factors: 
- Some of the capital stock is redundant, which requires an estimate of the size of the viable capital stock.

- Some of the human capital is also redundant. But unlike plants and equipment, humans can be retrained, and therefore some of the redundant skills can be transformed into usable skills. This may require an explicit policy of retraining.

- Given the education level of the population and the composition of the labor force, it seems that these countries have the capacity to learn and absorb Western technologies and organizational methods. They are therefore capable of following the lead of Japan and the NICs and use imitation as a development strategy.

- Their current policy trend to integrate into the world economy, and especially into Europe, will enhance the process described in the previous item.

One could conclude from these observations that predictions that are based on currently measured factor endowments may not be very reliable, unless these countries engage in explicit policies that will increase the survival value of their resources, especially their human resources. 



\section{Chapter 9}

\section{The Export Performance of the CSFR, Hungary, and Poland: Reform, Transformation, and Competitiveness}

Herman W. Hoen*

\section{Introduction}

During the first two decades after World War II, foreign trade of Eastern European countries was characterized by national self-sufficiency and an orientation toward the CMEA market. The economic systems of these countries were coordinated by instruments fundamentally different from the regulated markets of Western economies. The particular economic mechanism of the CMEA countries led to a seclusion from the international division of labor.

In the 1960 s the inward orientation of economic policy became a topic of debate in these countries, because it proved to be an obstacle to economic

*Thanks are especially due to Elhanan Helpman for critical comments on an earlier draft of this chapter. Helpful suggestions from Giovanni Graziani, Leslie Lipschitz, Gábor Oblath, Thomas A. Wolf, and other participants of the IIASA conference are also gratefully acknowledged. 
development. Hungary was the first country within the CMEA to introduce a reform program that was clearly inspired by the requirements of the international division of labor. The main elements of the New Economic Mechanism inaugurated in 1968 were new institutional arrangements for conducting foreign trade. Some Eastern European countries followed to a certain extent, but others introduced few reforms that would lead to a reorientation of international trade. All of these countries, however, had one characteristic in common: the state monopoly on foreign trade. This constituent element of foreign trade was never abolished in the 1970s or in the 1980s (Haendcke-Hoppe, 1988). Political constraints significantly hindered genuine liberalization.

In 1989 these political restrictions were eased. The system collapsed, because it was not immediately supplemented by a well-functioning regulated market economy. The legacy of the past thus became an important starting point for the transformation. This meant that not all Central and Eastern European countries were in the same boat. After the political revolution the former communist countries adhered to different policies of transformation. Strategies differed with respect to speed of transition and the sequence of steps in the transition process. An analysis of the importance of exports to the West as an effective way of enlarging the international division of labor leads to two interrelated questions. Firstly, was the development of relative competitiveness of Eastern European countries' exports in the 1970s and 1980s an inherited burden or a jumping board for the transformation? Secondly, how did these countries perform during the early stages of the transition period, as policies diverted? Both questions are discussed in this chapter.

The analysis is restricted to the so-called Visegrád countries - the former CSFR, Hungary, and Poland - for these countries explicitly declared cooperation in their efforts to become fully integrated with institutions of Western Europe. ${ }^{1}$ Moreover, they are closest to the EC market. The analysis compares their manufacturing exports. Agricultural and mining products are excluded, as these contain more homogeneous products and, therefore, are considered less suitable for a test on competitiveness. In order to get an indicator of changing competitiveness, a constant-market-shares (CMS)

${ }^{1}$ The Visegrád summit was held in February 1991. The presidents and the prime ministers of the former CSFR, Hungary, and Poland discussed possibilities for closer economic and political cooperation, as well as their relations with the former Soviet Union. See Senior Nello (1991) on the topic of tightening links between the Community and Central and Eastern Europe. 
analysis is applied. First, the advantages and drawbacks of this decomposition analysis are outlined; this is followed by a discussion on the choice of the data used and the presentation and analysis of the results. As the CMS analysis is not able to explain changes observed in exports, but only able to perceive alterations in trade flows in different markets, in the concluding section an attempt is made to evaluate the results, especially in the light of differences in the reform paths.

\section{Constant-Market-Shares Analysis}

With respect to export performance of the traditional centrally planned economies, supply constraints were effective. Internal factors severely hindered competitiveness on the world market. Therefore, research on foreign trade performance of the three Central European countries in transition should focus on changing patterns of competitiveness. The philosophy behind the CMS analysis is that to a certain extent demand and supply factors can be identified, that is, exports may increase relatively fast because either international demand is growing on specific markets which are favorable for the exporting country or the country's export products are more competitive.

CMS analysis is a decomposition technique frequently applied to foreign trade data. ${ }^{2}$ Basically, this method ascribes ex post a country's favorable or unfavorable export growth either to its export structure or to its "competitiveness." Structural export growth is calculated on the assumption of constant market shares within a certain reference group. Competitiveness comes to the fore as the residue between actual and structural change in exports. The basic identity of CMS analysis is:

$$
\frac{d q}{d t} \equiv s\left\{\frac{d Q}{d t}\right\}+\left\{\frac{d s}{d t}\right\} Q
$$

in which $q$ and $Q$ refer to the total value of exports of the country under investigation and the reference group, $s$ is the market share of the country in total exports of the reference group (that is, $s=q / Q$ ), $\frac{d q}{d t}, \frac{d Q}{d t}$, and $\frac{d s}{d t}$ are time derivates.

The analysis is mostly applied to discrete time intervals. Hence a secondorder effect appears. This component implies a change in the exports of the reference groups and in the market shares of the country investigated. The second-order effect clearly disturbs interpretation possibilities, as CMS

\footnotetext{
${ }^{2}$ For an extensive treatment of CMS analysis see Leamer and Stern (1970); Richardson (1971a, 1971b); and Jepma (1986).
} 
analysis, in principle, tries to keep one of them constant while the other varies. The appearance of this second-order effect leads to the identity:

$$
\Delta q \equiv s_{0} \Delta Q+\Delta s Q_{0}+\Delta s \Delta Q .
$$

In equation (9.2) $\Delta$ denotes discrete change and 0 refers to the starting year of the discrete period. The second-order effect is to be allocated to the first or second term in equation (9.2), which entails the following solutions:

$$
\begin{aligned}
\Delta q & \equiv s_{1} \Delta Q+\Delta s Q_{0} \\
\Delta q & \equiv s_{0} \Delta Q+\Delta s Q_{1}
\end{aligned}
$$

in which subscript 1 refers to the end of the discrete time interval.

$A$ priori there are no reasons for preferring equation (9.3) over equation (9.4) or vice versa, but in this chapter identity (9.4) is used. It must be kept in mind that the sensitivity of the analysis for the choice of the base year remains unsolved, for this choice influences the magnitude of the secondorder effect. ${ }^{3}$

In many applications the structural effect is subdivided into commodity and regional effects, for total exports can be thought of as a bundle of small export flows that are characterized by the nature of the product as well as by the nature of the region of destination. These effects can be examined separately, taking into account the fact that exports may be concentrated in commodities for which demand is growing relatively quickly (or slowly), or may be flowing primarily to relatively flourishing (or stagnant) regions. This analysis is referred to as a three-level analysis (Leamer and Stern, 1970, p. 174), and is based on the following identity:

$$
\begin{aligned}
\Delta q \equiv & s_{0} \Delta Q+\left\{\sum_{i} s_{0 i} \Delta Q_{i}-s_{0} \Delta Q\right\} \\
& +\left\{\sum_{i} \sum_{j} s_{0 i j} \Delta Q_{i j}-\sum_{i} s_{0 i} \Delta Q_{i}\right\}+\sum_{i} \sum_{j} \Delta s_{i j} Q_{1 i j},
\end{aligned}
$$

in which subscripts $i$ and $j$ refer to commodities and regions of destination.

From equation (9.5) the aforementioned scale, structural, and competition effects can be disentangled. The first term in (9.5) is the scale effect. As long as the market share in total exports of the reference group remains constant, the countries' export will change by the multiplication of the market share and change in total exports, that is, $s_{0} \Delta Q$.

\footnotetext{
${ }^{3}$ For the index-number problem, see Richardson (1971a, pp. 234-236) and Jepma (1986,
} pp. 25-32). 
The second (third) term between brackets shows the commodity (region) effect, and will be positive if the countries' export structure is confronted with commodities (destination regions) with a relatively large growth in demand. For example, the commodity effect will be positive if $s_{i}>s$ and $\Delta Q_{i}>0$. This implies that the export growth will be larger than could be expected in total market shares. Competitiveness is calculated as the residue, that is, the difference between actual and structural export changes. In equation (9.5) the competition effect is depicted in the last term.

Appealing as it may be, the CMS analysis has many methodological problems. Except for the above-mentioned index-number problem, which is related to the discrete time intervals, the frequently applied three-level analysis suffers from asymmetrical specification. The equation could as well be formulated such that the region effect is specified before the commodity effect. The choice is absolutely arbitrary, but does have consequences for the magnitude of both effects. The alternative equation is as follows:

$$
\begin{aligned}
\Delta q \equiv & s_{0} \Delta Q+\left\{\sum_{j} s_{0 j} \Delta Q_{j}-s_{0} \Delta Q\right\} \\
& +\left\{\sum_{i} \sum_{j} s_{0 i j} \Delta Q_{i j}-\sum_{j} s_{0 j} \Delta Q_{j}\right\}+\sum_{i} \sum_{j} \Delta s_{i j} Q_{1 i j} .
\end{aligned}
$$

The sum of the regional and commodity effects in equations (9.5) and (9.6) appears, nevertheless, to be identical. Jepma (1986, p. 24) solves this problem of asymmetry by introducing an interaction effect, which shows to what extent the commodity package and regional dispersion influence each other. Adding the interaction effect leads to the following identity:

$$
\begin{aligned}
\Delta q \equiv & s_{0} \Delta Q+\left\{\sum_{i} \sum_{j} s_{0 i j} \Delta Q_{i j}-\sum_{i} s_{0 i} \Delta Q_{i}\right\} \\
& +\left\{\sum_{i} \sum_{j} s_{0 i j} \Delta Q_{i j}-\sum_{j} s_{0 j} \Delta Q_{j}\right\} \\
& +\left\{\left[\sum_{i} s_{0 i} \Delta Q_{i}-s_{0} \Delta Q\right]-\left[\sum_{i} \sum_{j} s_{0 i j} \Delta Q_{i j}-\sum_{j} s_{0 j} \Delta Q_{j}\right]\right\} \\
& +\sum_{i} \sum_{j} \Delta s_{i j} Q_{1 i j} .
\end{aligned}
$$


In identity (9.7) the scale, region, and commodity effects are denoted in the first two lines. The region effect coincides with the homonymic effect in the asymmetric identity, in which it is specified after the commodity effect. Thus it corresponds with the region effect in equation (9.5). The same holds for the commodity effect, which stems from equation (9.6). Here the region effect is specified first. In equation (9.7) the region and commodity effects are purified from interactions. These are separately brought into the equation as the term in the third line. In case of negative interactions it holds that

$$
\left[\sum_{i} \sum_{j} s_{0 i j} \Delta Q_{i j}-\sum_{j} s_{0 j} \Delta Q_{j}\right]>\left[\sum_{i} s_{0 i} \Delta Q_{i}-s_{0} \Delta Q\right],
$$

which entails a relatively positive influence of regional dispersion on the commodity effect in comparison with the reference group. The last term in equation (9.7) contains the residual competition effect which corresponds to the last terms of both asymmetrical identities.

In this article identity (9.7) is applied in order to avoid the problem of asymmetry. Nevertheless, the remaining drawbacks of the CMS analysis have to be taken into account. One of these concerns the fact that the model is based on identities and, therefore, does not give causal interrelations. The empirical results obtained from the CMS approach do not suggest any explanation for slackening or improving conditions of competitiveness. The analysis is a useful tool in the numerical dissection of realized export change into different components, but is not able to clarify why exports changed in a certain manner. Hence, later attempts will have to be made to evaluate the analysis from another perspective, as will be done in the following sections. The CMS approach can be helpful in identifying the regions and commodities for which an explanation has to be found.

A final remark on the pitfalls of CMS analysis concerns implicitly defined competitiveness. The residue does not only contain aspects as quality, prices, time of delivery, and other services vis-à-vis competitors, as one would expect, but it also comprises matters which are not related to supply factors of the country under investigation such as nontariff barriers. In order to disentangle aspects such as nontariff barriers it is important to choose the proper destination market, as well as to split the effects into the separate markets. 


\section{Data and Results of the CMS Analysis}

\section{Data}

The problems with CMS applications, as mentioned in the preceding section, necessitate a well-considered choice of the data set. These complications may be summarized with the notion that outcomes are very sensitive to opted discrete years, reference group, commodity composition, and regional destinations. This sensitivity may hinder useful interpretations (see Richardson, 1971b).

In the literature one can find several solutions to the sensitivity of CMS analysis. For instance, Jepma (1986, pp. 158-160) suggests applying moving averages of export data. In this chapter, it has been decided to stick to the traditional discrete approach. Sensitivity of the analysis for the length of the period over which trade flow changes are being observed is unavoidable, of course, but in order to reduce the magnitude of disturbing second-order effects one should, from a theoretical point of view, prefer a period of just one year. Since one may be interested in structural developments of export changes over a longer time span, it is essential to discern as exactly as possible the several components of the analysis in each year. This condition is most closely to be met by choosing the base year as near as possible to the period under consideration. It is necessary to decompose export changes for a series of years, and subsequently cumulate the results, instead of just splitting up export changes over a longer period of time, which may yield enormous second-order effects. This procedure has been applied for the following discrete periods, namely, 1968-1973, 1973-1980, 1980-1984, 19841989, and 1989-1991. On the one hand, the choice of these benchmark years resembles periods of growth and stagnation in world trade: the first oil crisis in 1973, negative nominal growth in world trade in the period 1980-1984, after which a recovery took place. On the other hand, this choice also defines periods in which policy changes took place in the countries under investigation. Although the CSFR, Hungary, and Poland did not introduce their transformation programs simultaneously, the year 1989 certainly meant the end of communism. This implies that the period 1989-1991 takes into consideration the export changes in 1990 and 1991. As far as the other periods are concerned policy considerations are also taken into account. During the period 1968-1973, Hungary experienced the first years of the New Economic Mechanism, but institutional reform stagnated afterward approximately until 1980. In the case of Poland, these were the years of an import-led growth 
policy. The CSFR, during the period 1968-1973, continued with normalization and stabilization; this period, in contrast to the experiences of Poland and Hungary, was not followed by an import-led growth policy. In the late 1980s Hungary was active in speeding up reform measures. Although to a lesser extent, this was also true for Poland as far as foreign trade relations were concerned.

The purpose of this paper is to quantify relative export performance of the three Central Eastern European countries, in order to identify success or failure of different reform and transition strategies. Theoretically, it would make sense to take two of the countries as the standard, while investigating the third (Leamer and Stern, 1970, pp. 176-177). ${ }^{4}$ Due to sensitivity problems the choice of this standard of reference is problematic. The Western market shares of the CSFR, Hungary, and Poland are too small and, therefore, lead to unstable results of the analysis. A standard of reference that consists of all the other Central and Eastern European countries, unfortunately, is not able to ease the instability (Hoen and Wagener, 1989, p. 67). Thus total world exports have been taken as the standard of reference and the analysis is repeated for each country.

With regard to classification of commodities and regions of destinations it has to be realized, once again, that small export groups may effectuate large fluctuations. It enhances the robustness of analysis to restrict the amount of commodities and regions. A selected part of the Western European market has been chosen: Belgium and Luxembourg (have been grouped as one unit), the Federal Republic of Germany, France, Italy, the Netherlands, Austria, and Switzerland - hereafter referred to as EUR(8). These countries absorb approximately 70 percent of joint CSFR, Hungarian, and Polish exports to OECD Europe. They are important (potential) Western trading partners for the three countries considered. The choice to include EC member states, as well as EFTA countries, is deliberate, for possibly it facilitates statements on inaccessibility of the EC market, something which has often been put to the fore by authorities of the Central European countries.

Supply constraints in traditional central planning were manifested in a comparative disadvantage in those products characterized with a wide variety, and for which after-sales services play an important role. These aspects are very relevant to manufactures. Therefore, the analysis is restricted to

\footnotetext{
${ }^{4}$ Of course, in this case the CMS identity has to be written in growth rates, as it is impossible to calculate, for example, the Hungarian market shares in Polish and CSFR exports.
} 
these factors. In order to avoid deviating classifications used in Eastern European trade statistics, registrations of the importing Western countries have been relied on. From Standard International Trade Classification (SITC), the following division has been applied:

SITC 5: Chemicals.

SITC 6 (minus 68): Semimanufactures excluding nonferrous metals (nonferrous metals have been excluded because of low-grade processing).

SITC 7: Machines and transport equipment.

SITC 8 (minus 84): Manufactured consumer goods excluding clothing. SITC 84: Clothing.

This division is based on the fact that, during the period from 1968 to 1991 , these groups of products cover at least 10 percent of the manufacturing exports of all three countries under investigation. This approach increases the comparability of the three countries. Data are taken from OECD (various years).

\section{Results}

In 1968 Hungarian and Polish manufacturing exports to EUR(8) were less than US $\$ 100$ million. In 1989 , the year in which the collapse of the political system occurred, the manufacturing export of both countries comprised a nominal value of about US\$1.7 billion. During the same period the value of CSFR manufacturing exports to the EUR(8) increased tenfold and reached a similar level. A survey of the developments of manufactures' market shares in the EUR(8) is presented in Table 9.1. The table shows that Hungary and Poland have been able to increase manufactures' market shares in the period from 1968 to 1989 . It has to be acknowledged, though, that from the late 1970s until nearly the end of the communist regime both countries experienced comparable decreasing market shares. Although 1968 is somewhat tainted with interpretation problems, a similar pattern can be deduced for the CSFR, be it that the decreasing trend of market shares in the 1970 s came up earlier, and that for two decades the net result was a decline.

To what extent the observed changes in market shares are to be ascribed to regional and commodity dispersions of the manufacturing exports or to 
Table 9.1. Market shares in the $\operatorname{EUR}(8)$, in percent.

\begin{tabular}{llll}
\hline & CSFR & Hungary & Poland \\
\hline 1968 & 0.42 & 0.17 & 0.18 \\
1969 & 0.45 & 0.22 & 0.17 \\
1970 & 0.51 & 0.26 & 0.21 \\
1971 & 0.51 & 0.27 & 0.25 \\
1972 & 0.49 & 0.30 & 0.29 \\
1973 & 0.48 & 0.33 & 0.32 \\
1974 & 0.44 & 0.34 & 0.32 \\
1975 & 0.45 & 0.32 & 0.36 \\
1976 & 0.42 & 0.36 & 0.37 \\
1977 & 0.41 & 0.35 & 0.39 \\
1978 & 0.36 & 0.30 & 0.39 \\
1979 & 0.39 & 0.34 & 0.34 \\
1980 & 0.34 & 0.32 & 0.36 \\
1981 & 0.37 & 0.33 & 0.29 \\
1982 & 0.39 & 0.31 & 0.23 \\
1983 & 0.37 & 0.30 & 0.21 \\
1984 & 0.35 & 0.29 & 0.26 \\
1985 & 0.32 & 0.25 & 0.23 \\
1986 & 0.32 & 0.26 & 0.23 \\
1987 & 0.28 & 0.26 & 0.22 \\
1988 & 0.28 & 0.26 & 0.24 \\
1989 & 0.27 & 0.27 & 0.25 \\
1990 & 0.29 & 0.32 & 0.37 \\
1991 & 0.35 & 0.39 & 0.46 \\
\hline
\end{tabular}

competitiveness is found in Table 9.2, which contains the results of CMS decomposition according to identity $(9.7) .^{5}$

The following conclusions can be drawn from Table 9.2. On the whole, world trade effects (scale effects) have been the largest for all three countries. ${ }^{6}$ The period consisting of the first two years of the transition is an important exception in this respect. The influence of the other structural effects, however, appears to have been less decisive for export change. Especially since 1984 the size of these components relative to the export change never exceeded 10 percent for all three countries. In the late 1960s and 1970s

\footnotetext{
${ }^{5}$ The table contains the yearly cumulated effects and does not present the results of the decomposition for each year.

${ }^{6}$ For the period 1980-1984 negative scale effects do appear, as the dollar accounted value of world exports decreased due to the appreciation of the dollar and a relatively slow global economic growth.
} 
Table 9.2. Decomposition of the CSFR, Hungarian, and Polish manufactures' export change, in million dollars. ${ }^{a}$

\begin{tabular}{lrrrrr}
\hline & $1968-1973$ & $1973-1980$ & $1980-1984$ & $1984-1989$ & $1989-1991$ \\
\cline { 3 - 4 }$R$ & & & & & \\
Scale effect & 332 & 1,033 & -184 & 1,136 & 564 \\
Region effect & 111 & -60 & 53 & -8 & 87 \\
Commodity effect & 106 & 134 & 39 & -61 & -109 \\
Interaction effect & -101 & 48 & -122 & -9 & 22 \\
Competition effect & -90 & -450 & -12 & -301 & 603 \\
Export change & 358 & 706 & -225 & 756 & 1,167 \\
Hungary & & & & & \\
Scale effect & 178 & 835 & -251 & 941 & 568 \\
Region effect & 13 & 51 & 139 & 7 & 153 \\
Commodity effect & 17 & 462 & -14 & -39 & -17 \\
Interaction effect & -12 & -77 & -71 & -1 & 5 \\
Competition effect & 90 & -476 & -144 & 5 & 833 \\
Export change & 286 & 795 & -341 & 914 & 1,541 \\
Poland & & & & & \\
Scale effect & 165 & 921 & -255 & 833 & 561 \\
Region effect & 33 & -118 & 102 & -11 & 153 \\
Commodity effect & 30 & 140 & 4 & -22 & -36 \\
Interaction effect & -29 & 90 & -32 & 7 & 40 \\
Competition effect & 72 & -194 & -278 & 90 & 1,543 \\
Export change & 271 & 839 & -458 & 897 & 2,261 \\
\hline C. & & &
\end{tabular}

${ }^{a}$ Due to rounding, stated totals do not always correspond to the sum of the parts.

they were somewhat higher, but generally they did not contribute to a stable pattern. ${ }^{7}$

The competition effects, on the other hand, seem to have played a major role in manufactures' export change during the whole period from 1968 to 1991. For Hungary and Poland these exceeded region and commodity effects in all of the observed discrete changes. With the exception of the period from 1968 to 1973 , the magnitude of the yearly cumulated CSFR competition effects was of the same relative order. From the development of competitiveness a clear pattern can be disentangled. Hungary and Poland lost ground in the mid-1970s. They appeared unable to respond to increasing competition on world markets. In the period from 1984 to 1989 , thus

\footnotetext{
${ }^{7}$ Therefore, the further disaggregation of commodity and region effects is not included in the paper.
} 
before the collapse of the communist system, the export performance of Hungary and Poland stabilized, or even slightly improved. From the yearly decomposition, which is not given in the table, it appears that an enormous competitiveness improvement occurred in 1988. For the years 1986 and 1987 one could only speak of maintaining competitive positions in the $\operatorname{EUR}(8)$.

In the case of the CSFR the disappointing export performance was due to lacking competitiveness even in the late 1960 s and the early $1970 \mathrm{~s}$. With respect to this period, one is inclined to refer to the very conservative policy of the 1970s, which did not divert trade from East to West, but rather achieved the opposite effect. All industrial programs stemmed from CMEA agreements, which shaped the CSFR export products for these markets. Besides, the balancing of Western trade after the oil shock of 1979 was almost exclusively achieved by direct import cuts, while exports remained merely to finance necessary imports (Dyba and Kupka, 1987). Thus trade specialization was not accorded comparative advantages.

It is clear, however, that neither the CSFR nor Hungary and Poland were able to catch up in the 1970 s and 1980 s. It seems plausible to connect these results with the events of the oil price shocks in the $1970 \mathrm{~s}$, pressing the Western countries to implement important structural changes. Due to CMEA agreements, such price shocks did not materialize and thus adjustments in production were not enforced. Until the collapse of the communist system in 1989 there was a cumulative loss of export change due to competitive factors of about US $\$ 900$ million, US $\$ 500$ million, and US $\$ 300$ million for the CSFR, Hungary, and Poland, respectively. These figures are quite large, taking into account that export change in the period from 1968 to 1989 was some US $\$ 1.5$ billion for each country.

In the years of transition (1989-1991) the downward trend for the CSFR has been reversed; Poland and Hungary could further improve their export performance after their moderate successes in the late 1980s. Nevertheless, it remains to be seen whether they will experience a long-term improvement in competitiveness. The period from 1989 to 1991 is only two years. Moreover, the CSFR, Hungary, and Poland did not start their transformation programs at the same time. Hence, one has to be very careful in relating these results to the current policy strategies. Nevertheless, Poland and Hungary seem to be somewhat more successful than the CSFR. The Polish improvement might even be called dramatic. Different legacies have possibly played a role in this respect. While reforms were attempted in Poland and Hungary in the 1980s, they were rarely tried in the CSFR (Jermakowicz and Thompson Follis, 
1989). Thus not only current policy options but also different legacies of the past are to be taken into consideration. But to make further statements more information, is necessary, e.g., with respect to which markets contributed to the loss or gain of competitiveness.

Total competition effects can be split into the contribution of specific regions and commodities. Disaggregation of these effects might improve insight with respect to competitiveness on the various markets. For each market the disaggregations of the competition effect on regions and commodities is given by the following formulas:

$$
\sum_{i}\left\{q_{1 i j}-q_{0 i j} *\left(\frac{Q_{1 i j}}{Q_{0 i j}}\right)\right\} \text { and } \sum_{j}\left\{q_{1 i j}-q_{0 i j} *\left(\frac{Q_{1 i j}}{Q_{0 i j}}\right)\right\} .
$$

In formula (9.8) the first term denotes disaggregation to regions of destination, for it aggregates over commodities; the second refers to commodity disaggregation. ${ }^{8}$

Disaggregation of the competition effects on commodities is given in Table 9.3. While, in the three countries, total competition effects showed similar developments, it appears from Table 9.3 that disaggregation of commodities extricates diverging patterns. Before the collapse of the communist system, the CSFR performed constantly less satisfactorily than could be expected with machines and transport equipment and with manufactured consumer goods (clothing excluded). In the period comprising the first years of transition a significant improvement in machinery and semimanufactures is evident, while other commodity groups did not positively contribute as much to the total competition effect.

Right after the introduction of the New Economic Mechanism, clothing appeared to be Hungary's most competitive sector, followed by semimanufactures. Declining competitiveness since then has been manifested in the traditional strong sectors (clothing and semimanufactures) and has culminated in a dramatic overall picture for the period from 1980 to 1984. As was the case with Poland and the CSFR, negative results for clothing (SITC 84)

${ }^{8}$ This disaggregation has been criticized by Jepma (1986, pp. 47-49). According to Jepma it cannot be concluded that the disaggregation represents the size of the residue that can be solely attributed to the markets of destination or to the commodity market, because these are interlinked. The size of the residues on a certain market is also influenced by the competitiveness of the commodities actually sold on those markets and vice versa. A solution is proposed by normalizing the elements. In this paper the suggestion has not been followed, as it only allows cross-section analysis, while intertemporally the analysis becomes meaningless. 
Table 9.3. Competition effects of the CSFR, Hungary, and Poland, disaggregated to commodities, in million dollars. ${ }^{a}$

1968-1973 1973-1980 1980-1984 1984-1989 1989-1991

CSFR

SITC 5 Chemicals

SITC 6 Semimanufact.

SITC 7 Machines

SITC 8 Man. cons. goods

SITC 84 Clothing

Total

\begin{tabular}{rrrrr}
-4 & 30 & 11 & -33 & 20 \\
21 & -110 & 35 & -125 & 215 \\
-113 & -98 & -52 & -40 & 303 \\
-3 & -17 & -17 & -55 & 35 \\
8 & -254 & 12 & -49 & 30 \\
-90 & -450 & -12 & -301 & 603 \\
& & & & \\
7 & 57 & -17 & -26 & 64 \\
38 & -18 & -15 & 23 & 276 \\
-1 & 11 & -39 & 23 & 132 \\
1 & 15 & -37 & 21 & 365 \\
45 & -540 & -37 & -35 & -4 \\
90 & -476 & -144 & 5 & 833 \\
& & & & \\
1 & -25 & -23 & 51 & 481 \\
13 & 27 & -50 & 75 & 615 \\
20 & 2 & -144 & -70 & 73 \\
10 & 1 & -50 & 6 & 171 \\
27 & -200 & -11 & 29 & 202 \\
72 & -194 & -278 & 90 & 1,543 \\
\hline
\end{tabular}

Hungary

SITC 5 Chemicals

SITC 6 Semimanufact.

SITC 7 Machines

SITC 8 Man. cons. goods

SITC 84 Clothing

Total

\begin{tabular}{rrrrr}
-4 & 30 & 11 & -33 & 20 \\
21 & -110 & 35 & -125 & 215 \\
-113 & -98 & -52 & -40 & 303 \\
-3 & -17 & -17 & -55 & 35 \\
8 & -254 & 12 & -49 & 30 \\
-90 & -450 & -12 & -301 & 603 \\
& & & & \\
7 & 57 & -17 & -26 & 64 \\
38 & -18 & -15 & 23 & 276 \\
-1 & 11 & -39 & 23 & 132 \\
1 & 15 & -37 & 21 & 365 \\
45 & -540 & -37 & -35 & -4 \\
90 & -476 & -144 & 5 & 833 \\
& & & & \\
1 & -25 & -23 & 51 & 481 \\
13 & 27 & -50 & 75 & 615 \\
20 & 2 & -144 & -70 & 73 \\
10 & 1 & -50 & 6 & 171 \\
27 & -200 & -11 & 29 & 202 \\
72 & -194 & -278 & 90 & 1,543 \\
\hline
\end{tabular}

Poland

SITC 5 Chemicals

SITC 6 Semimanufact.

SITC 7 Machines

SITC 8 Man. cons. goods

SITC 84 Clothing

Total

${ }^{a}$ Due to rounding, stated totals do not always correspond to the sum of the parts.

were evident especially in the period from 1973 to $1980 .{ }^{9}$ A development of a backward-falling Hungarian clothing sector seemed to be persistent, as it even negatively contributed to the positive competition effect in the period from 1988 to 1991, while all other specified groups gained market shares. Other manufactured consumer goods and, to a lesser extent, machines and transport equipment were the best competing commodity groups in the early stages of transition.

Over time Poland's total competition effects developed in a way similar to Hungary's. Disaggregation, however, shows marked differences between the various commodities, except for the period from 1980 to 1984 , when both

\footnotetext{
${ }^{9}$ This development was due to a dramatic decline in Dutch clothing imports in 1979. At first glance one is inclined to believe that these poor results for all three countries stem from data errors. Such, however, is not the case. Table 9.4 also indicates the negative results on the Dutch market.
} 
Table 9.4. Competition effects in the CSFR, Hungary, and Poland, disaggregated to regions, in million dollars. ${ }^{a}$

\begin{tabular}{|c|c|c|c|c|c|}
\hline & $1968-1973$ & $1973-1980$ & $1980-1984$ & 1984-1989 & $1989-1991$ \\
\hline \multicolumn{6}{|l|}{$\overline{C S F R}$} \\
\hline Belgium/Luxembourg & -8 & -4 & -10 & -11 & -30 \\
\hline Germany & 29 & -51 & -38 & -117 & 493 \\
\hline France & -108 & -79 & 24 & -47 & 30 \\
\hline Italy & 3 & -67 & -14 & -48 & 47 \\
\hline Netherlands & -2 & -230 & 23 & -40 & 20 \\
\hline Austria & -4 & 9 & 4 & -21 & 45 \\
\hline Switzerland & 0 & -29 & -1 & -17 & -2 \\
\hline Total & -90 & -450 & -12 & -301 & 603 \\
\hline \multicolumn{6}{|l|}{ Hungary } \\
\hline Belgium/Luxembourg & -1 & -1 & 0 & 10 & 28 \\
\hline Germany & 70 & 85 & -140 & 2 & 382 \\
\hline France & -4 & -4 & -14 & 0 & 33 \\
\hline Italy & 10 & 2 & -24 & -15 & 152 \\
\hline Netherlands & 4 & -516 & 9 & -2 & 13 \\
\hline Austria & 9 & -28 & 21 & 27 & 218 \\
\hline Switzerland & 2 & -16 & 4 & -15 & 6 \\
\hline Total & 90 & -476 & -144 & 5 & 833 \\
\hline \multicolumn{6}{|l|}{ Poland } \\
\hline Belgium/Luxembourg & 11 & -31 & -4 & 3 & 110 \\
\hline Germany & 59 & -25 & -143 & 147 & 1,159 \\
\hline France & -17 & 4 & -42 & -50 & 133 \\
\hline Italy & -2 & 39 & -85 & -4 & 32 \\
\hline Netherlands & 17 & -196 & 9 & 5 & 79 \\
\hline Austria & 5 & 5 & -9 & 13 & 24 \\
\hline Switzerland & 0 & 9 & -4 & -23 & 6 \\
\hline Total & 72 & -194 & -278 & 90 & 1,543 \\
\hline
\end{tabular}

${ }^{a}$ Due to rounding, stated totals do not always correspond to the sum of the parts.

countries suffered under debt crises, preventing an improvement in competitiveness. While in the 1970s and the early 1980 s chemicals negatively contributed to the total competition effect, they significantly improved it afterward. The same holds true for semimanufactures. Machinery and transport equipment remains a rather poor group, also the least positively contributing in the first stage of transition. In contrast, clothing seems to recover from bad performance in the late 1970 s and early 1980 s. 
An overview of regionally disaggregated competition effects is given in Table 9.4. In the CSFR, regional disaggregated competition effects show negative contributions over the period from 1968 to 1989 , or at best small positive figures. Here, Germany takes an exception in the period of normalization and stabilization. If the period from 1980 to 1984 , which due to a very small total competition effect is somewhat tainted with interpretation problems, is disregarded, it has to be concluded that until the collapse of communism the CSFR performed badly in all the specified regions of destination. Afterward, its greatest improvement was on the German market.

In the 1970s Hungary's export performance on the German markets contributed positively to the total competition effects, even in the period from 1973 to 1980 when total competition effects dramatically declined. In the early 1980s it was particularly bad on German, French, and Italian markets. Since the start of the transition period, it has become competitive especially on the larger destination markets, to wit, Germany, France, and Italy, but also special ties with Austria seem to have been successfully exploited.

With respect to Poland's export performance before the collapse of communism, no striking conclusions can be drawn, except for the fact that the performance on German markets has for most of the time contributed significantly to the total competition effect. In the 1980s Poland was also performing badly on the French market. The positive turnaround after 1989 stems mostly from exports to Germany, while in the other countries smaller improvements were achieved.

As far as EC protectionism is concerned, the following has to be noted. Regional disaggregation does not confirm systematic differences between relative performance on EC and EFTA markets. Although market accessibility is under any circumstances to be preferred, there seems to be some indication to conclude that the revealed protectionism of the EC was no bigger than that of EFTA. ${ }^{10}$ Moreover, Germany's active Ostpolitik, which entailed strong pleas for Central and Eastern European integration, may possibly be reflected in the positive results in terms of competitiveness for the Visegrád countries. To a lesser extent, perhaps, the same holds true for Austria and Hungary.

\footnotetext{
${ }^{10}$ Hoen and Wagener (1989) included Scandinavian markets in the regions of destination for a study on Hungary's export performance. Performance on these markets also appeared not to exceed competitiveness in EC regions.
} 


\section{Economic Reform and Competitiveness}

The empirical results which were obtained by the CMS analysis do not suggest any explanation for slackening or improving competitiveness. A comprehensive analysis of the causes of poor competitiveness of the three countries in the period from 1968 to 1991 is not the goal of this study. A comparison of the performance of the three countries, however, raises questions about the impact of market-oriented reforms on competition in the framework of centrally planned economies.

Why did the empirical evidence not confirm the expectation that, for instance, in the 1970s and 1980s Hungary, which was put in the vanguard of communist reform attempts in Central and Eastern Europe, with the introduction of the New Economic Mechanism, would at least outcompete the CSFR, a country which neither took any significant decentralizing measures in respect to foreign trade nor stated any political intentions to shift trade relations from East to West?

Second, why did findings for 1989-1991 on improved competitiveness thwart expectations with respect to the effects of diverging opted policies on transformation? During the first years of transition Hungary, which to a large extent has followed a gradual approach, performed in-between the CSFR and Poland, the two countries that opted for the radical approach.

In linking competitiveness and collective interests Hoen (1992) evaluates the effectiveness of the New Economic Mechanism on Hungarian export performance, the CSFR serving as a point of reference. It could be inferred that the internal dynamics of the Hungarian reform attempts during the 1970s and 1980 s diverted from the initial aims of marketization. On the one hand, rent-seeking opportunities did emerge from foreign trade for protectionist import-substituting producers, while the CMEA market remained an attractive alternative virtually not affected by reforms, and, thus, generating welfare-distributing instead of welfare-creating effects.

As far as persistence in autarkic behavior is concerned, one has to admit that it is very difficult to pinpoint coalitions, as they are changing over time. Nevertheless, there appears to be convincing arguments for strong bargaining positions of import-substituting producers. Firstly, from the traditional environment of the centralized bureaucratic system of administrative allocation and control, they had long enduring relations with the ministries. Foreign trade merely served as a protective belt for domestic production targets, the function of exports coming to the fore as financing necessary imports. Exports had a residual status that did not stimulate lasting bargaining power 
at the higher levels of the hierarchy. Secondly, with the introduction of a strategy of diversifying exports, homogeneity of the exporters interested in free trade was to a certain extent distorted. Within the export sector, lobbies were dominated by producers relatively less dependent on (diversified) imports. The exports mostly entailed homogeneous commodities, such as grain, meat, basic chemicals, and steel (Wass von Czege, 1987, pp. 236239). Enterprises interested in genuine liberalization existed in a very large, but dispersed, group. In short, the trade structure in the 1980s in many ways still resembled the autarkic situation that existed during traditional central planning period.

With respect to the disappointing Hungarian competitiveness in the 1970s and 1980s, one has to take into account the survival of another important rent-seeking opportunity: the CMEA market. Foreign trade reforms during the period of the New Economic Mechanism only superficially affected the conducting of CMEA trade. Just as was the case with the other Central and Eastern European countries, trade was the result of bilateral negotiations. It was clear that these negotiations led to a trade-off between world market and CMEA market exports, the latter market being a noncompetitive outlet enfeebling the comprehensive reforms.

The persistence in autarkic behavior and inconsistencies due to unaltered CMEA trade may serve as an explanation for the relatively small differences in export performance between Hungary, the CSFR, and Poland, before the collapse of the system in 1989 . It remains questionable whether the reform package performed better at all than the traditional system of central planning in Hungary. On the one hand, the improvement of competitiveness in the period between 1968 and 1973 may be seen as a temporary break with former structures of power, recovering after a certain period of time and, once more, leading to the same institutional sclerosis (Olson, 1982). On the other hand, this temporary revival of competitiveness may have been due to the impetus of the introduction of an import-led growth policy. As Poland also appeared to be able to improve its export performance in the same period, without relying on the same sort of reform attempts, this argument seems to be more convincing. Moreover, it is not by accident that the export performances in Hungary and Poland were more severely hit by the debt crisis than in the CSFR, which at least in part was the result of this policy. Hence, differences in export performance were not so much due to system reforms, but reflected different policies. 
Broadly speaking, all three countries did perform very badly in the $1970 \mathrm{~s}$ and 1980s. Differences are to be noted with respect to the phasing and severity of decline in competitiveness. The CSFR was the first to be confronted with straggling export performance on Western markets, followed by Hungary and Poland. As far as severity is concerned, it can be concluded that, in the early 1980s, Hungary and Poland were to a larger extent hampered in their export possibilities due to debt-inspired import constraints, that is, by the boomerang effect of an import-led growth policy.

It has to be concluded that none of the three countries was able to improve export performance vis-à-vis the reference group, containing the rest of the world. It is true, in the period between 1968 and 1989 Hungary and Poland gained manufactures' market shares, but performance in the distinguished periods clearly showed that since the late 1970 s actual export growth was below expected change. The CSFR even lost market shares with respect to the total period before the collapse of the communist system. Manufactures' market shares in 1989 were below those in 1968. Declining competitiveness, and not destination and commodity composition of exports, seems to be responsible for these observed trends in manufacturing exports. In the late 1980s Poland and Hungary were able to maintain or even slightly improve their export performance, which may be partly due to intensified reform attempts.

Statements on the success or failure of shock therapies versus gradual reforms in respect to competitiveness during the first years of transition are rather premature. Moreover, the applied CMS analysis does not give any clues with respect to the effectiveness of the various policies. It rather points to a certain indifference. The moderate Hungarian approach to institutional change is clearly progressing and increasing competition, whereas the CSFR and Polish shock therapies coincide with significantly different competition effects, although positive for both countries. To stick to the policy seems more important than the policy itself. What is needed for the hoped-for supply response is a stable economic policy that diminishes uncertainties.

In accordance with other studies (e.g., Hughes and Hare, 1991), the CMS analysis shows diversity of the relatively strong commodity sectors within the Visegrád countries. While in 1989-1991, the CSFR has proved to be rather competitive in the exports of machines and transport equipment, and to a lesser extent in semimanufactures, strong sectors in Hungary have come to the fore especially in manufactured consumer goods (clothing excluded), while chemicals and semimanufactures have largely contributed 
to the improvement of Polish exports since the collapse of the communist system. This diversity allows international specialization within this group of countries, without too much competition.

\section{References}

Brada, J.C. (1991) "The political economy of communist foreign trade institutions and policies," Journal of Comparative Economics, Vol. 2, No. 1.

Clague, C., and Rausser, G.C. (eds.) (1992) The Emergence of Market Economies in Eastern Europe (Oxford: Basil Blackwell).

Drabek, Z., and Olechowski, A. (1989) Price and Quality Competitiveness of Socialist Countries' Exports, Policy, Planning and Research Working Paper 317 (Washington, DC: World Bank).

Dyba, K., and Kupka, V. (1987) "The adjustment of Czechoslovakian economy to external disturbances," Czechoslovak Economic Papers, 24.

Flam, H., and Helpman, E. (1987) "Vertical product differentiation and north-south trade, American Economic Review, Vol. 77, 810-822.

Haendcke-Hoppe, M. (ed.) (1988) Außenwirtschaftssysteme und Außenwirtschaftsreformen sozialistischer Länder: Ein intrasystemarer Vergleich (Berlin: Duncker \& Humblot).

Havrylyshyn, O., and Tarr, D. (1991) "Trade liberalisation," in P. Marer and S. Zecchini (eds.), The Transition to a Market Economy (Paris: OECD).

Hoen, H.W. (1992) Het Nieuwe Economische Mechanisme en de buitenlandse handel; de effecten van de Hongaarse hervormingen op de uitvoerprestaties (The New Economic Mechanism and Foreign Trade: The Effects of Hungarian Reform Attempts on Export Performance) (Groningen: Wolters-Noordhoff).

Hoen, H.W., and van Leeuwen, E.H. (1991) "Upgrading and relative competitiveness in manufacturing trade: Eastern Europe versus the newly industrializing economies," Weltwirtschaftliches Archiv, Vol. 127, No. 2.

Hoen, H.W., and Wagener, H.-J. (1989) "Hungary's exports to the OECD: A constant market shares analysis," Acta Oeconomica, Vol. 40, Nos. 1-2.

Hughes, G. and Hare, P. (1991) "Competitiveness and industrial restructuring in Czechoslovakia, Hungary, and Poland," European Economy, Special Edition 2.

Jepma, C. (1986) "Extensions and applications possibilities of the constant market shares analysis: The case of developing countries' exports," $\mathrm{PhD}$ thesis, Groningen.

Jermakowicz, W.W., and Thompson Follis, J. (1989) "Reform cycles in Eastern Europe, 1944-1987: A comparative analysis from a sample of Czechoslovakia, Poland, and the Soviet Union," Gießener Abhandlungen zur Agrar- und Wirtschafisforschung des Europäischen Osten, Band 163 (Berlin: Duncker \& Humblot).

Krueger, A.O. (1974) "The political economy of the rent-seeking society," American Economic Review, Vol. 44, No. 3. 
Leamer, E.E., and Stern, R.M. (1970) Quantitative International Economics (Chicago, IL: Aldine Publishing Company).

OECD (various years) Trade by Commodities, Series C (Paris: OECD).

Olson, M. (1965) The Logic of Collective Action: Public Goods and the Theory of Groups (Cambridge, MA: Harvard University Press).

Olson, M. (1982) The Rise and Decline of Nation, Economic Growth, Stagflation, and Social Rigidities (New Haven, CT: Yale University Press).

Richardson, J.D. (1971a) "Constant-market-shares analysis of export growth," Journal of International Economics, Vol. 1, No. 1.

Richardson, J.D. (1971b) "Some sensitivity tests for a 'constant-market-shares' analysis of export growth," The Review of Economics and Statistics, Vol. 53, No. 3 .

Rodrik, D. (1988) Industrial Organization and Product Quality: Evidence from South Korean and Taiwanese Exports, NBER Working Paper Series, 2722 (Cambridge, MA: National Bureau of Economic Research).

Senior Nello, S. (1991) The New Europe: Changing Economic Relations between East and West (New York and London: Harvester Wheatsheaf).

Wass von Czege, A. (1987) "Special-interest groups and their impact on balance of payments-oriented investment strategies," in A. Rába and K.-E. Schenk (eds.) Investment System and Foreign Trade Implications in Hungary (Stuttgart and New York: Gustav Fischer Verlag). 



\section{Part III}

Enterprises and Trade Restructuring 



\section{Chapter 10}

\section{Factors and Effects of Trade Reorientation in Hungary}

László Halpern*

\section{Introduction}

The collapse of the CMEA and the falling domestic demand have dramatically changed the economic environment of Hungarian firms. According to standard assumptions a typical firm in a centrally planned economy has a rather slow, if any, price and cost responsiveness. While these assumptions might have been true for other Eastern European economies until the $1990 \mathrm{~s}$, enterprise behavior in Hungary had already gone through significant

*This paper was produced as a part of the "Industrial Restructuring and Trade Reorientation and East-West European Integration" project of the ACE program of the Commission of European Communities and supported by grants from the Ford Foundation (No. 9100383) and from the SPES program of the Commission of the European Communities (No. E/90100033/PRO) for the Center for Economic Policy Research. The first results of this research were obtained while the author was a visitor at the Department of Applied Economics at Cambridge University with support from an ACE fellowship. Earlier versions of this paper have been presented at the Seventh Annual Congress of the European Economic Association in Dublin, September 1992, at the Second Conference of the European Association of Comparative Economic Studies (EACES) in Groningen, September 1992, and at the workshop of the ACE program in Vienna, November 1992. Comments and criticisms of the participants are gratefully acknowledged, but the views expressed remain the responsibility of the author. An earlier version of this paper was published as a CEPR discussion paper (Halpern, 1993). 
changes prior to the political landslide of $1989-1990$. This paper analyzes the most important foreign trade aspects of the more responsive enterprise behavior. Because most Hungarian enterprises currently exporting to Western economies were already operating under the previous regime, the pattern of changes in their behavior may be an indication for future rearrangements.

The paper combines time series and cross-sectional analysis. This twofold attempt is the only way one can analyze the problem of structural change and the evolution of the corporate sector at the same time. As trade reorientation from Eastern to Western markets mainly occurred in the second half of the 1980s and in 1991, it was impossible to verify empirically the specification of traditional trade models based on time series only; for this reason the use of cross-sectional analysis was unavoidable.

The first part of the paper describes and analyzes the performance of firms exporting regularly to both East and West. The regular exporters' position in this case did not necessarily imply the pressure of efficiency imposed by foreign markets on the firms, since the profitability of both ruble and dollar exports were heavily influenced by the impact of central regulation. ${ }^{1}$ In addition, the eventual losses of exporting activities might have been compensated for in the domestic market, which was more or less sheltered from the competition of imports by import licensing.

The sample used in the first part of this paper contains firms exporting in both ruble- and dollar-trade directions between 1981 and 1990. This sample certainly reflects the changing pattern of enterprise adjustment influenced by the internal and external environments.

In the second part of the paper the effect of trade reorientation is investigated on the profitability and growth of firms belonging to another sample, which includes all the firms with a significant amount of dollar exports between 1988 and 1991.

\section{Trade Reorientation}

The data base used for our analysis consists of the most important balance sheet as well as profit and loss accounts data, together with data on foreign trade activity, for 212 firms. These firms were selected from the population

\footnotetext{
${ }^{1}$ Dollar-accounted trade denotes trade flows settled in convertible currencies carried out with Eastern or Western countries. Ruble-accounted trade covers the trade with CMEA countries paid in transferable rubles. This distinction is of primary importance, since the same contracting agents behaved differently in a deal settled in transferable ruble compared with a deal settled in convertible currencies.
} 
Table 10.1. Share in the sample of regularly exporting firms as compared to the whole corporate sector, in percent.

\begin{tabular}{lll}
\hline & $1981-1989$ & 1990 \\
\hline Sales & $18-20$ & 16 \\
Ruble sales & $45-53$ & 37 \\
Dollar sales & $44-49$ & 36 \\
Assets & $18-22$ & 17 \\
Profit & $16-24$ & 14 \\
Number of employees & $18-19$ & 19 \\
Earnings & $17-20$ & 16 \\
\hline
\end{tabular}

Source: Own computation using KOPINT-DATORG data base.

of virtually all Hungarian firms on the basis of their trade profile. ${ }^{2}$ Table 10.1 shows, in several dimensions, the size of the share of regularly exporting firms in the Hungarian corporate sector. No newly established firms were taken into account in the sample due to the lack of information on their birth and early evolution. Nevertheless, the principal goal - namely, to analyze the behavior of those enterprises which already existed before largescale trade reorientation - can be fulfilled. The analysis of the link between enterprise performance and institutional transformation - commercialization or privatization - is beyond the scope of this paper.

The main deficiency of the data set is the lack of firm-specific price data and foreign-demand information. This means that only nominal variables were available. In the course of our analysis, however, aggregate sectoral price indices were used to compute real variables for our firms and also certain foreign-demand variables were constructed.

\section{Econometric estimations}

In this section the results of an empirical econometric analysis are presented. The detailed analysis of the sample is given in Halpern (1992a). The present estimation can be regarded as a continuation of previous works (Halpern, 1989; and Halpern and Székely, 1992) that focused on the econometric estimation of an aggregate export equation. Here an extension is offered: time series and cross-sectional data are used to estimate a panel model. The shift from macro level to micro level reflects our aim at analyzing microeconomic factors of trade reorientation.

\footnotetext{
${ }^{2}$ The data originate from the Ministry of Finance; access to it was arranged through KOPINT-DATORG.
} 
The first assumption made in the analysis is that in the period under investigation (1980-1991) there was no demand constraint on dollar exports of Hungarian firms. This is, of course, a rather strict assumption, since there were, and still are, certain Hungarian products which have to face quota regulations when entering, for example, the EC market. Because no enterprise-level information was available for quotas, we assumed, for the time being, a lack of demand constraint.

It is also assumed that the Hungarian firms could not be considered fully irresponsive, inward-oriented, centrally commanded economic agents; a certain degree of cost sensitivity and market orientation is assumed to be present in their action. ${ }^{3}$ A positive supply response to changes in subsidies, prices, and profitability is expected. The analysis does not intend to investigate the degree of profit-orientation or to test the eventual behavioral shift of the firms from wage maximization to profit maximization. ${ }^{4}$ Our analysis is confined to the quantification of supply responsiveness, which is assumed to be present and varying. This type of analysis is possible, because in Hungary during the 1980s the possibility of individual firms influencing the central regulation for advantageous discretionary treatment had largely been reduced.

It is widely known that for many years exporting in the framework of ruble-accounted trade was advantageous in many respects for Hungarian firms: instantaneous payment was guaranteed by the Hungarian government; delivery conditions were as a rule very loose; virtually no marketing and servicing costs were needed; and positive economies of scale effects could be achieved. Ruble exports gave rise to long-term losses by compelling Hungarian exporters to lower technical and quality standards; however, these were offset by the short-term gains. In fact, enterprises exerted constant pressure on the Hungarian government to increase the annual ruble-export quota. Enterprises always used their ruble-export quota at the maximum level. Due to decreasing willingness to supply raw materials or the emerging constraint on the capacity of raw material production in the Soviet Union in the late 1980s the Hungarian government had to adjust the export quotas to the expected value of imports, since no mechanism was accessible to convert

\footnotetext{
${ }^{3}$ In fact, in the macroeconomic context, it was shown that there was a significant supply responsiveness of exports (see Halpern, 1989; Halpern and Székely, 1992; and Oblath, 1988).

${ }^{4}$ It is supposed that the behavioral pattern in foreign trade can be investigated separately at this stage. Further research is needed to incorporate the results of this paper into a general model of the behavior of the firm during transition.
} 
the "transferable" ruble-trade surplus into hard currency or into imports of hard products.

The decreasing ruble-export quotas set by the Hungarian government resulted in the perception of a reduced demand at the enterprise level; therefore, in the case of ruble exports, demand at the enterprise level was (almost) always equal to supply. In the short run the falling ruble-export demand might have had an effect on inventory accumulation of finished goods or on domestic sales or on dollar exports. In this analysis the last direct impact will be quantified; the indirect effects through the changing domestic demand on the dollar exports are not investigated.

Trade reorientation means a growing share of dollar trade at the expense of ruble trade. This can be represented by the annual change in the share of dollar exports in total sales. That is why in our econometric estimation the dependent variable is the change in the share of dollar export volume in total sales volume of an enterprise $\left[\Delta\left(X_{D} / X\right)\right]$. The sketchy formula of the equation we tested is as follows:

$$
\Delta\left(X_{D} / X\right)=f\left(S_{D}, C_{D}, P_{D}, d_{D}\right) .
$$

Four groups of explanatory variables are distinguished: subsidies granted to dollar exports $\left(S_{D}\right)$, costs $\left(C_{D}\right)$, dollar export prices $\left(P_{D}\right)$, and demand $\left(d_{D}\right)$. Two types of demand variables are defined. The first is a proxy variable which tries to capture the effect of demand through the behavior of the inventory of finished goods, claiming that the effect of demand has its impact first on the inventory of finished goods. The second type of demand variable is simply the volume of ruble exports according to the considerations given above. The expected sign of price and subsidy coefficients is positive. It is expected that the coefficient will be negative in case of the costs and in the case of both demand variables: that is, the higher the inventory of finished goods and/or ruble-export demand, the lower the dollar-export supply, all things being equal.

It is supposed that trade reorientation may be influenced by other factors, too. These can be represented by the productivity level, the capacity utilization, the real wage, the technical level, and the level of inventories of intermediate inputs. In the course of the estimation it was tested whether these factors had an impact on the dependent variable. It was also tested whether the given parameters were stable over time. If the stability hypothesis of a parameter was rejected, then different parameters were used for different time periods for the same variable. 


\section{The results}

This section presents only the final specification of the panel model (see Table 10.2). According to these results the change in the share of dollar export was significantly influenced by the change of its relative profitability (represented by the cost variable), by the change in dollar-export subsidies, by the change of relative dollar-export price, and by the change of rubleexport demand. According to the Wald test these parameters jointly are significantly different from zero. Neither the second-order serial correlation test nor the Sargan test indicate misspecification.

The specification includes two lagged values of the dependent variables. No higher orders of lags showed a significant effect. The impact of the lagged dependent variables refers to the presence of adjustment costs. It is obvious that trade reorientation required efforts in terms of costs.

The two-digit figures after the name of a variable in parentheses refer to the period in which this explanatory variable had to be taken into account. For the remaining years the variable was set to zero.

The subsidy variable had an impact on the export shares only in the last two years, because prior to that period a major part of the subsidies was a flat-rate subsidy granted over the exchange rate. In the earlier period Hungarian economic policy preferred this type of general export-incentive to devaluation. The subsidy variable was significant neither for the whole estimation period nor for the period before 1989. This result seems to contradict the macroeconometric estimations presented in Halpern and Székely (1992). A direct comparison, however, may be misleading since the dollar-export subsidy was always higher for the irregular exporter firms than for the regular exporter firms making up our sample (Halpern, 1992). The dollar-export subsidy of the irregular exporters might have been a significant explanatory variable even before 1989 .

Two cost variables are taken into account in the equation. Their effect on trade reorientation was quite important in comparing the magnitude of these coefficients with that of the other explanatory variables. The first cost variable was only effective between 1984 and 1988, while the second one, the two-year lagged variable, was significant over the whole estimation period. Several attempts were made to specify the cost effect in the period of fast trade reorientation (i.e., in 1989 and 1990), but they were not successful. Significant cost adjustment took place during the period of slow trade reorientation (i.e., prior to 1989); when this process started to accelerate, the cost adjustment somehow disappeared. The estimated positive coefficients 
Table 10.2. Final results of the panel model. ${ }^{a}$

\begin{tabular}{lcr}
\hline Variables & Coefficient $^{b}$ & T stat \\
\hline Dependent & & \\
$\Delta\left(X_{D} / X\right)$ & & \\
Explanatory & & \\
$\Delta\left(X_{D} / X\right)(-1)$ & 0.2584 & -8.2 \\
$\Delta\left(X_{D} / X\right)(-2)$ & -0.0931 & 3.0 \\
$\Delta S_{D}(89-90)$ & 0.0376 & -23.2 \\
$\Delta C_{D}(84-88)$ & -0.1761 & -6.7 \\
$\Delta C_{D}(-2)$ & -0.0546 & 2.1 \\
$\Delta P_{D}(-1)$ & 0.0345 & -3.6 \\
$\Delta\left(X_{R} / X\right)(86-87)$ & -0.0354 & -2.0 \\
$\Delta\left(X_{R} / X\right)(89)$ & -0.0291 & {$[212]^{c}$} \\
Test for second-order serial correlation: & 0.390 & $8]$ \\
Wald test of joint significance: & 798.9 & {$[65]$} \\
Sargan test: & 84.7 &
\end{tabular}

$X_{D} / X$ (dollar-export sales/dollar-export prices)/(total sales/total sales prices).

$S_{D} \quad$ dollar-export subsidies/dollar-export sales.

$C_{D} \quad$ (dollar-export costs/dollar-export sales)/(total costs/total sales).

$P_{D} \quad$ dollar-export price/total sales prices.

$X_{R} / X$ (ruble-export sales/ruble-export prices)/(total sales/total sales prices).

$\Delta \quad$ difference operator.

a The estimation method was the so-called Generalized Method of Moments (see Arellano and Bond, 1988). The estimation period is 1984-1990 since three observations are lost because of the difference form and the two-year lagged explanatory variables. The details of the estimations and further results can be found in Halpern (1993).

${ }^{b}$ The coefficients refer to standardized variables (mean $=0$, standard deviation $=1$ ) for the sake of comparability of their effects on the dependent variable.

${ }^{c}$ Degree of freedom.

for the period between 1989 and 1990 were not significant in any specification. The available information was not sufficient to specify the causes of this disappearance of the cost adjustment during the period of intensified trade reorientation.

The explanatory variable of a one-year lagged change in relative price (measured in national currency) proved to be significant with positive coefficient. This conforms to the general assumption of an export-supply equation. 
The change in ruble-export sales significantly influenced the change in dollar exports over three years. The sign of the parameter conforms to our expectation.

In every specification time dummies were added. They were always jointly significant explanatory variables, and their parameter was rather high in 1990 and in 1988 showing that time-specific effects were also important and were not represented by other explanatory variables. One possible variable hiding behind the time dummies could have been the exchange rate, which has no firm-specific effect, only time-specific effects. It should be emphasized, however, that the exchange rate had been represented through the cost variables (though it had its impact only combined with other factors like the impact of foreign prices, the share of imported intermediate inputs, etc.).

Besides time dummies the effect of other dummies were also tested, like dummies for the specific industries, profitability, and asset size. It was assumed that these factors may add to the explanation of the difference in pace of trade reorientation in different firms. In general this assumption had to be rejected, since a significant effect was found only in one sector (services). The failure of finding additional significant dummies, however, might have been due to the inappropriate representation of the above-mentioned variables.

\section{Effects of Trade Reorientation}

Trade reorientation of Hungarian sales was accelerated in 1990 and 1991 by several factors such as the demise of the CMEA, the disintegration of the Soviet Union, and the unification of East and West Germany. Since in this analysis we record trade reorientation in the terms of ruble- and dollaraccounted trade, the decision to shift to convertible currencies in payments with former CMEA partners from 1991 onward was instrumental in speeding up the process.

Accordingly, trade reorientation in this sense was almost completed by 1991; no room for further trade reorientation was available, since the ruble export had practically vanished in 1991. In the second part of the paper the behavior of dollar-exporting firms is investigated during and after trade reorientation. For this analysis a new panel of firms was required. In the following, first the macro-performance of the Hungarian economy and the development of the profitability of the corporate sector are examined. Then 
Table 10.3. Ratio of direct and overhead costs to sales in the corporate sector, in percent.

\begin{tabular}{lllll}
\hline & 1988 & 1989 & 1990 & 1991 \\
\hline Direct costs, all sales & 82.7 & 81.6 & 81.3 & 76.6 \\
Domestic sales & 82.6 & 82.0 & 81.1 & 76.9 \\
Ruble exports & 89.5 & 85.2 & 98.1 & 80.2 \\
Dollar exports & 79.6 & 75.3 & 78.8 & 74.2 \\
Overhead costs & 13.0 & 13.9 & 16.3 & 22.8 \\
Total costs & 95.7 & 95.5 & 97.6 & 99.4 \\
\hline
\end{tabular}

a detailed analysis of cost structure and profitability of exporting firms in the period between 1988 and 1991 follows.

\section{Macro-performance and the profitability of the enterprises}

Since 1989 the Hungarian economy has fallen into a deep recession. During 1990 and 1991 the GDP fell by 14.8 percent, the gross output by 16.7 percent, and the consumer prices grew by 74.4 percent. Nevertheless, the volume of dollar trade increased: the dollar exports by 26.2 percent, the dollar imports by 22.2 percent compensating for the shrinking ruble trade. The current account balance which was in bad shape in 1988 and 1989 improved in 1990 and 1991 and became positive in spite of the huge amount of interest payments on Hungary's external debt.

The steep decline in domestic demand and the drop of trade with former CMEA economies resulted in a very steep increase in unemployment and capacity underutilization in the Hungarian economy.

The cost structure of the corporate sector reflected this crisis. The overall profitability (sales minus total costs related to sales) has almost disappeared; it was between 4.3 and 4.5 percent in 1988 and 1989, it then fell to 2.4 percent in 1990 , and in 1991 it was only slightly positive: 0.6 percent (see Table 10.3). The ratio of direct costs to sales improved in 1990 and 1991 for both domestic and dollar-export sales, while the sharply declining ruble exports were hardly able to cover the direct inputs the enterprises used for their production. This latter meant that exporting firms had no more possibility of rechanneling costs from domestic or dollar-export sales to ruble exports. The accounted high direct costs of ruble exports, as well as the alleged benefits of imported raw materials and energy from former CMEA countries, were the arguments that the enterprises used in bargaining for subsidies from the central authorities in these years. The share of overhead 
Table 10.4. Structure of sales in the sample of exporting firms, in percent.

\begin{tabular}{lrrrr}
\hline & 1988 & 1989 & 1990 & 1991 \\
\hline Domestic sales & 76.6 & 75.3 & 76.0 & 73.1 \\
Ruble exports & 9.1 & 8.5 & 5.3 & 0.4 \\
Dollar exports & 14.3 & 16.2 & 18.7 & 26.5 \\
Total sales & 100.0 & 100.0 & 100.0 & 100.0 \\
\hline
\end{tabular}

costs in total sales increased very fast: it was only 13.9 percent in 1989 , and after the increases of 2.4 and 6.5 percentage points arrived at 22.8 percent in 1991. This increasing tendency was mainly due to growing banking costs and the falling level of capacity utilization.

\section{Cost structure and profitability of exporting firms}

The sample of dollar-exporting firms selected for our analysis consists of those firms which exported more than US\$1 million in any year between 1988 and 1991.5

Within the four years of our analysis the number of firms belonging to the sample increased from 711 to 952 . They made up more than 96 percent of the dollar exports between 1988 and 1990, and 86.5 percent in 1991. Their share in ruble exports was also dominant.

The sales structure of the sample firms (see Table 10.4) reveals a very fast increase in dollar exports and the collapse of ruble exports, but the overall share of exports shows a substantial increase only in 1991. By 1991 the average firm in the sample exported more than one-fourth of its total sales for convertible currencies, which means that between 1988 and 1991 this share had almost doubled.

The cost structure of the sample firms showed very similar tendencies compared with that of the corporate sector. There was a substantial -4.3 percentage points - improvement (i.e., decrease) in the indicator of direct costs on dollar exports. The change of this indicator reveals many impacts like the effect of the exchange rate, foreign and domestic prices, and so on.

As a consequence of the large-scale decline of ruble exports in 1990, the level of even the direct costs exceeded the sales revenues. In 1991 a further increase of direct costs of ruble exports (by the level of 103.2 percent of sales

${ }^{5}$ This analysis is based on Halpern (1992b) contracted for the Hungarian Ministry of Finance. The data base covers the relevant balance sheet as well as the profit and loss account data for the sample firms. 
Table 10.5. Profit rate in the sample of exporting firms, in percent.

\begin{tabular}{llllr}
\hline & 1988 & 1989 & 1990 & 1991 \\
\hline Return on assets & 5.3 & 5.9 & 4.5 & 0.2 \\
Pre-tax profit rate & 4.1 & 5.0 & 3.4 & -0.1 \\
After-tax profit rate & 2.4 & 2.6 & 2.0 & 0.2 \\
\hline
\end{tabular}

revenue) was accompanied by a 5.5 percent jump in overhead costs. The different profitability indicators in Table 10.5 confirm the tendency outlined above: that the level of profit decreased after 1989, and in 1991 it was practically zero in the sample. ${ }^{6}$

This decline in profitability can partly be explained by the decrease in subsidies, especially for dollar exports (Table 10.6). Subsidies to ruble exports were with the exception of 1989 very high, but their macroeconomic effect became marginal by the end of the period.

Now we turn to an analysis of the profitability in different sales directions. As demonstrated above, direct costs revealed substantial improvement in the dollar-export sales and a deterioration in ruble exports. As far as indirect costs are concerned one cannot avoid the task of disaggregating the overhead costs to sales directions, since the overhead costs are also somehow covered by the revenue of the sales. The approach used in this analysis is disaggregation of the overhead costs at the firm level following the proportions of the direct costs of each sales direction. ${ }^{7}$ The result of this procedure gives the profitability measures which incorporate the effect of subsidies and the imputed overhead costs in addition to the direct cost indicators (see Table 10.7). As one can observe a significant drop in average profitability took place in 1991, which can almost exclusively be explained by the collapse of the profitability of domestic sales, which fell by 5.3 percentage points and became negative. The fall in ruble-export profitability was much larger; but, since the share of ruble sales fell even faster, it exerted, in fact, a positive effect on overall profitability. In contrast the small decrease of dollar-export profitability was fully compensated by the growing share of dollar-export sales within total sales.

Dollar export was the most profitable activity during the four years. The peak level of the profitability of dollar exports in 1989 was 10.6 percentage

\footnotetext{
${ }^{6}$ The after-tax profits in 1991 exceeded the pre-tax profits, since the firms were refunded their excess advance profit tax payments in 1990.

${ }^{7}$ The alternative approach could have been to make a similar calculation at the aggregate level or to follow the proportion of sales.
} 
Table 10.6. Ratio of net subsidies ${ }^{a}$ to sales in the sample of exporting firms, in percent.

\begin{tabular}{lrrrr}
\hline & 1988 & 1989 & 1990 & 1991 \\
\hline Domestic sales & -3.8 & -2.3 & -3.5 & -1.9 \\
Ruble exports & 18.6 & 7.2 & 18.7 & 17.6 \\
Dollar exports & 10.4 & 8.6 & 5.4 & 4.0 \\
Total sales & 0.2 & 0.2 & -0.7 & -0.2 \\
\hline
\end{tabular}

${ }^{a}$ Subsidies minus taxes.

Table 10.7. Profit rate in different sales directions in the sample of exporting firms, in percent.

\begin{tabular}{lrrrr}
\hline & 1988 & 1989 & 1990 & 1991 \\
\hline Domestic sales & 3.1 & 4.0 & 4.2 & -1.1 \\
Ruble exports & 3.9 & -2.7 & -12.7 & -32.1 \\
Dollar exports & 9.8 & 13.6 & 4.9 & 3.0 \\
Total sales & 4.1 & 5.0 & 3.4 & -0.1 \\
\hline
\end{tabular}

points higher than its bottom level in 1991. An analysis of the direct-cost indicators shows that the development of direct costs do not explain this decline.

The good profitability in 1989 can be explained by the coincidence of favorable price movements in the external markets and by the possibility of transferring the firms' costs from dollar to ruble exports. The comparison of domestic- and export-sales price indices shows that in spite of the accelerating domestic inflation the price index of exports did not lag behind that of the domestic sales. The difference between the average annual price indices of domestic and export sales between 1988 and 1991 was 1.7 points. The annual real effective exchange rate index was 92.9 percent, 99.4 percent, 101.3 percent, and 112.1 percent in the years $1988,1989,1990$, and 1991 respectively (Source: National Bank of Hungary Monthly Bulletin, 1993, Nos. 2-3). These two factors meant that the exporting firms managed to improve their dollar-export prices to counterbalance the effect of the real appreciation of the Hungarian currency in 1990 and, especially, in 1991.

The two main factors responsible for the sudden decline of the profitability of dollar exports after 1989 were the large fall of subsidies and the steep increase in overhead costs due to the decline of ruble exports and domestic sales. Since the growing share of dollar exports and the decreasing share of 
Table 10.8. Correlation between the share of exports to total sales and the return on assets in the sample of exporting firms, in percent.

\begin{tabular}{lcccc}
\hline & 1988 & 1989 & 1990 & 1991 \\
\hline Unweighted & & & & \\
$\quad$ Ruble & $-11.1^{a}$ & -3.3 & -3.5 & -3.7 \\
$\quad$ Dollar & $9.6^{b}$ & 1.5 & -1.4 & $11.0^{a}$ \\
Weighted by total sales & & & & \\
$\quad$ Ruble & -4.4 & $-8.1^{b}$ & $-8.0^{b}$ & -4.7 \\
Dollar & $12.0^{a}$ & 5.3 & $-11.3^{a}$ & 0.1 \\
\hline
\end{tabular}

${ }^{a}$ Significant at 1 percent level.

${ }^{b}$ Significant at 5 percent level.

ruble exports were the main trends between 1988 and 1991, two questions arise. Did a firm with a higher share of dollar exports (and with a lower share of ruble exports) have higher or lower profitability? Did a higher share of dollar exports improve the profit at the aggregate level? In static terms the answers depend on the link between the variables in questions.

The correlation coefficient between the export shares and the rate of return on assets reveals certain links ( Table 10.8). There is a weak significant negative correlation with ruble exports in 1988 , and over time this negative correlation did not change but became insignificant. In 1988 and in 1991 there was a weak significant positive correlation between the dollar exports and the rate of return on assets, while there was no correlation at all in 1989 and 1990. These results give a partial answer to the first question. The link between the profitability and the export share at the firm level may have stronger relation at the aggregate level if the size of the firm turns out to be a significant factor. The results of the calculations which take into account the size of the firms show a somewhat different picture. In 1988 the two correlation rates for dollar exports do not differ, while in 1991 the correlation taking into account the size factor is insignificant. Moreover, the correlation with size effect was weak, significant, and negative in 1990 .

These results somehow reflect the different effects of fast trade reorientation, and show that the role of cost adjustment, presented in the first part of the chapter, has diminished. It seems that the positive link between profitability and export exposure reappeared in 1991, but its effect has not yet materialized at the macro level. 


\section{Distribution of exporting firms}

On the basis of our diversified and comprehensive data base it is possible to further investigate the profitability situation of dollar-exporting firms. For this purpose nine criteria have been selected to calculate and analyze the distribution of dollar-exporting firms, their dollar exports, and the profitability ratios:

- Rate of return on assets (Table 10.9).

- Profitability of dollar exports (Table 10.10).

- Rate of growth of dollar exports (Table 10.11).

- Share of dollar exports (Table 10.12).

- Value of dollar exports (Table 10.13).

- Sectors (Table 10.14).

- Number of employees (Table 10.15).

- Share of foreign assets (Table 10.16).

- Organizational form (Table 10.17).

\section{Rate of Return on Assets}

The number of firms with negative profits increased by about 100 in 1990 and in 1991 ( Table 10.9). Their role in dollar exports was quite important. In $1990,17.9$ percent of the overall dollar exports was produced by lossmaking firms; in 1991 it was 23.8 percent. If the break-even firms are also included, their share in dollar exports amounts to almost one-third in 1991. On the other end of the distribution, the share of the most profitable firms also increased.

There was no major shift in the distribution of profits on domestic sales and dollar exports by the rate of return on assets. In the group with the highest rate of return, the profit rate of domestic sales remained practically unchanged; but, in the group with the smallest rate of return, there was a substantial decline. The same occurred with dollar exports in a reverse order: the most profitable ones with the highest rate of return lost more than half of the profit rate, but the profit rate in the group with the lowest rate of return remained the same. Because of these two changes, the profit of total sales has moved downward only in the groups with the lowest return on the assets. 
Table 10.9. Distribution and profitability of exporting firms by the rate of return on assets, in units and percent.

\begin{tabular}{|c|c|c|c|c|}
\hline Rate of return on assets & 1988 & 1989 & 1990 & 1991 \\
\hline \multicolumn{5}{|c|}{ Number of firms } \\
\hline Negative & 36 & 56 & 155 & 267 \\
\hline Zero & 30 & 39 & 75 & 111 \\
\hline $0-2$ percent & 93 & 102 & 133 & 158 \\
\hline $2-5$ percent & 154 & 187 & 132 & 128 \\
\hline $5-15$ percent & 303 & 287 & 214 & 172 \\
\hline Above 15 percent & 92 & 120 & 116 & 115 \\
\hline Total $^{a}$ & 708 & 791 & 825 & 951 \\
\hline \multicolumn{5}{|c|}{ Dollar exports } \\
\hline Negative & 2.5 & 2.8 & 17.9 & 23.8 \\
\hline Zero & 1.6 & 1.5 & 6.6 & 8.9 \\
\hline $0-2$ percent & 12.2 & 15.3 & 13.9 & 15.9 \\
\hline $2-5$ percent & 22.4 & 16.7 & 12.2 & 10.9 \\
\hline $5-15$ percent & 49.0 & 45.6 & 34.5 & 23.6 \\
\hline A bove 15 percent & 12.2 & 18.1 & 14.8 & 16.9 \\
\hline Total & 100.0 & 100.0 & 100.0 & 100.0 \\
\hline \multicolumn{5}{|c|}{ Profit rate of domestic sales } \\
\hline Negative & -2.2 & -6.6 & -6.9 & -15.4 \\
\hline Zero & -0.6 & -6.3 & -9.8 & -12.4 \\
\hline $0-2$ percent & -1.4 & -1.8 & 2.1 & -1.5 \\
\hline $2-5$ percent & 1.5 & 2.5 & 3.3 & 2.0 \\
\hline $5-15$ percent & 4.4 & 4.8 & 7.4 & 5.9 \\
\hline Above 15 percent & 8.2 & 9.4 & 9.5 & 7.4 \\
\hline Average & 3.1 & 4.0 & 4.2 & -1.1 \\
\hline \multicolumn{5}{|c|}{ Profit rate of ruble exports } \\
\hline Negative & -6.7 & -12.8 & -14.2 & -39.2 \\
\hline Zero & 5.4 & -4.6 & -3.9 & -20.5 \\
\hline $0-2$ percent & 16.2 & 5.4 & -11.8 & -46.0 \\
\hline 2-5 percent & -4.4 & -2.5 & -6.5 & -8.6 \\
\hline $5-15$ percent & 6.2 & -11.8 & -22.8 & -21.7 \\
\hline Above 15 percent & -3.4 & 8.0 & 9.9 & -51.4 \\
\hline Average & 3.9 & -2.7 & -12.7 & -32.1 \\
\hline \multicolumn{5}{|c|}{ Profit rate of dollar exports } \\
\hline Negative & -8.6 & -9.4 & -1.0 & -8.0 \\
\hline Zero & -0.8 & 2.6 & -7.4 & -8.3 \\
\hline $0-2$ percent & 5.5 & 6.3 & -1.2 & 14.4 \\
\hline $2-5$ percent & 11.2 & 10.3 & 3.7 & 3.0 \\
\hline $5-15$ percent & 8.8 & 15.6 & 10.1 & 5.2 \\
\hline Above 15 percent & 21.0 & 22.1 & 12.1 & 10.7 \\
\hline A verage & 9.8 & 13.6 & 4.9 & 3.0 \\
\hline \multicolumn{5}{|c|}{ Profit rate of total sales } \\
\hline Negative & -3.0 & -8.2 & -6.5 & -13.3 \\
\hline Zero & 0.2 & -4.7 & -8.5 & -11.0 \\
\hline 0-2 percent & 1.4 & 1.0 & 0.9 & 1.7 \\
\hline $2-5$ percent & 2.6 & 3.2 & 2.8 & 2.2 \\
\hline $5-15$ percent & 5.2 & 5.6 & 6.5 & 5.7 \\
\hline Above 15 percent & 9.3 & 11.3 & 9.8 & 8.3 \\
\hline Average & 4.1 & 5.0 & 3.4 & -0.1 \\
\hline
\end{tabular}

${ }^{a}$ Due to missing data the total number of firms is less than the number of firms in the sample. 


\section{Profitability of Dollar Exports}

In 1989, more than half of the dollar exports was carried out with a profit rate over 15 percent, whereas in 1991 only 18.5 percent of dollar exports was exported with a profit as high (Table 10.10). At the same time the share of dollar exports with a profit rate below 5 percent increased threefold. The distribution was modified mainly in 1990 .

It is worth mentioning that the average profit rate of the best-performing dollar exporters (i.e., those achieving a profit rate of more than 15 percent) increased by one-third in the year 1991 from 26.1 percent to 34.7 percent. Accordingly the most profitable (over 15 percent) firms were selling a much smaller share of Hungary's exports, but achieving a higher average profit rate.

One can find no correlation between the profitability of dollar exports and that of domestic sales. The average profit rate of domestic sales did not reveal any differentiation according to the profit of dollar exports. In 1991 the best and the worst dollar-exporting firms had almost the same, slightly negative, profit rate on their domestic sales.

\section{Rate of Growth of Dollar Exports}

Between 1989 and 1991 some 50 firms in the sample were able to double the volume of their dollar exports. Approximately the same number of firms belonged to the group that achieved an export growth between 50 and 100 percent (Table 10.11). On the other hand, an increasingly large number of firms suffered a loss in their export volume on dollar markets.

In the first two years the impact of the most dynamic firms was rather low; they represented only between 3 and 4 percent of the total value of dollar exports, thus supporting the view that only small firms were able to grow fast. By 1991 these firms accounted for 18.2 percent of dollar exports and their role became significant.

The change in the link between the growth rate and the profit rate of dollar exports has been fundamental. In 1989 firms with stagnating dollarexport volume had higher profits than firms with positive growth, and even the firms with declining export volumes had higher profits than the firms with the fastest growth rate of dollar exports. In 1990 and particularly in 1991 this correlation turned around: the fastest growing firms had significantly higher profit rates, while those firms which had to reduce the volume of their dollar exports suffered losses. 
Table 10.10. Distribution and profitability of exporting firms by the profit rate of dollar exports, in units and percent.

\begin{tabular}{|c|c|c|c|c|}
\hline Profit rate of dollar exports & 1988 & 1989 & 1990 & 1991 \\
\hline \multicolumn{5}{|c|}{ Number of firms } \\
\hline$<-5$ percent & 179 & 182 & 264 & 362 \\
\hline$-5-0$ percent & 66 & 70 & 91 & 102 \\
\hline $0-5$ percent & 61 & 89 & 85 & 102 \\
\hline $5-15$ percent & 124 & 143 & 150 & 156 \\
\hline$>15$ percent & 232 & 269 & 209 & 199 \\
\hline Total & 662 & 753 & 799 & 921 \\
\hline \multicolumn{5}{|c|}{ Dollar exports } \\
\hline$<-5$ percent & 16.1 & 8.7 & 25.6 & 26.6 \\
\hline$-5-0$ percent & 10.9 & 8.7 & 13.5 & 16.0 \\
\hline $0-5$ percent & 11.4 & 14.0 & 6.8 & 15.7 \\
\hline $5-15$ percent & 24.7 & 17.7 & 24.2 & 23.3 \\
\hline$>15$ percent & 36.9 & 50.9 & 29.9 & 18.5 \\
\hline Total & 100.0 & 100.0 & 100.0 & 100.0 \\
\hline \multicolumn{5}{|c|}{ Profit rate of domestic sales } \\
\hline$<-5$ percent & 6.1 & 5.2 & 4.2 & -1.7 \\
\hline$-5-0$ percent & 4.6 & 5.9 & 3.7 & 0.1 \\
\hline $0-5$ percent & 5.5 & 2.5 & 3.4 & -0.9 \\
\hline $5-15$ percent & 2.9 & 4.0 & 2.5 & 0.6 \\
\hline$>15$ percent & 0.9 & 3.7 & 5.4 & -1.4 \\
\hline Average & 3.1 & 4.0 & 4.2 & -1.1 \\
\hline \multicolumn{5}{|c|}{ Profit rate of ruble exports } \\
\hline$<-5$ percent & 8.1 & 5.0 & -4.3 & -45.6 \\
\hline$-5-0$ percent & -0.2 & -6.8 & -4.4 & -24.4 \\
\hline $0-5$ percent & 3.5 & 1.0 & -20.4 & -45.2 \\
\hline $5-15$ percent & 4.8 & -0.5 & -9.2 & -16.4 \\
\hline$>15$ percent & 0.9 & -9.4 & -29.7 & -37.9 \\
\hline Average & 3.9 & -2.7 & -12.7 & -32.1 \\
\hline \multicolumn{5}{|c|}{ Profit rate of dollar exports } \\
\hline$<-5$ percent & -20.7 & -22.3 & -19.4 & -21.0 \\
\hline$-5-0$ percent & -1.8 & -2.5 & -2.0 & -2.4 \\
\hline $0-5$ percent & 1.3 & 3.2 & 2.6 & 2.7 \\
\hline $5-15$ percent & 11.2 & 8.9 & 8.9 & 9.2 \\
\hline$>15$ percent & 28.3 & 26.9 & 26.1 & 34.7 \\
\hline Average & 9.8 & 13.6 & 4.9 & 3.0 \\
\hline \multicolumn{5}{|c|}{ Profit rate of total sales } \\
\hline$<-5$ percent & 3.2 & 2.2 & -1.0 & -6.6 \\
\hline$-5-0$ percent & 3.1 & 3.7 & 1.8 & -1.0 \\
\hline $0-5$ percent & 4.8 & 2.5 & 2.3 & 0.4 \\
\hline 5-15 percent & 4.7 & 4.6 & 3.1 & 3.4 \\
\hline$>15$ percent & 4.8 & 6.9 & 7.1 & 4.2 \\
\hline Average & 4.1 & 5.0 & 3.4 & -0.1 \\
\hline
\end{tabular}


Table 10.11. Distribution and profitability of exporting firms by the growth rate of dollar exports, in units and percent. ${ }^{a}$

\begin{tabular}{lcrr}
\hline Growth rate of dollar exports & 1989 & 1990 & 1991 \\
\hline & Number of firms & \\
n.a. & & & \\
Decrease more than -10 percent & 34 & 17 & 20 \\
Between -10 and +10 percent & 125 & 196 & 238 \\
Increase between 10 and 50 percent & 132 & 116 & 69 \\
Increase between 50 and 100 percent & 160 & 121 & 132 \\
Increase more than 100 percent & 43 & 50 & 43 \\
Total & 55 & 49 & 47 \\
& 549 & 549 & 549
\end{tabular}

n.a.

Decrease more than -10 percent

Between -10 and +10 percent

Increase between 10 and 50 percent

Increase between 50 and 100 percent

Increase more than 100 percent

Total

Dollar exports

$\begin{array}{rrr}0.6 & 0.5 & 0.2 \\ 11.2 & 23.0 & 23.9 \\ 35.9 & 32.5 & 15.7 \\ 42.9 & 34.0 & 33.9 \\ 5.3 & 6.7 & 8.1 \\ 4.1 & 3.3 & 18.2 \\ 100.0 & 100.0 & 100.0\end{array}$

n.a.

Decrease more than -10 percent

Between -10 and +10 percent

Increase between 10 and 50 percent

Increase between 50 and 100 percent

Increase more than 100 percent

Average

n.a.

Decrease more than -10 percent

Between -10 and +10 percent

Increase between 10 and 50 percent

Increase between 50 and 100 percent

Increase more than 100 percent

Average

n.a.

Decrease more than -10 percent

Between -10 and +10 percent

Increase between 10 and 50 percent

Increase between 50 and 100 percent

Increase more than 100 percent

Average

Profit rate of domestic sales

$\begin{array}{rrr}3.7 & 14.0 & -1.5 \\ 2.5 & 3.2 & -0.7 \\ 2.4 & 3.1 & -3.3 \\ 5.4 & -0.1 & -3.4 \\ 3.7 & 5.1 & 8.4 \\ 4.2 & 0.9 & -9.7 \\ 4.0 & 4.2 & -1.1\end{array}$

Profit rate of ruble exports

$\begin{array}{rrr}14.2 & 30.9 & -49.7 \\ 0.2 & -17.3 & -43.8 \\ 2.9 & -5.4 & -29.2 \\ -14.4 & -26.6 & -36.3 \\ -4.4 & -12.8 & -43.7 \\ 15.2 & -6.6 & -14.6 \\ -2.7 & -12.7 & -32.1\end{array}$

Profit rate of dollar exports

$\begin{array}{rrr}0.9 & 24.3 & 0.4 \\ 11.7 & -0.8 & -5.9 \\ 16.0 & 0.9 & 4.6 \\ 14.6 & 13.3 & 1.6 \\ 13.9 & 9.9 & 10.4 \\ 5.1 & 8.9 & 22.0 \\ 13.6 & 4.9 & 3.0\end{array}$

n.a.

Decrease more than -10 percent

Between -10 and +10 percent

Increase between 10 and 50 percent

Increase between 50 and 100 percent

Increase more than 100 percent

Profit rate of total sales

\begin{tabular}{lrr}
3.8 & 14.3 & -1.4 \\
3.1 & 1.4 & -1.7 \\
6.0 & 2.0 & -0.6 \\
5.5 & 1.5 & -1.2 \\
4.5 & 4.6 & 8.5 \\
4.6 & 1.8 & 0.3 \\
5.0 & 3.4 & -0.1 \\
\hline
\end{tabular}

Average

5.0

3.4

${ }^{a}$ Sectoral price indices were used to compute growth rates.

${ }^{b}$ In the base year the dollar export was zero. 
There was no link at all between the growth rate of dollar exports and the profitability of domestic sales in 1989 and in 1990 . In 1991 it turned out that a decline of exports had a less detrimental impact on the profit rate of domestic sales, while firms with the fastest growing dollar exports had the highest losses in their domestic sales. There was only one class of firms with positive profit rate, the firms with a growth rate between 50 and 100 percent.

Was there any correlation between the growth rates of dollar exports and domestic sales? It turned out that in 1989 and in 1991 a positive connection between the two growth rates existed: the higher the growth rate of dollar exports, the higher the growth rate of domestic sales. Moreover only those firms had a positive rate of growth of domestic sales which increased the volume of their dollar exports by more than 50 percent. This link was totally missing in 1990, however, partly because in this year domestic- and ruble-export sales declined at almost the same pace.

\section{Share of Dollar Exports}

Dollar exports have played an increasing role in the activity of the sample enterprises: by 1991 more than half of the firms had a higher than 25 percent dollar-export share in contrast to less than one fourth of the firms with such an export share in 1988 (Table 10.12). Firms with higher than 25 percent dollar-export share in sales made up more than 80 percent of dollar exports in 1991, a 20 percentage point increase in three years (from 59.1 percent in 1988 to 83.1 percent in 1991).

In 1988 firms with a higher share of dollar exports in sales were more profitable than those with lower share, but this rule ceased to exist in the subsequent years. Until 1991 there was no clear connection between the share of dollar exports and the profit rate of domestic sales either. In 1991, however, we see the emergence of an interesting relation: the higher the share of dollar exports, the higher the loss on domestic sales. The only exception here was the group of firms with no dollar exports.

\section{Size of Dollar Exports}

The number of firms with dollar exports between US\$1 million and US\$25 million has increased considerably (Table 10.13). The small and large exporters increased their share at the expense of medium exporters. The mushrooming number of small exporters and their role in dollar exports could 
Table 10.12. Distribution and profitability of exporting firms by the share of dollar exports in total sales, in units and percent.

\begin{tabular}{|c|c|c|c|c|}
\hline Share of dollar exports & 1988 & 1989 & 1990 & 1991 \\
\hline \multicolumn{5}{|c|}{ Number of firms } \\
\hline Zero & 40 & 29 & 28 & 34 \\
\hline $0-10$ percent & 291 & 287 & 202 & 181 \\
\hline $10-25$ percent & 212 & 244 & 265 & 221 \\
\hline $25-50$ percent & 119 & 168 & 228 & 279 \\
\hline$>50$ percent & 43 & 55 & 105 & 237 \\
\hline Total & 705 & 783 & 828 & 952 \\
\hline \multicolumn{5}{|c|}{ Dollar exports } \\
\hline Zero & 0.0 & 0.0 & 0.0 & 0.0 \\
\hline $0-10$ percent & 12.5 & 10.4 & 6.9 & 5.3 \\
\hline $10-25$ percent & 28.5 & 24.4 & 26.6 & 11.6 \\
\hline $25-50$ percent & 43.2 & 51.2 & 42.4 & 36.2 \\
\hline$>50$ percent & 15.9 & 14.0 & 24.1 & 46.9 \\
\hline Total & 100.0 & 100.0 & 100.0 & 100.0 \\
\hline \multicolumn{5}{|c|}{ Profit rate of domestic sales } \\
\hline Zero & 1.5 & 3.4 & -1.3 & -9.3 \\
\hline $0-10$ percent & 4.1 & 4.9 & 6.4 & 2.9 \\
\hline $10-25$ percent & 2.5 & 3.6 & 1.8 & -0.7 \\
\hline $25-50$ percent & 1.1 & 2.6 & 3.1 & -5.9 \\
\hline$>50$ percent & 1.1 & -5.1 & 0.6 & -10.1 \\
\hline Average & 3.1 & 4.0 & 4.2 & -1.1 \\
\hline \multicolumn{5}{|c|}{ Profit rate of ruble exports } \\
\hline Zero & -10.5 & 5.8 & -66.1 & -93.0 \\
\hline $0-10$ percent & 0.8 & -1.6 & -4.8 & -23.6 \\
\hline $10-25$ percent & 9.0 & 4.4 & -8.3 & -50.2 \\
\hline $25-50$ percent & 0.5 & -14.0 & -4.3 & -20.8 \\
\hline$>50$ percent & -3.5 & 1.0 & -80.2 & -37.9 \\
\hline Average & 3.9 & -2.7 & -12.7 & -32.1 \\
\hline \multicolumn{5}{|c|}{ Profit rate of dollar exports } \\
\hline Zero & - & - & - & - \\
\hline $0-10$ percent & 4.8 & 12.5 & 5.9 & 6.8 \\
\hline 10-25 percent & 5.1 & 6.0 & 8.8 & -2.8 \\
\hline $25-50$ percent & 13.9 & 17.7 & -1.0 & 3.0 \\
\hline$>50$ percent & 11.1 & 12.4 & 10.5 & 4.0 \\
\hline Average 9.8 & 13.6 & 4.9 & 3.0 & \\
\hline \multicolumn{5}{|c|}{ Profit rate of total sales } \\
\hline Zero & 1.4 & 3.5 & -1.3 & -9.5 \\
\hline $0-10$ percent & 3.9 & 4.8 & 6.2 & 3.0 \\
\hline $10-25$ percent & 3.9 & 4.1 & 2.2 & -1.2 \\
\hline 25-50 percent & 5.0 & 6.2 & 1.1 & -2.8 \\
\hline$>50$ percent & 7.2 & 7.7 & 1.7 & -0.8 \\
\hline Average & 4.1 & 5.0 & 3.4 & -0.1 \\
\hline
\end{tabular}


increasingly counterbalance the impact of the dozen firms that exported almost 30 percent of the overall dollar exports in 1991.

The largest exporters always had the highest profit rate on their dollar exports, but this rate has rapidly been falling. It was close to 25 percent in 1989 and went below 10 percent in 1991 .

The activity of large exporters in the domestic market was not very successful: in 1988 and 1991 their profit was the lowest and, in fact, negative. Their overall profit was also falling and was only 0.6 percent in 1991 .

The medium-sized and small exporters had to cope with a falling profit on their dollar exports. There was a major difference between mediumsized and small exporters though; the medium-sized exporters improved their profitability on the domestic market, while the small exporters in this market became loss-makers in 1991.

\section{Sectors}

Mechanical engineering, transport, and foreign trading activities increased their share in dollar exports at the expense of metallurgy, chemicals, and domestic trade (Table 10.14). Food processing and agriculture also suffered very heavy losses in profitability: the former in 1990, the latter in 1991.

\section{Number of Employees}

The number of large firms in the sample in terms of employees decreased a bit in 1991 (Table 10.15). This implies that the number of small and medium-sized firms increased very fast. The share of large firms in dollar exports was above 95 percent in 1988 and 1989 and this ratio went down to 82.1 percent by 1991 . On balance mainly the share of medium-sized firms increased.

The large and medium-sized firms had similarly very high (above 10 percent) profit rates on their dollar exports in 1988 and 1989. The fall was very dramatic for medium-sized firms; their profit went below zero, while the large firms preserved part of their advantage in the next years. On the other hand, the small firms had huge losses in 1988, while in 1991 their profit rate on dollar exports was at 8.4 percent.

There were no differences among the different size firms in profit rates on domestic sales. The profit of small firms in 1988 is an exception. All the three groups lost profit in 1991, and, as a consequence, the only group with positive profit on overall sales was the group of small firms. 
Table 10.13. Distribution and profitability of exporting firms by the value of dollar exports, in units and percent.

\begin{tabular}{|c|c|c|c|c|}
\hline Value of dollar exports & 1988 & 1989 & 1990 & 1991 \\
\hline \multicolumn{5}{|c|}{ Number of firms } \\
\hline$<\mathrm{US} \$ 1$ million & 169 & 183 & 109 & 159 \\
\hline US\$1 million-25 million & 490 & 558 & 668 & 737 \\
\hline US\$25 million-100 million & 40 & 42 & 42 & 44 \\
\hline$>$ US $\$ 100$ million & 9 & 8 & 9 & 12 \\
\hline Total & 708 & 791 & 828 & 952 \\
\hline \multicolumn{5}{|c|}{ Dollar exports } \\
\hline$<$ US\$1 million & 1.1 & 1.2 & 0.6 & 0.8 \\
\hline US $\$ 1$ million-25 million & 44.1 & 44.3 & 48.2 & 47.4 \\
\hline US $\$ 25$ million-100 million & 29.6 & 30.6 & 24.5 & 22.5 \\
\hline > US\$100 million & 25.1 & 23.9 & 26.6 & 29.4 \\
\hline Total & 100.0 & 100.0 & 100.0 & 100.0 \\
\hline \multicolumn{5}{|c|}{ Profit rate of domestic sales } \\
\hline$<$ US\$1 million & 5.1 & 3.5 & 0.3 & 0.2 \\
\hline US $\$ 1$ million-25 million & 3.7 & 4.4 & 5.1 & -1.5 \\
\hline US $\$ 25$ million-100 million & 2.9 & 2.4 & 4.9 & 4.6 \\
\hline$>$ US\$100 million & -2.3 & 5.9 & 1.1 & -8.8 \\
\hline Average & 3.1 & 4.0 & 4.2 & -1.1 \\
\hline \multicolumn{5}{|c|}{ Profit rate of ruble exports } \\
\hline$<$ US\$1 million & 7.9 & 0.7 & -15.9 & -44.3 \\
\hline US\$1 million-25 million & 3.2 & 0.0 & -6.2 & -34.1 \\
\hline US\$25 million-100 million & 8.0 & 2.8 & -5.6 & -38.4 \\
\hline$>$ US $\$ 100$ million & -15.9 & -57.0 & -61.7 & -21.5 \\
\hline Average & 3.9 & -2.7 & -12.7 & -32.1 \\
\hline \multicolumn{5}{|c|}{ Profit rate of dollar exports } \\
\hline$<$ US\$1 million & 4.1 & 20.3 & -6.5 & -15.4 \\
\hline US $\$ 1$ million- 25 million & 6.2 & 8.8 & 3.4 & 0.4 \\
\hline US $\$ 25$ million-100 million & 7.5 & 11.6 & -3.2 & 1.5 \\
\hline > US\$100 million & 19.1 & 24.6 & 15.3 & 8.8 \\
\hline Average & 9.8 & 13.6 & 4.9 & 3.0 \\
\hline \multicolumn{5}{|c|}{ Profit rate of total sales } \\
\hline$<$ US\$1 million & 5.2 & 3.8 & -0.3 & -0.1 \\
\hline US $\$ 1$ million-25 million & 3.9 & 4.6 & 4.4 & -1.2 \\
\hline US $\$ 25$ million-100 million & 4.7 & 4.5 & 1.6 & 3.4 \\
\hline$>\mathrm{US} \$ 100$ million & 4.9 & 9.7 & 3.5 & 0.6 \\
\hline Average & 4.1 & 5.0 & 3.4 & -0.1 \\
\hline
\end{tabular}


Table 10.14. Sectoral distribution and profitability of exporting firms, in percent.

\begin{tabular}{|c|c|c|c|c|}
\hline Sector & 1988 & 1989 & 1990 & 1991 \\
\hline \multicolumn{5}{|c|}{ Dollar exports } \\
\hline Mining & 0.6 & 0.6 & 0.6 & 0.4 \\
\hline Electricity & 0.0 & 0.0 & 0.2 & 0.0 \\
\hline Metallurgy & 11.1 & 12.6 & 13.3 & 6.9 \\
\hline Mechanical engineering & 15.2 & 15.1 & 15.4 & 20.9 \\
\hline Building materials & 1.5 & 1.4 & 1.4 & 1.6 \\
\hline Chemicals & 18.1 & 17.5 & 17.0 & 14.5 \\
\hline Light industry & 8.9 & 8.2 & 8.0 & 7.2 \\
\hline Other industries & 0.0 & 0.0 & 0.1 & 0.1 \\
\hline Food processing & 16.7 & 16.8 & 15.2 & 15.5 \\
\hline Construction & 1.3 & 1.5 & 1.7 & 1.9 \\
\hline Agriculture & 3.3 & 3.7 & 3.2 & 3.5 \\
\hline Forestry & 1.5 & 1.3 & 1.9 & 1.6 \\
\hline Transport & 9.1 & 9.0 & 10.6 & 12.0 \\
\hline Telecommunication & 0.4 & 0.5 & 0.5 & 0.7 \\
\hline Domestic trading & 6.0 & 6.1 & 4.7 & 4.5 \\
\hline Foreign trading & 6.4 & 5.7 & 6.1 & 8.4 \\
\hline Water supply & 0.0 & 0.0 & 0.1 & 0.0 \\
\hline Other material services & 0.0 & 0.1 & 0.1 & 0.1 \\
\hline Total & 100.0 & 100.0 & 100.0 & 100.0 \\
\hline \multicolumn{5}{|c|}{ Profit of dollar exports } \\
\hline Mining & 26.1 & 18.7 & 31.5 & 4.5 \\
\hline Electricity & 28.4 & -14.5 & 17.6 & 15.8 \\
\hline Metallurgy & 18.8 & 22.0 & 5.2 & -8.5 \\
\hline Mechanical engineering & 1.3 & 4.2 & -1.8 & 1.1 \\
\hline Building materials & 16.7 & 13.2 & 11.3 & -9.9 \\
\hline Chemicals & 10.0 & 18.2 & 3.1 & 0.1 \\
\hline Light industry & 3.0 & 4.7 & 2.1 & -2.1 \\
\hline Other industries & -0.1 & 8.2 & 4.3 & -16.2 \\
\hline Food processing & 9.6 & 15.6 & -1.3 & -0.4 \\
\hline Construction & -1.6 & 9.4 & 12.8 & 7.2 \\
\hline Agriculture & 11.4 & 13.0 & 7.2 & 0.9 \\
\hline Forestry & 33.4 & 30.4 & 19.1 & 13.9 \\
\hline Transport & 19.7 & 16.1 & 19.9 & 19.4 \\
\hline Telecommunication & 1.6 & 36.8 & -5.6 & 35.2 \\
\hline Domestic trading & 11.2 & 13.1 & 8.1 & 12.0 \\
\hline Foreign trading & 1.8 & 3.7 & 5.1 & 1.9 \\
\hline Water supply & - & 0.7 & -1.5 & 41.9 \\
\hline Other material services & 45.4 & 1.7 & 9.4 & 8.7 \\
\hline Average & 9.8 & 13.6 & 4.9 & 3.0 \\
\hline
\end{tabular}


Table 10.15. Distribution and profitability of exporting firms by the number of employees, in units and percent.

\begin{tabular}{|c|c|c|c|c|}
\hline Number of employees & 1988 & 1989 & 1990 & 1991 \\
\hline \multicolumn{5}{|c|}{ Number of firms } \\
\hline$<51$ & 11 & 33 & 45 & 80 \\
\hline $51-300$ & 51 & 81 & 125 & 241 \\
\hline$>300$ & 644 & 657 & 652 & 627 \\
\hline Total & 706 & 771 & 822 & 948 \\
\hline \multicolumn{5}{|c|}{ Dollar exports } \\
\hline$<51$ & 0.7 & 1.3 & 1.7 & 2.4 \\
\hline $51-300$ & 2.5 & 3.4 & 6.0 & 15.5 \\
\hline$>300$ & 96.7 & 95.3 & 92.3 & 82.1 \\
\hline Total & 100.0 & 100.0 & 100.0 & 100.0 \\
\hline \multicolumn{5}{|c|}{ Profit rate of domestic sales } \\
\hline$<51$ & 36.5 & 4.8 & 2.1 & -0.8 \\
\hline $51-300$ & 4.9 & 3.4 & 5.4 & -1.4 \\
\hline$>300$ & 3.0 & 4.0 & 4.2 & -1.1 \\
\hline Average & 3.1 & 4.0 & 4.2 & -1.1 \\
\hline \multicolumn{5}{|c|}{ Profit rate of ruble exports } \\
\hline$<51$ & 1.6 & $-3: 0$ & -13.9 & -34.9 \\
\hline $51-300$ & 0.3 & -0.4 & 11.8 & -5.8 \\
\hline$>300$ & 4.0 & -2.7 & -14.3 & -37.2 \\
\hline Average & 3.9 & -2.7 & -12.7 & -32.1 \\
\hline \multicolumn{5}{|c|}{ Profit rate of dollar exports } \\
\hline$<51$ & -27.6 & -0.4 & 0.9 & 8.4 \\
\hline $51-300$ & 10.1 & 11.3 & -2.7 & -0.5 \\
\hline$>300$ & 10.1 & 13.8 & 5.4 & 3.5 \\
\hline Average & 9.8 & 13.6 & 4.9 & 3.0 \\
\hline \multicolumn{5}{|c|}{ Profit rate of total sales } \\
\hline$<51$ & 1.9 & 2.1 & 1.0 & 2.5 \\
\hline $51-300$ & 5.4 & 4.6 & 4.0 & -1.0 \\
\hline$>300$ & 4.1 & 5.0 & 3.5 & -0.1 \\
\hline Average & 4.1 & 5.0 & 3.4 & -0.1 \\
\hline
\end{tabular}

\section{Share of Foreign Assets}

The number of firms in the sample with a significant share of foreign assets increased very rapidly (Table 10.16): in 1989 it was 77 and in 1991, 206. In 1991, 27 percent of the dollar exports was produced by firms with some foreign ownership. 
Table 10.16. Distribution and profitability of exporting firms by the share of foreign assets, in units and percent.

\begin{tabular}{|c|c|c|c|c|}
\hline Share of foreign assets & $1988^{a}$ & 1989 & 1990 & 1991 \\
\hline \multicolumn{5}{|c|}{ Number of firms } \\
\hline Zero & 708 & 714 & 705 & 745 \\
\hline $0-10$ percent & & 34 & 38 & 48 \\
\hline $10-25$ percent & & 3 & 16 & 31 \\
\hline $25-50$ percent & & 33 & 39 & 72 \\
\hline$>50$ percent & & 7 & 24 & 55 \\
\hline Total & 708 & 791 & 822 & 951 \\
\hline \multicolumn{5}{|c|}{ Dollar exports } \\
\hline Zero & 100.0 & 88.4 & 85.0 & 73.0 \\
\hline $0-10$ percent & & 8.2 & 6.5 & 7.2 \\
\hline $10-25$ percent & & 0.1 & 2.5 & 6.6 \\
\hline $25-50$ percent & & 3.2 & 5.0 & 9.4 \\
\hline$>50$ percent & & 0.2 & 0.9 & 3.8 \\
\hline Total & 100.0 & 100.0 & 100.0 & 100.0 \\
\hline \multicolumn{5}{|c|}{ Profit rate of dollar exports } \\
\hline Zero & 9.8 & 14.1 & 6.4 & 3.7 \\
\hline $0-10$ percent & & 8.8 & -2.0 & -1.2 \\
\hline $10-25$ percent & & -11.8 & -10.2 & 10.3 \\
\hline $25-50$ percent & & 13.8 & -4.3 & -2.6 \\
\hline$>50$ percent & & -4.4 & 1.7 & -0.8 \\
\hline Average & 9.8 & 13.6 & 4.9 & 3.0 \\
\hline
\end{tabular}

${ }^{a}$ In this year no information was collected by the authorities on foreign assets; however, their share was significantly lower than in 1989.

Higher share of foreign ownership does not necessarily mean a higher profit rate of dollar exports. Only two positive rates were observed in 1991: in the group with no foreign shares and in the group with foreign assets between 10 and 25 percent.

\section{Organizational Form}

The privatization and the commercialization of state-owned firms brought about the proliferation of firms with new organizational forms (Table 10.17). These firms had one-third share in dollar exports in 1991, while the traditional state-owned firms still maintained their share above 60 percent.

Surprisingly the traditional state-owned enterprises (SOEs) managed to keep afloat: in 1991 they had a profit rate above 10 percent on dollar exports, 
Table 10.17. Distribution and profitability of exporting firms by the organizational form of enterprises, in units and percent.

\begin{tabular}{|c|c|c|c|c|}
\hline Organizational form & 1988 & 1989 & 1990 & 1991 \\
\hline \multicolumn{5}{|c|}{ Number of firms } \\
\hline Traditional SOEs ${ }^{a}$ & 175 & 180 & 188 & 179 \\
\hline Self-governing SOEs & 326 & 327 & 329 & 321 \\
\hline Limited companies & 13 & 52 & 90 & 175 \\
\hline Joint-stock companies & 52 & 93 & 119 & 176 \\
\hline Agricultural cooperatives & 28 & 28 & 28 & 33 \\
\hline Other cooperatives & 46 & 49 & 50 & 49 \\
\hline Others & 71 & 65 & 27 & 19 \\
\hline Total & 711 & 794 & 831 & 952 \\
\hline \multicolumn{5}{|c|}{ Dollar exports } \\
\hline Traditional SOEs & 37.5 & 37.2 & 37.4 & 29.4 \\
\hline Self-governing SOEs & 35.5 & 33.9 & 32.2 & 34.4 \\
\hline Limited companies & 6.8 & 8.8 & 12.2 & 15.4 \\
\hline Joint-stock companies & 12.4 & 13.2 & 14.3 & 17.6 \\
\hline Agricultural cooperatives & 1.0 & 1.4 & 1.2 & 1.0 \\
\hline Other cooperatives & 1.3 & 1.7 & 1.6 & 1.5 \\
\hline Others & 5.5 & 3.8 & 1.1 & 0.7 \\
\hline Total & 100.0 & 100.0 & 100.0 & 100.0 \\
\hline \multicolumn{5}{|c|}{ Profit rate of domestic sales } \\
\hline Traditional SOEs & 2.1 & 3.8 & 5.8 & -0.3 \\
\hline Self-governing SOEs & 5.0 & 4.4 & 2.0 & -2.9 \\
\hline Limited companies & -2.4 & 9.0 & 6.3 & -0.1 \\
\hline Joint-stock companies & 3.3 & 4.8 & 3.5 & 0.4 \\
\hline Agricultural cooperatives & 4.1 & 3.6 & 1.3 & -7.0 \\
\hline Other cooperatives & 2.3 & 1.8 & -1.8 & -4.8 \\
\hline Average & 3.1 & 4.0 & 4.2 & -1.1 \\
\hline \multicolumn{5}{|c|}{ Profit rate of dollar exports } \\
\hline Traditional SOEs & 12.2 & 18.4 & 7.5 & 10.5 \\
\hline Self-governing SOEs & 8.5 & 10.7 & 2.9 & 0.1 \\
\hline Limited companies & 22.5 & 20.1 & 10.3 & 0.2 \\
\hline Joint-stock companies & 4.0 & 8.0 & -3.0 & -2.6 \\
\hline Agricultural cooperatives & 15.2 & 11.5 & 6.3 & -2.3 \\
\hline Other cooperatives & 13.9 & 14.1 & 15.0 & 11.8 \\
\hline Average & 9.8 & 13.6 & 4.9 & 3.0 \\
\hline \multicolumn{5}{|c|}{ Profit rate of total sales } \\
\hline Traditional SOEs & 3.5 & 5.9 & 5.9 & 1.8 \\
\hline Self-governing SOEs & 5.1 & 4.7 & 0.9 & -2.2 \\
\hline Limited companies & 3.5 & 3.9 & 3.0 & 0.1 \\
\hline Joint-stock companies & 5.0 & 5.7 & 1.6 & -0.6 \\
\hline Agricultural cooperatives & 5.3 & 5.1 & 2.0 & -6.2 \\
\hline Other cooperatives & 5.1 & 4.4 & 1.3 & -0.0 \\
\hline Average & 4.1 & 5.0 & 3.4 & -0.1 \\
\hline
\end{tabular}

${ }^{a}$ State-owned enterprise. 
a rate that other significant exporters could not even approach. On the other hand, only the joint-stock companies could achieve a positive profit on domestic sales in 1991 among the most important four enterprise groups; their advantage over these groups, however, was marginal. As a result, in total sales the traditional SOEs had the highest profit rate, followed by the limited liability and joint-stock companies with profit rates around zero.

\section{Summary}

The collapse of the CMEA dramatically changed the foreign trade environment of the former member states and of the individual firms in these economies. In the Hungarian case trade reorientation had begun earlier, and unambiguous results had been achieved. The responsiveness of firms to changing foreign market conditions has been improving. These improvements, however, have taken place still in the framework of the modified centrally planned economy. Many other institutional changes have been necessary to establish a market economy proper, where further structural changes in trade would inevitably take place.

Econometric estimations show the presence of immediate cost adjustment until 1988 in respect to trade reorientation. In the period of the more intensive trade reorientation this cost adjustment has dissipated. In 1989 and 1990 export subsidies played an active role, showing that the reduction of the subsidies does not necessarily mean that their effect will disappear. Relative dollar prices with a one-year lag always turned out to be a significant explanatory variable of the trade reorientation in the whole period. The direct impact of the reduction of ruble exports on dollar exports was important only in 1986,1987 , and 1989.

Exporting firms managed to adjust their activity to the consequences of the collapse of regional integration and to increase their dollar exports. In 1991 after the period of trade reorientation (in the sense of disappearance of ruble trade) the direct costs of dollar exports were lowered. The profitability, however, declined, which was the compound effect of a real exchange rate appreciation, foreign price increase, cost adjustment, and a steep increase in overhead costs. The increase in overhead costs was an outcome of rising banking costs and the falling demand in domestic market leading to capacity underutilization.

The profitability of dollar exports had an increasing effect on the overall profitability of exporting firms. The factors behind this were the growth of 
the share of dollar exports, the rising differentiation of profitability, and the falling profitability on domestic sales.

The positive relationship between the growth rate and the profitability of dollar exports was the first aspect of this differentiation instrumental in furthering the differentiation of exports from domestic sales. On the other hand, there was a strengthening positive link between the growth rates of domestic and dollar-export sales.

The reorientation of trade to dollar markets still has further dimensions, since the potential positive effects of foreign ownership and the new corporate forms have not yet been realized.

\section{References}

Arellano, M., and Bond, S. (1988) Dynamic Panel Data Estimation Using DPD: A Guide for Users (London: Institute for Fiscal Studies).

Halpern, L. (1989) "Effects of devaluation in a macro-econometric model for Hungary," Acta Oeconomica, Vol. 41, pp. 293-312.

Halpern, L. (1992a) "The effect of costs and subsidies on trade reorientation in Hungary (1981-90)," Structural Change and Economic Dynamics, Vol. 3, pp. 403419.

Halpern, L. (1992b) A külgazdasági orientációváltás hatása az exportáló vállalatokra (1988-1991) (The effect of foreign trade reorientation on exporting firms) (Budapest: Institute for Economic Analysis and Information Technology, Ministry of Finance).

Halpern, L. (1993) Factors and Effects of Trade Reorientation in Hungary, CEPR Discussion Paper No. 772 (London: Center for Economic Policy Research).

Halpern, L., and Székely, I.P. (1992) Export Supply and Import Demand in Hungary: An Econometric Analysis for 1968-1989, CEPR Discussion Paper No. 620 (London: Center for Economic Policy Research).

Oblath, G. (1988) "Exchange rate policy in the reform package," Acta Oeconomica, Vol. 39, Nos. 1-2, pp. 81-93. 


\section{Chapter 11}

\section{The Effects of Privatization on Enterprise Production and Trade Strategy*}

Janusz M. Dabrowski

\section{Introduction}

Privatization of state-owned enterprises is a major component of economic transformation in the countries of Eastern and Central Europe and the former Soviet Union. Finding private owners for state-owned firms, which in the late $1980 \mathrm{~s}$ still accounted for more than 80 percent of the gross national product in the region, is not an easy task. If we take into account

*This study uses results of monitoring research on privatization processes that has been carried out by the Gdansk Institute for Market Economics (Dabrowski et al., 1992a, 1992c; Kamiński, 1992). It covers the operation of more than 60 enterprises in various stages of privatization and subject to various transformation formulas. The firms analyzed differ from one another in terms of size, location, and branch affiliation (Tables 11.1 and 11.2 present the structure of the sample). The occurring changes are monitored comprehensively (the research involves the operations of privatized firms in all fields of their activity, the progress of the privatization process and its effects, and the barriers to privatization) and dynamically (the research is repeated every six months). The analyses provide, first of all, the comparison of the four major privatization paths in Poland. The justification for this approach stems from the fact that the four individual paths distinguish themselves both in scope and in the set of measures they are supported with. 
Table 11.1. Privatization path and size of the firms in the sample.

\begin{tabular}{lccccc}
\hline & \multicolumn{2}{l}{ Number of employees } & & \\
\cline { 2 - 5 } & & & & Very & \\
Privall & Medium & Large & large & \\
Privatization path & $<200$ & $201-500$ & $501-1000$ & $>1,000$ & Total \\
\hline Capital path & - & 1 & 4 & 4 & 9 \\
$\quad$ Public offering & - & - & 2 & 2 & 4 \\
Invitation to negotiate & - & 1 & 2 & 1 & 4 \\
$\quad$ Employee buy out & - & - & - & 1 & 1 \\
Liquidation & & & & & \\
through privatization & 8 & 11 & 3 & 2 & 24 \\
$\quad$ Sales of assets & 2 & 2 & - & - & 4 \\
$\quad$ Contribution to equity & - & - & - & 1 & 1 \\
$\quad$ Leasing & 6 & 9 & 3 & 1 & 19 \\
Liquidation & & & & & \\
by bankruptcy & 9 & 2 & 1 & 1 & 13 \\
$\quad$ Sales of assets & 8 & 2 & 1 & 0 & 11 \\
Contribution to equity & - & - & - & 1 & 1 \\
Leasing & 1 & - & - & - & 1 \\
Commercialization & - & 2 & 3 & 4 & 9 \\
Total & 17 & 16 & 11 & 11 & 55 \\
\hline
\end{tabular}

Table 11.2. Sectors, branches, and privatization paths of firms in sample.

\begin{tabular}{lllllr}
\hline Branch & $\begin{array}{l}\text { Capital } \\
\text { path }\end{array}$ & $\begin{array}{l}\text { Liquid. } \\
\text { through } \\
\text { privat. }\end{array}$ & $\begin{array}{l}\text { Liquid. } \\
\text { by bank- } \\
\text { ruptcy }\end{array}$ & $\begin{array}{l}\text { Commer- } \\
\text { cializa- } \\
\text { tion }\end{array}$ & Total \\
\hline $\begin{array}{l}\text { Industry } \\
\text { Metallurgical }\end{array}$ & 7 & 7 & 8 & 7 & 29 \\
Electromachinery & 1 & - & - & - & 1 \\
Chemical industry & - & 2 & 4 & 6 & 13 \\
Mineral industry & - & 3 & - & - & 3 \\
Paper industry & - & - & - & 1 & 1 \\
Light industry & 2 & - & 1 & - & 1 \\
Food processing & 3 & 2 & 2 & - & 3 \\
Construction & 1 & 6 & 2 & - & 7 \\
Transportation & - & 2 & 2 & - & 11 \\
Trade \& services & 1 & 8 & - & - & 4 \\
Agriculture & - & 1 & 1 & - & 9 \\
Total & 9 & 24 & 13 & 9 & 2 \\
\hline
\end{tabular}


the lack of market links and institutions, the small number of professional managers, and the shortage of real capital resources needed to take over the privatized assets, we can assess the scope and difficulty of this venture more realistically. Privatizing a major part of state-owned assets in a relatively short time, however, seems to be the necessary prerequisite for upgrading the economies of the region from their levels of efficiency and production quality. It is also a prerequisite for overcoming the atrophy of economic motivation and establishing firms that are viable to respond to the challenge of competition in the world market.

It became apparent already in the first, stormy months of the "autumn of nations" that the countries of Eastern and Central Europe have no way out but to restore the capitalist, market-type economy. This is the only option open if they want to join the world economy and if they want to overcome the economic and functional inefficiencies of their former economic regimes. ${ }^{1}$ Hence, the discussion has very quickly moved from the issue of whether it is right to restore the market and private ownership to the problem of how fast and in what way this should be done. It turned out that the characteristic features of the economic, social, and motivational relations were so unique that applying related international experiences, e.g., privatization methods used in Britain or stabilization programs in Latin American countries, was in fact not possible. The need for specific policies was also strengthened by the individual characteristics of each country in the region, such as the differences in the strength of former market relations, the different rates of inflation, the importance of foreign trade, and the size of the private sector. These factors pushed each country to look for its own road to the market economy.

The search for new solutions is particularly true for the privatization of state-owned enterprises. The range of possible solutions is very broad. Each country has worked out its own specific measures and policies. ${ }^{2}$ For example,

${ }^{1}$ An interesting evaluation of post-communist economies at the "starting point" of the transformation process and of privatization prospects has recently been presented by $P$. Reynolds and P. Young of the Adam Smith Institute (Reynolds and Young, 1992).

${ }^{2}$ The Hungarian policy is, for instance, dominated by the sale of a large majority of enterprises to strategic (including foreign) investors. In the former CSFR the stress was put on "voucher privatization," while in the former GDR, in a situation different from that of the other countries of the region, investors who would be willing to invest in and restructure state-owned enterprises (contract price is of secondary importance here) are actually sought. Yet different privatization routes are preferred in the Balkan countries and in the countries that have emerged from the former Soviet Union (e.g., the idea of “overnight privatization" in Lithuania and free privatization vouchers in Russia). 
in Poland intensive privatization processes were started in the mid-1990. Poland's framework is still being revised and supplemented; an example of the latter is the program of mass privatization. The pattern of privatization in Poland differs considerably from those adopted by the other countries, mainly because of its multi-tier structure.

The experience of Polish privatization gives rise to questions about the incentive structures after privatization, the pace of the process, and the obstacles it faces. A crucial issue is the effect of privatization on enterprise behavior. The following analysis concentrates on the operation of privatized firms, especially on market strategies, changes in the production process and on the financial standing of the enterprises. These aspects of enterprise behavior are interrelated. The sales opportunities of a firm define the scope of necessary production adjustments, which are, in turn, defined (limited) by the financial capacities of the firm and influence its sales structure.

The process of ownership transformation can possibly influence each field mentioned above. An ideal combination would be the increase of ownership pressure (creating a "real" owner and setting up control institutions) and additional contributions to develop managerial skills. These two factors should exert their impacts on the quality and intensity of production and market strategies. If the aforementioned factors are complemented with capital and technology transfer, a chance of production restructuring is provided, on the one hand, and a chance of financial restructuring, on the other. The potential for sales of products manufactured by the company are facilitated by access to selling outlets, which can also be extended as a result of privatization.

Not every ownership transformation means that all these leverages come into force. In this paper I attempt to analyze the impact of the transformation on major fields of enterprise activity and to find out whether the above-mentioned leverages have been present.

To enhance the analysis of the complex process of privatization in Poland, a comprehensive description of all privatization paths applied to Polish enterprises is presented in the next section. The following section gives an account of changes in the responses of privatized firms in the context of developing market strategies. Another section is devoted to production adjustment in enterprises, followed by a discussion on their financial standings. In the last section, I summarize the lessons of the analysis. 


\section{The Legal Framework of Privatization in Poland}

The privatization law adopted by the Polish Parliament (the Sejm) on July 13, 1990, provides for ownership transformation of state-owned enterprises, by means of differentiated privatization formulas and instruments. This law is partly the result of the long and extensive political and economic debate of the 1980s (see Proposals, 1989), but it is also an attempt to find a compromise between the opinions and preferences (and interest groups) of those involved in the process. The privatization law and supplementary laws provide the possibility of ownership transformation of an enterprise through the following basic paths: "capital path," liquidation by privatization, liquidation because of bankruptcy, commercialization, and (still not fully adopted by the Parliament) participation in the mass privatization program. Each has slightly different economic and social objectives, and usually also applies to different groups of state-owned enterprises.

Creating a capital market in the Polish economy, with a stock exchange as its central institution, is seen as the basic objective of capital privatization (capital path). Besides, capital privatization allows wide distribution of ownership titles among the public. Privatization through public offer is the first privatization technique within this framework. A state-owned enterprise is transformed into a joint-stock company owned by the state treasury, and then the company's shares are sold (according to the valuation of assets). The law provides for 20 percent of the shares to be sold to the company's employees, who are entitled to preferential purchases of shares (for half of the selling price). This results from the strong impact the employees' (selfgovernment) lobby exerted on the final version of the law and from the widespread popularity of the employee stock ownership concept pursued in the 1980s (see Ludwiniak, 1989; Groszek and Ruszkowski, 1989). By the end of June 1992, 12 enterprises (of 36 firms privatized in the capital path) had been transformed by public offering.

Some shares may be sold to a chosen investor or to the management. After the shares have been subscribed for, potential small shareholders are given preference or applications are considered successively.

Another capital privatization technique is the method of public invitation to negotiations. Compared with the public offer, it requires less time and effort to prepare a firm for privatization. In this method, large parcels of shares are offered to potential active investors, with 20 percent of the shares 
reserved for employees. During negotiations between the investor, the representative of the state treasury, and the firm, the price for a parcel of shares to be purchased by the investor is set. This technique makes it possible for a particular firm to choose a specific active investor, thus encouraging technology transfer, and funds are earmarked for new investments and new outlets, quite aside from the buy out. This method was used in 16 cases up to mid-1992.

Sale by tender is another privatization technique within the framework of the capital path. It is usually connected with the so-called quick sale method and refers to relatively small enterprises (by June 1992 this method had been used in six cases). In this case, privatization procedures are limited to a necessary minimum. Detailed and comprehensive information is made available about enterprises, which are then put out for tender by the Ministry of Ownership Transformations in packages of several firms. Potential buyers may purchase at auction an entire firm, with the exception of the 20 percent parcel of shares reserved for employees.

Another technique applied in the capital path provides for employee or management buy out, with the majority of shares acquired by employees or the management. In this case various forms for the supplementary financing of the privatization process are usually applied (e.g., leveraged buy out). Those acquiring the enterprise pay only part of its real value to the state treasury; the rest is to be contributed by repaying a collateral credit secured by the enterprise assets. No lengthy, preliminary procedures are necessary, as investors have perfect knowledge of the entity they buy. By mid 1992 only two enterprises have been privatized through this method.

The liquidation path allows, then, for the implementation of two different forms of privatization. The first is based on the law on state-owned enterprises and concerns firms liquidated due to their bad economic condition (this type of transformation was applied in 707 firms up to mid-1992). The second form, based on the privatization law, provides for liquidation and then ownership transformation of firms in good financial condition ( 542 firms used this during the same period). In both cases three liquidation procedures are possible: the sale of an entire enterprise or a part of it, contributing the enterprise's assets (in full or in part) to a company's equity, and various kinds of leasing.

The procedure of selling the assets of an enterprise is applied, first of all, in the case of bankruptcy. Parts of the assets of a bankrupt enterprise may 
be sold to potential buyers. To this end, a liquidator representing the state treasury is appointed by the founder body. The tasks of the liquidator include: making an inventory of the firm's assets, setting principles regulating the sale of those assets, and carrying out those sales.

Contributing all or part of the assets of an enterprise to a company's equity means starting the process of evaluation of an enterprise, setting the principles of sale in agreement with the buyer of the enterprise, as well as transforming the firm and transferring the organized assets of an enterprise to an already existing company. To this end, a liquidator representing the state treasury is also appointed.

Leasing the whole or part of enterprise's assets is possible when, for instance, the move for liquidation has been initiated by the employee council, the majority of employees of the liquidated enterprise has joined the new company, and the amount of share capital or initial capital is not less than 20 percent of the book value of the enterprise. Leasing is based on an agreement concluded on behalf of the state treasury by the founder body. The amount charged for using the assets of the state treasury and the value of those assets are determined by an appraisal done by the founder body. The total charge for using the state treasury assets consists of a principal and an annuity set at the level of three-quarters of the current interest rate.

The liquidation path, due to its specific privatization technique, has an important advantage over the capital method. It is much more efficient (in the sense of the number of firms privatized in a given period) than capital privatization, as it does not have to be either managed or organized from the beginning to the end by the state administration (the Ministry of Ownership Transformations and/or the founding bodies). It requires a great deal of initiative from potential owners, but at the same time releases the central administration from time-consuming preparations for privatization. It allows for the simultaneous privatization of a large number of state-owned enterprises (a largely autonomous process), while by the capital method the number of privatized firms is limited by the capacities of the central administration, the banking system, etc. Besides, in the liquidation path method analysis requirements (financial analyses, preparation of prospectuses, etc.) are much smaller than in the capital method. Another advantage of the liquidation path is the possibility of purchasing the enterprise under favorable conditions provided by long-term credits, substantially alleviating the financial barrier privatization has to face. 
Commercialization means the transformation of a state enterprise into a joint-stock company owned by the state treasury, without a commitment to further steps toward privatization (in fact it is not real privatization). As a result of commercialization, a joint-stock company or a limited liability company owned solely by the state treasury is established. In a commercialized enterprise a board and a supervisory council are appointed. Two-thirds of the council are to be state treasury representatives and one-third employee representatives. At the same time the employee council is dissolved (having first agreed to enterprise transformation). Commercialization also means the possibility of reducing the financial burdens imposed on state enterprises by the special capital tax and excessive wage increase taxes.

By the end of June 1992, 464 enterprises had been "commercialized," among which 36 were privatized through capital way and 178 firms were included in the mass privatization program. This program takes on the problem of the capital barrier to privatization. This is done by an almost free distribution (small registration fee) of state-owned assets among the population (Lewandowski and Szomburg, 1989, 1990a, 1990b).

The mass privatization program (Program, 1992) provides for the privatization of about 600 relatively large and healthy state enterprises. After preliminary selection these enterprises are to be transformed into companies owned by the state treasury. At the same time, a number (10-20) of "national investment funds" are to be set up (in the form of joint-stock companies with limited issuing capacities) to deal with investment in and turnover of the securities of the enterprises included in the program. Each fund will have small shares ( 1 to 3 percent) in many of the privatized enterprises and large shares (33 percent) in 10 to 15 chosen companies. The funds are to have boards and supervisory councils, which will hire foreign firms to manage investment portfolios.

Adult Polish citizens will be given investment certificates representing one share in each investment fund. The fund's shareholders will be mainly or entirely ordinary citizens with investment certificates.

The funds are allocated share portfolios (33 percent of shares in each firm owned by a single fund and 27 percent distributed among the remaining funds). Employees of privatized enterprises will be given 10 percent of their shares cost-free. The remaining 30 percent will be reserved for the state treasury, which in the future will have the right to sell these shares on the open market or use in another way. 


\section{Market Strategies of Privatized Enterprises}

The measures aimed at stabilizing the Polish economy which were undertaken in early 1990 resulted in a fairly sharp decline in production. According to estimates, by the end of the first quarter of 1992, the real value of the sales of Polish enterprises declined by almost 40 percent. This can be attributed to the "tough money" policy, adoption of realistic interest rates, limitation on the rise of household incomes (e.g., through the imposition of excess wage tax), and price liberalization, which has brought about a decline of effective demand in the economy. Consequently, the production of goods which were "useless," of poor quality, or manufactured at excessively high costs was almost immediately eliminated (import competition effect). Hence, the first result of the stabilization program was the "self-purification" of the economy which got rid of production rejected by the market, especially with regard to consumer goods production. In the following periods the cuts in production started to affect the manufacturers of semi-processed goods to a constantly growing extent. This was the consequence of reducing production costs by firms operating in consumer goods markets, of getting rid of excessive inventories of raw materials and semi-processed goods (elimination of shortages), and of abandoning import substitution (see Dabrowski et al., 1991a).

In the sample, the extent to which privatized enterprises were hit by the recession differed considerably. Only very few firms were able to maintain the output levels of early 1990 (in real terms). The output in real terms of most enterprises plummeted quite considerably (in the bankruptcy liquidation cases, liquidation was preceded by a production decline of more than 70 percent). It can be stated that firms privatized following the capital path were able to adjust themselves the best to the new conditions of operation. On the average, the real value of their sales dropped by only 10 percent. Their advantages lay in manufacturing good-quality products, maintaining stable market positions, and being well established on the dollar markets for some time. In early 1990 the share of exports (mostly to the EC, North America, and Asia) in those firms' sales amounted to 47 percent on the average. Following two years of economic and ownership transformations this figure fell to some 38 percent. This was not a result of falling exports in those enterprises, but rather was due to a decline in the real value of the US dollar in that period (see Jasiński, 1992). It is difficult to estimate precisely the rate of growth of production for exports in those companies, as some of them exported to the former CMEA countries back in 1990. Conservative 
estimates, however, put the rise in their dollar exports at some 20 to 30 percent.

It is worth remembering here that firms chosen for capital method privatization should, by definition, show high shares of export production. Only one of them, at the moment of privatization, did not export its products as a result of loss of Western markets in 1989 (due to obsolete technology and lack of finances to purchase a packaging line). In this firm the consequences of privatization are most noticeable. As a result of selling 80 percent of its shares to a foreign investor, the necessary funds were gained for investment and for access to the American market. Three months after privatization had been completed the share of exports in the company's turnover (which in the meantime doubled) increased to some 90 percent.

At the same time, privatization through public offer and through "capital" employee buy out had no significant impact on the change of market strategies of companies in transition. The fact that they were able to keep their positions on foreign markets, and especially on domestic markets, indicates that their market activity was already relatively intense. Between 1990 and 1992 the enterprises in question stepped up sales promotion on the domestic markets through the development of advertising activities (formerly neglected or unnecessary), established networks of company shops, and set up special marketing departments. As compared with other firms (privatized and state-owned), their activities in these areas were much more intensive. It is worth pointing out that these enterprises were trying to maintain their Western markets even if sales became less profitable than those on the home market (due to the fixed exchange rate). Most were ready to build their future on expansion into those markets. The obstacles, however, were the absence of new channels of distribution (there were no new investors with access to such markets) and the lack of funds for modernizing production and upgrading the quality of products (this badly needed fresh capital was not secured by privatization).

The situation of firms privatized through the sale to a chosen investor was slightly different. The positive impact exerted on the enterprise by a large foreign active investor is quite apparent here. This usually involved capital support, transfer of technology, and access to new selling outlets. In both firms analyzed in this group, their situations improved substantially after privatization.

In addition, the takeover of large parcels of shares in privatized companies by major domestic investors has produced only meager results. The 
barriers have been the lack of ideas for restructuring the firms (which were troubled by financial difficulties at the time of buy out), as well as difficulties in acquiring new markets. Consequently, privatization of these firms, at least in the early stages, has not changed the ways in which they function. Ownership transformation has involved only the change in legal status. It seems that without overcoming the barriers mentioned above it will be difficult to achieve positive effects of privatization with this method.

There are similar problems with so-called commercialization. One may argue that it should not be regarded as one of the privatization paths (100 percent of shares are owned by the state), but only as the first step in that direction. Commercialized companies are firms selected for further privatization either separately or in the mass privatization program. They must register better than average financial standings at the moment of transformation.

In these firms, real turnover declined by more than 35 percent from 1990 to 1992 . What is more important, the bulk of the decline took place in late 1991 and early 1992, i.e., shortly after the transformation of most of these firms was completed. It seems that the "purification" of management structures from the influence exerted by employees and giving the management boards more power in fact weakened the position of the boards instead of strengthening them. In the firms there were no new means allotted for investment purposes, and there was neither new know-how and experience nor "open-minded people seeing into the future." This means that most of the companies followed the strategy of waiting for further developments (they left it to the state to initiate new solutions).

Most of these firms export part of their output to foreign markets (mostly Western ones). The bulk of the established trade contracts were concluded in the 1980s. This is why the share of exports in total sales of those enterprises amounted to some 25 percent. Two years later this share fell to 20 percent. A part of this decline could, as in the capital path, be attributed to the depreciation of the dollar and the loss of traditional foreign markets (mostly the former CMEA).

The transformation itself did not result in an intensification of the activities of these firms on the domestic market. Changes in the economic environment, however, induced them to attach more importance to their marketing activities, to develop distribution networks, and to participate more often in promotion activities (advertising, fairs). As in many other cases, these 
changes being launched in early 1990 had a much more pronounced impact on enterprise behavior than the transformation process itself.

For most firms privatized through liquidation the process of transformation was part of a strategy worked out in early 1990 . These firms, unlike firms privatized following the capital and commercialization paths, are small enterprises conducting their activities in a competitive environment and operating mostly in the domestic market. In early 1990 the share of exports in their total sales amounted to some 8 percent, on average, and increased to more than 9 percent in early 1992 . The real value of turnover declined in that period, on average, by 29 percent.

Since the start of systemic transformation the firms privatized through liquidation have concentrated on protecting their positions in the domestic market. This is why their activities have involved making their offers on the market more attractive. To this end they have allowed price discounts, developed acquisition activities, and established specialized sales departments. At the same time, they usually have not had sufficient financial means for advertising or for setting up distribution networks. They have been fairly flexible in modifying their procurement systems (choosing new suppliers and new raw material sources, including foreign ones), which have made it possible to cut down costs and to be flexible in setting prices for their products.

In the group of firms privatized through liquidation positive effects were found in those with large ( 20 to 70 percent) parcels of shares or stocks sold to active investors. Nevertheless, in some cases (sales of whole companies) the effects of privatization were less beneficial. The most advantageous changes took place in one company with foreign participation ( 50 percent), where the transfer of knowledge and experience, as well as moving the company into the international distribution network, contributed to a substantial rise in turnover and to a sizable improvement of financial standing. This was a natural effect of the long-term cooperation between the Polish and the foreign firms.

In most companies with a dominating employee and management capital participation, the transformation brought about few changes in market strategy. In some of them, however, the value of exports recorded a constant fall, mostly due to deteriorating profitability (caused by rising costs and nominal exchange rate "rigidity"), and consequently these companies started to lose to their competitors on Western markets. The companies were too weak to afford subsidizing export production even in the short run. 
A major problem they are facing now is that of maintaining their positions in the domestic market; in the future, they must expand their activities into foreign markets. The firms willing to accomplish this task need substantial capital support (their assets are usually depreciated) and potential investors will have to provide their own channels to enable these firms to gain access to new markets. In view of this, development chances of employee-owned companies are much smaller here.

The absence of development chances is a major problem that firms liquidated due to poor financial standing are facing. Transformation means, in most cases, the annihilation of a firm. Perhaps a few enterprises will manage to survive, following the introduction of extremely radical cuts in employment and wages, as well as the sale of part of the fixed assets.

Of course, this form of liquidation can hardly be regarded as a classical privatization method. In this case, compulsory transformation results from the very bad economic condition of the firms. This has usually been caused by the lack of adjustment measures or lack of preparedness for the challenge of competition (mostly foreign) in the domestic market and by the fact that in the 1980s large shares of the production were oriented toward the former CMEA countries. The decline in sales in this group of firms (in real terms) amounted to some 65 percent from 1990 to 1992 . Its nadir was recorded in early 1991 and was the delayed effect of opening up the Polish economy and the collapse of trade with Eastern Europe. In this group of firms the share of exports in sales dropped from some 16 percent in early 1990 to less than 7 percent in 1992 .

It should be added that most firms liquidated due to poor financial standing did not implement the necessary changes into their strategies in 1990 when they were still doing well. As a result, they started to be "drawn" rapidly by the new circumstances. It is true, however, that the necessary changes required more or less investments. These firms usually had no sufficient means, while the credit conditions of 1990 did not encourage decisions involving external financing.

Thus, it can be said that in the period of working out new market strategies, ownership transformations had a positive impact on the operations of the firms that attracted a foreign active investor, but only when know-how, technology, or investments for the modernization of the enterprise were provided. Still, the opening of external outlets for the firms' products by the investor seems to be most important. Privatization did not bring about any substantial changes in the market strategies of firms privatized following the 
capital path, liquidation, or commercialization. Most of them had instituted some measures in this field prior to privatization by responding to changing market environment. As a result they managed to maintain their positions on foreign markets as well as their links with foreign markets.

\section{Production Changes and Investment}

In early 1990 , state-owned enterprises were at first shocked by the totally changed market conditions. Many of them began immediately thinking over their current conditions, production opportunities, and prospects for future development. The need for coming to terms with these problems was made even more acute by the sluggish demand for their own products, by falling profits, and by more difficult (due to high nominal interest rate) access to financial means. Enterprises that under the old regime were not used to performing an active role started very quickly to look for opportunities for adjusting their activities to the changed and still-changing market demand structure. They preferred actions that did not require new investments. Adjustments were mostly reflected in the increased output of one item at the expense of discontinuation or reduction of output of another, as well as in enhancing the quality and attractiveness of manufactured goods, if this were possible without too heavy a financial burden. Adjustments of this kind were most frequently found in firms facing the biggest difficulties in selling their output and in those which first encountered such difficulties (foodprocessing, light, and electronics industries). The bulk of these changes took place in 1990 and early 1991. In this period most of the opportunities for extensive production adjustments in enterprises were used up (Dabrowski, et al., 1991b).

Thus, privatization has not exerted a decisive impact on intensifying basic production adjustments, since such adjustments had been enforced by the economic environment even prior to ownership transformations. In principle, however, the activity in this field has proved insufficient for being able to match the increasingly more unfavorable market conditions, i.e., growing foreign competition. For most Polish enterprises depreciated assets and obsolete technologies do not allow competition with foreign firms on an equal footing. High production costs also result from inefficient employment structures, inappropriate organization of production, and heavy social burdens. ${ }^{3}$

\footnotetext{
${ }^{3}$ For example, nurseries, schools, enterprise-administered housing, holiday resorts, local heating plants, and even playgrounds and sports clubs.
} 
Many firms need production modernization or sometimes changes in the scope of production and new technologies to stay on the market. The scale of necessary changes usually goes far beyond the investment opportunities of an enterprise on its own.

Ownership transformation is often seen as a chance for changing the production patterns of a privatized firm. It turns out, however, that only in a limited number of cases were the expected results achieved. In this context the situation of those firms is better where privatization by the capital path and through liquidation was carried out. In more than half of them production modification was introduced during or after the privatization process. These changes involved diversification of the supplies, a substantial quality upgrading, and changes in production techniques. Such activities usually resulted from long-term modernization processes in the enterprises, combined with the introduction of new employment and organization structures. However, in only very few cases were deep assortment changes or restructuring of production patterns introduced. For example, considerable modernization was carried out in all firms privatized following the capital path (except cases of buy outs by domestic investors) and in more than half of the enterprises privatized through liquidation (leasing).

Even less frequent were the cases of making major investments in production with the aim of introducing new technologies. They were found almost exclusively in firms in which the foreign investor took upon himself a prior commitment for technology transfer and/or a modernization investment. The positive effect of capital support (rise in sales and in profitability) was recorded in all firms included in this category after a very short time (three to six months).

It is also worth noting that the majority of privatized firms used their own funds to finance investment projects, because they thought a bank credit was too expensive. Only in six cases (three in the capital path and another three in privatization through liquidation) a large bank credit was used. However, this was characteristic for firms enjoying a very good or good economic standing, having a stable market position, and hoping for a quick return on invested capital. In several cases small credits were taken as a supplementary source for carrying out production changes in connection with getting new, nontypical orders. Applications for foreign credits are becoming more and more frequent because of the lower nominal interest rates on those credits. 
Commercialized firms and those privatized through liquidation recorded relatively rare and superficial production changes. In the former, ownership transformation did not enhance adjustment activity (lack of both managerial new blood and investment means). In several cases there were only attempts at minor modernization of the firms or adjusting production capacities to new orders. Again, however, they did not result from transformation but resulted from the pressure exerted by the market environment that had been realized earlier.

In firms liquidated due to bad financial standing, production changes were also rare. Their reactions to the new situation usually came very late. Although in the first year of economic transformation they were not hit particularly hard, still little was done to prevent the difficulties looming ahead. In the following year there was a rapid accumulation of unfavorable developments (collapse of Eastern markets, losses in dollar trade, shrinking domestic market as a result of growing foreign competition), and, despite desperate attempts, the enterprises in question gradually plunged into a no-way-out situation. Since there were no investment opportunities, extensive measures (closing down subsidiaries or departments, group layoffs, wage reductions, sales of some fixed assets) were mostly applied. It seems that in only two out of thirteen cases examined did such measures give the enterprises a chance to survive.

Generally, production adjustments of privatized enterprises were, as in the case of sales strategies, the result of the necessity to adjust the fields of activities of state-owned firms to new market conditions rather than direct effects of transformation. The extent of necessary changes usually went far beyond the financial and staff capacities of the privatized enterprises. In many of the enterprises (mostly those transformed by way of the capital path or leasing) the transformation was a natural part of long-term adjustment strategies based on an evolutionary modernization of the firms. The scope, however, was limited by their own investment means. Only in firms with foreign capital participation, were sizable modernization investment projects, involving transfer of know-how, completed. In several other firms with relatively good financial standing, decisions were made to take bank credits for financing replacement or modernization investments. It should also be added that the firms whose reaction to systemic changes were relatively quick (at the beginning in 1990 or earlier) managed, to a considerable extent, to avoid later difficulties. Those who missed that moment lost twice. 
They wasted their time and a chance of "fitting themselves" into the new reality that emerged in 1990 .

\section{Financial Standing of Privatized Enterprises}

The description of the changes taking place in the fields of market strategy and adjustment in production cannot be complete without the analysis of the financial standing of the privatized enterprises. It constitutes a part of both the production and market strategies and determines possible changes in these fields.

The financial standings and economic conditions of privatized enterprises have been and still remain very differentiated. On the one hand, this results from natural differences between economic performances achieved by particular firms. On the other hand, the placement of a firm on a particular privatization path is to a great degree related to its financial standing.

In as much as the above statement is obvious and does not require further explanation, it also calls for the examination of the dynamics of basic financial indicators describing a company's performance in relation to a privatization path chosen. From this point of view, the most relevant indicators are the firm's ability to create profits (profitability rate) and its financial liquidity (receivables to payables ratio, the share of receivables/payables in total sales, or payables to gross profit ratio). These measures provide an approximate and comprehensive picture of the economic standing of a firm, describing its investment (restructuring) capacities and limits to access to current money revenues (in Poland this aspect is of particular importance due to the acute problem of constantly growing payment arrears, bad debts, and so on).

Between 1990 and 1992 the profitability of privatized firms was subject to substantial changes (see Table 11.3): both in average level and in differentiation along the different paths of privatization. It should be noted, first of all, that irrespective of the transformation method privatized firms experienced a relatively sharp decline in profitability from January 1990 on. It should be added, however, that in the same period a similar drop in profitability was recorded for the whole economy, including all state-owned enterprises (see Dabrowski et al., 1991a, 1992a). Hence, the rapid decline in financial performances of privatized firms should be interpreted not as a result of ownership transformations, but rather as the consequence of the introduction of the stabilization program in Poland. 
Table 11.3. Profitability ${ }^{a}$ relative to the privatization path, in percent.

\begin{tabular}{|c|c|c|c|c|c|}
\hline \multirow[b]{2}{*}{ Privatization path } & \multicolumn{2}{|l|}{1990} & \multicolumn{2}{|l|}{1991} & \multirow{2}{*}{$\frac{1992}{\text { Jan-Mar }}$} \\
\hline & Jan-Jun & Jul-Dec & Jan-Jun & $\mathrm{Jul}-\mathrm{Dec}$ & \\
\hline Capital path & 47.4 & 32.4 & 23.3 & 12.8 & 15.3 \\
\hline $\begin{array}{l}\text { Liquidation through } \\
\text { privatization }\end{array}$ & 35.7 & 25.5 & 17.9 & 5.5 & -2.1 \\
\hline Liquidation by bankruptcy & 31.6 & 9.5 & -25.5 & -44.0 & -40.3 \\
\hline Commercialization & 52.7 & 58.8 & 28.3 & 19.9 & 9.5 \\
\hline Total & 39.9 & 29.5 & 9.7 & -2.7 & -6.4 \\
\hline
\end{tabular}

${ }^{a}$ Profitability: gross profits/costs.

Table 11.4. Credit arrears and privatization path: receivables to payables ratio.

\begin{tabular}{|c|c|c|c|c|c|}
\hline \multirow[b]{2}{*}{ Privatization path } & \multicolumn{2}{|l|}{1990} & \multicolumn{2}{|l|}{1991} & \multirow{2}{*}{$\frac{1992}{\text { Jan-Mar }}$} \\
\hline & Jan-Jun & Jul-Dec & Jan-Jun & Jul-Dec & \\
\hline$\overline{\text { Capital path }}$ & 2.43 & 3.40 & 1.45 & 1.82 & 1.06 \\
\hline $\begin{array}{l}\text { Liquidation through } \\
\text { privatization }\end{array}$ & 3.28 & 2.02 & 1.65 & 1.34 & 1.12 \\
\hline Liquidation by bankruptcy & 1.81 & 1.02 & 0.47 & 0.40 & 0.54 \\
\hline Commercialization & 2.77 & 2.42 & 1.53 & 2.08 & 1.90 \\
\hline Total & 2.47 & 2.07 & 1.32 & 1.30 & 1.10 \\
\hline
\end{tabular}

Nevertheless, the rate of profitability decline was not similar for all groups of firms. The relatively smallest decline was recorded in firms privatized following the capital path. In early 1992 the downward trend was even halted. Still, claiming that this was due to adjustment measures and, in more general terms, that it was the first result of privatization would definitely be premature.

The problem of payment arrears, posing a barrier to the operation of most Polish firms, is also relatively less acute in the group of enterprises privatized following the capital path. In just over two years in the whole sample the receivables to payables ratio declined by almost 2.5 times (see Table 11.4). It is worth adding here that after the act of privatization, generally there was a steady improvement of the receivables to payables ratio. Most privatized firms managed to balance receivables with payables and to improve the ratio of their sums to the amounts of turnover. Hence, these firms improved their financial liquidity, although the relevant measures for the whole economy were very unfavorable at that time. 
It can be stated that firms following the capital path managed the best recovery from the "stabilization shock" and their financial performance is still much better than that of an average firm in the economy or those firms that were transformed in another way.

The situation of firms liquidated according to the provisions of the privatization law was slightly different. Within more than two years profitability in this group of enterprises declined, on the average, by almost 40 percent. However, the most important fact is that the biggest decline took place in the second half of 1991. For most of these firms it was a period in which the ownership transformation process was under way or had just been completed. It would probably be unjustified to claim that privatization was the primary cause of financial troubles of many of these firms (e.g., repayment of leasing installments), but it surely had its impact on their financial standings. As a result of privatization their contributions to the central budget increased (leasing installments were higher than taxes paid before). Moreover, production costs also increased due to a substantial rise in average wages after privatization (the share of wages in production costs increased in that period from some 22 percent to some 30 percent). Wage increases in these companies were similar to the increases in the capital path and much bigger than in commercialized firms, although the financial performance of liquidated firms was much worse in that period. This was true mostly for firms whose principal shareholders were their own employees.

Although in 1990 most of the firms achieved very good economic performance (all the enterprises examined gained profits), in early 1992 the average profitability was already negative (this was, however, mostly due to the performance achieved by firms liquidated through the sale of assets). In the group of firms liquidated within the framework of the privatization law there was a more than threefold decline in the receivables to payables ratio in the period analyzed. In early 1992 one could in fact talk about reaching a balance in payment arrears. Nevertheless, an improvement of this ratio is still, to a lesser degree, a result of measures aimed at the execution of collecting the dues or a result of privatization, and should be attributed, rather, to a steady fall in those firms' profitability and a rise in payables. The economic condition of enterprises liquidated due to poor financial standing is, for obvious reasons, much worse. In early 1990 the average profitability of these firms was relatively high. Since late 1990 there has been a quick and uninterrupted deterioration of their financial standings. Although in early 1992 the average profitability of these firms showed an improvement, this 
was due not to well-established strategies but to ad hoc measures made under actual pressures. These measures included the curtailment of the scope of activities, employment reduction, and the sale of some fixed assets.

It should be added that in the group of firms to be liquidated through bankruptcy the situation involving payment arrears was also disastrous. In these firms the receivables to payables ratio was constantly declining. This, of course, was the consequence of a systematic financial "collapse" of these companies and their rapidly growing payables. It is also striking that as recently as 1990 an average firm in this group needed only one month's profit to fully meet its payables.

On the other hand, during the entire period analyzed, enterprises transformed into companies still owned solely by the state treasury (commercialization) enjoyed relatively favorable financial conditions. In 1990 they definitely showed the highest profitability ratios, but in the second half of 1991 the standing of these firms started to deteriorate relatively quickly. Because by this period commercialization of most of these firms was completed, we might conclude that commercialization did not bring about an improvement of the financial standing of these enterprises. Nevertheless, the time perspective is too short to venture to say that this form of transformation had negative consequences for the financial situation of enterprises in transition. Basic causes of decline of profitability in this group of firms are similar to those found for other privatization paths. A possible additional cause, however, might have been the repeated evaluation of former and present management that led to the postponement of necessary actions toward restructuring (including financial changes).

In the context of payment arrears the position of commercialized companies is peculiar (see Table 11.4). After cutting their receivables/payables ratio in mid-1991 these companies again produced high credit arrears. This points to a lack of interest, suitable strategy, or real possibilities of balancing receivables with payables.

In summary, it should be stated that the deteriorating financial standing of the firms privatized in the recent years did not result from the starting up or the completion of the process of ownership transformations, but was a consequence, first of all, of the implementation of the stabilization program. Hence, one may venture to say that capital privatization gave enterprises a chance for financial restructuring and allowed them to halt, at least for the time being, the drop in profitability (see Table 11.5 for summary of effects 
Table 11.5. First effects of ownership changes and methods of privatization.

\begin{tabular}{lllllll}
\hline $\begin{array}{l}\text { Privatization } \\
\text { path }\end{array}$ & & $\begin{array}{l}\text { Manage- } \\
\text { rial know- } \\
\text { ledge }\end{array}$ & $\begin{array}{l}\text { Owner- } \\
\text { ship } \\
\text { pressure }\end{array}$ & $\begin{array}{l}\text { Capital } \\
\text { injec- } \\
\text { tion }\end{array}$ & $\begin{array}{l}\text { Transfer } \\
\text { of } \\
\text { technol. }\end{array}$ & $\begin{array}{l}\text { Access } \\
\text { to } \\
\text { markets }\end{array}$ \\
\hline \multirow{2}{*}{ Capital } & A & +- & + & + & + & + \\
& B & +- & + & - & - & +- \\
Liquidation & C & - & +- & - & - & - \\
through & A & +- & + & + & + & +- \\
privatization & D & +- & + & - & - & +- \\
Liquidation by bankruptcy & - & - & +- & - & - & - \\
\multicolumn{2}{l}{$\begin{array}{l}\text { Commercialization } \\
\text { A }\end{array}$} & - & - & - & - & - \\
\hline
\end{tabular}

$\mathrm{A}=$ Foreign investor.

$\mathrm{B}=$ Domestic investor.

$\mathrm{C}=$ Dispersed property rights (most public offering).

$\mathrm{D}=$ Insider owners (employee buy out).

of privatization methods). At the same time, the first phenomenon accompanying privatization along the liquidation and commercialization paths was a quick drop in profitability and constantly deteriorating financial liquidity. The story with bankruptcy liquidation was a different one, since in this case the transformation, in fact, resulted from bad economic condition of these enterprises. Quite often, however, there was an improvement in the conditions of liquidated firms due to employment reductions and sales of fixed assets.

\section{Closing Remarks}

Summing up the findings and observations discussed in this chapter, the following general conclusions may be formulated:

1. In the years between 1990 and 1992 most Polish enterprises embarked on more or less profound adjustments in the fields of production, as well as in market strategies. These measures, however, have been stimulated not by the process of ownership transformation but rather by the qualitative changes in the economic environment as a result of the implementation of the national program of economic transformation and stabilization. The more demanding market environment uncovered the 
size of technology and organization gaps and outlined the scope of indispensable production and market-related changes in Polish enterprises. It became apparent that most firms were unable to meet the challenge of both foreign competition (first of all) and domestic competition, by solely relying on their own resources.

2. Most changes that had been implemented by enterprises prior to the launching of ownership transformation were simple, unsophisticated measures mobilizing the firms' internal reserves. Most of these resources were relatively quickly exhausted, while more sophisticated, qualitative adjustments (e.g., entering new markets, modernization of production, changes in the organization and management of the company) encountered substantial internal barriers (financial and human).

3. The first experience of the Polish privatization shows that due to the legacy of a substantial technology gap, depreciation of assets, rigid market links, and lack of cooperation, as well as the generally poor financial standing of most enterprises, the change of property rights (in the sense of visible pressure of an owner) and the inflow of new managerial knowhow are by far inadequate for leading most privatized firms to recovery. The change of legal status alone brought positive results only in a few cases of good firms privatized in the capital way and in a few cases of firms privatized through liquidation. These, however, were usually relatively modern enterprises, well established on markets, with skilled employees, and already with very good management.

4. Clearly, positive consequences of privatization emerged relatively quickly in the firms in which control parcels of shares have been acquired by foreign investors. Usually, as a result of such a privatization scheme a firm gets access to new selling outlets, together with capital support and technology transfer. Firms experiencing this kind of transformation, however, are still rather few in number; these are mostly large and medium-size firms.

5. The takeover of a company (or of its major part) by a domestic investor usually does not produce results as positive as in cases where an enterprise is bought out by a foreign investor. The experience gathered so far seems to indicate that domestic investors are much less aware of the decisions they take: at the moment of purchase of shares they are not well acquainted with the firm, cannot specify their position in it, and have no ideas about how it should operate. Moreover, cases of giving capital support to firms privatized by domestic takeover are not very 
common, and the examples of privatized firms accessing new markets or new domestic orders or initiating technological modernization are very rare.

6. The first results of taking over the firms by employees (both by "capital" employee buy out and through lease of assets by employees) seem to confirm the expectations about a consumption-oriented approach of most employees as owners of their firm. On the one hand, following privatization, wages in these firms rapidly increase while their economic performance deteriorates. On the other hand, these enterprises maintain the flexibility adjustment that was worked out earlier, and aggressively defend their market positions (rise in dollar export, staying on the domestic market). Undoubtedly, the lack of inflow of investment means is a major problem faced by these firms.

7. In a vast majority of cases, commercialization does not have a positive impact on a firm's operation. Moreover, commercialization sometimes petrifies the inefficient organization and management structure in an enterprise, bringing about nothing in exchange.

8. Privatization through liquidation as a specific form of a firm's bankruptcy has so far been performing its function to the extent that it allowed for reallocation of the means of production from "dying" firms to efficient ones. So far, this mechanism has been working, although not very smoothly, in most firms that were selling some of their assets. It also makes it possible to rescue some firms, although in a mutilated form, through the sale of their unessential capital assets. Nevertheless, the shortage of new investments may make further activities of these firms impossible.

9. If ownership transformation is to contribute to intensified restructuring in production and markets, as well as to raise economic efficiency at the micro and macro levels, and, by the same token, to increase the competitiveness of Polish products, the following steps seem necessary:

(a) Enhancing the attractiveness of privatized enterprises as a target for foreign investment (promotion, economic stability, clarity, and permanence of legal provisions and financial incentives).

(b) At least partial departure from the formula of the equivalent sale of assets of "collapsing" state-owned companies that has made reallocation of production resources and restructuring of enterprises after transformation difficult. 
(c) Allowing enterprises to retain a part of the privatization revenues (e.g., as a long-term, low-interest loan with a grace period) in order to facilitate financial restructuring and to initiate additional adjustment processes.

(d) "Flattening" the financial burdens imposed on firms that lease their assets, avoiding excessively high contributions to the budget paid by them in the early months (years) after their transformation.

\section{References}

Dabrowski, J.M., Federowicz, M., and Levitas, A. (1990) Stabilization and State Enterprise Adjustment: January-June 1990, Program on Central and Eastern Europe Working Paper Series, No. 6 (Cambridge, MA: Harvard University).

Dabrowski, J.M., Federowicz, M., and Levitas, A. (1991a) "Polish state enterprises and the properties of performance: Stabilization, marketization, privatization," Politics and Society, No. 4.

Dabrowski, J.M., Federowicz, M., and Levitas, A. (1991b) "Collapse of state sector: Stage of truth," Economic Transformation, No. 18 (Gdansk: Gdansk Institute for Market Economics).

Dabrowski, J.M., Federowicz, M., Levitas, A., and Szomburg, J. (1992a) "Privatization process in the Polish economy in 1991," Economic Transformation, No. 23 (Gdansk: Gdansk Institute for Market Economics).

Dabrowski, J.M., Federowicz, M., and Levitas, A. (1992b) "State-owned enterprises during the second year of the economic transformation," Economic Transformation, No. 27 (Gdansk: Gdansk Institute for Market Economics).

Dabrowski, J.M., Federowicz, M., and Szomburg, J. (1992c) "Privatization process of the Polish state-owned enterprises: Report II," Economic Transformation, in press (Gdansk: Gdansk Institute for Market Economics).

Dynamics of Privatization (1990) Department of the Privatization Analysis, Nos. 1-4 (Warsaw: Ministry of Ownership Transformation).

Dynamics of Privatization (1991) Department of the Privatization Analysis, Nos. 5-6 (Warsaw: Ministry of Ownership Transformation).

Groszek, M., and Ruszkowski, P. (1989) "The state-self-managed enterprise," $Z m i$ any, No. 32 .

Jasiński, L. (1992) "Small depreciation," Gazeta Bankowa, No. 40.

Kamiński, T. (1992) "Privatization abandoned: Case studies," (Gdansk: Gdansk Institute for Market Economics).

Kawalec, S. (1989) "The outline of the program of the privatization of the Polish economy," in Proposals of the Transformation of the Polish Economy, PTE (Warsaw: Polish Economic Association, Warsaw Branch). 
Lewandowski, J., and Szomburg, J. (1989) "Ownership changes as a foundation of socio-economic reform: Outline of the program," in Proposals of the Transformation of the Polish Economy, PTE (Warsaw: Polish Economic Association, Warsaw Branch).

Lewandowski, J., and Szomburg, J. (1990a) "Transformation model of Poland's economy," Economic Transformation, No. 1 (Gdansk: Gdansk Institute for Market Economics).

Lewandowski, J., and Szomburg, J. (1990b) "The strategy of privatization," Economic Transformation, No. 7 (Gdansk: Gdansk Institute for Market Economics).

Ludwiniak, K.S. (1989) "Democratization of the socialist economy," Zycie Gospodarcze, No. 45.

Mass Privatization Program (1992) Department of Mass Privatization, Mimeo (Warsaw: Ministry of Ownership Transformation).

Proposals of the Transformation of the Polish Economy (1989) PTE (Warsaw: Polish Economic Association, Warsaw Branch).

Reynolds, P., and Young, P. (1992) "Priority for microeconomics," Rzeczpospolita, No. 244. 


\section{Comments on Janusz M. Dabrowski's Paper}

\section{Sándor Richter}

Dabrowski's paper is a pioneering work. The author addresses the problems of privatized enterprises in Poland, in the sense that privatization in the former centrally planned economies is an unprecedented phenomenon, with which privatization in no other part of the world economy compares. Further, privatization in the former socialist economies has begun only now and for the most part is in its initial stage. Thus, Dabrowski's investigation provides one of the first insights into the "brave new world" of newly privatized enterprises in former centrally planned economies through the careful analysis of a sample of enterprises.

Dabrowski is right in saying that Eastern Europe cannot learn much from the privatization experiences in Latin America or Great Britain. It is all the more important to compare the experiences of former centrally planned economies with one another since in this situation just the opposite is true: the similar preconditions and external and internal environments of transition from central planning to market economies make the comparison of privatization techniques invaluable to finding solutions which are the most efficient and involve the least social tension. This is especially true for the "latecomers" in privatization where merits and shortcomings of the pioneers can still influence the privatization strategies to be applied.

Dabrowski describes the four ways of Polish privatization: "the capital path," liquidation through privatization, liquidation by bankruptcy, and commercialization. The first three ways have three subcases. The sample, in which there are enterprises from all groups and subgroups, consists of 55 newly privatized firms. Of these 55 enterprises no less than nine belong to the group of commercialized enterprises, which went through the stage of transformation from traditional state enterprise to joint-stock company but have not been privatized yet. I have reservations about commercialization as a way of privatization. True, commercialization is a sine qua non of privatization but the example of the Hungarian privatization demonstrates that commercialization is the easiest path to the privatization process. There can be, and at least in the Hungarian case there has been, a substantial time lag between commercialization and privatization. I think commercialized but not yet privatized enterprises constitute a separate group between traditional state enterprises and privatized enterprises, hence interpreting commercialization as one way of privatization is not fully justified. This group cannot be regarded as a transitional category. There will always be a fluctuation since some of these enterprises leave this group when they become completely privatized and other enterprises will join this group after being commercialized. Most probably this category will prevail for a couple of years. It is very difficult to create clear categories in privatization: to mention only one example, is a joint-stock company whose majority shareholder is a bank, which is 60 percent state owned, really a private firm?

The time span between privatization and the investigation of the performance of the enterprises was very short, one to two years. This makes interpretation of the 
findings extremely difficult. Nevertheless, the author promises to repeat this survey every six months. The results of this first survey will be even more important when the results of surveys over a longer period are available.

Dabrowski compares the performance of the enterprises in the sample with one another, since his main purpose is to analyze the impact of various forms of privatization on the ensuing performance of these enterprises. In the paper the firms in the sample are compared with traditional state-owned enterprises, as well. Since for a discussant nothing is "too expensive," for the future, I would find a comparison with the enterprises of the "genuine" private sector, i.e., with those firms which were established as private enterprises, very interesting, too.

The description of the differences according to the impact of recession on the performance of the various groups of enterprises in the sample is especially interesting. In Poland, as the author writes, the real value of sales in the economy declined by nearly 40 percent from early 1990 to the end of the first quarter of 1992 . The drop of sales in the four main groups of the sample varied substantially from -10 percent in those enterprises following the "capital path" to privatization to -65 percent in the case of those firms which were privatized by bankruptcy. It is, I think, impossible to find an unambiguous explanation for the variation in the rates of decline, since, on one hand, the various ways of privatization must have had an impact on the performance and, on the other hand, for each way of privatization a group of enterprises with a similar financial stance was attached: e.g., only the best firms could follow the "capital path" to privatization. Nevertheless, I have problems with the qualification of decline in the various groups of the sample. In those enterprises that were liquidated by privatization the decline was -29 percent, whereas in those enterprises liquidated by bankruptcy contraction amounted to -65 percent. Decline in the first group, for which typically profitable small firms were selected, may cover streamlining, elimination of uncompetitive capacities and production, a process that will soon result in increased efficiency which lays down the basis for a forthcoming expansion of the output. Contrary to this, when privatization took place through liquidation by bankruptcy decline may be explained partly by inertia which does not bring about preconditions of recovery. In this group, however, even the "good" type of decline may be very strong as the bad initial conditions demand more sacrifice than they do in the other group.

An important lesson from the paper is that in nearly all of the few successful cases within the sample a foreign investor was involved. In these cases investment occurred not only in the financial sense. (The distinction of foreign direct investment between capital inflow into a bank account and actual investment in a technological sense is very important. In Hungary, which received at least one-third of all foreign direct investment in Eastern Europe in the last three years, the first type of foreign investment makes up a substantial part of total foreign direct capital inflow.) New technology, financial injection, integration into the sourcing process of the foreign mother company, and new sales channels seem to be the main components of success for newly privatized companies. Most probably this will apply to other countries in Eastern Europe. 



\section{Chapter 12}

\section{Monopoly Power, Import Competition, and Price Liberalization in the CSFR}

John S. Earle and Andreas Wörgötter*

It is pointless to liberalize prices in a monopolistic environment. Vaclav Klaus, 1990.

\section{Introduction}

The post-socialist countries have inherited monopolistic market structures, in which few but large firms produce for the home market in many branches of the economy. ${ }^{1}$ Beyond the standard microeconomic arguments that pricesetting firms tend to produce lower quantities and charge higher prices compared to price-takers, the possible presence of monopoly elements in the transition economies of Eastern and Central Europe is of special concern for a number of reasons. First, it is apparent that the enormous level of concentration under central planning was well beyond the degree justified by the

\footnotetext{
*We would like to thank Alena Buchtikova and Jarko Fidrmuc for valuable research assistance with the calculations and data gathering.

${ }^{1}$ This feature has been particularly widespread in the former Soviet Union. See Snyder (1993) for an informative presentation of these distorted market structures.
} 
possible presence of scale economies. Second, as large enterprises are privatized, there is reason to fear that the hoped-for benefits of the economic reform package will be swallowed up by monopoly profits, with negative consequences for both growth and distribution. Third, one of the most important, and still unresolved, issues in privatization is the timing of restructuring - one of the most important components of which is the breakup of the large enterprises into firms that are smaller and "more competitive" (in every sense). Finally, the domination of enterprise managements by members of the "nomenklatura" imparts a political aspect to the problem of monopoly: the public is likely to have especially low tolerance for the reform policy if this class is perceived as its prime beneficiary.

For these reasons, it has sometimes been argued that transition policy should first seek to break the power of the monopolies, prior to liberalizing prices. This sequencing argument that demonopolization must precede price liberalization and privatization has been countered by the proposition that import liberalization, implemented simultaneously with price liberalization, would create sufficient competition. Empirically ${ }^{2}$ and theoretically, ${ }^{3}$ however, the issue remains unresolved.

In practice, most of the post-socialist economies have chosen the second route: rapid "big bang" liberalization of many areas of the economy simultaneously. It has been hoped that freeing prices would create positive incentives and that import competition would dampen "excessive" price increases. The results of these policies are well known: among other things, prices skyrocketed and output collapsed. In many of the countries, these results are attributed in large part to the freedom now granted to monopolies to exercise their previously restrained power. Several countries, for example, Lithuania, Romania, and Ukraine, are considering reintroducing price controls for just this reason. But the degree to which the price increases actually reflect the presence of monopolies, rather than a number of other factors, remains unknown.

${ }^{2}$ See, for instance, Jacquemin and Sapir (1990) in a study on the the completion of the European internal market, who make the following statement: "External trade liberalisation is, however far from being a perfect substitute for domestic competition and could even have perverse effects - for instance, when a small number of foreign firms dominate the market."

${ }^{3}$ See Ross (1988) who provides a theoretical treatment of this issue and concludes, "In some cases the lower tariff did serve to control price increases, but in others it did not." 
This paper presents a preliminary analysis of price behavior of Czechoslovak industries in the first year after liberalization, in an attempt to assess the competing views on policy sequencing. We examine the behavior of prices and other variables at both the industry and firm levels, and consider the relationships of the movements of these variables with concentration ratios by industry. In the next section, we examine the patterns of price changes by 2 -digit industries after price liberalization in 1991. Remarkably, prices in nearly all industries jumped almost immediately in the first quarter of 1991 to new levels at which they then more or less remained. The following sections catalogue the factors that may have contributed to this price behavior and report preliminary results of a test of the import discipline hypothesis. The last section contains conclusions and our ideas for future research.

\section{Price Behavior in the Year after Liberalization}

In the classic centrally planned economy, prices are per definition regulated. Unlike some of its neighbors, Czechoslovakia under socialism retained most of the features of classic central planning, including the setting of prices by a central authority, right up to the changes in 1989. Czechoslovak prices were massively and rapidly liberalized starting in January 1991, reducing the regulation ratio (proportion of goods and services set by the state) from 85 percent in 1990 to between 5 percent and 6 percent in October 1991. At the same time, maximum ceiling prices for "sensitive" goods and services like public utilities, rent, coal, fuel and oil products, and metallurgical products were introduced. An additional regulation covered industrial sectors with a "high degree of market power," which were made subject to obligatory prior notification of price increases, the "time-related price regulation" (OECD, 1991) ${ }^{4}$

Price liberalization was hardly the only systemic change in the transformation process of Czechoslovakia after the fall of the old regime in late 1989. Already in 1990 exchange rates were devalued several times until pegged to a currency basket after January 1991. The first steps to introduce current account convertibility were made, and most parts of trade with former CMEA

${ }^{4}$ Although price liberalization started in January 1991, for several energy, fuel, and chemicals prices administered increases were carried out beginning in the last quarter of 1990. In the following section, we focus on the outcome of price liberalization which was introduced in January 1991. 


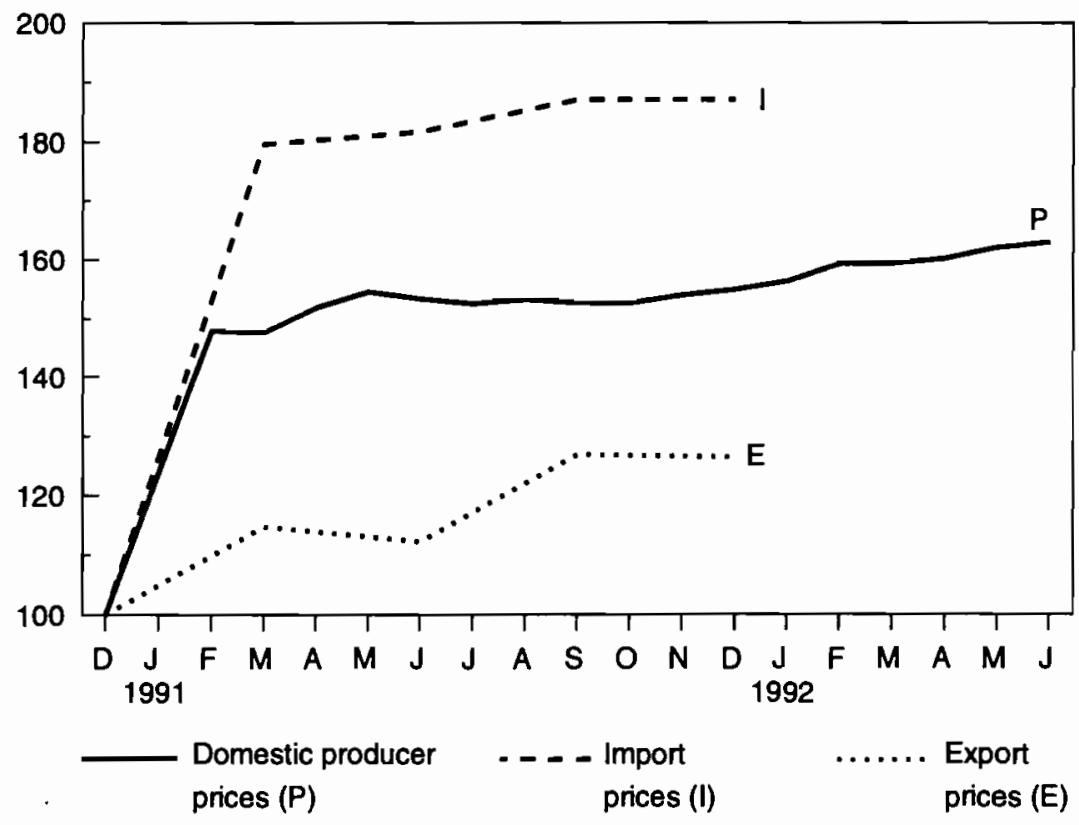

Figure 12.1. Total domestic producer, import, and export prices in the CSFR, December 1990 to June 1992, 1990 December $=100$ percent. Source: Federal Statistical Office.

countries had to be carried out with hard currency transactions. ${ }^{5}$ The evolution of domestic prices therefore cannot be studied in isolation. In the following analysis we compare the movements of import and export prices and evaluate and interpret domestic producer price movements during the introduction of price liberalization.

Figure 12.1 displays the aggregate import and export prices and the domestic producer prices. This graph provides a drastic image of the most important stylized facts of the aggregate outcome of price liberalization. First, it is remarkable that most of the price change in 1991 was completed by February. Between December 1990 and February 1991 prices rose (in two steps) by more than 50 percent. After February 1992, the monthly price increase averaged below 1 percent.

\footnotetext{
${ }^{5}$ Hrnčír and Klacek (1991) mention price liberalization, privatization, and convertibility as foundations for the new economic, social, and political developments described as the return of the CSFR to Europe.
} 
The second remarkable feature is the simultaneous deterioration of the terms of trade. By March 1991 aggregate import prices rose by more than 80 percent relative to the level of December 1990. Export prices increased by only one-fourth of this value. The reason for this disparity is only indirectly related to price liberalization. In the course of the dissolution of the CMEA, energy import prices increased by almost four and a half times. This increase was larger and hit the CSFR economy much harder than the energy price increases in 1973 and $1979-1980$ could affect the OECD countries. Currently energy imports account for nearly one-quarter of total CSFR goods imports. This is by orders of magnitude greater than in all OECD countries. Energy prices alone accounted for more than three-quarters of the aggregate import price increase.

The other factor contributing to the strong terms-of-trade loss was the breakdown of trade with other CMEA economies. The trade with Eastern European economies was reduced dramatically within a short period of time, an enormous shock in itself. For the CSFR, only a strong increase of foreign trade with OECD countries could replace the loss of markets in the East. In order to overcome entry barriers to new markets in the West, export prices had to be kept low.

Figures 12.2 to 12.4 reveal the development of domestic producer prices during the period of price liberalization for 19 industries grouped into energy and basic materials (Figure 12.2), heavy industries (Figure 12.3), and light industries (Figure 12.4). The abbreviations can be identified in Table 12.1. Table 12.1 shows the levels of domestic wholesale prices for all industries in January, April, July, and October 1991.

Figure 12.2 presents the image of stable energy and raw material prices in Czechoslovakia after the first price level adjustments were made. Prices of fuels had already increased by 50 percent in the last quarter of 1990 . Price liberalization, therefore, did not bring many additional price changes. Energy prices (basically electricity) had also already increased in 1990, but price liberalization contributed to a further considerable price adjustment. Iron and noniron metallurgic product prices nearly doubled in the 18 months after price liberalization was introduced in January 1991 . Whereas noniron metallurgic products show some overshooting, iron metallurgic product prices exhibit a more gradual approach to their new equilibrium level. It may seem justified to talk about equilibrium prices not only in these two cases, because after May 1991 not many price changes may be observed. Fuels and raw materials have approximately changed in the same proportion as the 
Table 12.1. Domestic wholesale prices in CSFR industry in 1991, 1 January $1989=100$ percent.

\begin{tabular}{lllll}
\hline Sector & Jan. 1991 & Apr. 1991 & Jul. 1991 & Oct. 1991 \\
\hline Total & 145.2 & 177.8 & 178.6 & 178.7 \\
Fuels (F) & 154.3 & 173.4 & 176.9 & 177.1 \\
Energy industry (E) & 154.2 & 254.3 & 258.1 & 265.4 \\
Iron metallurgy products (I) & 150.6 & 183.3 & 188.3 & 189.7 \\
Noniron metallurgy products (N) & 156.6 & 213.5 & 201.7 & 201.2 \\
Chemicals, rubber, asbestos (C) & 210.4 & 222.9 & 221.4 & 223.7 \\
Machinery (M) & 123.7 & 165.5 & 175.3 & 177.0 \\
Electrical eng. products (E) & 129.4 & 174.0 & 173.8 & 169.7 \\
Building materials (B) & 133.5 & 168.0 & 171.7 & 168.3 \\
Wood (W) & 128.3 & 165.5 & 168.4 & 167.9 \\
Metal processing (W) & 160.3 & 205.2 & 204.3 & 206.7 \\
Paper and pulp (P) & 131.7 & 192.7 & 191.1 & 184.7 \\
Glass, ceramics, porcelain (G) & 154.6 & 194.9 & 195.3 & 195.9 \\
Textile (X) & 145.2 & 183.8 & 176.3 & 172.4 \\
Clothing (C) & 131.4 & 152.7 & 154.9 & 154.9 \\
Leather (L) & 161.0 & 183.1 & 185.8 & 177.5 \\
Printing (P) & 101.3 & 215.6 & 214.3 & 214.7 \\
Foodstuffs and seasonings (F) & 117.3 & 127.1 & 122.2 & 121.7 \\
Tobacco, frozen food, & & & & \\
$\quad$ mineral water (B) & 226.4 & 230.9 & 232.0 & 232.0 \\
Other industry production (O) & 116.3 & 160.9 & 159.7 & 153.4 \\
\hline
\end{tabular}

Letters in parentheses refer to letters in Figures 12.2 to 12.4 .

Source: Federal Statistical Office.

average price index (relative to 1989). Only energy prices rose considerably more.

Figure 12.3 shows the price development for heavy industry. Again one has to consider that prices of chemicals had already increased by threequarters in late 1990. Once more we find that large price changes only occurred during the first month of price liberalization. Later, the monthly price variation is by orders of magnitude smaller than the initial jumps.

More action can be seen in Figure 12.4, illustrating the evolution of prices in the light industries. The initial price jumps not only vary much more, but the subsequent behavior of prices also shows more variation.

A sectoral disaggregation of import and export price data replicates the general features of domestic price data. Price adjustment takes place mainly in the first months of 1991 , and relative price changes are considerable. 


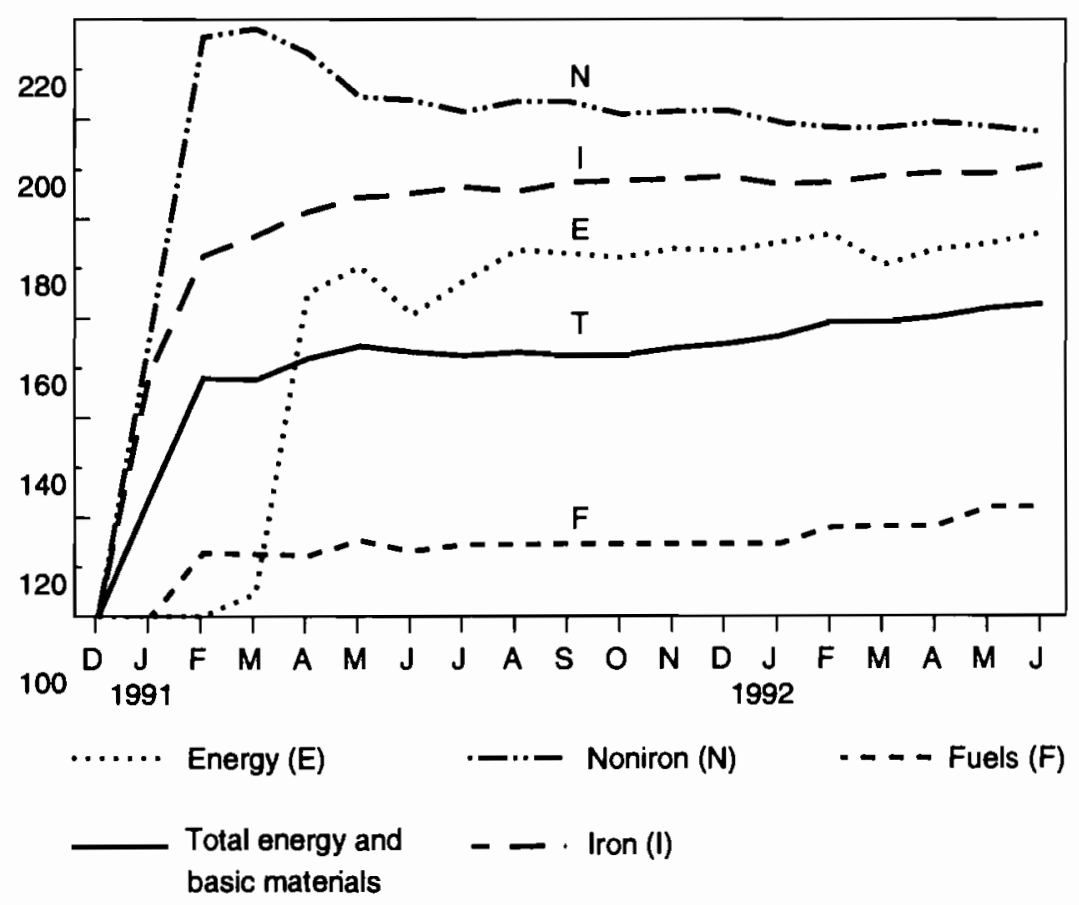

Figure 12.2. Development of domestic producer prices of energy and basic materials, December 1990 to June 1992, 1990 December $=100$ percent. Source: Federal Statistical Office.

On this basis, let us summarize two stylized facts of Czechoslovak price behavior after the liberalization:

1. There was a considerable price jump in all industries, which was in nearly all cases essentially completed within two or three months. After April 1991 aggregate producer prices stayed approximately constant. Thus price liberalization increased the average price by about 80 percent above the 1989 level. Price liberalization allowed a rapid adjustment of price levels without contributing to higher inflation.

2. Relative prices changed considerably. Energy prices rose 50 percent faster than the average producer price and food prices increased by 30 percent less. This span is approximately equal to the size of the aggregate price increases during the liberalization period. Price liberalization thus allowed a considerable adjustment of relative prices. 


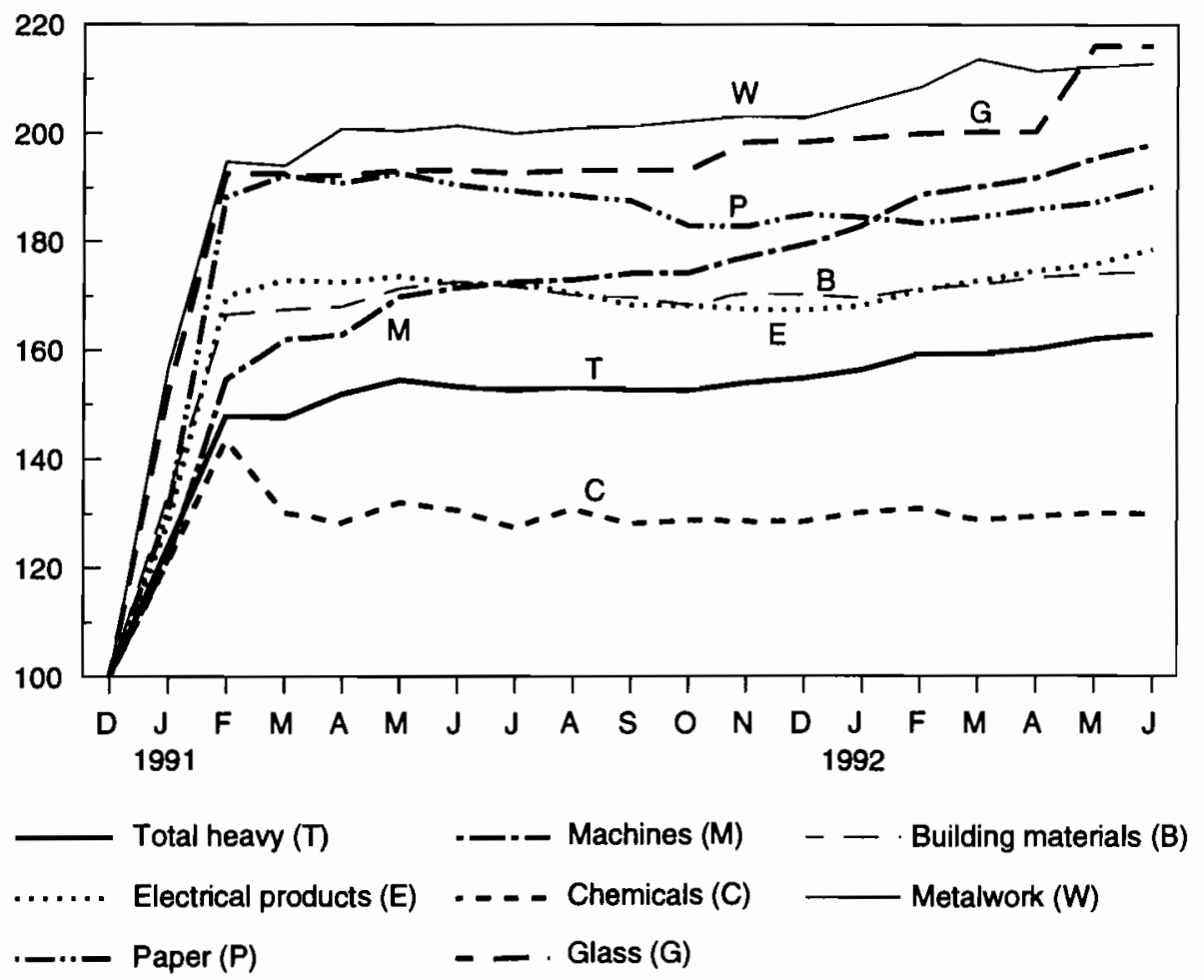

Figure 12.3. Development of domestic producer prices of heavy industries, December 1990 to June 1992, 1990 December $=100$ percent. Source: Federal Statistical Office.

\section{Factors Affecting the Price Behavior of Enterprises}

What factors could explain the interindustry pattern of price jumps in 1991? The real socialist economies were characterized by monetary overhang and widespread shortages; most obviously, elimination of these shortages would be accomplished through price increases in competitive markets. The Czechoslovak economy is often considered to have had relatively little macroeconomic imbalance (see, for instance, Angelis, 1991), but queues were also common for many goods. Moreover, since prices bore little relation to relative scarcities, even if there was little aggregate overhang, the degree of shortage likely varied from industry to industry. Thus, even if everything else were constant across industries, price increases would vary with the prior degree of shortage. 


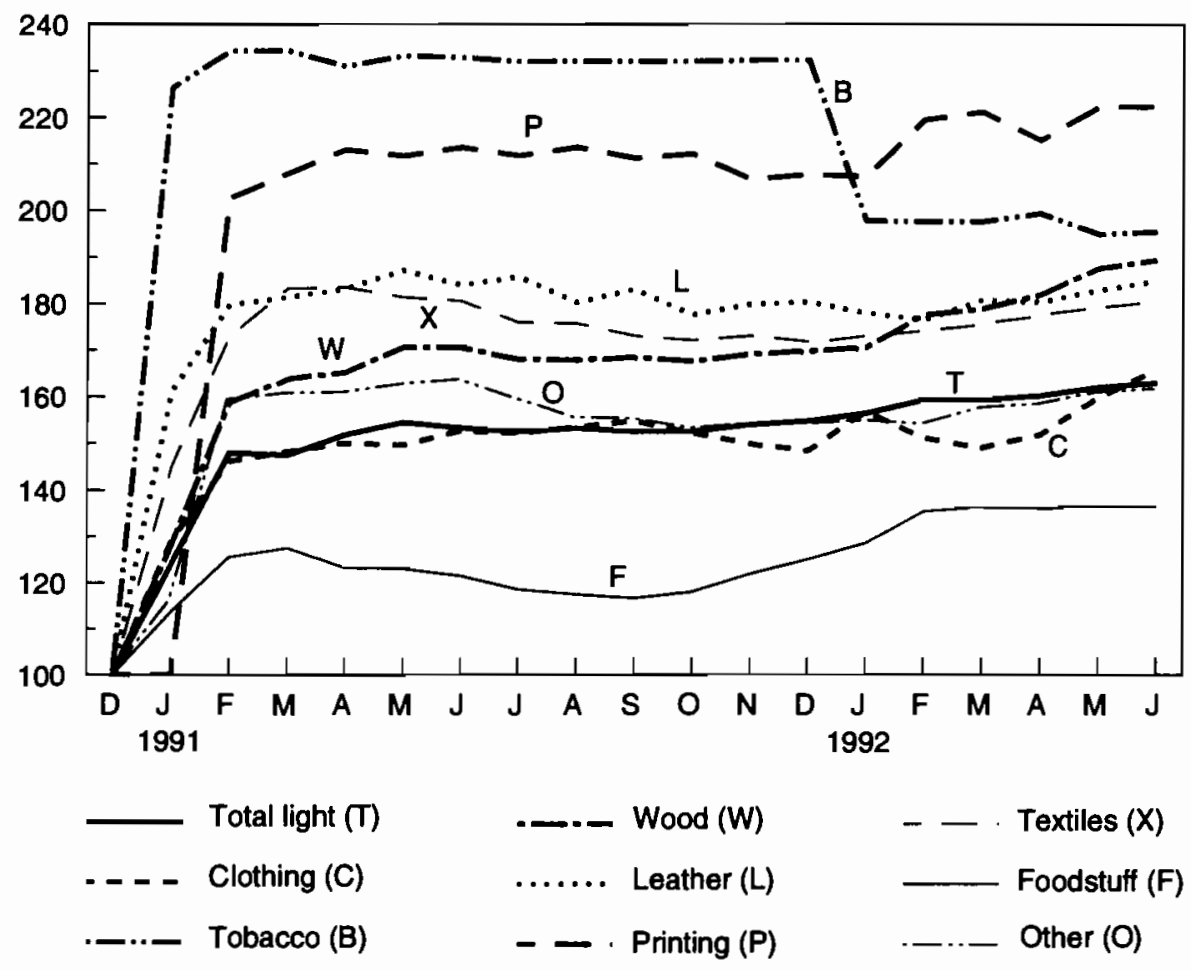

Figure 12.4. Development of domestic producer prices of light industries, December 1990 to June 1992, 1990 December $=100$ percent. Source: Federal Statistical Office.

Interindustry variations in price increases may also be a reflection of variations in cost functions. A relatively steep marginal cost function implies that shortages would be eliminated more through price increases rather than by increases in output. The apparent lack of aggregate "supply response" to price liberalization has been considered at length by macroeconomists, but it is also clear that supply responsiveness can differ from sector to sector.

Differences in the demand functions faced by industries, and by individual firms within industries, may also account for differences in price behavior. Industrial structure and therefore behavior and performance varies significantly from sector to sector. Some industries are characterized by a high degree of concentration, while others have many small producers. All else equal, industries characterized by monopoly would have raised prices more and quantities less, relative to competitive industries. It is important to 
note, however, that while competitive industries always increase output as well as prices to eliminate a shortage, the output behavior of monopolists depends on the pre-existing degree of shortage. If prices were fixed at a very low level prior to liberalization, it is possible that profit-maximizing monopolists would increase output after price liberalization.

Nonetheless if this were the whole story, then the finding that output had fallen in a particular sector would be sufficient to conclude that monopoly power existed in that sector. Only the characterization of sectors which experienced output increases would remain in doubt. As we have seen, however, output declined in nearly all sectors. Simultaneous with the price liberalization occurred a number of other changes that render quite difficult the assessment of the role of monopoly in the price jumps.

First, as mentioned above, foreign trade was liberalized and currency convertibility for current account transactions was introduced. Trade liberalization involved a removal of most licensing requirements and granting permission to any registered enterprise to engage in foreign trade, thereby abolishing the monopoly of the Foreign Trade Organizations (Benacek and Mejstrik, 1991). ${ }^{6}$ From the perspective of domestic producers of tradable goods, this was equivalent to a demand shock. Consumers substituted imported for domestic goods for reasons of quality and variety as well as price. This demand shock by itself could not have resulted in reduced output in competitive industries, as long as prices rose, and thus the inference that reduced output implies the presence of monopoly is not directly overturned. The structure of many industries, however, was affected: domestic demand became more elastic. In the extreme case, domestic monopolists became competitive firms in the world market. Other markets simply became less monopolistic. This, of course, is the "import discipline hypothesis" that import competition can dampen monopolistic behavior (see De Melo and Urata, 1986; Caves, 1980; Jacquemin, 1982; and Jacquemin and Sapir, 1990).

For the sake of completeness, a second change with a potentially similar effect should also be listed: entry of domestic producers was liberalized. Although in the long run, the development of new private firms and the

\footnotetext{
${ }^{6}$ To complicate the picture, a temporary import surcharge of 20 percent was introduced simultaneously and applied to consumer goods such as food, cigarettes, textiles, clothing, consumer electronics, cars, and furniture. The surcharge was reduced to 18 percent in May and 15 percent in June 1991. There were also global import quotas for some agricultural products. Furthermore, access to foreign exchange was supposed to be free, but the State Bank required many imports to be financed through trade credits; this was abolished in October 1991 (see OECD, 1991).
} 
restructuring of the product lines of old state enterprises may be the most important factors in creating a competitive environment, it was clearly a minor factor in the short time since liberalization of prices of those goods that we are considering. ${ }^{7}$

Third, the Czechoslovak koruna was successively devalued in late 1990 and early 1991. A 55 percent devaluation in October 1990 and 16 percent on 28 December 1990 resulted in a rate of CSK 28 to the US dollar. This policy had at least two effects: it raised the costs of imports, including many important raw materials, but it also limited the competitiveness of imports in domestic markets. The first effect is a type of negative supply shock, the second a positive demand shock; both could differ from sector to sector. With regard to the former, because negative supply shocks would reduce output, even competitive industries may have experienced output declines. ${ }^{8}$ With regard to the latter, interindustry differences in structure and in cost functions implies that the level of the exchange rate also matters for the ability to import a price structure from abroad.

Fourth, the shift to hard currency in internal CMEA trading also functioned as a supply shock, raising import prices for inputs. Accompanying this was a tighter budget constraint on hard currency (which after internal convertibility had to be purchased at market rates) for enterprises, which prevented many from obtaining needed inputs.

Fifth, the breakdown of the coordination of central planning meant that the supply of inputs was reduced and became in general less reliable. Again, this functioned as a supply shock to domestic producers.

In addition to these simultaneous changes, a number of special factors of these economies in transition make it difficult to draw conclusions about market structure.

First, despite the rhetoric of the imposition of hard budget constraints on enterprises, a number of avenues of soft support still existed. Banks still engaged in lending that was not tied to rational evaluations of the profitability of alternative investments, and real interest rates were negative. Moreover, inter-enterprise debts (together with the expectation, which was later partly realized) provided an escape from hard constraints.

\footnotetext{
${ }^{7}$ The domestic output response becomes important for the working of the import discipline hypothesis if foreign firms are the source of monopoly power (Geroski and Jacquemin, 1981).

${ }^{8} \mathrm{~A}$ further negative aggregate supply shock resulted from the real balance effect of the price increases consequent upon the devaluation.
} 
Second, enterprises may have continued to behave in their old, irrational (at least, from the social point of view) mode. Perhaps the interests of workers dominated the maximization of profits in enterprise behavior. For instance, if enterprises behaved like producer cooperatives, then theory would predict the response of a reduction in output to an increase in price.

Third, it is important to note that the degree to which these price increases were anticipated affected behavior even prior to the liberalization. For instance, an important part of the story is inventory behavior, both of inputs and of finished goods. To the degree that industries vary in their capability to hold inventories, price behavior may be affected. For instance, industries that accumulated output inventories in 1990 probably had smaller price and output movements in 1991 (Blinder, 1982).

Anticipated price changes also affected demand. It is well known that goods of all kinds were hoarded and store shelves were empty just prior to the liberalization on 1 January 1991. As long as firms were on their supply functions (a heroic assumption, for reasons just cited), this expectational effect only served to exacerbate shortages beforehand, and should therefore not have shifted demand either before or after the price liberalization.

\section{A Test of the Import Discipline Hypothesis}

Although the movements of the price variables described in the previous section may be intrinsically interesting and could appear sometimes to be suggestive of the possible presence of monopoly power, their usefulness in this analysis suffers from a basic weakness: nearly all the variables are endogenous. Moreover, while it is tempting to draw inferences on the basis of the magnitudes of the changes from pre- to post-liberalization, in fact, such inferences are very difficult, since it is practically impossible to know what the pre-existing degree of distortion was. A large change (for instance, in price or in output) may simply be the result of a larger prior distortion.

In the preliminary results reported here we maintain the hypotheses that concentration and imports may be regarded as exogenous in the case of CSFR enterprises in $1991,{ }^{9}$ and seek to measure their relationship with monopoly elements, as represented by profitability. We can test the relative importance of imports and concentration for the exercise of monopoly power, as measured by profitability, with the help of a simple regression. First we

\footnotetext{
${ }^{9}$ Imports were found exogenous by De Melo and Urata (1986). This is a hypothesis that we plan to test in future research.
} 
Table 12.2. Industry indicators in the CSFR in $1991 .^{a}$

\begin{tabular}{lrrrr}
\hline & $\begin{array}{c}\text { Production } \\
\text { Sector }\end{array}$ & $\begin{array}{c}\text { Real production } \\
\text { in mill. CSK }\end{array}$ & $\begin{array}{l}\text { Profit in } \\
\text { 1984 }\end{array}$ & \multicolumn{2}{c}{$\begin{array}{c}\text { Concentra- } \\
\text { mill. CSK }\end{array}$} & tion ratio \\
\hline Fuels & 92,619 & 57.1 & 28,235 & 0.58 \\
Energy & 95,784 & 40.2 & 35,608 & 0.84 \\
Ferrous metallurgy & 142,129 & 91.2 & 9,575 & 0.71 \\
Nonferrous metallurgy & 31,672 & 72.0 & 2,204 & 0.50 \\
Chemicals & 184,014 & 88.4 & 18,236 & 0.47 \\
Mechanical engineering & 258,231 & 78.5 & 20,226 & 0.22 \\
Electrical engineering & 57,398 & - & 4,561 & 0.15 \\
Building materials & 34,306 & - & 2,605 & 0.21 \\
Woodworking & 38,538 & 96.1 & 3,011 & 0.19 \\
Metalworking & 59,618 & 109.7 & 5,890 & 0.22 \\
Paper and pulp & 31,592 & 85.6 & 2,267 & 0.48 \\
Glass and porcelain & 25,056 & 101.3 & 4,083 & 0.33 \\
Textile & 54,835 & 79.3 & 4,664 & 0.13 \\
Clothing & 12,185 & 80.4 & 686 & 0.48 \\
Leather & 29,141 & 69.9 & 2,027 & 0.60 \\
Printing & 9,635 & - & 1,156 & 0.31 \\
Foodstuffs and seasonings & 172,289 & 72.5 & 13,999 & 0.11 \\
Tobacco & 9,486 & 69.6 & 2,856 & 0.84 \\
Others & 18,997 & - & 2,223 & 0.40 \\
Industry total & $1,357,525$ & 75.9 & 164,112 & - \\
\hline For explanation & & & & \\
\hline
\end{tabular}

${ }^{a}$ For explanation see footnote 10 .

examine the pair-wise correlations of profitability and concentration and of profitability and imports, and then we conduct a multivariate analysis of the relationships among them.

Most studies of profitability and concentration have found only a small and statistically weak relationship (see Schmalensee, 1989). We constructed four-firm concentration ratios using data on medium and large enterprises in Czechoslovakia for each 2-digit industry. ${ }^{10}$

\footnotetext{
${ }^{10}$ The data set contains all enterprises in industry with 100 employees or more. The concentration ratio for a given industry is defined as the ratio of the sum of the output of the four largest enterprises in the industry to the total output of all firms that are in the industry and that are represented in the data set. Thus, small firms (less than 100 employees) are excluded; if there is significant variation across industries in the importance of smaller firms, then these ratios could be biased. We are also aware that the concentration ratio should best be defined in terms of total domestic sales, including imports in the denominator and excluding exports from both numerator and denominator; we are working to obtain the data necessary to calculate this better measure.
} 
In Table 12.2 we find the concentration ratios for 19 industrial sectors. The range is quite large, from 0.11 in food and 0.13 in textiles to 0.84 in both energy and tobacco, with a mean of 0.41 and standard deviation of 0.23 . The highest concentration ratios can be found in energy, tobacco, fuels, ferrous and nonferrous metallurgy, and leather industries. Low concentration ratios are present in food industries, textiles, wood products, building materials, metalworks, and mechanical and electrical engineering.

It is very difficult to judge how much the past concentration ratios tell about today's market power in the CSFR. The large privatization only began in 1992, and especially the large enterprises are in a process of reconstruction and reform. Again a safe conclusion seems to be that concentration ratios vary considerably from branch to branch.

We calculated the correlation of this concentration ratio with profitability, defined as the ratio of profits to sales revenue. The correlation for 1991 was large (0.613) and significant at 1 percent level. Thus, there seems to be a strong association of concentration and profitability across Czechoslovak industries, which is evidence for the presence of monopoly elements.

The import discipline hypothesis suggests that the ability of monopolies to exercise their power may be disciplined by foreign competition that increases demand elasticity. It is an implication of oligopoly models with conjectural variation that the greater the elasticity of demand, the lower the price-cost margin (see Tirole, 1988). We therefore constructed import penetration measures, defined as the ratio of imports to domestic sales, for each industry. ${ }^{11}$ The variable's range is from 2 percent (energy) to 33 percent (electrical engineering) in 1990 and from 3 percent (energy and glass and porcelain) to 48 percent (fuel) in 1991. There is a very high correlation (0.85) of import penetration across the two years, possibly implying that little change in the structure of imports occurred. Moreover, the correlation of this variable with profitability is weak: 0.11 for 1991 . Perhaps imports did not constrain domestic monopolists much after all.

To consider the joint effects of concentration and imports on profitability in 1991 , we specified a regression function with profitability $(\pi)$ as the

\footnotetext{
${ }^{11}$ Disaggregated data have been obtained from the Federal Ministry of Foreign Trade for import products, which we then matched with our industry data to obtain industry import estimates. Imports were unavailable for two industries, printing and other, for the year 1990, so we have only 17 observations for that year. Unfortunately, we had no industry export data for 1991, so the denominator of the import penetration variable includes exports; we are working to obtain this 1991 data to improve this measure.
} 
dependent variable and the concentration ratio $(C R)$ and the measure of import penetration $(I P)$ as independent variables:

$$
\pi_{i}=\beta_{1}+\beta_{2} C R_{i}+\beta_{3} I P_{i}+u_{i},
$$

where $i$ indexes industries and $u$ is an additive disturbance. This specification treats $C R$ and $I P$ as exogenous. Since 1991 was the first year of liberalization, the former exogeneity assumption seems easily acceptable; the second should perhaps be amended, but other studies (e.g., De Melo and Urata, 1986) have rejected the endogeneity of imports (albeit with different data for a different country). Previous studies of the effects of imports add other covariates (see Schmalensee, 1989), such as the export ratio and various proxies for the presence of scale economies and diseconomies, to the equation, but the justification for their inclusion is not entirely clear. Our simple specification has the added virtue of parsimony.

The results of estimation with the 19 2-digit industries for 1991 were as follows:

$$
\pi_{i}=\underset{(0.451)}{0.008}+\underset{(0.794)}{0.250 C R_{i}}+\underset{(0.145)}{0.093 I P_{i}}+u_{i}
$$

with estimated standard errors shown in parentheses, $\mathrm{R}^{2}=0.39$, and standard error of the regression (SER) equal to 0.077 . Concentration is positive and strongly significant, but the coefficient on imports has the wrong sign, although it is not statistically different from zero. Of course, in the long run, imports should not affect the profitability of a competitive industry, but it is somewhat surprising that they seem to have so little impact in the disequilibrium environment of a transition economy. Collusion between foreign and domestic producers could also generate a positive coefficient, but again this seems unlikely in the case of Czechoslovakia in 1991. This result therefore seems to further support the hypothesis that imports provided little effective competition for the domestic monopolists.

The industrial organization literature contains some basis for the argument that the more appropriate specification allows the effect of imports on profitability to vary with the level of concentration. The specific hypothesis is that high concentration is associated with a stronger (negative) impact of imports on profitability. We therefore added an interaction term: the product of $I P$ and $C R$. This term could also be interpreted as the effect of 
imports on the concentration-profitability relationship. In either case, we would expect its coefficient to be negative. The results were as follows:

$$
\pi_{i}=\underset{(0.064)}{0.029}+\underset{(0.130)}{0.200 C R_{i}}-0.049 I P_{i}+0.336 C R \cdot I P+u_{i}
$$

with $\mathrm{R}^{2}=0.40$ and SER $=0.079$. The coefficient on imports now has the predicted sign, but it is still insignificant. The interaction term has an effect opposite to that predicted: either imports increase the effect of concentration on profitability or concentration lowers the (negative) effect of imports on profitability, but neither is very intuitive.

Among others, we also tried a specification that dropped the $C R$ variable. The variable $I P$ had a negative and almost statistically significant effect, ${ }^{12}$ but the interaction term remained large, positive, and quite significant. It seems, paradoxically, that the negative effect of imports on profits is less, the more concentrated the industry.

A final specification examined the effect of changes in the measure of import penetration from 1990 to 1991 , the argument being that it is only the new imports, responding to profitable opportunities, that represent real competition for domestic monopolists. This variable $(\Delta I P)$ was defined simply as $I P_{91}-I P_{90}$. The results using only this and $C R$ as independent variables were as follows:

$$
\pi_{i}=\underset{(0.035)}{0.027}+\underset{(0.075)}{0.226 C R_{i}}+\underset{(0.266)}{0.582 \Delta I P_{i}}+u_{i}
$$

where $\mathbf{R}^{2}=0.54$ and $\mathrm{SER}=0.072$. These results imply that an increase in import penetration actually raises profits, even holding the concentration ratio constant! Don't look for any empirical support for the import discipline hypothesis here.

\section{Conclusion}

The discussion in this paper remains preliminary because we believe this topic merits treatment at the firm level, or as disaggregated as possible. Unfortunately, our price data are only at the level of major sectors (2-digit); we intend to re-examine these relationships with at least 3 -digit price and other data. Furthermore, the fundamental question of the degree to which

\footnotetext{
${ }^{12}$ The small sample size, arguing for the use of a higher significance level, should be borne in mind.
} 
monopoly power is exercised in the Czechoslovak economy, and therefore what the optimal policy sequence may be, can only be answered with structural estimation. This requires formalizing the choice problem of enterprises, including all the considerations and constraints suggested by the analysis in this paper. We hope to report on the results of such an inquiry at some future date.

Nevertheless we would like to mention a few pieces of basic statistical information which we consider remarkable. At first it is clear that price liberalization did bring a great deal of relative price changes. This has been the main goal of eliminating most price controls and thereby allowing prices to reflect relative scarcities. It has to be remembered that, at least for our analysis, unfortunately quite a lot happened simultaneously in Czechoslovakia in 1990 and 1991. Not only did domestic prices reveal many relative changes, import and export price changes also varied considerably by sector.

The simultaneity of devaluation, energy price shocks, and price liberalization makes it difficult to isolate the relation between foreign trade and domestic monopoly power. Our simple regression experiments delivered a positive relation between the increase of import penetration from 1990 to 1991 and profitability. Under the assumption that profits are a result of the past, while imports are responding to above average profit opportunities, we could conclude that import competition will finally have a dynamic effect reducing domestic monopoly power.

The static effects of current monopoly power on average inflation of producer prices during price liberalization in 1991 are certainly negligible relative to the contribution of the devaluation in 1990 and the fuel price increases to the price level jump in 1991.

The merits of foreign trade liberalization may therefore have more to be seen in their dynamic effects contributing to incentive-related supply effects through productivity increases which are generated by international integration.

\section{References}

Angelis, M.I. (1991) "Czech and Slovak Federal Republic," in P. Marer and S. Zecchini (eds.) The Transition to a Market Economy, Vol. 1 (Paris: OECD). Benacek, V., and Mejstrik, M. (1991) Czechoslovak Foreign Trade Performance Analysis: January-June 1991, CERGE Working Paper (Prague: Center for Economic Research and Graduate Education). 
Bergsten, C.F., and Williamson, J. (1990) "Currency convertibility in Eastern Europe," in Central Banking Issues in Emerging Market-Oriented Economies (Kansas City: Federal Reserve Bank of Kansas City).

Blinder, A.S. (1982) "Inventories and sticky prices: More on the microfoundations of macroeconomics," American Economic Review, Vol. 72, No. 3, June.

Blommestein, H., and Marrese, M. (1991) "Developing competitive markets," in

P. Marer and S. Zecchini (eds.) The Transition to a Market Economy, Vol. 2 (Paris: OECD).

Caves, R. (1980) "Symposium on international trade and industrial organization," Journal of Industrial Economics, Vol. 29.

De Melo, J., and Urata, S. (1986) "The influence of increased foreign competition on industrial concentration and profitability," International Journal of Industrial Organization, Vol. 4, No. 3.

Fischer, S., and Gelb, A. (1991) "The process of socialist economic transformation," Journal of Economic Perspectives, Vol. 5, No. 4.

Geroski, P., and Jacquemin, A. (1981) "Imports as a competitive discipline," Recherches Economiques de Louvain, Vol. 47.

Hrnčír, M., and Klacek, J. (1991) "Stabilization policies and currency convertibility in Czechoslovakia," European Economy, Special Edition, No. 2.

Jacquemin, A. (1982) "Imperfect market structure and international trade: Some recent research," Kyklos, Vol. 35.

Jacquemin, A., and Sapir, A. (1990) "Competition and imports in the European market," Discussion Paper No. 474 (London: Center for Economic Policy Research).

Lipton, D., and Sachs, J. (1990) "Creating a market economy in Eastern Europe: The case of Poland," Brookings Papers on Economic Activity, Vol. 1 (Washington, DC: Brookings Institution).

OECD (1991) Economic Survey: Czech and Slovak Federal Republic (Paris: OECD). Ross, T.W. (1988) "On the price effects of mergers with freer trade," International Journal of Industrial Organization, Vol. 6, No. 2.

Schmalensee, R. (1989) "Interindustry studies of structure and performance," in R. Schmalensee and R.D. Willig (eds.) Handbook of Industrial Organization, Vol. 2 (Amsterdam: North-Holland).

Snyder, T. (1993) "Soviet monopoly," in J. Williamson (ed), Economic Consequences of Soviet Disintegration (Washington, DC: Institute for International Economies).

Tirole, J. (1988) The Theory of Industrial Organization (Cambridge, MA: MIT Press).

Williamson, J. (1993) Economic Consequences of Soviet Disintegration, (Washington, DC: Institute for International Economics). 


\section{Comments on John S. Earle and Andreas Wörgötter's Paper}

\section{Michael Jones}

Professors Earle and Wörgötter present an informative paper on a transition economy. The reforms of internal price liberalization and unrestricted international trade in goods aim to promote efficiency of resource allocation and the usefulness of money. Prerequisites for markets to work well in this sense are profit-maximizing incentives on the part of firms and the absence of pervasive market failures. When privatization is incomplete and/or significant market power is unleashed, the move to markets replaces old problems with new ones. If it can be shown that convertibility in the absence of a fully competitive environment implies greater transitional costs and delays than would a future, simultaneous movement on all fronts, there may be a case for gradualism. For most of the formerly planned economies, this issue is largely hypothetical: to maintain credibility, there is no turning back on the key reforms. Nonetheless, it is important to understand the functioning of the economy caught in the gray area of liberalized markets but perverse incentives, both to measure the cost of this reform sequence (relative to the competitive ideal and to no reform) and to recommend policies to ease the transition.

Czechoslovakia exemplifies this gray area. It aggressively freed internal prices from administrative control. It offered unlimited convertibility to hard currencies at a unified exchange rate for most current account transactions, and now has an average tariff which is low, even by Western standards. On the other hand, Czechoslovakia has moved more cautiously toward privatization than some of its neighbors; and it lacked the experience with Western markets and the tradition of small-scale market experiments of Hungary or Poland. Potential market power, as reflected in concentration ratios, exists. Unfortunately, as the authors document, Czechoslovakia has been subjected to so many shocks between 1990 and 1992 that it is impossible to infer from the aggregate data how market imperfections have affected the adjustment to liberalization or what the pattern of adjustment implies about the extent of market imperfections. The authors are appropriately cautious in drawing detailed conclusions. Accordingly, I limit my comments to three aspects of the role of monopoly power in the CSFR transition.

First, the paper suggests but does not resolve the extent and cost of monopoly power in Czechoslovakia. The authors construct four-firm concentration ratios and profit rates for 19, 2-digit industries. Comparisons between these ratios and those of the West and those of the other transition economies would be informative. The concentration ratio average of 40 percent at the 2-digit level is very high by Western standards, and the anecdotal evidence suggests high potential power in many industries. On the other hand, the profit rates tell a more moderate story. If we crudely estimate Harberger deadweight losses by assuming a unitary demand elasticity and using the estimated markups which average at 12 percent, we obtain a cost of monopoly power on the order of 1 percent of industrial output. This moderate deadweight loss is dwarfed by the real output reductions of recent years. 
A convincing analysis awaits a refinement of the profit rates and a sharper sectoral breakdown, but I am surprised that the initial data do not show more dramatic inefficiencies.

Indeed, deadweight losses based on profit rates will overstate the cost of monopoly, for at least two reasons. First, such calculations do not account for the countervailing pressures in an economy where market failures are pervasive. In essence, if production inputs are in fixed supply, then not all sectors can produce too little, and power exercised in one market will mitigate the impact of monopoly in another. Also, monopoly power indirectly lessens the environmental damage of the large industries. Piecemeal application of antimonopoly policy can do harm in this second best setting. Second, a snapshot of monopoly cannot reveal the dynamic process of future entry and the cost-saving incentives of potential competition. Few Czechoslovak industries are natural monopolies: current concentrations are the residue of central planning rather than scale economies. The profits we observe now are the incentive for new entry. It will be interesting to see whether entry can substitute effectively for formal restructuring and antimonopoly law. My sense is that entry will resemble a desirable piecemeal policy with pervasive monopoly, because entry should occur most readily in sectors where market power has generated the highest monopoly profits and inefficiency. For these reasons, the paper has just begun to penetrate the extent and cost of market power in the CSFR.

A second focus of the paper is on how heavily Czechoslovakia can rely on the forces of free trade for antitrust. Czechoslovakia took the essential steps of stopping the rationing of hard currency among importers and minimizing quantitative restrictions on imports. Without these steps, the monopoly power of firms which serve the domestic market with import substitutes would be maintained and perhaps enhanced by facilitating collusion. Tariffs retain the fundamental feature of free trade: the unlimited availability of imports which substitute for domestic goods must increase the elasticity of demand for home goods and hence lower market power. Exactly how effective this check on monopoly power will be depends on the cross price elasticity of demand between imports and domestic goods. If import penetration is positively related to the cross price elasticity in the cross section, then high import penetration should result in small profit rates if free trade is restraining market power. Instead, the authors find a weak and sometimes positive relationship between import penetration and profits rates.

I do believe that free trade has limited antitrust potential, but the authors' regressions cannot tell us this. Surely, import penetration is sensitive to the profit markup; thus, the regressions suffer from a simultaneous determination of import penetration and the profit rate. The regressions may simply show that sectors which attempt large markups attract imports. What we need is independent evidence on the cross price elasticities, which awaits empirical demand studies. Perhaps we might appeal for guidance from the many studies on goods substitutability in international trade. Purchasing power parity studies on tradable, homogeneous goods reveal significant violations of the law of one price. Econometric studies of substitution elasticities between home goods and import substitutes in the USA 
reveal a wide range of elasticities but an average between 2.5 and 3 . These numbers tell us that markups over cost in a monopolized domestic industry could be as high as 50 percent. Especially in the short run, the absence of quantitative restrictions lessens, but will not eliminate, monopoly power.

A third issue is: short of restructuring to promote competition, what should be done to lessen the monopoly problem? The goal is to increase the flow of resources to the monopolized sectors. Unfortunately, of the several ways to do this, none is compelling or immediately available to the transition economies.

1. We could intervene directly in the monopolized market. For example, we could subsidize production, enriching the monopolist. Or we could impose a scientifically determined price ceiling, which could avoid the increase in profit. Either way, we reintroduce the controls that liberalization was meant to replace. This is unacceptable, for it would destroy the credibility of the reforms.

2. We could act indirectly to drive resources out of other markets. In particular, we could raise tariffs on the consumption imports which compete with home goods. This policy can increase real income, but it is risky. It is a fine-tuning policy, which balances one distortion against another. Also, in the sector with market power, the gain is an increased profit which outweighs consumer loss. Because of this distribution, if the expansion is funded from abroad or through direct investment, the home country is likely to hurt itself.

3. Finally, and most attractive, Czechoslovakia might encourage capital inflows. The expansion of new enterprises that foreign capital finances will disperse monopoly power, even in the nontradable sector. As profits are shifted from home firms, a gain is not guaranteed - but in many instances there will be net national gain. Direct investment has the further advantage of bringing productivity-enhancing knowledge. From the perspective of antimonopoly, as well as general needs for growth and transition, we must wonder when and how Czechoslovakia can begin to run a larger current account deficit. 



\section{Contributions to Economics}

The series "Contributions to Economics" contains publications in the fields of economics and management science. These publications are primarily monographs and multiple author works containing new research results, but conference and congress reports are also considered.

Apart from the contribution to scientific progress presented, it is a notable characteristic of the series that actual publishing time is very short thus permitting authors and editors to present their results without delay.

Manuscripts could be sent directly to Physica-Verlag:

Physica-Verlag $\mathrm{GmbH} \&$ Co.

P.O. Box 105280

69042 Heidelberg, FRG 